\begin{tabular}{|l|l|}
\hline $\begin{array}{l}\text { 2. To: (Receiving Organization) } \\
\text { Distribution }\end{array}$ & $\begin{array}{l}\text { 3. From: (Originating Organization) } \\
\text { Mechanical Engineering/454 }\end{array}$ \\
\hline $\begin{array}{l}\text { 5. Proj./Prog./Dept/Div.: } \\
\text { Spent Nuclear Fuels Project }\end{array}$ & $\begin{array}{l}\text { 6. Design Authority/Design Agent/Cog. Engr.: } \\
\text { K. J. McCracken }\end{array}$ \\
\hline
\end{tabular}

8. Originator Remarks:

For document approval and release

4. Related EDT No.:

NA

7. Purchase Order No.:

NA

9. Equip./Component No:

NA

10. System/Bldg./Facility:

CVD

12. Major Assm. Dwg. No.:

NA

11. Receiver Remarks:

11A. Design Baseline Document? $\bigcirc$ Yes

No

13. Permit/Permit Application No.:

NA

14. Required Response Date:

$3 / 29 / 99$

15

DATA TRANSMITTED

\begin{tabular}{|l|l|}
\hline $\begin{array}{c}\text { (A) } \\
\text { Item } \\
\text { No. }\end{array}$ & (B) Document/Drawing No. \\
\hline 1 & HNF -4057 \\
\hline & \\
\hline & \\
\hline & \\
\hline & \\
\hline & \\
\hline
\end{tabular}

\begin{tabular}{|l|l|l|}
$\begin{array}{c}\text { (C) Sheet } \\
\text { No. }\end{array}$ & $\begin{array}{c}\text { (D) Rev. } \\
\text { No. }\end{array}$ & (E) Title or Description of Data Transmitted \\
\hline All & 0 & Cold Vacuum Drying Proof \\
\hline & & of Performance (First \\
\hline & & Article Testing) Test \\
\hline & & \\
\hline
\end{tabular}

(F)

(G)

\begin{tabular}{|c|c|c|c|}
\hline $\begin{array}{l}\text { Approval } \\
\text { Desig- } \\
\text { nator }\end{array}$ & $\begin{array}{c}\text { Reason } \\
\text { for Trans- } \\
\text { mittal }\end{array}$ & $\begin{array}{c}\text { Origi- } \\
\text { nator } \\
\text { Dispo- } \\
\text { stion }\end{array}$ & $\begin{array}{l}\text { Receiv- } \\
\text { er } \\
\text { Dispo- } \\
\text { sition }\end{array}$ \\
\hline$N=Q$ & 1 & 1 & 1 \\
\hline $8 \%$ & 2 & & \\
\hline $3 / 9$ & & & \\
\hline & & & \\
\hline & & & \\
\hline & & & \\
\hline & & & \\
\hline
\end{tabular}

16.

KEY

\begin{tabular}{|c|l|}
\hline Approval Designator $(F)$ & \\
\hline E, S, Q, D OR N/A & 1. Approval \\
(See WHC-CM-3-5, & 2. Release \\
Sec. 12.7) & 3. Information \\
\hline
\end{tabular}

Reason for Transmittal (G)

Disposition (H) \& (I)

17.

4. Review
5. Post-Review
6. Dist. (Receipt Acknow. Required)

\begin{tabular}{|ll}
\hline \multicolumn{2}{|c}{ Disposition $(\mathrm{H})$ \& (I) } \\
$\begin{array}{ll}\text { 1. Approved } & \text { 4. Reviewed no/comment } \\
\text { 2. Approved w/comment } & \text { 5. Reviewed w/comment } \\
\text { 3. Disapproved w/comment } & \text { 6. Receipt acknowledged }\end{array}$
\end{tabular}
SIGNATURE/DISTRIBUTION

(See Approval Designator for required signatures)

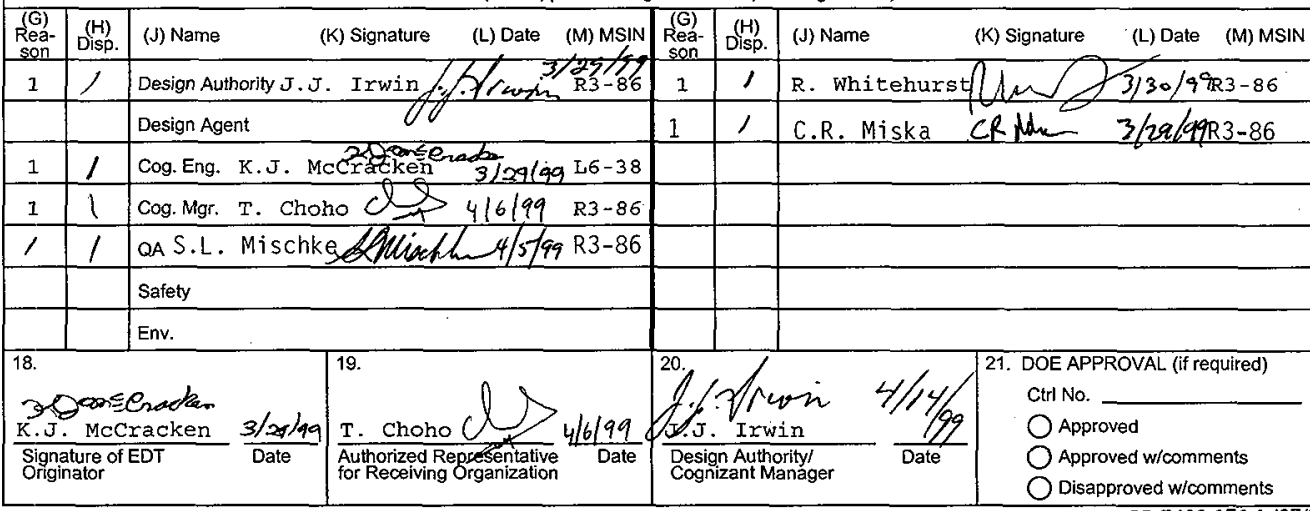




\section{Cold Vacuum Drying Proof of Performance (First Article Testing) Test Results}

K. J. Mocracken

Fluor Daniel Northwest

Richland, WA 99352

U.S. Department of Energy Contract DE-AC06-96RL13200

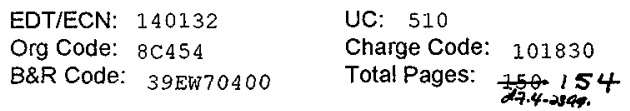

Key Words: First Article Testing; Cold Vacuum Drying; Test Results spent Nuclear Fuel; W-441

Abstract: This report presents and details the test results of the first of a kind process referred to as cold Vacuum Drying (CVD). The test results are compiled from several months of testing of the first process equipment skid and ancillary components to de-water and dry Multi-Canister overpacks (MCO) filled with spent Nuclear Fuel (SNF). The tests results provide design verifications, equipment validations, model validation data, and establish process parameters.

TRADEMARK DISCLAIMER. Reference herein to any specific commercial product, process, or service by trade name, trademark, manufacturer, or otherwise, does not necessarily constitute or imply its endorsement, recommendation, or favoring by the United States Government or any agency thereof or its contractors or subcontractors.

Printed in the United States of America. To obtain copies of this document, contact: Document Control Services, P.O. 80x 950, Mailstop H6-08, Richland WA 99352, Phone (509) 372-2420; Fax (509) 376-4989.
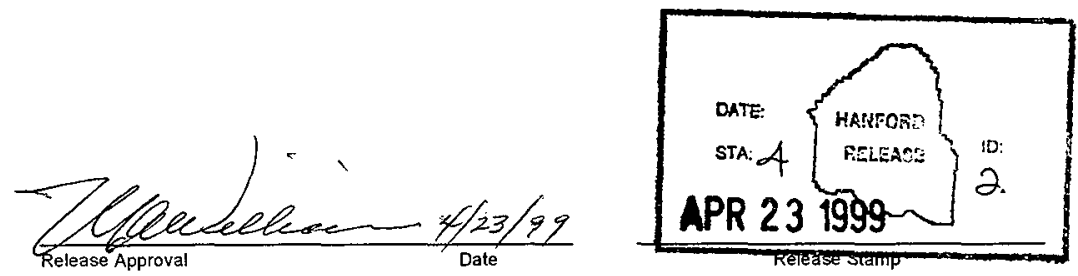


\section{RECORD OF REVISION}

(1) Document Number

HNF -4057

Page 1

(2) Title

Cold Vacuum Drying Proof of Performance (First Article Testing) Test Results

Change Control Record

(3) Revision

(4) Description of Change - Replace, Add, and Delete Pages

(7)

- RS
Original Release EDT \# 140132
Authorized for Release

(5) Cog. Engr. (6) Cog. Mgr. Date

boronseratan els 4/6/99




\section{NHC \\ Numatec Hanford Corporation An SGN/Cogema, Inc. Company}

\section{Cold Vacuum Drying Proof of Performance (First Article Testing) Test Results HNF-4057 Revision 0}

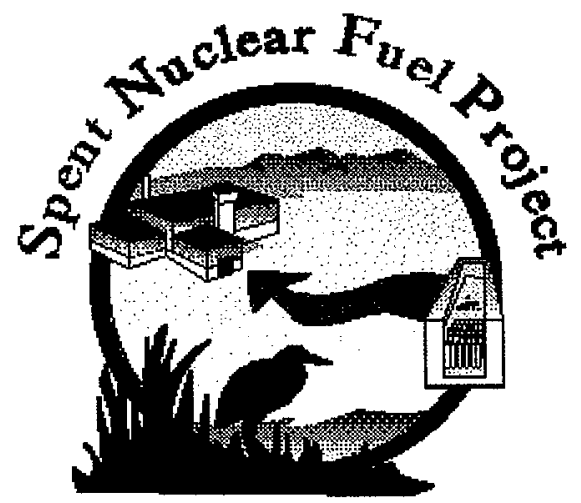

K. J. McCracken

L. R. Schroeder

B. C. Fryer

for

Duke Engineering Services Hanford

P.O. Box 1970

Richland, WA 99352

March 1999

Prepared for the U.S. Department of Energy under Contract DE-AC06-96RL13200 


\section{Executive Summary}

This document provides the test results from the Cold Vacuum Drying (CVD) first article testing program conducted in the Hanford 300 Area 306E building. Many test runs were conducted to determine MCO drying times, equipment reliability, and control system performance. While determining the Multi-Canister Overpack (MCO) drying times, the equipment reliability issues and the control system operation problems were identified and solutions provided. The MCO drying times, with a nominal fuel loading and a normal drying sequence, averaged slightly more than thirty $(30)$ hours. With a load of damaged fuel including scraps and fines the drying time was over fifty $(50)$ hours. This was with a retained water loading of 22 liters. The drying time for actual fuel will depend on the amount and extent of damage and therefore amount of retained water. The extended drying time can significantly affect the total drying and process time for each MCO. For pristine fuel, the drying time was just under thirty (30) hours. The total cycle time, from cask lid removal to the lid being reinstalled for a nominal fuel loading, was over seventy (70) hours. The total cycle time includes time for: initial connections; system integrity and leak checks; $\mathrm{MCO}$ and fuel heating; system purges; $\mathrm{MCO}$ draining; MCO drying and thermal resetting; pressure rebound testing; dryness verification testing; $\mathrm{MCO}$ cooling; MCO leak checking; cask purging and drying; system draining; and removal of connections. This report also discusses the amount of helium usage during typical processing conditions and system effects during selected upset conditions. 


\section{Quality Assurance}

This work was conducted under the Quality Assurance Program, DE\&S Hanford, Inc, AP-11-014, Spent Nuclear Fuel Project Quality Assurance Program Plan and project specific procedures, specifications, and plans, such as: HNF-2402, Hanford Spent Nuclear Fuel Cold Vacuum Drying Proof of Performance Test Procedure and HNF-SD-SNF-TP-036, Hanford Spent Nuclear Fuel Cold Vacuum Drying Proof of Performance Test Specification and Test Plan. AP-11-014 has been evaluated and determined to effectively implement the requirements of HNF-MP-599, Project Hanford Quality Assurance Program Description. Compliance with AP-11-014 and procedure, specification and test plan requirements was mandatory for developmental testing activities. 


\subsection{Basket Water Retention}

3.1.1 Water Retention Test Apparatus

3.1.2 Water Retention Test Procedure Summary

3.1.4 Basket Water Retention Discussion of Results

3.1.5 Basket Water Retention Conclusions and Recommendations

3.2 Ventilation Hood Air Flow Establishment

3.2.1 Ventilation Hood Test Apparatus

3.2.2 Ventilation Hood Test Procedure Summary

Ventilation Hood Test Results

3.2.4 Ventilation Hood Discussion of Results

3.2.5 Ventilation Hood Conclusions and Recommendations

\subsection{Seal Ring Testing}

3.3.1 Seal Ring Testing Apparatus

3.3.2 Seal Ring Test Procedure Summary

3.3.3 Seal Ring Test Results

3.3.4 Seal Ring Test Discussion of Results

3.3.5 Seal Ring Test Conclusions and Recommendations 3-10

3.4 Process Connector Flushing and MCO Water Ingress 3-11

3.4.1 Process Connector Flushing and MCO Water Ingress Testing Apparatus 3-11

3.4.2 Process Connector Flushing and MCO Water Ingress Test Procedure Summary 3-11

3.4.3 Process Connector Flushing and MCO Water Ingress Test Results 3-12

3.4.4 Process Connector Flushing and MCO Water Ingress Test Discussion of Results 3-14

3.4.5 Process Connector Flushing and MCO Water Ingress Test Conclusions and Recommendations 3-15

\subsection{Bulk Water Removal and Totalization}

3.5.1 Bulk Water Removal and Totalization Apparatus

Bulk Water Removal and Totalization Test Procedure Summary

3.5.5 Bulk Water Removal and Totalization Test Conclusions and Recommendations

\subsection{PRIMARY TESTS RESULTS}

\subsection{Baseline Establishment}

4.1.1 Baseline Test Apparatus

4.1.2 Clean Dry Empty Helium Filled MCO

4.1.2.1 Clean Dry Empty Helium Filled MCO Test Procedure Summary 4-1

4.1.2.2 Clean Dry Empty Helium Filled MCO Test Results

4.1.2.3 Clean Dry Empty Helium Filled MCO Discussion of Results

4.1.2.4 Clean Dry Empty Helium Filled MCO Conclusions and Recommendations 4-2

4.1.3 Clean Dry Empty Helium Filled MCO

4.1.3.1 Clean Dry Empty MCO with $1.9 \mathrm{scfm}$ Helium Purge Test Procedure Summary $\quad$ 4-2

4.1.3.2 Clean Dry Empty MCO with 1.9 scfm Helium Purge Test Results

4.1.3.3 Clean Dry Empty MCO with $1.9 \mathrm{scfm}$ Helium Purge Discussion of Results

4.1.3.4 Clean Dry Empty MCO with $1.9 \mathrm{scfm}$ Helium Purge Conclusions and Recommendations $\quad 4-3$

4.1.4 Clean Dry Empty Helium Filled MCO

4.1.4.1 Clean Dry Empty MCO with 3.0 scfm Helium Purge Test Procedure Summary

4.1.4.2 Clean Dry Empty MCO with 3.0 scfm Helium Purge Test Results 
4.2.1 32 Liters of Water Drying Apparatus $\quad$ 4-4

4.2.2 32 Liters of Water Drying Test Procedure Summary

4.2.3 32 Liters of Water Drying Test Results $\quad$ 4-4

4.2.4 32 Liters of Water Drying Discussion of Results

4.2.5 32 Liters of Water Drying Conclusions and Recommendations 4-6

$\begin{array}{lll}4.3 & \text { Fuel Heating Establishment }\end{array}$

4.3.1 Fuel Heating Apparatus $\quad$ - • ·-6

4.3.2 Fuel Heating Test Procedure Summary

4.3.3 Fuel Heating Establishment Test Results

$\begin{array}{ll}\text { 4.3.4 Fuel Heating Discussion of Results } & \text { 4-8 }\end{array}$

4.3.5 Fuel Heating Conclusions and Recommendations $\quad$ 4-8

4.4 Nominal Fuel Load Drying Tests $\quad$ 4-9

4.4.1 Nominal Fuel Drying Test

4.4.2 Normal Operation Sequence Drying (8-4-4 Sequence) 4-9

4.4.2.1 8-4-4 Sequence Test Procedure Summary $\quad$ 4-9

4.4.2.2 8-4-4 Sequence Test Results $\quad$ 4-10

4.4.2.3 8-4-4 Sequence Discussion of Results

4.4.2.4 8-4-4 Sequence Conclusion and Recommendations $4-11$

4.4.3 Vacuum Pump and Condenser with 1.9 scfm Helium Purge $\quad$ 4-12

4.4.3.1 Vacuum Pump and Condenser with $1.9 \mathrm{scfm}$ Helium Purge Test Procedure Summary 4-12

4.4.3.2 Vacuum Pump and Condenser with $1.9 \mathrm{scfm}$ Helium Purge Test Results 4-12

4.4.3.3 Vacuum Pump and Condenser with $1.9 \mathrm{scfm}$ Helium Purge Discussion of Results

4.4.3.4 Vacuum Pump and Condenser with $1.9 \mathrm{scfm}$ Helium Purge Conclusion and Recommenđations 4-13

4.4.4 Vacuum Pump Drying with 1.9 scfm Helium Purge 4-13

4.4.4.1 Vacuum Pump Drying Test Procedure Summary $\quad 4-13$

4.4.4.2 Vacuum Pump Drying Test Results

4.4.4.3 Vacuum Pump Drying Discussion of Results $\quad$ 4-14

4.4.4.4 Vacuum Pump Drying Conclusion and Recommendations 4-14

4.4.5 Normal Operation Sequence Drying with 1.1 sefm Helium Purge 4-14

4.4.5.1 Normat Operation with1.1 Purge Rate Test Procedure Summary 4 4-15

4.4.5.2 Normal Operation with1.1 Purge Rate Test Results 4-15

4.4.5.3 Normal Operation with1.1 Purge Rate Discussion of Results 4-15

4.4.5.4 Normal Operation with1.1 Purge Rate Conclusion and Recommendations 4-15

4.4.6 Normal Operation Sequence Drying with Reduced Bath Temperature 4-15

4.4.6.1 Normal Operation Sequence Drying with Reduced Bath Temperature Test Procedure Summary 4-15

4.4.6.2 Normal Operation Sequence Drying with Reduced Bath Temperature Test Results 4-16

4.4.6.3 Normal Operation Sequence Drying with Reduced Bath Temperature Discussion of Results 4-16

4.4.6.4 Normal Operation Sequence Drying with Reduced Bath Temperature Conclusion and

Recommendations

4-16 
4.4.7 Redesigned Hood Piping and Revised Normal Operating Sequence Drying

4.4.7.1 Redesigned Hood Piping and Revised Normal Sequence Test Procedure Summary

4.4.7.2 Redesigned Hood Piping and Revised Normal Sequence Test Results

4-18

4.4.7.3 Redesigned Hood Piping and Revised Normal Sequence Discussion of Results

4-18

4.4.7.4 Redesigned Hood Piping and Revised Normal Sequence Conclusion and Recommendations

4.4.8 Flooded Filter Drying

4.4.8.1 Flooded Filter Drying Test Procedure Summary

4.4.8.2 Flooded Filter Drying Test Results

$4-21$

4.4.8.3 Flooded Filter Drying Discussion of Results

$4-21$

4.4.8.4 Flooded Filter Drying Conclusion and Recommendations

$4-21$

4-21

4.5 Pristine Fuel Drying

4.5.1 Pristine Fuel 8-4-4 Sequence Apparatus

4.5.2 Pristine Fuel 8-4-4 Sequence Test Procedure Summary

4.5.3 Pristine Fuel 8-4-4 Sequence Test Results

4.5.4 Pristine Fuel 8-4-4 Sequence Discussion of Results

4.5.5 Pristine Fuel 8-4-4 Sequence Conclusions and Recommendations

4.6 Damaged Fuel Drying

4.6.1 Damaged Fuel 8-4-4 Sequence Apparatus

4.6.2 Damaged Fuel 8-4-4 Sequence Test Procedure Summary

4.6.3 Damaged Fuel 8-4-4 Sequence Test Results

4.6.4 Damaged Fuel 8-4-4 Sequence Discussion of Results

4.6.5 Damaged Fuel 8-4-4 Sequence Conclusions and Recommendations

\subsubsection{Proof Drying Apparatus}

4.7.2 Proof Drying Test Procedure Summary

4.7.3 Proof Drying Test Results

4.7.4 Proof Drying Discussion of Results

\subsection{MCO Cooling}

\subsubsection{MCO Cooling Apparatus}

4.8.2 MCO Cooling Test Procedure Summary 4-26

$\begin{array}{lr}\text { 4.8.3 MCO Cooling Test Results } & \text { 4-27 }\end{array}$

$\begin{array}{lr}\text { 4.8.4 MCO Cooling Discussion of Results } & \text { 4-27 }\end{array}$

4.8.5 MCO Cooling Conclusions and Recommendations $\quad$ 4-27 
4.9 Cask Purging

4.9.1 Cask Purging Apparatus

4.9.2 Cask Purging Test Procedure Summary $\quad$ 4-28

4.9.3 Cask Purging Test Results $\quad$ 4-28

4.9.4 Cask Purging Discussion of Results $\quad$ 4-29

4.9.5 Cask Purging Conclusions and Recommendations $\quad$ 4-29

4.10 Upset Condition Tests $\quad$ 4-29

4.10.1 Loss of Air Upset $\quad$ 4-29

4.10.1.1 Loss of Air Upset Apparatus $\quad$ · $\quad 4-30$

4.10.1.2 Loss of Air Upset Test Procedure Summary

4. 10.1.3 Loss of Air Upset Test Results $\quad$ 4-30

4. 10.1.4 Loss of Air Upset Discussion of Results

4. 10.1.5 Loss of Air Upset Conclusion and Recommendations

4.10.2 Loss of Computer/PLC Upset

4.10.3 Loss of Power Upset $\quad$ 4-31

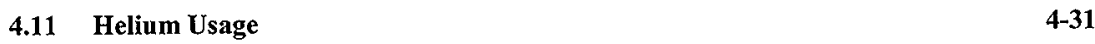

4.12 Special Tool Contingents $\quad$ 4-32

4.13 Sequence Logic and Hardware Enhancements - 4-33

4.13.1 SCHe Logic and Hardware Enhancements 4-33

$\begin{array}{lc}\text { 4.13.2 PWC Logic and Hardware Enhancements } & \text { 4-33 }\end{array}$

4.13.3 Helium Injection Logic and Hardware Enhancements $\quad$ 4-34

4.13.4 Vacuum Pump Cooling Logic and Hardware Enhancements 4-34

5.0 CONCLUSIONS $\quad 5-1$

5.1 First Article Testing Conclusions $\quad 5-1$

5.2 Continued First Article Testing Recommendations 5-1

5.3 Facility Process Start-Up Testing Recommendations 5-3

5.3.1 Recommended Process Tests $\quad$ 5-3

5.3.1.1 Helium Filled MCO Testing $\quad$ 5-3

$5.3 .1 .2 \quad 3.0$ SCFM Helium Purge Testing

5.3.1.3 1.9 SCFM Helium Purge Testing $\quad 5-4$

5.3.1.4 MCO Repressurization Testing $\quad$ 5-4

5.3.2 32 Liter Bulk Water Drying Testing

5.3.3 Nominal Mock Fuel Loading with 8-4-4 Automatic Sequence Testing 5-5

$\begin{array}{llr}5.4 & \text { Issues of Awareness } & 5-5\end{array}$

5.4.1 Flexible Line Routing $\quad$ 5-6

5.4.2 Electrical HeatTrace Settings $\quad$ 5-6

5.4.3 Gas Operated Ball Valve Operation and Status Indication 5-6 
5.4.4 Vacuum Pump Seal Purge Gas $\quad$ 5-7

5.4.5 Process Connector Flushing $\quad$ 5-7

5.4.6 Line Purging $\quad$ 5-7

$\begin{array}{lr}\text { 5.4.7 Cask Purging } & 5-8\end{array}$

5.4.8 Instruement Ranges · $\quad$ 5-8

5.4.9 MCS Full Revision Testing $\quad 5-8$

5.5 Facility Operation Recommendations $\quad 5-9$

6.0 REFERENCES 6-1

\section{LIST OF TABLES}

Table 2-1 - Cupped Scrap Fuel

Table 2-2 - Scrap Basket $3 / 32$ " thickness Fines

Table 2-3 - Scrap Basket $5 / 32$ " thickness Fines

2-13

Table 2-4 - Scrap Basket 1.255" \& 2.378" thickness Fines

$2-13$

Table 2-5 - Thermocouple Location and Function

Table 3-1 - Basket Water Retention Results

Table 3-2 - Basket Water Retention vs. Fuel Type Results

Table 3-3 - Basket Water Retention Expected Error Results

Table 3-4 - Process Ventilation Hood Flow Test Point Data

Table 3-5 - Seal Ring Leak Rate Test Results

Table 3-6 - PWC Operating Parameters

3-16

Table 3-7 - Bulk Water Totalization Test Results

Table 4-1 - Drying Time Comparison (New vs. Old Hood Design) 4-18

Table 4-2 - Pristine Fuel Water Retention Tests Results $\quad$ 4-22

Table 4-3 - Helium Usage $\quad$ 4-32

Table 5-1 - First Article Testing Drying Times $\quad 5-2$

\section{LIST OF FIGURES}

$\begin{array}{ll}\text { Figure 2-1 - Process Equipment Skid (Backside) } & 2-2\end{array}$

Figure 2-2 - Tempered Water area on Process Equipment Skid (Backside) 2-3

Figure 2-3 - Vacuum Purge System area on Process Equipment Skid (Front) 2-3

$\begin{array}{lr}\text { Figure 2-4 - Gas Operated Valve (GOV-2228) } & 2-3\end{array}$

$\begin{array}{lr}\text { Figure 2-5 - Pressure Transducer (PIT-3208) } & 2-3\end{array}$

Figure 2-6-Pressure Transmitter (PT-2208)

Figure 2-7 - Temperature Transducer $\quad 2-4$

Figure 2-8 - Flow Transmitter (FIT-3216)

Figure 2-9 - Flow Transmitter (FIT-1219) $\quad 2-4$

$\begin{array}{lr}\text { Figure 2-10 - Flow Transmitter (Hood) } & 2-4\end{array}$ 
Figure 2-11 - Moisture Transmitter (MT-1216) $2-5$

Figure 2-12 - RGA

Figure 2-13 - TWS pump

Figure 2-14 - VPS pump

Figure 2-15 - TWS Heat Exchanger

Figure 2-16 - VPS Condenser

Figure 2-17 - TWS Heater

Figure 2-18 - PWC Tank

Figure 2-19 - PWC Pump

Figure 2-20-PWC Ejector

Figure 2-21 - MCO Shield Plug

Figure 2-22- $\mathrm{MCO}$

Figure 2-23 - Fuel Basket

Figure 2-24 - Bottom of a Fuel Basket

Figure 2-25 - Scrap Basket with Mock Fuel Scrap

Figure 2-26 - Mock Fuel Elements

$2-10$

Figure 2-27 - Mock Fuel in a Basket

$2-11$

Figure 2-28 - Mock Scrap

2-11

Figure 2-29 - Pristine Fuel

2-14

Figure 2-30 - Damaged Fuel

2-14

Figure 2-31 - Mixed Fuel

2-14

Figure 2-32 - Thermocouple locations $\quad 2-16$

Figure 2-33 - Cask

$2-17$

Figure 2-34 - Seal Ring

$2-17$

Figure 2-35 - Ventilation Hood

$2-18$

Figure 2-36 - Process Connector in Storage Lacation

$2-18$

Figure 2-37 - Process Connectors

$2-18$

Figure 2-38 - SCHe

$2-18$

Figure 2-39 - PLC Cabinet

$2-19$

Figure 2-40 - Input/Output Cabinet $\quad 2-20$

Figure 2-41 - MCS

Figure 3-1 - Water Retention Apparatus $\quad 3-1$

Figure 3-2 - Equation 3-1

Figure 3-3 - Process Hood Plan View Initial Test Points

Figure 3-4 - Process Hood Plan View Final Test Points

Figure 3-5 - Ventilation Flow Test Position A

Figure 3-6 - Ventilation Flow Test Position B

Figure 3-8 - Ventilation Flow Test Position I

Figure 3-9 - Seal Plate O-Rings

Figure 3-10 - Process Connector Test Rig

Figure 3-11 - MCO Test Rig

Figure 3-12 - Process Connector Before Initial Test

Figure 3-14 - MCO Process Plug Valve Before Initial Test 
Figure 3-21 - MCO Bottom During DI Flushing (Second)

Figure 3-23 - Bulk Water Removal and Totalization Test Results

Figure 4-1 -Vacuum Pump Baseline $\quad 4-35$

Figure 4-2 - Vacuum Pump Low Pressure Baseline 4-36

Figure 4-3 - MCO and Vacuum Pump Low Pressure - New Hood Design Initial Baseline 4-37

Figure 4-4 - 1.9, 1.6, $1.3 \mathrm{scfm}$ Helium Pumpdown $\quad 4-38$

Figure 4-5 - $3.0 \mathrm{scfm}$ Helium Pumpdown $\quad 4-39$

$\begin{array}{lr}\text { Figure 4-6 - MCO Pressures } & 4-40\end{array}$

Figure 4-7 - MCO Pressure and Condenser Temperatures $\quad 4-41$

Figure 4-8 - MCO Pressures and Flow $\quad$ 4-42

Figure 4-9 - MCO Pressure and Condenser Temperatures (Retest) 2 4-43

Figure 4-10 - Hood Piping Low Spots (Ice Development Locations) 4-5

Figure 4-11 - Flange Gasket $\quad$ 4-5

Figure 4-12 - System Pressure Losses Before Gasket Removal 4-44

Figure 4-13 - System Pressure Losses After Gasket Removal $\quad 4-45$

Figure 4-14 - Process Hood Flexible Hoses Properly Angled 4-6

Figure 4-15 - MCO Thermocouple Location $\quad$ 4-7

Figure 4-16 - Water Filled MCO Heating Temperature Profiles $\quad$ 4-46

Figure 4-17 - Helium Filled MCO Heating Temperature Profiles

Figure 4-18 - Fuel Basket Loaded With Mock Mixed Fuel Loading 4-9

Figure 4-19 - MCO Pressure and Helium Flow 8-4-4 Sequence Revision N 4-48

Figure 4-20 - MCO Pressure and Condenser Temperatures vs. Time 8-4-4 Sequence Revision N $\quad 4-49$

Figure 4-21 - MCO Pressure and Dew Point Temperatures 8-4-4 Sequence Revision N 4-50

Figure 4-22 - Fuel Temperatures during Drying Sequence 8-4-4 Sequence Revision N 4-51

Figure 4-23 - MCO Differential Pressures 8-4-4 Sequence Revision N 4-52

Figure 4-24 - MCO Pressure and Helium Flow Vacuum Pump and Condenser 4-53

Figure 4-25 - MCO Pressure and Condenser Temperatures Vacuum Pump and Condenser 4-54

Figure 4-26 - MCO Pressure and Helium Flow Vacuum Pump Only - Initial Test 4-55

Figure 4-27 - MCO Pressure and Helium Flow Vacuum Pump Only - Retest Test 4-56

Figure 4-28 - Fuel Temperatures during Drying Sequence Vacuum Pump Only - Retest Test $\quad$ 4-57

Figure 4-29 - MCO Pressure and Helium Flow 8-4-4 Sequence 1.1 SCFM Helium Flow 4-58

Figure 4-30 - MCO Pressure and Condenser Temperatures vs. Time-4-4 Sequence 1.1 SCFM Helium Flow

$4-59$

Figure 4-31 - MCO Pressure and Helium Flow 8-4-4 Sequence $35^{\circ} \mathrm{C}$ Bath Temperature 4-60

Figure 4-32 - MCO Pressure and Helium Flow 8-4-4 Sequence $35^{\circ} \mathrm{C}$ Bath Temperature Retest $\quad 4-61$

Figure 4-33 - MCO Pressure and Condenser Temperatures 8-4-4 Sequence $35^{\circ} \mathrm{C}$ Bath Temperature 4-62

Figure 4-34 - MCO Pressure and Condenser Temperatures 8-4-4 Sequence $35^{\circ} \mathrm{C}$ Bath Temperature Retest

4-63

Figure 4-35 - MCO Pressure and Flow 8-4-4 Sequence Revision 2

Figure 4-36 - Fuel Temperatures during Drying Sequence 8-4-4 Sequence Revision 2 ' 4-65

Figure 4-37 -MCO Low Pressures 8-4-4 Sequence Revision 2 . 4-66

Figure 4-38 - High and Low MCO Pressures vs. Time 8-4-4 Sequence Revision 2

Figure 4-39 - MCO Pressure and Condenser Temperatures vs. Time 8-4-4 Sequence Revision 2 4-68

Figure 4-40 - MCO Pressure and Dew Point Temperature vs. Time 8-4-4 Sequence Revision 2 4-69

Figure 4-41 - Heat Tracing Temperatures 8-4-4 Sequence Revision $2 \quad 4-70$

$\begin{array}{ll}\text { Figure 4-42 - 0.1 Torr Pressure Test } & 4-71\end{array}$

Figure 4-43-0.3 Torr Pressure Test $\quad$ 4-72

Figure 4-44 - Pump Base Pressure 4-73

Figure 4-45 - MCO Pressure and Helium Flow 8--4-4 Sequence Revision 2 Flooded HEPA Filter 4-74 
Figure 4-46 - MCO Draining, DI Flushing and Purging 8--4-4 Sequence Revision 2 Flooded HEPA Filter

Figure 4-47 - Basket With Mock Pristine Fuel Configuration

4-75

4-22

Figure 4-48 - MCO Pressure and Helium Flow Pristine Fuel 8-4-4 Sequence Retest 4-76

Figure 4-49 - MCO Pressure and Flow Pristine Fuel Initial Test

4-77

Figure 4-50 - Fuel Temperatures Pristine Fuel Initial Test

4-78

Figure 4-51 - Fuel Temperatures Pristine Fuel Retest

4-79

Figure 4-52 - MCO Pressure and Condenser Temperatures Pristine Fuel Retest

4-80

Figure 4-53 - Basket With Mock Damaged Fuel Configuration

4-24

Figure 4-54 - MCO Pressure and Helium Flow Damaged Fuel 8-4-4 Sequence

4-81

Figure 4-55 - Fuel Temperatures Damaged Fuel Test

$4-82$

Figure 4-56 - MCO Pressure and Condenser Temperatures Damaged Fuel Test

4-83

Figure 4-57 - Heat Tracing Temperatures Damaged Fuel Test

4-84

Figure 4-58 - MCO Pressures During Proof Drying

4-85

Figure 4-59 - Helium Filled MCO Cooling Temperature Profiles

4-86

Figure 4-60 - Inside and at Bottom of a Cask Initial Test

$4-28$

Figure 4-61 - Bottom of MCO Final Test Observation

4-28

Figure 4-62 - Cask Internal Area - Bottom After Second Test

4-29

Figure 4-63 - Helium Supply Tube Trailer

4-31 


\section{GLOSSARY}

BULK or FREE WATER

CLEAN AND DRY

CVD (Cold Vacuum Drying)

DRY

EDUCTOR

MOCK FUEL
Water that is easily removed from the $\mathrm{MCO}$ or test apparatus by suction and helium backfill.

Visually clean and dry to the touch.

The process of removing water from the $\mathrm{MCO}$ and drying of the fuel using vacuum technology to change liquid water into vapor and drawing the vapor out of the $\mathrm{MCO}$ and into a condenser.

A pressure rise of less than 3 torr in the system over a one hour period.

Same as EJECTOR, or Venturi Jet Pump. A pump with no moving parts that uses fluid circulation to create a low pressure area and draw liquid to this area. As the liquid flows through a gentle constriction in the pump walls, the velocity is increased and a low pressure point is formed just downstream of the smallest constriction point. At the point of low pressure, a line tap is introduced and this tap is the suction point for evacuating a chamber. The liquid pulled in from the chamber is mixed with the already circulating liquid and this action of recirculation keeps the low pressure area established and maintains a suction on the chamber.

Unpainted carbon steel tubing that simulates the $\mathrm{N}$ Reactor fuel, consisting of an inner and outer fuel element with approximately the same outside and inside diameter and wall thickness. The mock fuel will closely approximates the surface area of the real fuel. All the mock fuel elements were allowed to rust throughout the testing and some elements were initially damaged to provide water retention sites and scrap as seen on the $\mathrm{K}$ Basin fuel and scrap. Cups were added to the top of the mock fuel elements to represent water retention sites.

The process connectors are valve bodies bolted to the $\mathrm{MCO}$ that allow for MCO and the Vacuum Purge System (VPS) communication for processing. The process connectors were prototypic and fabricated from carbon steel for this testing. 
NO PURGE VACUUM CHECK

NORMAL SEQUENCE (8-4-4 Cycle)
A system verification near the end of the drying cycle with the condenser bypassed to check for MCO pressure below 9 torr. If system pressure is 9 torr or less the helium purge of $1.9 \mathrm{scfm}$ can be stopped during vacuum evacuation cycles. This point signifies that there is not enough pressure to cause a radioactive release in the event of a hydrogen deflagration.

test is an 8 hour operation with the vacuum pump, condenser and helium purge (at $1.9 \mathrm{scfm}$ ). This is followed by a 4 hour helium purge, initially the helium flow is increased to 10 $\mathrm{scfm}$ to quickly change from vacuum to pressure at one half psig then reduced to (Thermal Reset) $1.9 \mathrm{scfm}$ while pressure continues to rise to one psig. The Thermal Reset is followed by 4 hours of vacuum pump evacuation, similar to the initial 8 hour evacuation. The condenser may or may not be bypassed during this cycle. The sequence now repeats the 4 hour Thermal Reset and 4 hour vacuum evacuation cycles for the duration of the MCO drying.

RETAINED WATER

SLUDGE SIMULANT

TEST LOGBOOK

TEST PROCEDURE

THERMAL RESET
Water remaining on MCO internals after bulk water has been removed.

The sludge simulant represents the expected material generated during transport of the MCO to CVDF and during the heat up process at the CVDF. The sludge simulant used for testing was cerium oxide due to it's similarity to uranium oxide in density and particle size.

A logbook for recording all data and observations during each phase of testing by the test performer, or test participants, which are not included in a test procedure.

A procedure that determines the sequential steps for each test and provides documentation for process parameters that will be established during the testing.

A helium purge to provide a cooling medium for radioactive decay heat removal from the Spent Nuclear Fuel (SNF) to maintain temperatures below the $50 \mathrm{C}$ design criteria. Thermal Reset starts by initially raising helium flow to 10 scfm. The increased flow is used to quickly take the system from vacuum to a slightly pressurized condition. As the system reaches $.5 \mathrm{psig}$, the helium flow is reduced to 1,9 $\mathrm{scfm}$. The $1.9 \mathrm{scfm}$ flow rate is continued for the remainder of the 4 hour cycle and pressure within the system will be raised to one psig. 


\section{ACRONYMS/ABBREVIATIONS}

\begin{tabular}{|c|c|}
\hline APV & Manufacturer name for canned motor \\
\hline CVD & Cold Vacuum Drying \\
\hline CVDF & Cold Vacuum Drying Facility \\
\hline CSB & Canister Storage Building \\
\hline DOE & Department of Energy \\
\hline $\mathrm{ECN}$ & Engineering Change Notice \\
\hline EDL & Engineering Development Laboratory \\
\hline GOV & Gas Operated Valve \\
\hline HEPA & High Efficiency Particulate Filter \\
\hline HMI & Human Machine Interface \\
\hline HNF & Hanford \\
\hline I \& $\mathrm{C}$ & Instrumentation and Control \\
\hline $\mathrm{I} / \mathrm{O}$ & Input/Output \\
\hline IWTS & Integrated Water Treatment System \\
\hline JHA & Job Hazard Analysis \\
\hline LCU & Local Control Unit \\
\hline $\mathrm{MCO}$ & Multi Canister Overpack \\
\hline MCS & Monitoring and Control System \\
\hline M\&TE & Measurement and Test Equipment \\
\hline MSDS & Material Safety Data Sheet \\
\hline $\mathrm{NDE}$ & Non Destructive Examination \\
\hline PES & Process Equipment Skid (VPS/TWS) \\
\hline PLC & Programmable Logic Controller \\
\hline PWC & Process Water Conditioning \\
\hline QA/QC & Quality Assurance/Quality Control \\
\hline RGA & Residual Gas Analyzer \\
\hline RTD & Resistance Temperature Detector \\
\hline $\mathrm{SC}$ & Safety Class \\
\hline SCFM & Standard Cubic Feet per Minute \\
\hline $\mathrm{SCHe}$ & Safety Class Helium \\
\hline SCIC & Safety Class Instrumentation and Control \\
\hline SD & Supporting Document \\
\hline SNF & Spent Nuclear Fuel \\
\hline SNFP & Spent Nuclear Fuel Project \\
\hline $\mathrm{TP}$ & Test Plan \\
\hline TRB & Test Review Board \\
\hline TWS & Tempered Water System \\
\hline VPS & Vacuum Purge System \\
\hline WRT & Water Retention Tank \\
\hline
\end{tabular}




\subsection{INTRODUCTION}

\subsection{BACKGROUND}

The Hanford Spent Nuclear Fuel Project has developed a plan to remove and provide interim storage for the Spent Nuclear Fuel (SNF) that is in the Hanford K-reactor fuel storage basins. The fuel will be removed from storage, cleaned, repackaged and stored in tubular containers called Multi-Canister Overpacks (MCOs) that will be backfilled with helium. Prior to interim storage in the 200 area Canister Storage Building (CSB), the free water must be removed to ensure that the fuel does not degrade further by corrosion. The water/fuel corrosion would result in pressurized MCOs with high concentrations of hydrogen. Given the proper circumstances, an upset condition could provide a spark, rupture an MCO, allowing air ingress, and ignite the hydrogen rich $\mathrm{MCO}$ atmosphere. This could send radioactive contamination beyond the site boundaries. A facility and equipment has been designed to remove and dry the free water from approximately $440 \mathrm{MCOs}$ each containing SNF. This facility is the Cold Vacuum Drying Facility (CVDF).

The CVDF contains process equipment specifically designed to dry a MCO in each CVDF operational process bay. This processing equipment consists of: a Process Equipment Skid (PES), a process ventilation hood piping and seal ring assembly, a Process Water Conditioning (PWC) system, a Safety Class Helium injection system (SCHe), and a Monitoring and Control System (MCS) together with a transportation cask, and MCO. The process system, consisting of these actual (first article) and prototypic components, has been assembled to test the viability, equipment and system operation, and certain features of the SNF Cold Vacuum Drying (CVD) process. The "first article" test assembly is housed in the Hanford 300 area, 306-E building.

\subsection{OBJECTIVE}

This report details the equipment used for the first article test program, results from the initial pre-test findings, results from the process tests, details the programming and hardware changes made during the testing. This report is the second and final report for the first article testing program. The first report, HNF3342, Hanford SNF CVD First Article Initial Test Finding Report, detailed initial testing impacts to the hardware and process design (procurement specifications, fabrication drawings, and piping and instrumentation diagrams).

The test plan (HNF-SD-SNF-TP-036, Hanford SNF CVD Proof of Performance Test Specification and Test Plan), under which the initial testing was completed, described process parameters such as water retention amounts, establishment of vacuum process, and drying times as part of the data generated by the first article testing program. Additional testing described as feature tests were also completed, including verifying the performance of specific hardware such as: the vacuum pump, the condenser/chiller, MCO process connectors, ventilation hood, and the system piping and valving.

The tests described in the following report were conducted in accordance with HNF 2402, Hanford Spent Nuclear Fuel Cold Vacuum Drying Proof of Performance Test Procedure governed by HNF-SD-TP-036 Rev. 0A, Hanford Spent Nuclear Fuel Cold Vacuum Drying Proof of Performance Test Plan and Test Specification, and reported in HNF 4288, Hanford Spent Nuclear Fuel Cold Vacuum Drying Proof of Performance Test Report. 


\subsection{FIRST ARTICLE TESTING SYSTEM}

\subsection{First Article Testing Systems Overview}

The Vacuum Purge System (VPS) and Tempered Water System (TWS) constitute the first article Process Equipment Skid (PES) for Cold Vacuum Drying (CVD) to undergo proof of performance testing. The remaining components of the CVD system include: the Multi-Canister Overpack (MCO), the cask, the Process Water Conditioning (PWC) skid, the MCO/Cask Seal Ring and the Local Process Ventilation Hood systems and the Safety Class Helium (SCHe) injection system are actual components, prototypes or mockups. These components, prototypes and mock-ups will be described in more detail in the following sections. Refer to Figure 4 (First Article Test Bed Layout) of HNF-2402, (Hanford Spent Nuclear Fuel Cold Vacuum Drying Proof of Performance Test Procedure), and the drawing H-1-83770 First Article Testing, Piping and Instrumentation Diagram, for additional information on the first article testing components. Miscellaneous instrumentation and hand isolation valving will be included in any of the test. components fabricated in the test facility.

- $\quad$ Process Equipment Skid (PES) - The skid houses the various system components, piping, and instrumentation for the Vacuum Purge System (VPS) and the Tempered Water System (TWS). This skid is the first article for performance testing (first article testing).

- VPS - contains the vacuum pump, helium purge system, heat exchanger (condenser), Residual Gas Analyzer (RGA), piping, valving, and instrumentation required for the vacuum drying process.

- TWS - contains the pump, heater, cooler, piping, valving, and instrumentation designed to heat the $\mathrm{MCO}$ (to $85^{\circ} \mathrm{C}$, or cool it to $10^{\circ} \mathrm{C}$ ) while inside the transporter cask. During normal operations, the TWS will operate between $25^{\circ} \mathrm{C}$ $\left(77^{\circ} \mathrm{F}\right)$ and $50^{\circ} \mathrm{C}\left(122^{\circ} \mathrm{F}\right)$.

- Process Water Conditioning (PWC) System - This skid contains the pumps, eductor, storage tanks, piping, valving, and instrumentation required to remove bulk water from one full $\mathrm{MCO}$, to remove $\mathrm{MCO} /$ cask tempered water from the cask, and to remove condensate drop out tank water. The water collected is processed for return to the Integrated Water Treatment System (IWTS) in the basins. A mock-up was used for this performance testing.

- Multi-Canister Overpack (MCO) - The MCO is the vessel that will hold nearly 5 metric tons of SNF assemblies within specially designed baskets during interim storage. A full scale prototype with mock fuel elements was utilized for the first article testing program.

- Cask - The cask is the vessel that holds the MCO during transport from the CSB to the KBasins where the $\mathrm{MCO}$ baskets are loaded with SNF. The cask, $\mathrm{MCO}$ and loaded baskets are then transported to the CVDF for drying. Finally the cask and MCO loaded with dry $\mathrm{SNF}$ are returned to the $\mathrm{CSB}$ for $\mathrm{MCO}$ interim storage. The cask is reloaded with another $\mathrm{MCO}$ and baskets for the process cycle to start again.

- $\quad$ Process Hood and Piping Assembly - The hood piping assembly is the piping, valves, and instrumentation that provides the interface between the $\mathrm{MCO}$ /cask and the PES. 
- Seal Ring Assembly - The seal ring is the apparatus that is bolted to the cask top to create a seal between the cask and the MCO to complete the tempered water closed loop system. Inflatable O-Rings provide the seal. The process ventilation hood attaches permanently to the seal ring and provides airflow for removing airborne contaminants (in the CVDF) at the top of the MCO. The hood is also used to house the process connectors. The seal ring/process ventilation hood assembly was a prototype rather than fabricated as a first article for these performance tests.

- Process Ventilation Hood - The ventilation hood provides engineered radiological control of the area surrounding the top of the MCO. The process hood is designed to pull airbome particulate away from the operator breathing zone at a velocity of $125 \mathrm{ft} / \mathrm{min}$.

- $\quad$ Safety Class Helium (SCHe) Injection and Safety Class Instrumentation and Control Systems (SCIC) - Safety Class Helium and Safety Class Instrumentation and Controls are defined as the stand alone redundant systems that are fail safe to prevent hydrogen burn and thermal runaway reactions inside the MCO in the CVDF. These systems will be a mock up for performance test applications.

- Monitoring and Control System (MCS) - The MCS is the computer hardware and software including the programmable logic controllers, remote I/O panels, and instrumentation to monitor and control the CVD process.

\subsection{Process Equipment Skid}

The PES contains the piping, valving, instrumentation, pumps, and heat exchangers to process an MCO. As defined above the PES consists of the VPS for drying the retained water inside the MCO and the TWS for heating and cooling the MCO, cask, and SNF.

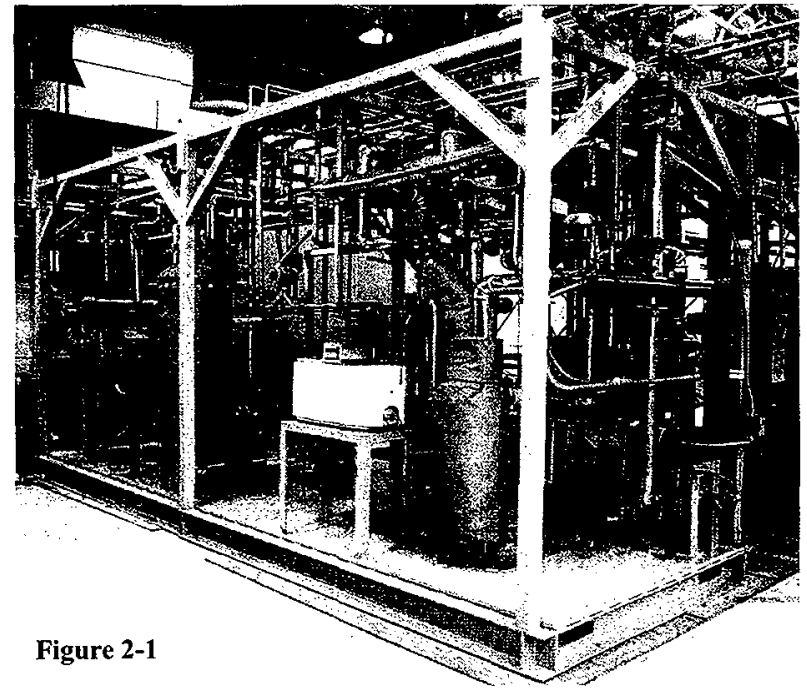




\subsubsection{Piping and Valving}
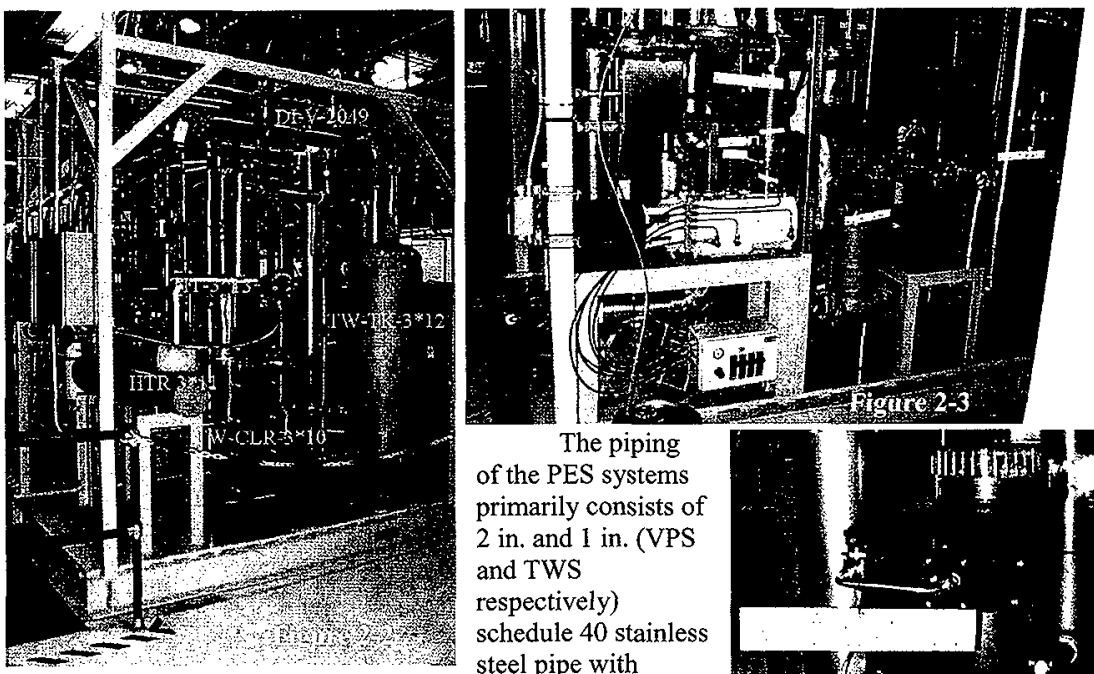

$\quad$ The piping
of the PES systems
primarily consists of
2 in. and 1 in. (VPS
and TWS
respectively)
schedule 40 stainless
steel pipe with

reducers to Worcester ${ }^{(B)} 1$ in. isolation, air actuated ball valves with reinforced Teflon seats and seals. The helium system consists of 1 in. schedule 40 stainless steel pipe and the same 1 in. ball valves.

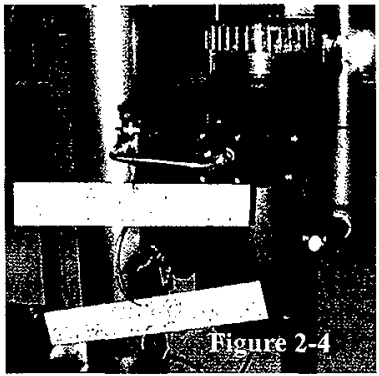

\subsubsection{Instrumentation}

The instrumentation on the PES and Hood piping provide valuable information about the MCO dryness, process status, and system diagnostics. The instrumentation consists of several pressure transducers, vacuum pressure transmitters, platinum RTD temperature transmitters, water and gas flowmeters, a dew point sensor, and a RGA.

The pressure transducers are Rosemont ${ }^{\text {B }} 1151$ GP gage pressure transducers. Gage pressure transducers, selected in design, determines the pressure inside the MCO relative to atmosphere. These, in conjunction with the system Fisher pressure control valves and the MCS, monitor and provide helium pressure in the MCO from near 0 psia to 27 psia during thermal reset helium purges, cooldown, or safety class activation events (1153 GP).

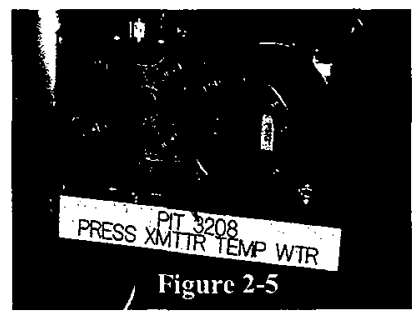




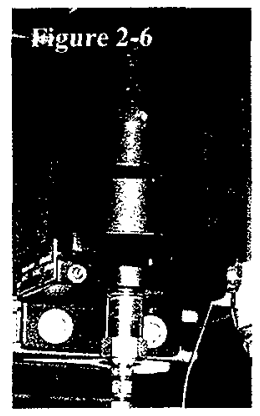

The vacuum pressure is indicated by MKS ${ }^{\circledR} 430$ series, capacitance manometer, vacuum pressure transducers on the vacuum skid and $\mathrm{MKS}^{(B)} 230$ and 427 series vacuum pressure transducers or the hood piping prototype in the first article testing. These instruments provide the vacuum pump inlet pressure and the MCO internal pressure respectively ranging from $10^{-2}$ to 100 torr.

The Rosemont ${ }^{\circledR} 2500$ series dual RTDs and Rosemont ${ }^{\circledR}$ 3244 series transmitters provide the process temperatures for system control. and trip points. The RTDs measure temperatures from $0^{\circ} \mathrm{C}$ to $100^{\circ} \mathrm{C}$ The RTDs are mounted in thermowells for maintenance and calibration ease. Each thermowell and RTD varies in length depending on its location in the process piping to ensure gas stream conductivity.
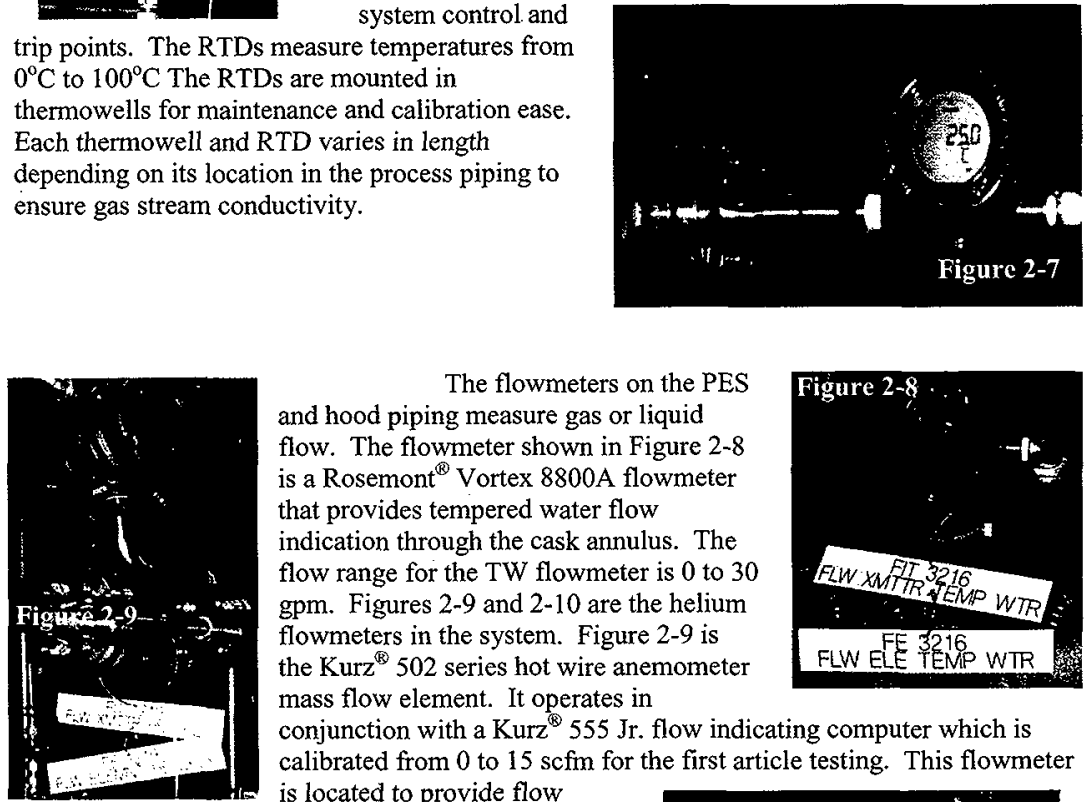

The flowmeters on the PES and hood piping measure gas or liquid flow. The flowmeter shown in Figure 2-8 is a Rosemont ${ }^{\circledR}$ Vortex $8800 \mathrm{~A}$ flowmeter that provides tempered water flow indication through the cask annulus. The flow range for the TW flowmeter is 0 to 30 gpm. Figures 2-9 and 2-10 are the helium flowmeters in the system. Figure 2-9 is the Kurz ${ }^{1} 502$ series hot wire anemometer

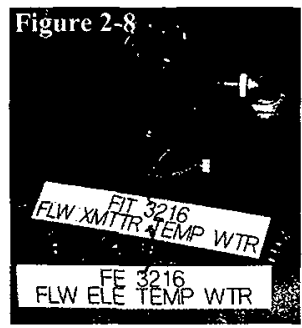
mass flow element. It operates in conjunction with a Kurz ${ }^{\circledR} 555$ Jr. flow indicating computer which is calibrated from 0 to $15 \mathrm{scfm}$ for the first article testing. This flowmeter is located to provide flow indication during both normal drying helium flow operations and reverse flow draining operations. Figure $2-10$ is the $\mathrm{FCI}^{\circledR} \mathrm{LT} 87$ hot wire mass flowmeter. This flowmeter provides the safety class flow indication 0 to $15 \mathrm{scfm}$ of helium into the MCO in the actual CVD process.

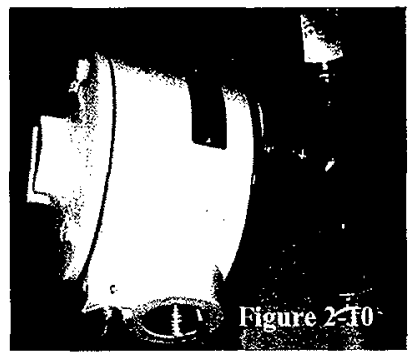




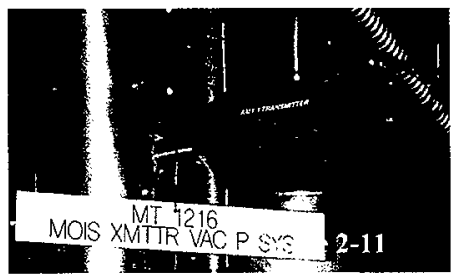

The Panametrix ${ }^{(8)}$ AMX 1 dew point sensor also provides indication of MCO dryness. Dew point is an indication of dryness in a vacuum. The lower the dew point, the dryer the system. The dew point indication is recorded from $-60^{\circ} \mathrm{C}$ to $20^{\circ} \mathrm{C}$

The Residual Gas Analyzer (RGA) is a Balzers ${ }^{\circledR}$ Omnistar ${ }^{\mathrm{M}}$ with a gas dosing valve that allows the analyzer to operate at slightly above atmospheric pressures. This particular RGA provides analysis of the gas stream from the MCO from 0 to $100 \mathrm{amu}$ with detectable limits in the parts per billion $(\mathrm{ppb})$ range. This instrument provides diagnostic information by detecting air or steam concentrations of the gases in the gas stream. The RGA will detect radioactive gases released from breached cladding when

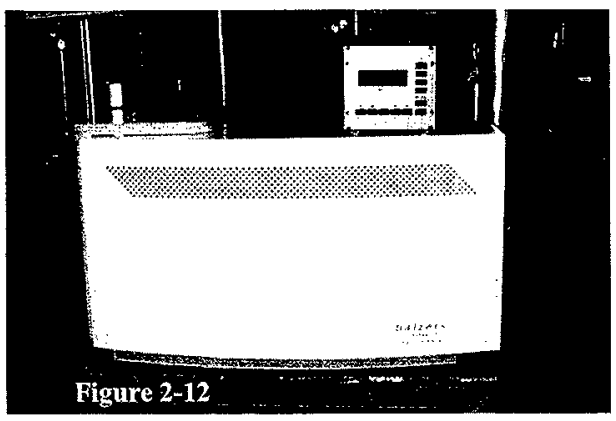
used with SNF. The RGA used in the final design will be 0 to $200 \mathrm{amu}$ for detection of fission gases higher than 100 amu (Xenon).

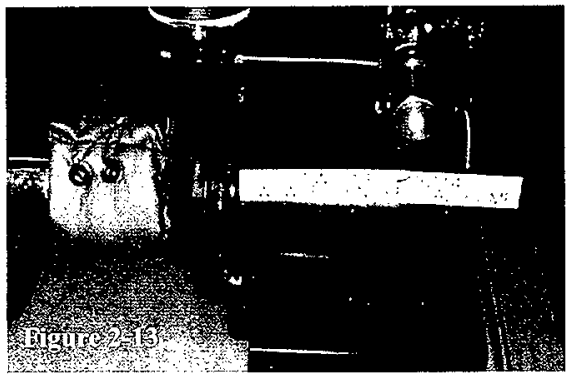

\subsubsection{Pumps}

The pump that provides the circulation for the TWS is an APV $V^{(1)}$ canned motor pump. The canned motor pump uses the circulation medium as bearing cooling. This particular pump provides $20 \mathrm{gal} / \mathrm{min}$ at 35 psi head pressure.

The Pfeiffer ${ }^{(\otimes)}$ Unidry ${ }^{\mathrm{TM}} 50$ 4-stage Roots vacuum pump provides the driver for drying the $\mathrm{MCO}$ and is the heart of the VPS. This pump is designed to evacuate a chamber from above atmospheric pressures to vacuum ranges near $1 \times 10^{-2}$ torr range with a throughput of $35 \mathrm{scfm}$. The Unidry requires a main bearing purge gas (helium) to ensure gear lube from the pump crankcase does not enter the vacuum chamber. The pump also has interstage gas purges to ballast and dry the pump as necessary.

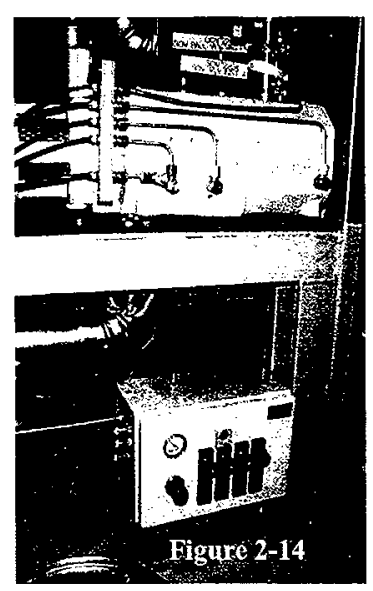




\subsubsection{Heat Exchangers}

The TWS heat exchanger provides cooling for the cask and MCO. The heat exchanger is controlled by an isolation ball valve and is supplied by $10^{\circ} \mathrm{C}$ water at $20 \mathrm{gpm}$ at $50 \mathrm{psig}$ from the CVDF ventilation chilled water system. For the first article testing, the $306 \mathrm{E}$ facility chilled water supplied the cooling water at $13^{\circ} \mathrm{C}$ with a flow of $3 \mathrm{gpm}$ at $50 \mathrm{psig}$. The heat exchanger is designed to cool the $\mathrm{MCO}$ wall from $50^{\circ} \mathrm{C}$ to $25^{\circ} \mathrm{C}$ within 6 hours.

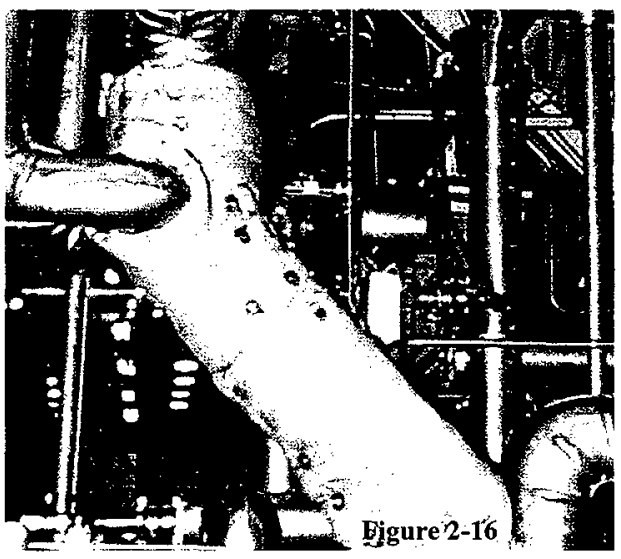

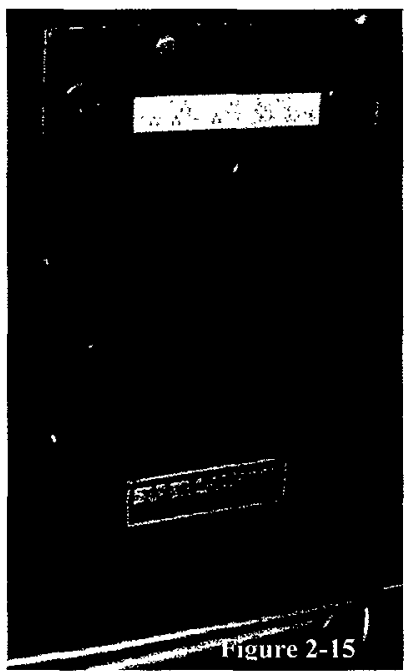

The VPS also utilizes a heat exchanger more commonly referred to as a condenser for this process. The condenser provides a cold spot in the vacuum system for the steam to condense out of the system. The condensed liquid is collected in a tank for later treatment. The condenser

becomes a high capacity vacuum pump for condensable species once the temperature is lowered below the saturation temperature of water for the partial pressure of water in the process stream.

\section{2 .5 Heater}

The TWS heater is a 100 -kilowatt heater controlled by Silicon Controlled Rectifiers (SCR) and the MCS. The MCS is programmed with a Proportional and Integral (PI) control algorithm which uses the temperature set point and heater outlet temperatures as control points. The PI controller activates the SCR which controls the amount of power to the heater coils. The PI controller is programmed such that the heater outlet temperature closely approaches the temperature set point without overshoot.

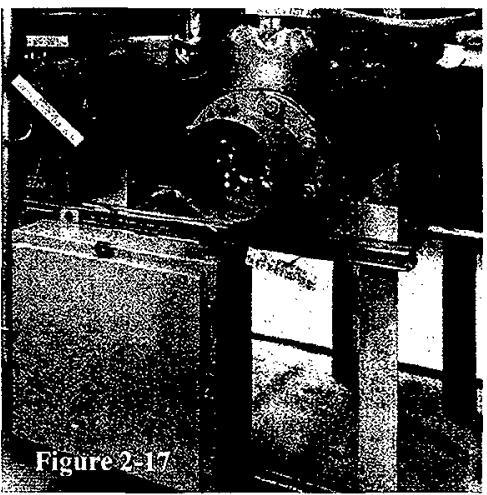




\subsection{PWC System}

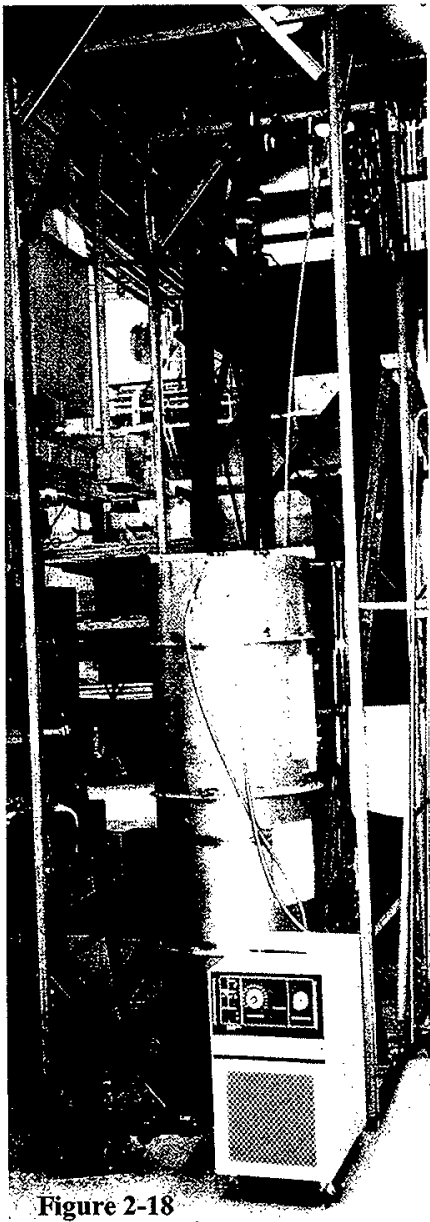

The Process Water Conditioning Skid utilized the design specified per W-441-P2 Revision N procurement specification as a basis for fabrication. The PWC system mock-up consists of a design specified ejector jet pump, a non-prototypic pump that closely matches the flow characteristics of the design specified pumps, a single tank which doubles as the water retention tank, and one other tank for overflow during certain process sequences. The system includes the capability for heated water refill of the $\mathrm{MCO}$ by siphoning water from the tank to the $\mathrm{MCO}$ through the long dip tube (only for testing).

\subsubsection{Piping and Valving}

The piping of the circulation system is fabricated from PVC pipe with removable unions to allow basket water inventory measurements to be completed. All piping to the PWC skid from the VPS skid is prototypic (equivalent length and inside diameter) and the piping from the PWC skid boundary flange to the ejector is prototypic. The equivalent length piping also includes system check valves for typical flow path characteristics. The check valves were installed with manual bypass valves so that the $\mathrm{MCO}$ could be refilled by reversing the flow from the PWC tanks to the MCO. Accurate water volumes were obtained using the water retention apparatus described in Section 3.1.1.

\subsubsection{Tanks}

The tanks in the PWC system were not prototypic. As stated earlier one tank was also utilized as the water retention and totalization device. The additional tank was utilized only during automatic sequences to provide an additional reservoir for the water during the bulk water drain and line-flushing portion of the operation.

The PWC tank had the capability of being heated to reduce MCO heating time. A small water heat exchange pumping system would circulate water between the PWC tanks during processing. The heated water would be transferred to the MCO by bypassing the PWC system check valves, evacuating the $\mathrm{MCO}$ with the PES vacuum pump, opening a diptube inserted in the PWC tank, and opening the process hood piping PWC isolation valve. 


\subsubsection{Pump}

The pump in the PWC mock-up is a Eastern centrifugal pump ECH3 that provides 48 gpm at $144 \mathrm{ft}$. of head, comparable to the design specified APV canned motor pump which provides $45 \mathrm{gpm}$ at $139 \mathrm{ft}$. of head.
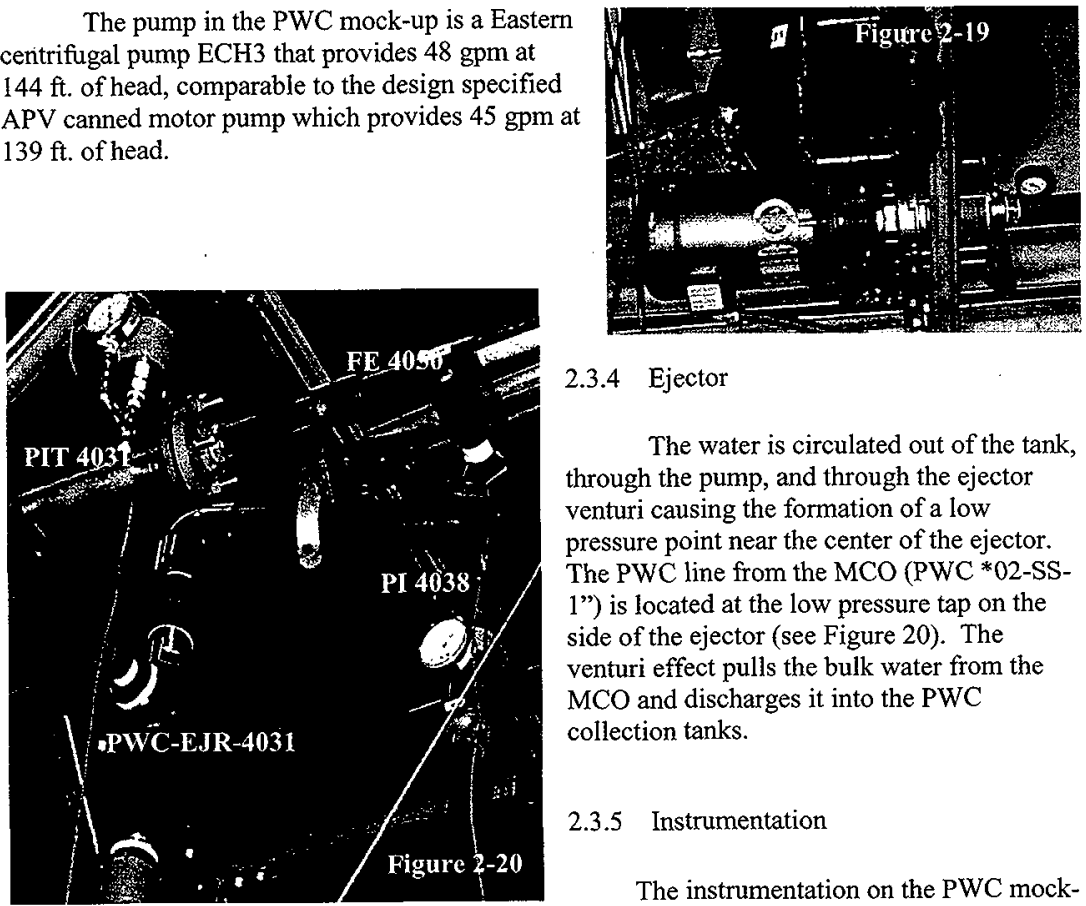

\subsubsection{Ejector}

The water is circulated out of the tank, through the pump, and through the ejector venturi causing the formation of a low pressure point near the center of the ejector. The PWC line from the MCO (PWC *02-SS1 ") is located at the low pressure tap on the side of the ejector (see Figure 20). The venturi effect pulls the bulk water from the $\mathrm{MCO}$ and discharges it into the PWC collection tanks.

\subsubsection{Instrumentation}

The instrumentation on the PWC mockup skid. is all non-prototypical but has similar functions to the design specified instrumentation. The flow meter is a rotary vane flow meter that detects the liquid to gas phase change because flow will quickly increase. The pressure transducers measure and transmit system pressures and tank levels to the MCS.

Weld Cap

\section{Port \#3 Long Dip Tube}

Locking Ring

Shield Plug

HEPA Filters

MCO Parts

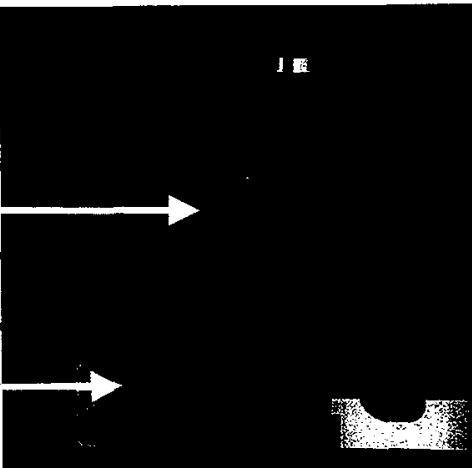

Figure 2-21 


\subsection{MCO}

The MCO for the CVD first article testing is the Phase 1 prototypic mechanical closure MCO (see Figure 222). The MCO shell, collar, bottom, and miscellaneous components (except the shield plug, locking ring, and set screws see figure 2-21) were fabricated with 316 stainless steel. The shield plug and locking ring were fabricated with carbon steel castings. The shield plug required extensive modifications to simulate the actual MCO process connections that CVDF operations personnel will be required to perform in the field. The modifications included provisions for simulating the shield plug flow paths and pressure losses through the filter guard plate, the internal HEPA filters, and the shield plug.

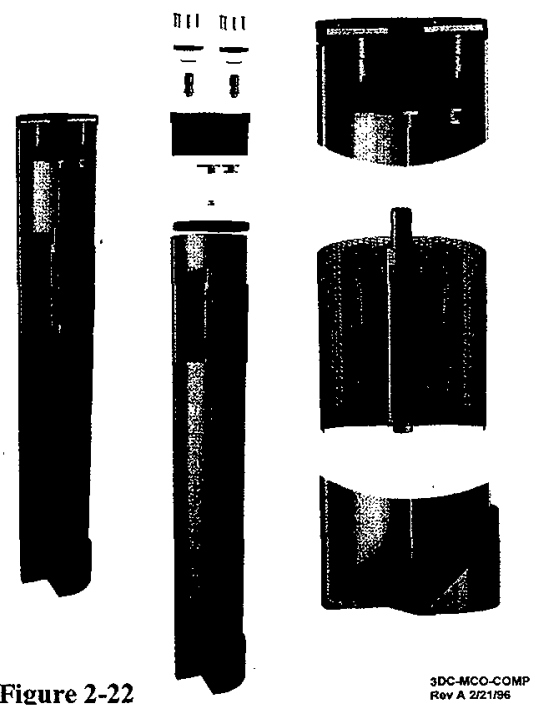

\subsubsection{Fuel Baskets}

The Mark IV fuel baskets were fabricated to a $90 \%$ MCO final design, nearly 18 months before the commencement of first article testing. The four fuel baskets were constructed with carbon steel components rather than stainless steel for fabrication ease. During set-up of this testing program, design modifications to the MCO Mark IA and the Mark IV fuel baskets were being considered by the MCO sub project. These modifications included a solid basket baseplate with two $1 / 2$ in. drainage holes per fuel element pocket (see Figure 2-24). This solid baseplate would have a definite impact against the first article water totalization and locations tests. 
Additional baseplates (with drain holes located per the design modification) were fabricated from $1 / 4$ in. Carbon steel plate and welded on to the existing basket baseplates.
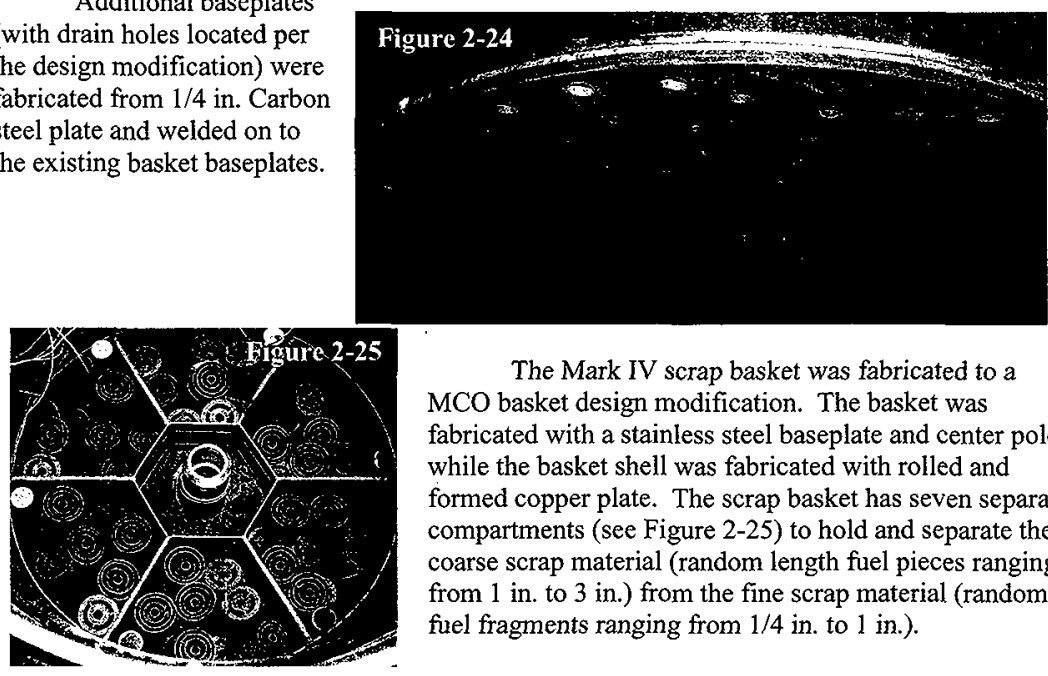

The Mark IV scrap basket was fabricated to a MCO basket design modification. The basket was fabricated with a stainless steel baseplate and center pole while the basket shell was fabricated with rolled and formed copper plate. The scrap basket has seven separate compartments (see Figure 2-25) to hold and separate the coarse scrap material (random length fuel pieces ranging from 1 in. to 3 in.) from the fine scrap material (random fuel fragments ranging from $1 / 4$ in. to $1 \mathrm{in}$.).

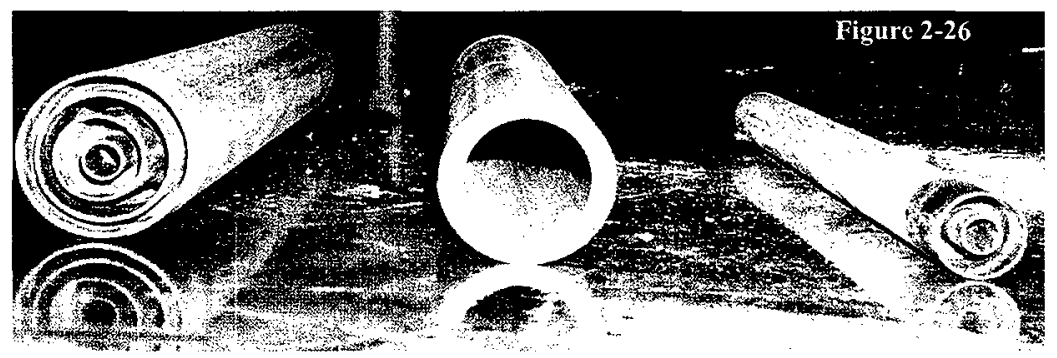

\subsubsection{Fuel Type}

The mock fuel was fabricated from readily available carbon steel tubing. A standard tubing size was selected that most closely matched the inside and outside diameters of the inner and outer Mark IV fuel assemblies (see Figure 2-26). Each fuel element was fabricated with a pristine end and a damaged end. The damaged end consisted of two pieces of thin wall tubing, 2 in. long, being welded to the ends of each inner and outer fuel assemblies. The two thin wall tubing pieces were sized to correspond to the inside and outside diameters of the perspective fuel assembly. These formed a 2 in. deep cavity on one end of the fuel assembly. This allows the MCO fuel configuration to be changed by easily turning the fuel element upside down in the fuel basket. 
The carbon steel elements do not posses the same radioactive decay heat as the actual fuel elements but carbon steel has about twice the thermal conductivity and volumetric specific heat of Uranium which will provide better heat transfer and help offset the lack of radioactive decay heat. The Mark IV fuel configuration was chosen over the Mark IA fuel because of slightly more fuel surface area to retain water during the bulk water removal process. Painting of the fuel elements was also considered to prevent rusting during the CVD process but if the fuel elements were allowed to rust this would simulate an ever increasing sludge layer on the fuel that may retain more water and become increasingly harder to dry after repeated testing.

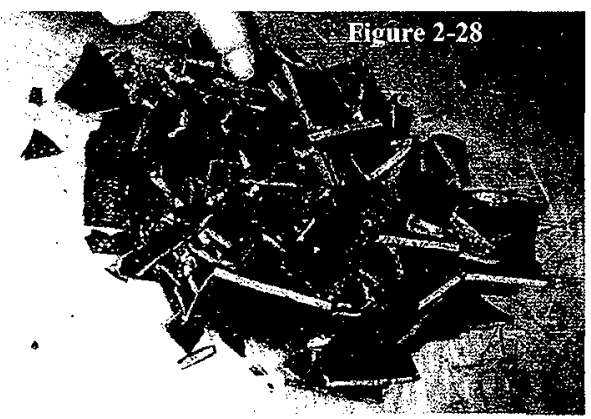

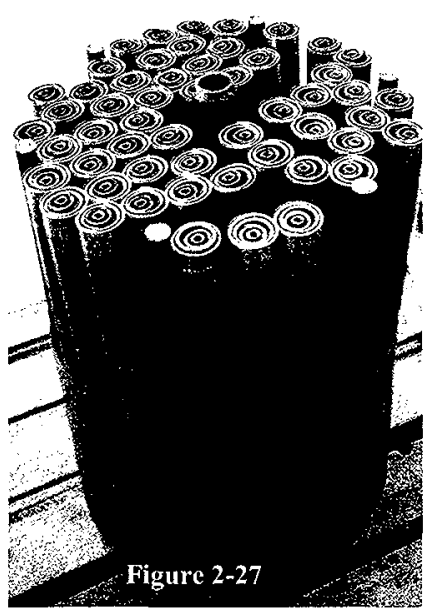

The coarse scrap was fabricated from carbon steel mock fuel elements. The elements were cut into pieces (see Figure 2-27) ranging in length from $1 / 4$ in. to 3 in. (see Table 2-1). A majority of the fines were fabricated from cast iron pipe (see Figure 2-28) crushed into pieces ranging in size from $1 / 4$ in. to 1 in. square. Supplemental pieces were fabricated from mock fuel elements $1 / 4$ in. long and cut into quarters. Table 22, 2-3 and 2-4 have a distribution list of the fine scrap pieces. 


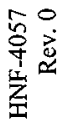
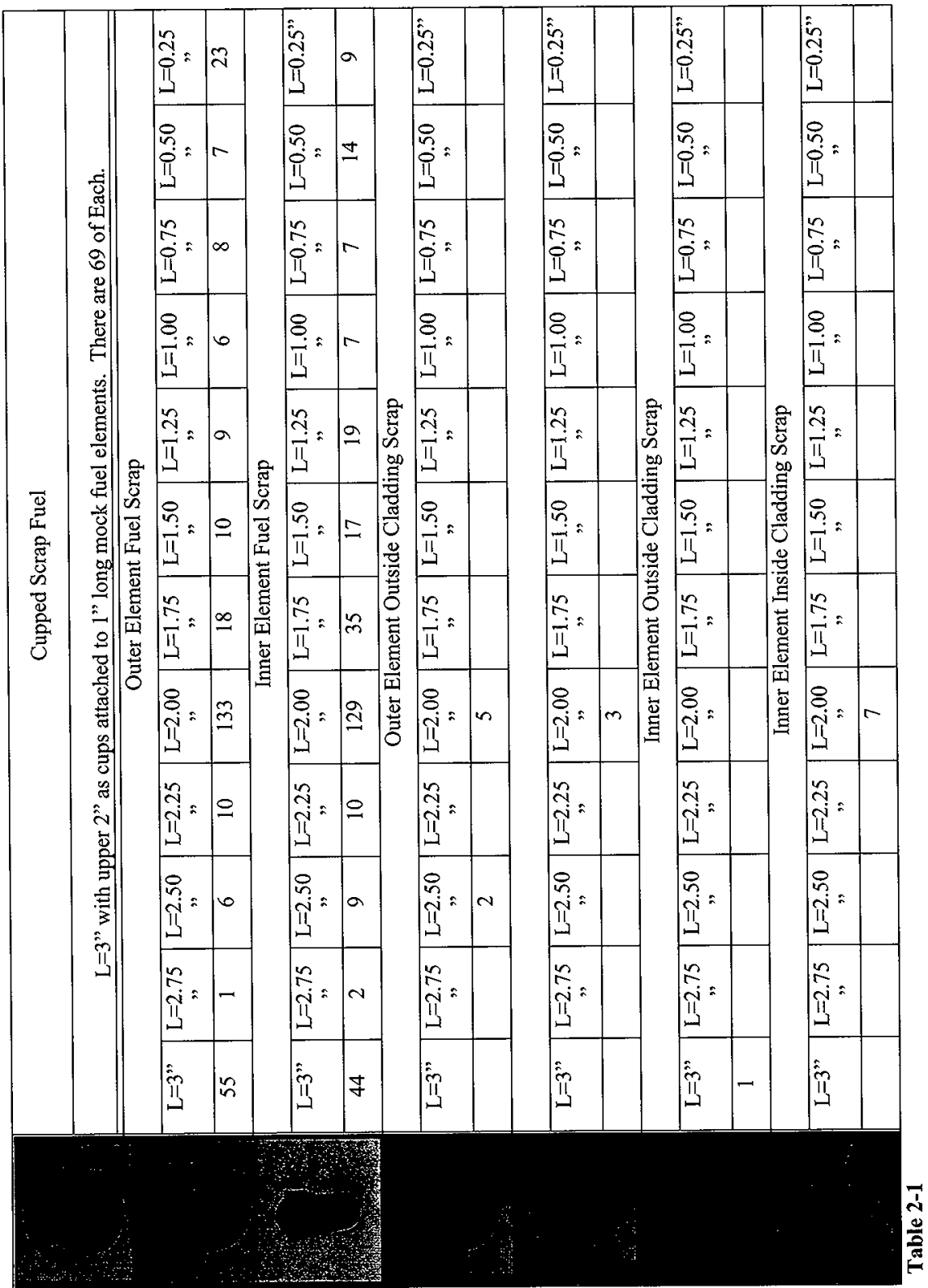


\begin{tabular}{|c|c|c|c|c|c|c|c|c|c|c|}
\hline \multicolumn{10}{|c|}{ Scrap basket 3/32" thickness fines totals } \\
\hline Square & $0-0.1$ & $0.1-$ & $0.2-$ & $0.3-$ & $0.4-$ & $0.5-$ & $0.6-$ & $0.7-$ & $0.8-$ & $0.9-$ \\
& & 0.2 & 0.3 & 0.4 & 0.5 & 0.6 & 0.7 & 0.8 & 0.9 & 1.0 \\
\hline 43 & 5 & 6 & 9 & 8 & 7 & 5 & 3 & & & \\
\hline Triangle & $0-0.1$ & $0.1-$ & $0.2-$ & $0.3-$ & $0.4-$ & $0.5-$ & $0.6-$ & $0.7-$ & $0.8-$ & $0.9-$ \\
& & 0.2 & 0.3 & 0.4 & 0.5 & 0.6 & 0.7 & 0.8 & 0.9 & 1.0 \\
\hline 31 & 10 & 13 & 4 & 4 & & & & & & \\
\hline Other shapes & $0-0.1$ & $0.1-$ & $0.2-$ & $0.3-$ & $0.4-$ & $0.5-$ & $0.6-$ & $0.7-$ & $0.8-$ & $0.9-$ \\
& & 0.2 & 0.3 & 0.4 & 0.5 & 0.6 & 0.7 & 0.8 & 0.9 & 1.0 \\
\hline 31 & 1 & 4 & 6 & 7 & 3 & 5 & 1 & 3 & 1 & \\
\hline
\end{tabular}

Table 2-2

\begin{tabular}{|c|c|c|c|c|c|c|c|c|c|c|}
\hline \multicolumn{10}{|c|}{ Scrap basket 5/32" thickness fines totals } \\
\hline Square & $0-0.1$ & $0.1-$ & $0.2-$ & $0.3-$ & $0.4-$ & $0.5-$ & $0.6-$ & $0.7-$ & $0.8-$ & $0.9-$ \\
& & 0.2 & 0.3 & 0.4 & 0.5 & 0.6 & 0.7 & 0.8 & 0.9 & 1.0 \\
\hline 78 & 3 & 14 & 12 & 19 & 12 & 8 & 2 & 4 & 1 & 3 \\
\hline Triangle & $0-0.1$ & $0.1-$ & $0.2-$ & $0.3-$ & $0.4-$ & $0.5-$ & $0.6-$ & $0.7-$ & $0.8-$ & $0.9-$ \\
& & 0.2 & 0.3 & 0.4 & 0.5 & 0.6 & 0.7 & 0.8 & 0.9 & 1.0 \\
\hline 56 & 16 & 20 & 11 & 3 & 3 & 2 & & 1 & & \\
\hline Other shapes & $0-0.1$ & $0.1-$ & $0.2-$ & $0.3-$ & $0.4-$ & $0.5-$ & $0.6-$ & $0.7-$ & $0.8-$ & $0.9-$ \\
& & 0.2 & 0.3 & 0.4 & 0.5 & 0.6 & 0.7 & 0.8 & 0.9 & 1.0 \\
\hline 68 & 1 & 11 & 14 & 9 & 13 & 9 & 3 & 5 & 2 & 1 \\
\hline
\end{tabular}

Table 2-3

\begin{tabular}{|c|c|}
\hline \multicolumn{2}{|c|}{$\begin{array}{c}\text { Scrap basket } 1.255^{\prime \prime} \\
\text { and 2.378" diameter } \\
\text { fines totals }\end{array}$} \\
\hline $1.255^{\prime \prime}$ & 19 \\
\hline $2.378 "$ & 4 \\
\hline
\end{tabular}

Table 2-4 
Tests were conducted with three mockup fuel configurations in the $\mathrm{MCO}$ without sludge. The fuel configurations are defined as:

\subsubsection{Pristine Fuel}

Unpainted carbon steel tubing that simulates the N Reactor fuel in geometry, assembled in a fuel basket. Consisting of an inner and outer fuel element with nearly the same outside and inside diameter and wall thickness. Scrap fuel with no cavities, scrap "fines" and the scrap fuel basket were included in this fuel loading but scrap fuel with

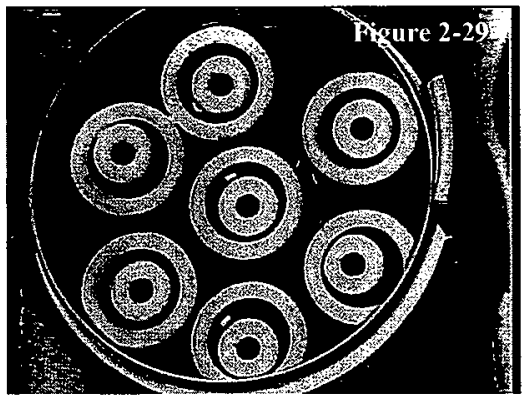
cavities were not.

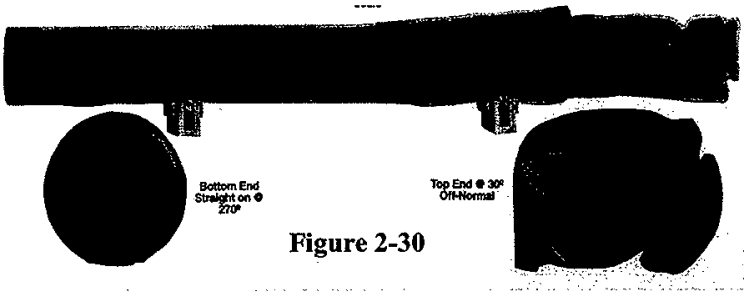

\subsubsection{Damaged Fuel}

Same as pristine fuel, except that all fuel elements are damaged to provide water retention sites and debris similar to that observed for K-Basin fuel with open end caps. Scrap fuel (damaged), the scrap fuel basket and scrap fines were

included. End caps were set up for water retention.

\subsubsection{Mixed Fuel}

Combination of pristine and damaged fuel (approximately $37 \%$ damaged fuel); scrap fuel (damaged and undamaged), the scrap fuel basket and scrap fines are included (see Figure 25). The fuel and fuel baskets were placed in the MCO with an orientation that would provide even steam distribution during evacuation.

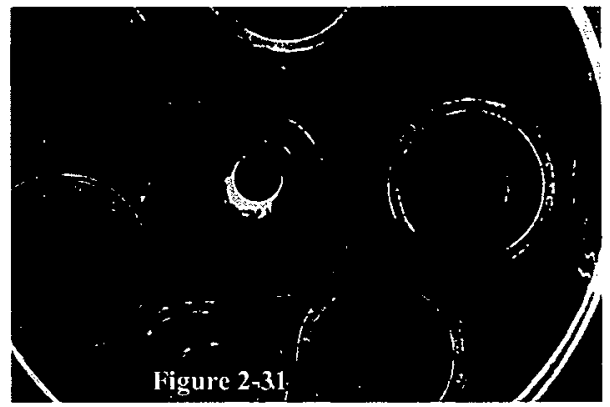

\subsubsection{Instrumentation}

Thermocouples were attached to several locations external to the MCO and to several fuel elements in different baskets locations throughout the MCO. Table 2-5 gives approximate thermocouple locations for the first article tests, and describes each thermocouple function with regards to the first article testing. 


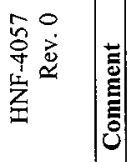

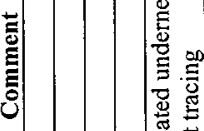

60

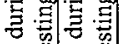

可语

营

$<$ 过《

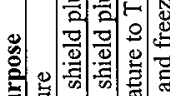

引)

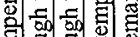

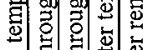

竎总

항

क ज

过氙

을.열.열.

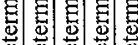

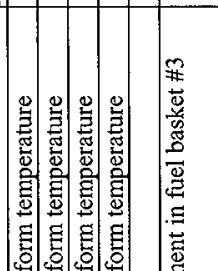

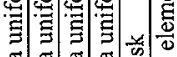

일

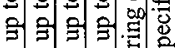

च

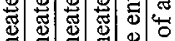

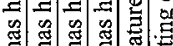

○ 0 잉

北空要

$=\div \div \leftrightarrows$ क

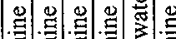

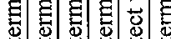

包

\#

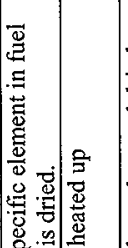

z

苞

E

항

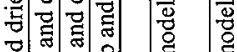

总

I

菏

蛋

梦 N

苞

क

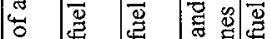

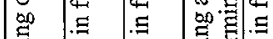

营 焉

五 五吾

要

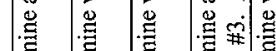

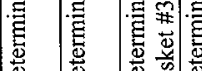

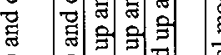

을

을

苟

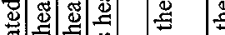

व्य

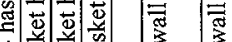

m 寸

\#

政

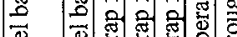

휴

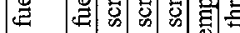

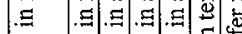

른

उ ब ब ब छ

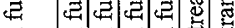

ธ बี

0

홍

รั

놈

总要

융 형

\%일

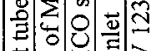

년일

产密

苍苛

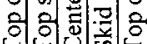

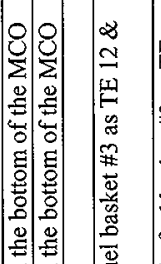

킁 छำ

(

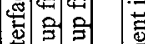

स⿺辶⿻

言

4

:

寻

형혀 형

잉일

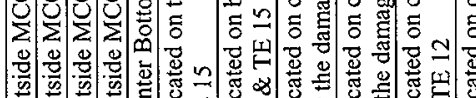

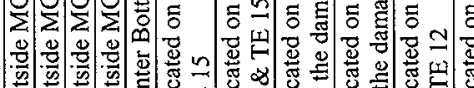

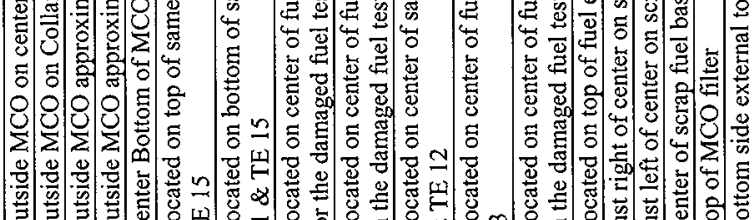

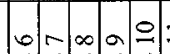

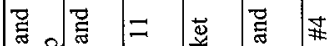

* 웧도

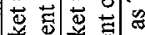

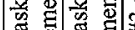

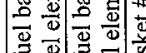

焉焉

萑

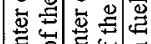

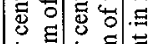

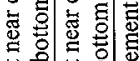

년 范잉

馬 웜

형 5

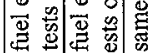

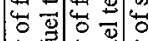

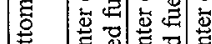

这

営

离 $\frac{\Phi}{0}$

艼

武至

旡㟔苛

矛

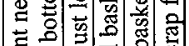

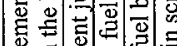

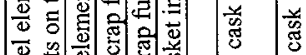

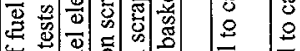

岁

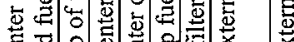

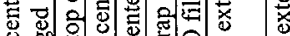

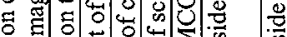

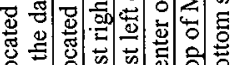

$\frac{n}{i}$

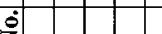

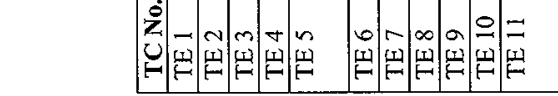

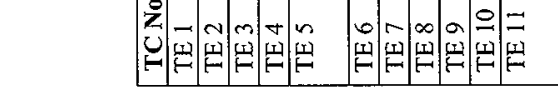

3

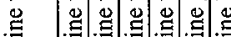

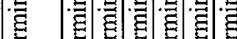

क्षे क्षे

\%

를

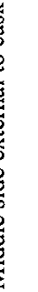




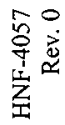
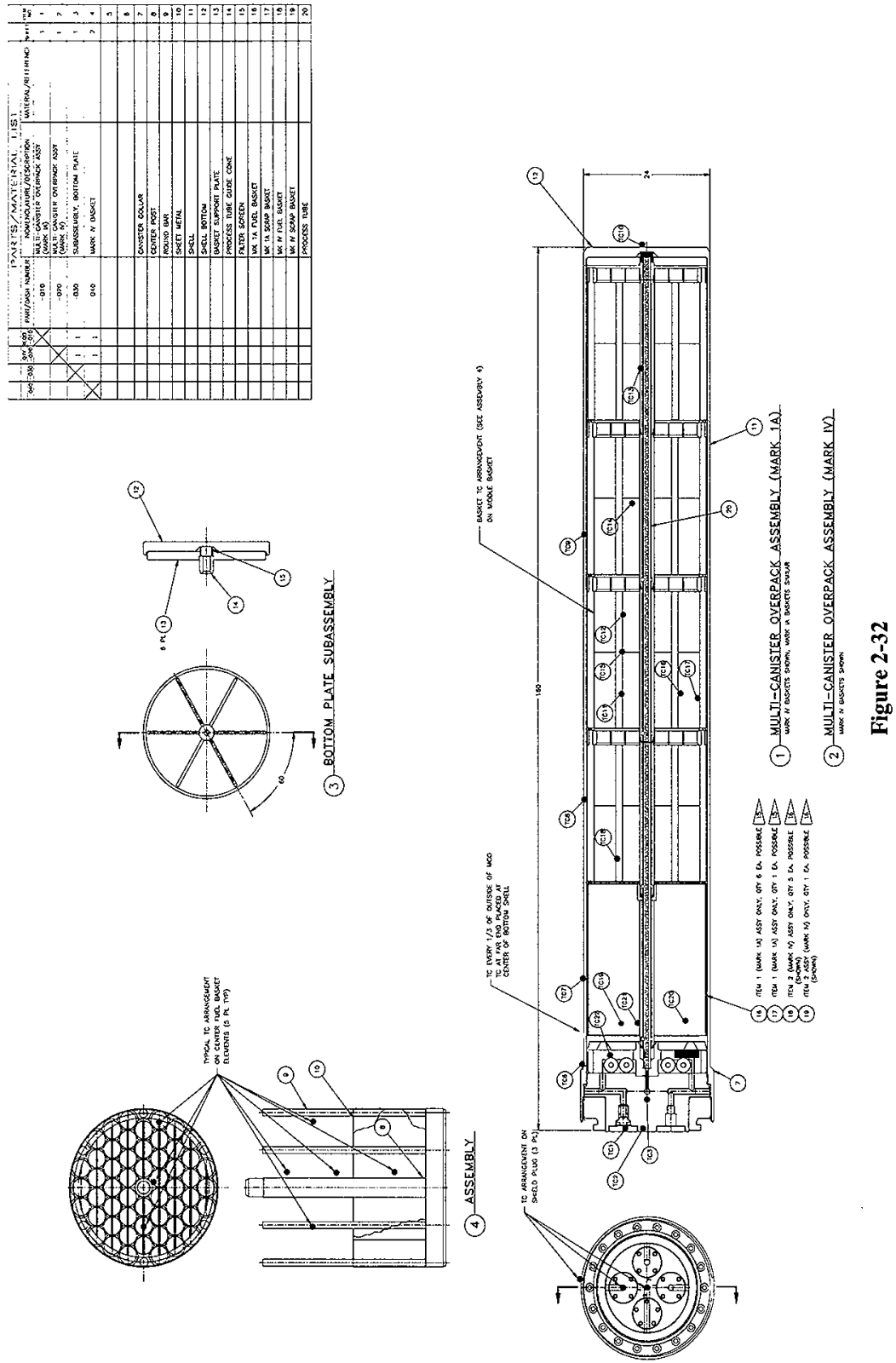


\subsection{Cask}

The cask used in 306E Building proof of performance testing is an actual transportation cask identical to those that will be used to transport an MCO to the CVDF and CSB. Due to $306 \mathrm{E}$ facility limitations, the cask was removed from the cask transporter and placed on a cask load distribution frame that will closely simulate the transporter deck height and access catwalk. The distribution frame will also simulate the bottom cask port access.

\subsection{Seal Ring Assembly}

The seal ring prototype provides the closure of the Cask/MCO annulus. The seal ring was fabricated per the design specified in the Process Hood, Seal Ring and Piping Assembly W-441-P4 Revision N procurement specification utilizing carbon steel components. The inflatable seals for the prototype were from the same manufacturer as the actual seals. The actual seals are made for higher pressure ( $45 \mathrm{psig}$ vs $35 \mathrm{psig}$ ). The seal ring is bolted to the process ventilation hood assembly which is described in section 2.8 .
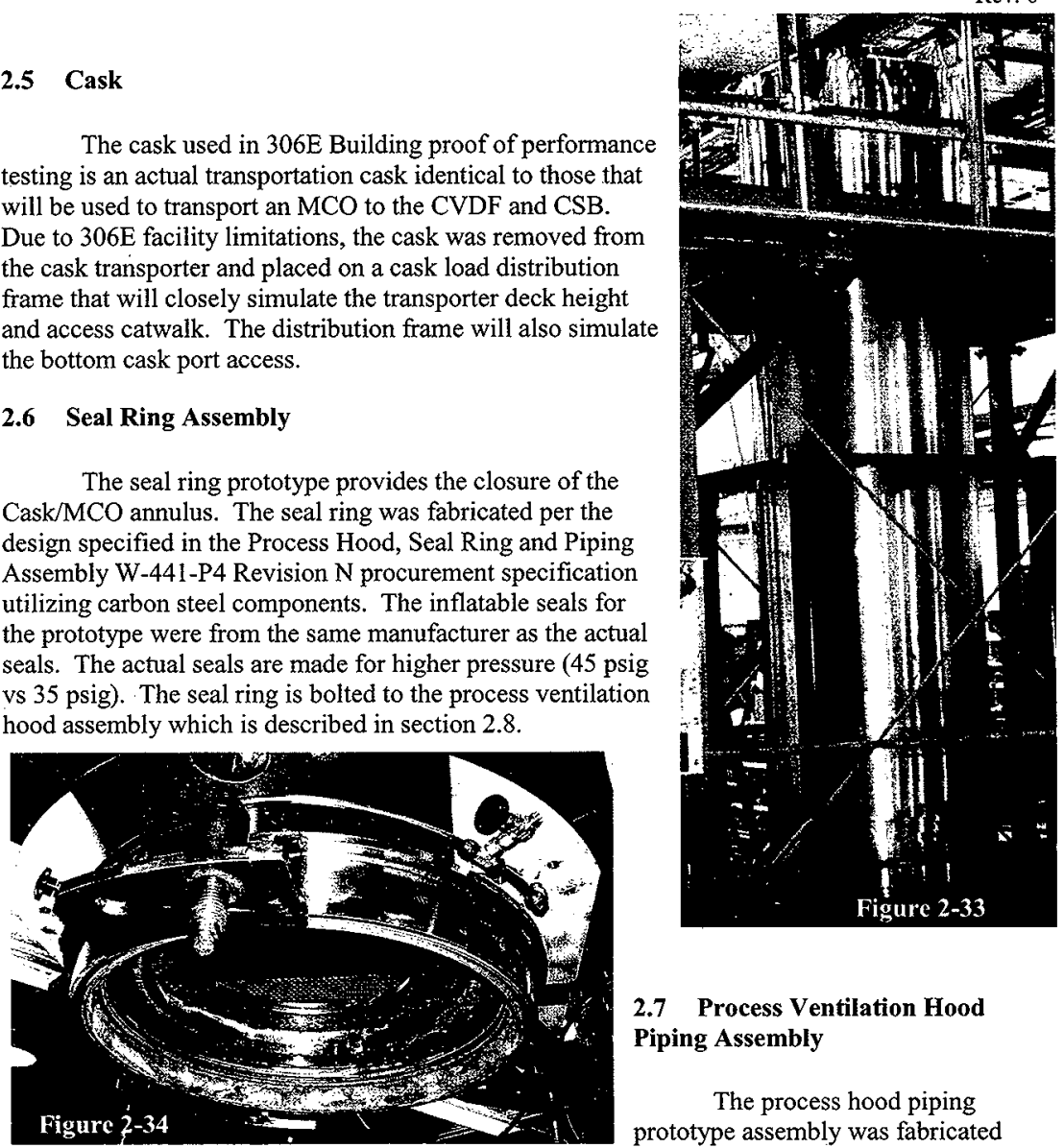

\subsection{Process Ventilation Hood Piping Assembly}

The process hood piping prototype assembly was fabricated

per the Process Hood, Seal Ring and Piping Assembly W-441-P4 Revision N procurement specification utilizing carbon steel or stainless steel schedule 40 piping and valving. (Later in the testing, the hood piping configuration was changed to match the W-441-P4 Revision 2 procurement specification and was retested.) The piping assembly does not have redundant isolation valves or redundant instrumentation as required by the design. The framework to hold the piping was constructed entirely from uni-strut rather than the design specified 3 in. by 3 in. angle iron. The framework provided a home position for the process ventilation hood and seal ring assemblies when disconnected from the cask. The framework was mounted to the cask load distribution frame catwalk for ease of fabrication. Heat tape and insulation will not be installed for the first article testing, however if testing results indicate the heat trace and insulation needs, they will be installed. 


\subsection{Process Ventilation Hood}

The process ventilation hood prototype was fabricated to the dimensions specified in the Process Hood, Seal Ring and Piping Assembly W-441-P4 Revision $\mathrm{N}$ procurement specification utilizing galvanized carbon steel riveted together rather than welded per the design. The procurement specification for the process ventilation hood requires fabrication with welded stainless steel. For the purpose of verifying air flow distribution and for interference checks the method used was appropriate.
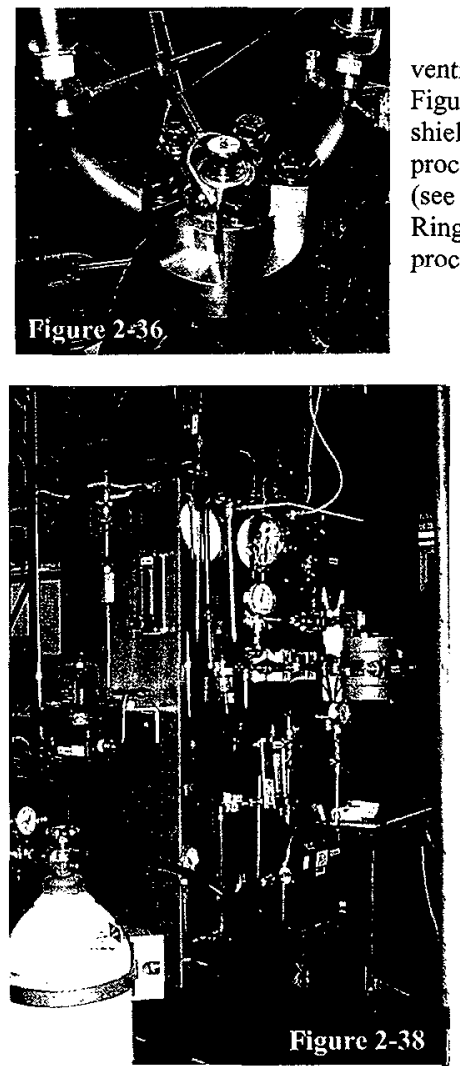

The process

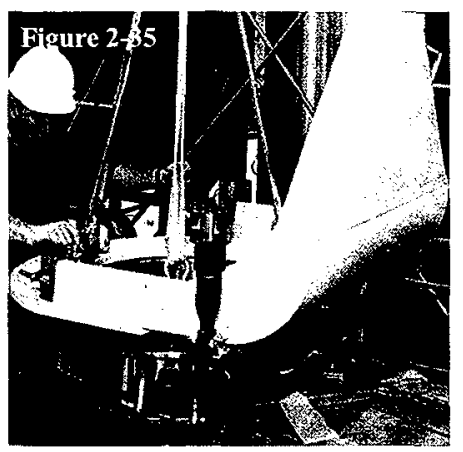
ventilation hood also houses the process connectors (see Figure 2-36). The process connectors attach to the MCO shield plug processing ports that allow the PES and $\mathrm{PWC}$ to process the fuel inside the $\mathrm{MCO}$. The process connectors (see Figure 2-37) were fabricated per the Process Hood, Seal Ring and Piping Assembly W-441-P4 Revision N procurement specification utilizing carbon steel.

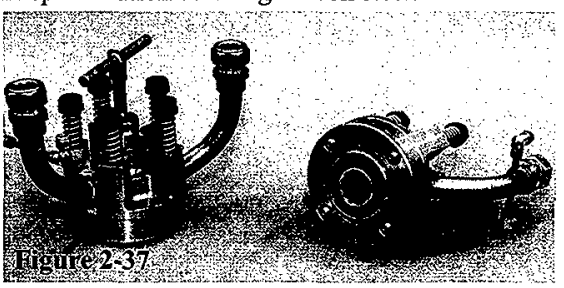

\subsection{SC Helium Injection and SCIC Systems}

The SC Helium Injection system was mocked up referencing Safety Class Helium System Equipment W-441-P5 Revision N procurement specification. The mock-up provided helium injection to $\mathrm{MCO}$ process connectors from both a single bottle and the VPS/TWS skid main helium supply. All system redundancy was removed for the purpose of this testing. The injection system was fabricated from $1 / 4$ in. tubing rather than pipe and welded fittings. The system pressure was maintained using readily available regulators at the test facility. System back pressure regulators were procured referencing the Safety Class Helium System Equipment W-441-P5, Revision N procurement specification. Tubing runs simulate the design specified piping runs. 
The Safety Class Instrumentation and Controls (SCIC) will not be utilized during first article testing, however many of the instruments and valves designated in the SCIC are required for proper operation of the process. Redundancy was not included in the fabrication of the safety class system mock-ups.

\subsection{MCS}

The MCS is the primary data acquisition and process control system for the first article testing and for operation of the CVDF. The MCS consists of Programmable Logic Controllers (PLC) with remote Input/Output (LO) cards and the Human/Machine Interface (HMI) computers. The MCS is designed to provide automatic performance of operational cycles and data acquisition/storage operations. It monitors the instrumentation, controls equipment, displays status information, and accepts operator input. However, once an automatic process has been initiated, the sequence operates semi-automatically. Password protected manual control is available for off-normal control in the actual operating system. During testing, manual control was primarily used when conducting tests with different operating parameters than programmed in the normal control logic sequences. Tests were conducted using automatic sequencing to ensure compatibility and operation between the software and the system.

\subsubsection{PLC}

The PLCs are redundant Modicon Quantum series PLCs with remote I/O. The Local Control Unit (LCU) cabinet contains the PLCs, the RGA arcnet server, and an audible alarm and silence button. During first article testing the LCU was located in the control room mock-up and it will be located in the CVDF control room.

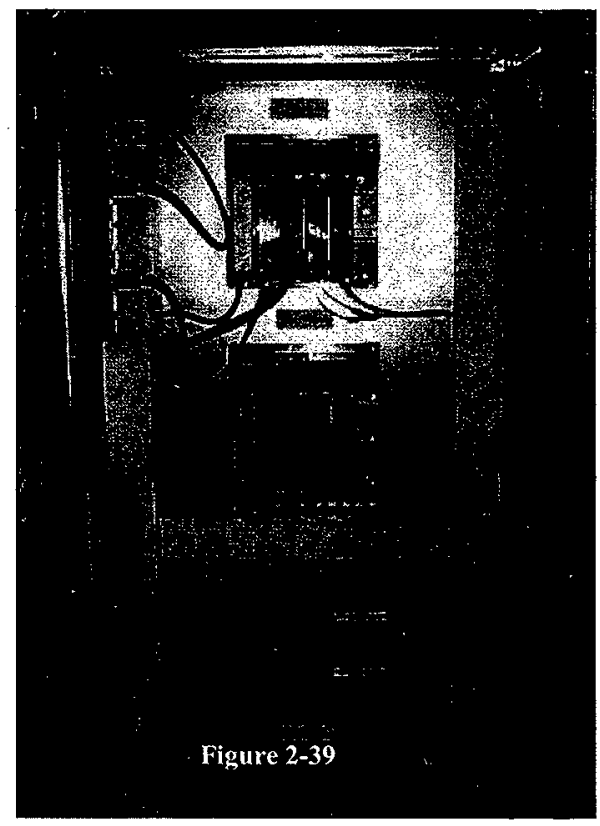




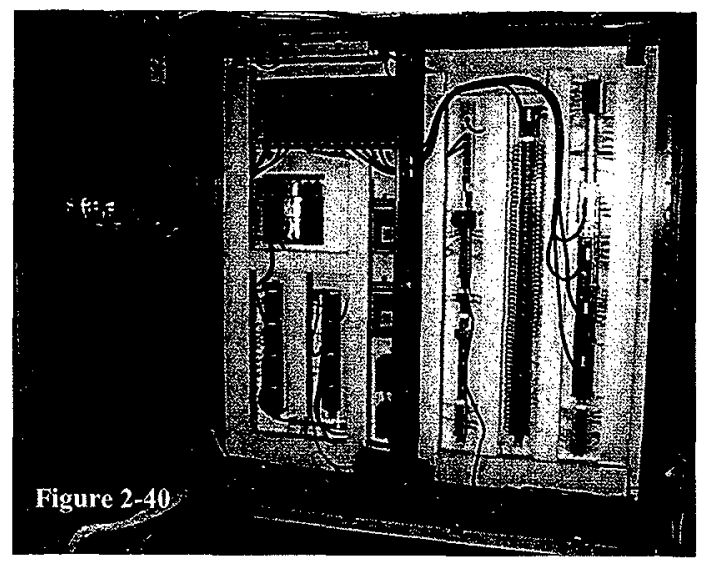

\subsubsection{Remote I/O}

The remote $/ / O$ operates in conjunction with the PLC providing the interface between the field instruments on the PES and the PLC. For testing purposes, another standalone Modicon Quantum series PLC was used to provide input to the MCS PLC from the field instruments located on the PWC system, the $\mathrm{SCHe}$ injection system, the cask, and the MCO.

\subsubsection{HMI Computer}

The HMI computer provides the interface between the PLC and RGA to the process operators and engineers. The computer stores the process data for further evaluation and long term storage. The information collected at the CVDF will be backed up and used for record retention. The computers used were Micron ${ }^{\circledR}$ Millennium ${ }^{\mathrm{TM}} 200 \mathrm{MHz}$ machines with 21 in. Super VGA monitors and internal 2 GB hard, IOMEGA ${ }^{\circledast} \mathrm{JAZ}^{\mathrm{TM}}$, and IOMEGA ${ }^{\mathrm{TM}} \mathrm{ZIP}^{\mathrm{TM}}$ drives. The printer was a Tektronics ${ }^{\mathrm{TM}} 240 \mathrm{E}$ Phaser ${ }^{\mathrm{TM}}$ photo quality printer. The HMI software was Intellution ${ }^{\circledR}$ FIX ${ }^{\mathrm{TM}}$ version 6.12 MMI.

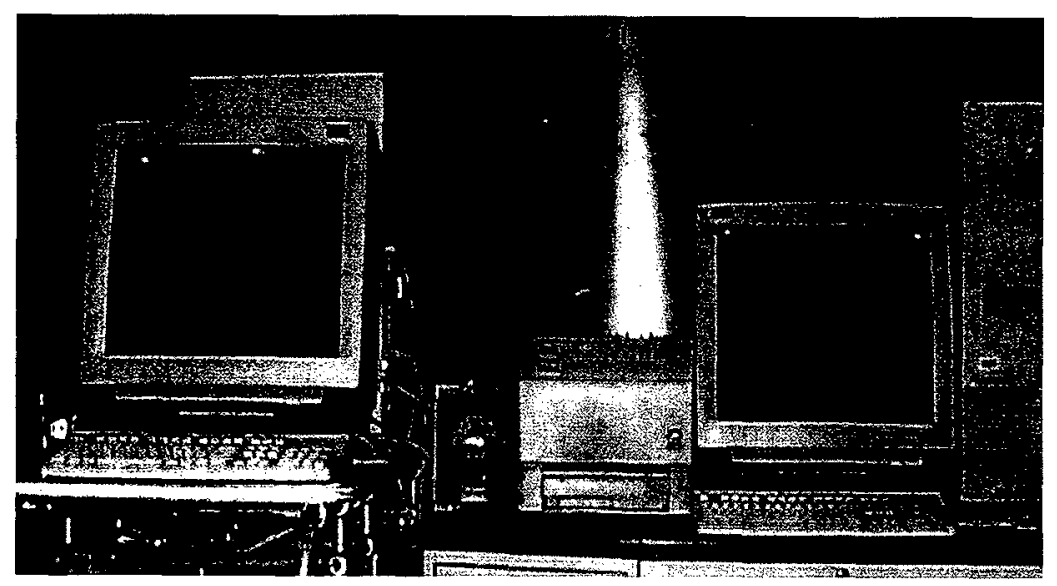




\subsection{PRELIMINARY TEST RESULTS}

This section provides the test description, apparatus description, general test procedure description, test results, discussion of test results, model predictions, and conclusions for preliminary tests performed for the first article testing program.

\subsection{Basket Water Retention}

This series of tests examined the amount and location of water retained on a prototypic, single MCO fuel basket containing mock fuel in a variety of conditions ranging from pristine to fully damaged with simulated scrap. These tests were conducted with the basket and clean, mock fuel and repeated with scrap fuel with and without fines. The purpose of this test is to provide an optimum drip-dry time for each fuel type after the majority of the water was removed.

\subsubsection{Water Retention Test Apparatus}

The water retention tank was specifically design to measure the water retained on the baskets, fuel, and in the MCO (see Figure 3-1). The water level was initially measured with a hook gauge and recorded, then the basket and fuel were lowered into the tank. When the basket and fuel were removed and allowed to drain, the tank level was again measured with the hook gauge and recorded.

\subsubsection{Water Retention Test Procedure Summary}

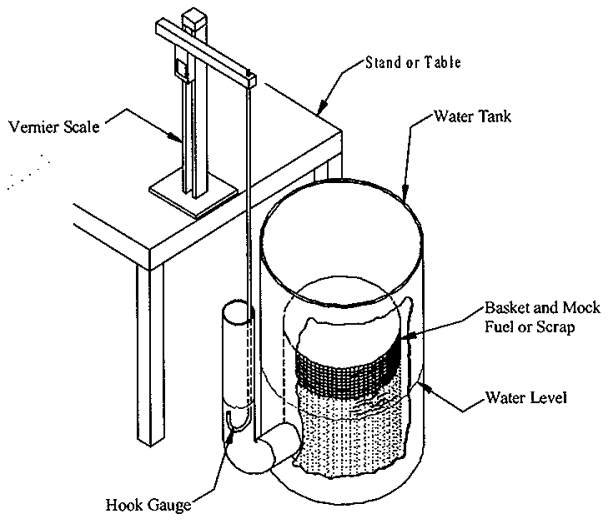

The water level is initially

Figure 3-1 measured with the hook gauge and recorded. The basket and fuel are lowered into the tank and allowed to soak for 10 minutes. The basket and fuel are then removed to just above the tank water level, but not into the room air, and allowed to drain for one minute, 15 minutes, and 30 minutes. Each time the level in the tank is measured with the hook gauge and recorded. The hook gauge readings are compared against a calibration curve previously established for the tank contents. 


\subsubsection{Basket Water Retention Results}

Table 3-1

\begin{tabular}{|l|c|c|c|c|}
\hline $\begin{array}{l}\text { Basket/Fuel } \\
\text { Configuration }\end{array}$ & $\begin{array}{l}\text { Average Water } \\
\text { Retained after 2 } \\
\text { min drip dry (L) }\end{array}$ & $\begin{array}{l}\text { Average Water } \\
\text { Retained after 15 } \\
\text { min drip dry (L) }\end{array}$ & $\begin{array}{l}\text { Average Water } \\
\text { Retained after 30 } \\
\text { min drip dry (L) }\end{array}$ & $\begin{array}{l}\text { Basket/Fuel Dry } \\
\text { Weight (lbs) }\end{array}$ \\
\hline $\begin{array}{l}\text { Scrap Basket w/ no } \\
\text { fines and no } \\
\text { damaged elements } \\
\text { (pristine) }\end{array}$ & 1.09 & 0.89 & 0.89 & 1015 \\
\hline $\begin{array}{l}\text { Scrap Basket w/fines } \\
\text { and 32 elements } \\
\text { damaged (nominal) }\end{array}$ & 3.49 & 3.13 & 3.13 & $\begin{array}{c}1050 \text { (1080 added } \\
\text { fines after } \\
\text { retention test) }\end{array}$ \\
\hline $\begin{array}{l}\text { Scrap Basket w/fines } \\
\text { and 69 elements } \\
\text { damaged (damaged) }\end{array}$ & 5.55 & 5.31 & 5.27 & $\begin{array}{c}1050 \text { (1080 added } \\
\text { fines after } \\
\text { retention test) }\end{array}$ \\
\hline $\begin{array}{l}\text { Fuel Basket w/ } \\
\text { Pristine fuel }\end{array}$ & 0.60 & 0.33 & 0.33 & 1360 \\
\hline $\begin{array}{l}\text { Fuel Basket w/ } \\
\text { Nominal fuel }\end{array}$ & 1.70 & 1.55 & 1.55 & 1360 \\
\hline $\begin{array}{l}\text { Fuel basket w/ } \\
\text { Damaged fuel }\end{array}$ & 4.11 & 3.92 & 3.90 & 1355 \\
\hline
\end{tabular}

\subsubsection{Basket Water Retention Discussion of Results}

In the majority of fuel configurations, the difference between the water removed by dripping after fifteen (15) minutes and thirty (30) minutes was negligible. However, the difference between the water removed by dripping at time zero to fifteen (15) minutes after removal from the water averaged from $5 \%$ for damaged to $58 \%$ for pristine fuel baskets and ranged from $4 \%$ for damaged to $20 \%$ for to pristine scrap baskets. When the difference between time zero and 15 minutes later (see Equation 3-1) are compared to the expected water remaining in the entire MCO after the bulk water drain, the results indicate that the added time for dripping may not be necessary in all fuel cases. Table 3-2 displays the comparison with regards to the fuel type.

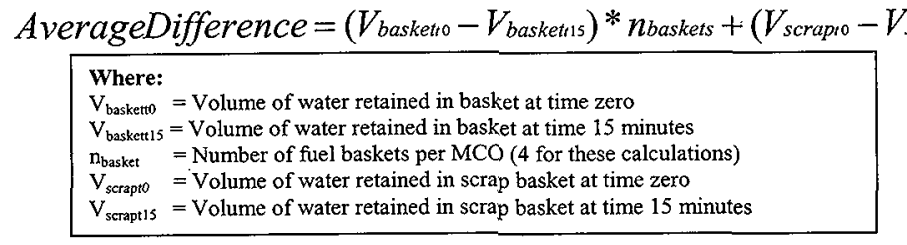

Eq. 3-1

Figure 3-2

Table 3-2

\begin{tabular}{|c|c|c|c|}
\hline $\begin{array}{c}\text { Fuel Type (MCO } \\
\text { loading) }\end{array}$ & $\begin{array}{c}\text { Average Expected } \\
\text { in MCO after bulk } \\
\text { water drain }\end{array}$ & $\begin{array}{c}\text { Average difference } \\
\text { between } t_{0} \text { and } t_{15}\end{array}$ & $\begin{array}{c}\text { Percent of total water } \\
\text { that could be removed } \\
\text { from MCO during wait }\end{array}$ \\
\hline Pristine & 5 liter & 1.28 liter & $25.6 \%$ \\
\hline Nominal (Mixed) & 12 liter & 0.96 liter & $8.0 \%$ \\
\hline Damaged & 32 liter & 1.00 liter & $3.1 \%$ \\
\hline
\end{tabular}


This water retention test also provided an initial baseline of the amount of water expected to remain in the test apparatus $\mathrm{MCO}$ after bulk water draining. This will provide a percent error for drying times from the actual field MCO to the test apparatus (see Table 3-3).

Table 3-3

\begin{tabular}{|l|c|c|c|}
\hline $\begin{array}{c}\text { Fuel Type (MCO } \\
\text { loading) }\end{array}$ & $\begin{array}{c}\text { Average Expected in MCO } \\
\text { after bulk water drain }\end{array}$ & $\begin{array}{c}\text { Average Expected in MCO } \\
\text { during testing from baskets only }\end{array}$ & Percent error \\
\hline Pristine & 5 liter & 3.5 liter & $30.0 \%$ \\
\hline Nominal (Mixed) & 12 liter & 10.3 liter & $14.1 \%$ \\
\hline Damaged & 32 liter & 22.0 liter & $31.3 \%$ \\
\hline
\end{tabular}

\subsubsection{Basket Water Retention Conclusions and Recommendations}

The basket water retention test results indicated that the water removed from the $\mathrm{MCO}$ during the bulk water drain may not be significantly increased by allowing additional time for the fuel to drip dry. The total water volume that dripped from the fuel baskets increased $3 \%$ for damaged fuel, $8 \%$ for nominal fuel, and $25 \%$ for pristine fuel over a 15 minute period. The water volume did not increase after the 15 minute period. Without knowing exactly what type of fuel is in each $\mathrm{MCO}$, the recommendation is to proceed with vacuum drying immediately after bulk water draining. The water amount remaining on the fuel and baskets will not significantly increase the drying time.

The test also provided initial indications of the amount of water expected to be remaining in the test $\mathrm{MCO}$ after bulk water draining for each fuel configuration. With the test article (mock fuel) physical constraints, this water volume for the drying tests would be difficult to change and to distribute evenly throughout the fuel. It is recommended the model validation program change the total amount of water evenly distributed in the MCO to these predicted levels. After the validation is complete, the retained water numbers for the actual fuel could replace the numbers seen in the first article testing.

\subsection{Ventilation Hood Air Flow Establishment}

This test validated the design parameters of the process ventilation hood. The primary requirements to be validated were the design face velocity requirements (125 fpm) and the absence of eddy currents from the operator breathing zone.

\subsubsection{Ventilation Hood Test Apparatus}

The process ventilation hood air flow measurements were conducted using a full scale mock-up (see Figures 2-35 and 3-3). This test was conducted by qualified vent and balance personnel using operators and smoke tests to establish the air flow patterns. The apparatus was set-up to supply the specified volumetric hood flow rate and included prototypical hood face obstructions. 


\subsubsection{Ventilation Hood Test Procedure Summary}

The test fan was set to produce the design rated flow rate of $1300 \mathrm{scfm}$ while testing the ventilation hood. The airflow was measured by a hot anemometer at the capture point and recorded. A smoke generator was then utilized to determine if particles would get into the operator-breathing zone during process connector manipulation.

\subsubsection{Ventilation Hood Test Results}

Table 3-4 provides the final test results for the process ventilation hood test and Figures 3-5 through 3-8 provide confirmation of the air flow direction during testing.

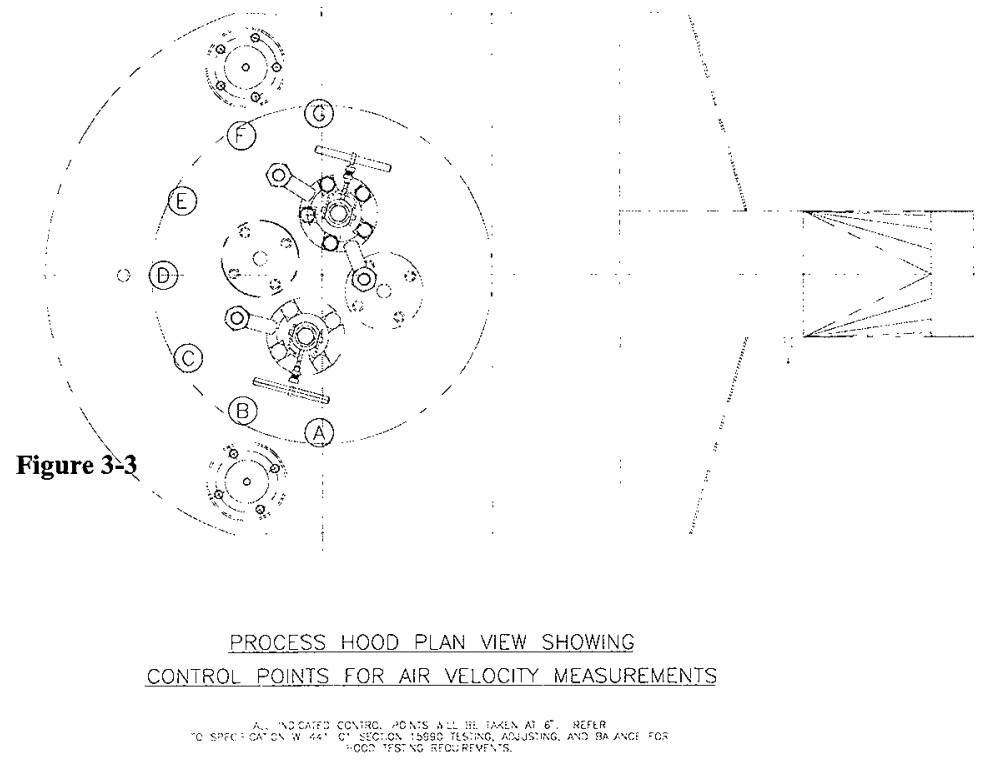




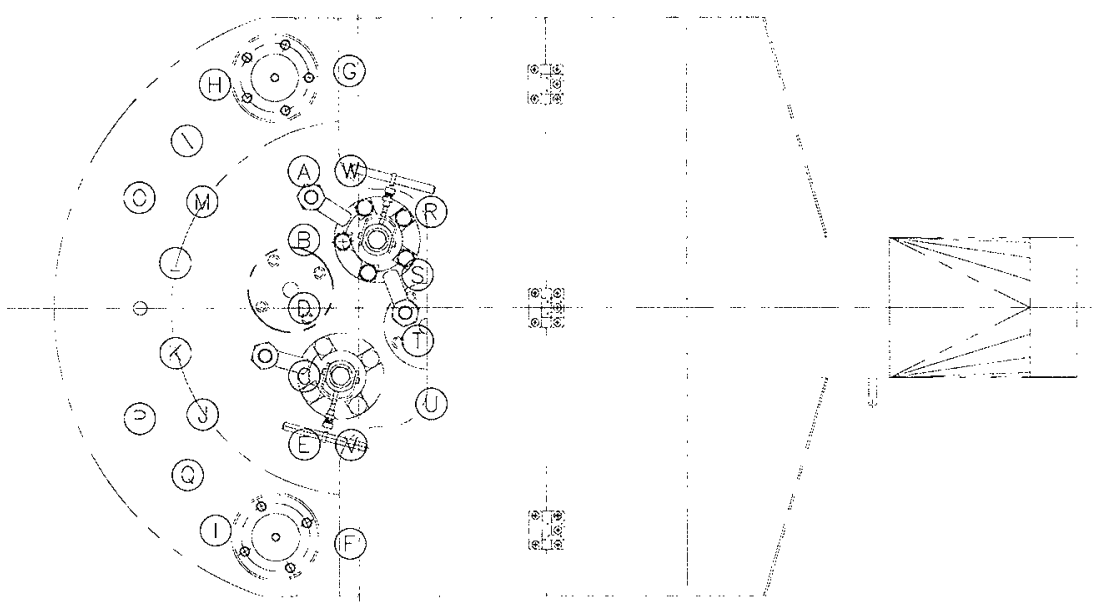

Figure 3-4

\section{PROCESS HOOD PLAN VIEW SHOWING \\ CONTROL POINTS FOR AIR VELOCITY MEASUREMENTS}

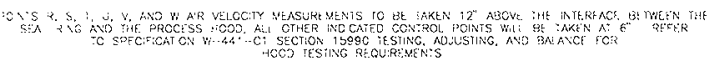

Table 3-4

\begin{tabular}{|c|c|c|c|c|c|c|c|c|c|c|c|c|}
\hline \multicolumn{13}{|c|}{ Process Ventilation Hood Flow Test Point Data } \\
\hline \multirow{2}{*}{$\begin{array}{l}\text { Initial Velocity } \\
@ \text { hood location } \\
\text { (fpm) with an } \\
\text { initial stack } \\
\text { velocity } \\
1717 \text { cfm }\end{array}$} & $\begin{array}{c}\text { A } \\
178\end{array}$ & $\begin{array}{c}\text { B } \\
155\end{array}$ & $\begin{array}{c}C \\
116\end{array}$ & $\begin{array}{c}\text { D } \\
127\end{array}$ & $\begin{array}{c}E \\
145\end{array}$ & $\begin{array}{c}\mathrm{F} \\
125\end{array}$ & $\begin{array}{c}\mathrm{G} \\
191\end{array}$ & & & & & \\
\hline & & & & & & & & & & & & \\
\hline \multirow{3}{*}{$\begin{array}{l}\text { Final Velocity } \\
\text { @ hood location } \\
\text { (fpm) with a final } \\
\text { stack velocity } \\
\text { _ } 1325 \text { _cfm }\end{array}$} & A & B & C & D & $\mathrm{E}$ & $\mathrm{F}$ & $\mathrm{G}$ & $\mathrm{H}$ & I & $\mathrm{J}$ & $\mathrm{K}$ & L \\
\hline & 224 & 128 & 333 & 113 & 267 & 795 & 707 & 160 & 155 & 130 & 110 & 102 \\
\hline & $\begin{array}{c}\mathrm{M} \\
129\end{array}$ & $\begin{array}{l}\mathrm{N} \\
64\end{array}$ & $\begin{array}{c}\mathrm{O} \\
46\end{array}$ & $\begin{array}{c}P \\
64\end{array}$ & $\begin{array}{c}\mathrm{Q} \\
131\end{array}$ & $\begin{array}{c}\mathrm{R} \\
197\end{array}$ & $\begin{array}{c}\mathrm{S} \\
246\end{array}$ & $\begin{array}{c}\mathrm{T} \\
256\end{array}$ & $\begin{array}{c}\mathrm{U} \\
156\end{array}$ & $\begin{array}{c}\mathrm{V} \\
148\end{array}$ & $\begin{array}{c}\text { W } \\
193\end{array}$ & \\
\hline
\end{tabular}



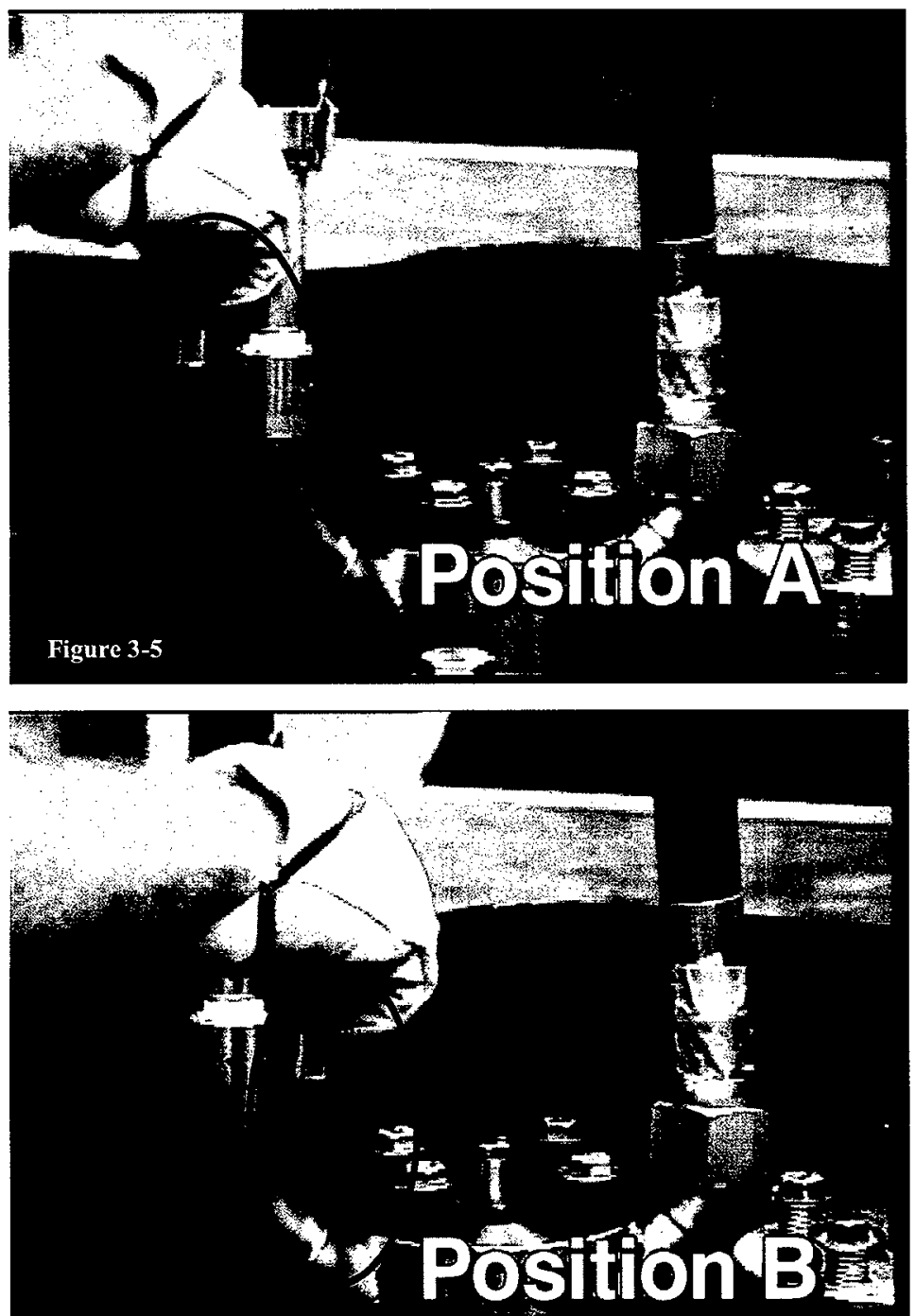

Figure 3-6 

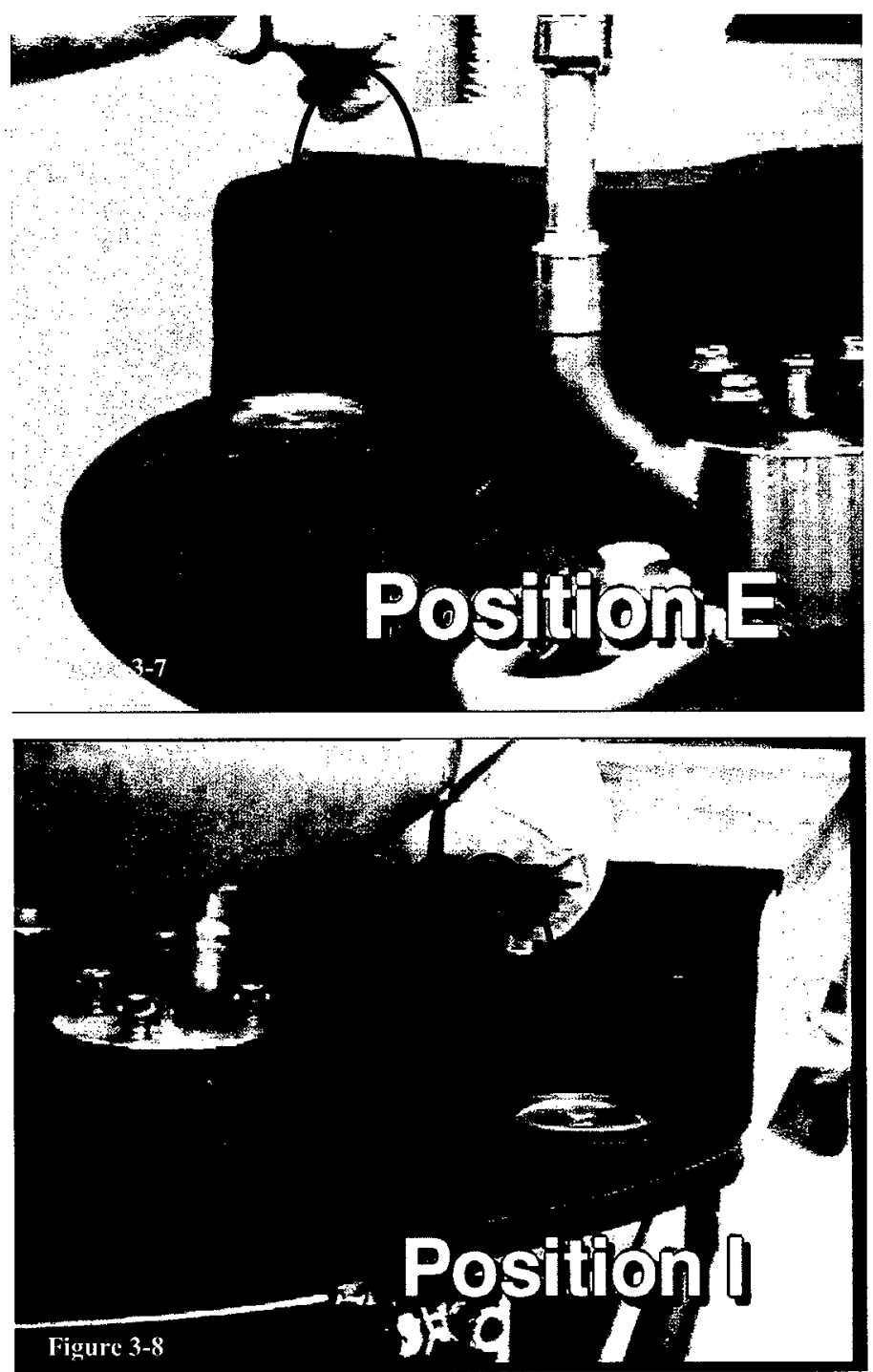


\subsubsection{Ventilation Hood Discussion of Results}

The initial test was conducted with air velocity points around the exterior of the $\mathrm{MCO}$ as shown in Figure 3-3. Point $D$ is the control point for the specification of the design basis of 125 fpm. The initial test conducted on the $90 \%$ design of the process hood yielded unexpected results. In order to maintain the required design face velocity, the required flow rate was 131\% higher than the design flow rate. Modifications had to be made either to the process ventilation hood itself or the facility process ventilation system that would require resizing of HEPA filter housings and fan sizes.

Temporary modifications to the hood mock-up were fabricated and the test was repeated with new air velocity points as shown in Figure 3-4, again with point $D$ as the primary control point. Modifications included: decreasing the gap between the hood base plate and seal ring assembly; closing bolt hole penetrations through the hood base plate; and the addition of a removable cover to effectively move the control point closer to the operation.

As presented in the results section, the modifications were successful in lowering required flow rate to the design flow rate to meet the hood face velocity requirements. Video taped results of the smoke tests also revealed no eddy currents to the operator-breathing zone during instaliation and removal of the process connectors. The direction of flow was indicated by the smoke trails at several locations (see Figures 3-5 through 3-8).

\subsubsection{Ventilation Hood Conclusions and Recommendations}

With the modifications to the ventilation hood, the design hood face velocity of $125 \mathrm{ft} / \mathrm{min}$ could be maintained with the $1300 \mathrm{scfm}$ design airflow. The modifications to the hood removed the need for facility HVAC system redesign and the need for increasing fan size and adding more HEPA filters. Smoke tests also concluded that particles would not enter the operator-breathing zone. The modifications to the ventilation hood were incorporated into the design specification.

\subsection{Seal Ring Testing}

The seal ring assembly testing consisted of determining if the seal ring design would make a leak tight seal against the MCO and cask to complete the TWS. The test would also verify the design to assist in drying the $\mathrm{MCO}$ shield plug and locking ring assembly and leak test the MCO main seal with the auxiliary vacuum system. The seal ring also acts as a retainer to keep the $\mathrm{MCO}$ from floating out of the cask.

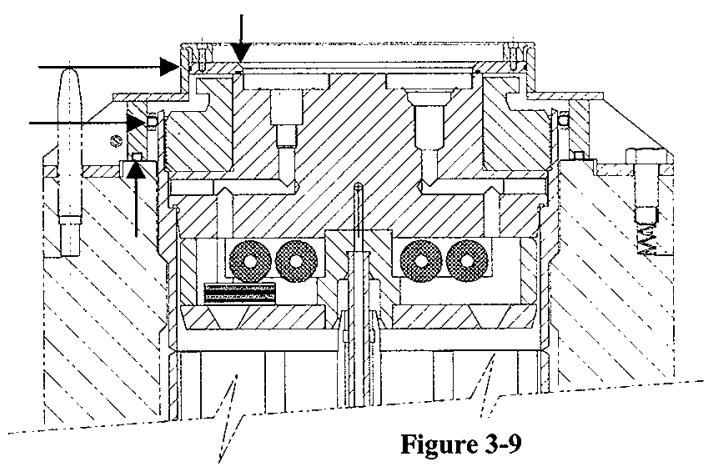




\subsubsection{Seal Ring Testing Apparatus}

The test apparatus consisted of a prototype $\mathrm{MCO}$ seal ring, a prototypic auxiliary vacuum system, the prototypic MCO, and cask. The seal ring completes the tempered water system with inflatable o-rings against the cask and $\mathrm{MCO}$. The seal also dries the MCO locking ring area and leak checks the $\mathrm{MCO}$ main seal using the $\mathrm{MCO}$ inflatable O-ring and two O-rings on the seal plate which sits on the MCO shield plug (see Figure 3-9).

\subsubsection{Seal Ring Test Procedure Summary}

The seal ring leakage was determined during the normal operation of the TWS, which was described in section 9.1.1 of HNF-2402, Hanford Spent Nuclear Fuel Cold Vacuum Drying Proof of Performance Test Procedure. The seal ring o-rings were inflated to $35 \mathrm{psig}$ and the TWS system was started. Observations were conducted during the entire heat-up and cool down of the MCO. The MCO main seal leak check seal ring test was conducted per section 8.2 .7 of HNF-2402. The seal ring inflatable seals were inflated to 35 psig then the cask was pressurized to 40 psig with air. The MSLD evacuated the locking ring area of the MCO. Each individual seal was taped and helium was injected under the tape. The MSLD was used to detect any helium leakage through the $\mathrm{O}$-rings.

\subsubsection{Seal Ring Test Results}

During the normal testing, the inflatable seals in the seal ring had no apparent leaks when they were inflated to $35 \mathrm{psig}$ and the TWS was operating at $37 \mathrm{psig}$. With the TWS operating at $37 \mathrm{psig}$, the MCO loaded with mock fuel slowly floats to contact the seal ring structure then stops.

The following table establishes an o-ring leak rate for each individual seal. In order for the MCO to be leak checked at $1 \times 10^{-4} \mathrm{std}$. atm. cc/ sec of Helium, the o-ring seals must be leak tight to at least $1 \times 10^{-5} \mathrm{std}$. atm. $\mathrm{cc} / \mathrm{sec}$ of Helium.

Table 3-5

\begin{tabular}{|l|c|l|}
\hline \multicolumn{1}{|c|}{ Seal Description } & $\begin{array}{c}\text { Test 1 Seal Leak Rate (std. atm. } \\
\mathrm{cc} / \mathrm{sec} \text { of He) }\end{array}$ & $\begin{array}{l}\text { Test 2 Seal Leak Rate (std atm } \\
\mathrm{cc} / \mathrm{sec} \text { of He) }\end{array}$ \\
\hline $\begin{array}{l}\text { MCO inflatable (w/40 psig in } \\
\text { cask and inflated to 35 psig) }\end{array}$ & $3.2 \times 10^{-6}$ & $\begin{array}{l}\text { Not tested (acceptance criteria } \\
\text { met during first test) }\end{array}$ \\
\hline MCO seal plate o-ring & No detectable leaks & $\begin{array}{l}\text { Not tested (acceptance criteria } \\
\text { met during first test) }\end{array}$ \\
\hline Seal plate bore seal & $1.6 \times 10^{-5}$ & No detectable leaks \\
\hline
\end{tabular}




\subsubsection{Seal Ring Test Discussion of Results}

The seal ring performed its designed $\mathrm{MCO}$ retaining function by halting the $\mathrm{MCO}$ from floating out of the cask with minimal torquing of the mounting bolts (finger tight). The inflatable seals also provided an adequate seal to the MCO and also to the cask. However, MCO main seal leak testing revealed that the seal plate bore seal of the seal ring assembly had a leak rate of $1.5 \times 10^{-5} \mathrm{std}$. atm. $\mathrm{cc} / \mathrm{sec}$ of helium. The seal plate was remanufactured to provide less tolerance between the o-ring groove and the bore seal. In other words: to provide a "heavier squeeze" on the bore seal o-ring.

The NDE group also tested a prototypic auxiliary vacuum system utilizing the seal ring test assembly. These tests are documented in Cogema-98-803, Summary Report for MCO Nondestructive Examination Activities. The auxiliary vacuum tests were conducted to determine the drying time of the shield plug locking ring area and to determine an MCO main seal leak rate. Coordinating the $\mathrm{NDE}$ and $\mathrm{CVD}$ testing involved removing the $\mathrm{MCO}$ locking ring and injecting $80 \mathrm{ml}$ of water between the shield plug and locking ring. The water amount was calculated from the amount of free space between the shield plug and locking ring. The auxiliary vacuum system proved that it could remove the water within 90 minutes given ambient equipment ( $\mathrm{MCO}$ and seal ring) temperature.

\subsubsection{Seal Ring Test Conclusions and Recommendations}

The seal ring functions adequately for its intended function. The seal ring provides excellent $\mathrm{MCO}$ retention with minimal mounting bolt torque. The inflatable o-rings provide adequate sealing to the cask and the MCO to complete the cask annulus portion of the TWS. The MCO inflatable o-ring and the seal plate assembly along with the auxiliary vacuum system dries out the shield plug/locking ring area of the cask within 90 minutes of pulling a vacuum on the area. The auxiliary vacuum system and the seal ring are capable of leak testing the MCO to better than design leak tightness of $1 \times 10^{-5} \mathrm{std}$. atm. $\mathrm{cc} / \mathrm{sec}$ of helium.

Given the short time to dry the shield plug/locking ring area, first article testing recommends a preliminary leak check of the $\mathrm{MCO}$ main seal prior to any $\mathrm{MCO}$ draining or vacuum drying. During heat-up, a preliminary leak check could be complete while the MCO head space is pressurized with helium during a pressure vent cycle. Although this would by no means be a substitute for the final leak check to be performed at the end of drying, it would give a rough indication if the main seal is leaking and needs further torquing or replacement prior to draining and drying of the MCO. 


\subsection{Process Connector Flushing and MCO Water Ingress}

An apparatus shown in Figures 3-10 and 3-11 was fabricated to test the VPS de-ionized water flush after the bulk water draining process. The purpose of this test is three fold: to identify any sludge traps in the process connector, to optimize flow settings providing maximum sludge clean-out without introducing added water back into the $\mathrm{MCO}$; and to test the sealing and isolation capabilities of the valve after the introduction of sludge. These tests will determine if sludge will remain in the process connector, piping, and valves after rinsing. If so, significant connector redesign and valve seat specification may be necessary to reduce any radioactive dose an operator may receive while handling the connector.

The MCO drain process is controlled primarily by the VPS 1230 valve for isolation. This valve has the potential for seat and seal scarring from the MCO sludge being trapped prior to rinsing. The component must remain suitable for its intended use. A sludge simulant/water mixture was flowed through the valve and rinsed. This process may be repeated any number of times and valve leak tightness re-verified.
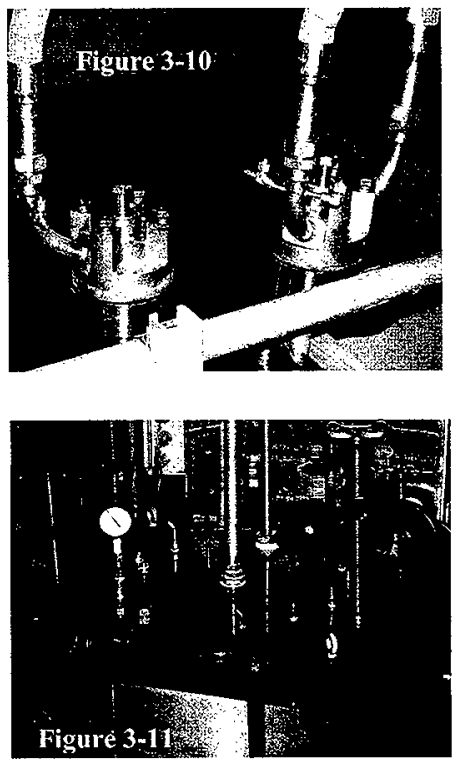

\subsubsection{Process Connector Flushing and MCO Water Ingress Testing Apparatus}

The apparatus consists of a process connector and shield plug valve assembly prototype and a Gas Operated ball.Valve (GOV) down stream of the process connector. This GOV will utilize the same seats and seals as specified in the $90 \%$ Cold Vacuum Drying System Equipment Process Equipment Skid, W-441-P1 Revision N procurement specification for GOV 1230 and GOV 1203.

\subsubsection{Process Connector Flushing and MCO Water Ingress Test Procedure Summary}

After a through visual inspection under a microscope, a thick mixture of cerium oxide and water was applied to the underside of the process connector. The process connector was connected to a simulated empty MCO and a DI rinse cycle was initiated. During the rinse cycle, observations were made to identify any water entry into the $\mathrm{MCO}$. After the rinsing step was completed the process connector was removed and again visually inspected. Any indication of sludge remaining in the process connector means the test has failed. 
A sludge carry over test was conducted to identify the amount of sludge (cerium oxide) is carried to the PWC system from a normal draining cycle and if any of the sludge remained internal to the process connector. The process connector sludge retention test is conducted using a process connector and a half full ( $\sim 75$ gallons of water) MCO mixed with 500 grams of cerium oxide and 18-2mm Tungsten spheres, 9 of which were placed in the MCO bottom cup. The $\mathrm{MCO}$ was drained through a test set-up to bypass the simulated facility line length in the test setup in an effort to account for sludge and the $2 \mathrm{~mm}$ spheres. The process connector was removed from the test body after the draining and DI rinsing cycle and visually inspected with a microscope to qualitatively determine the amount of sludge simulant on the process connector. If the connector shows signs of build-up after repeated tests, the process connector should be redesigned and retested to minimize sludge build-up.

\subsubsection{Process Connector Flushing and MCO Water Ingress Test Results}

Figure 3-12 and 3-13 show a before and after results of a process connector of the initial process connector flushing test. Figures 3-14 and 3-15 display the before and after results of a $\mathrm{MCO}$ process valve.
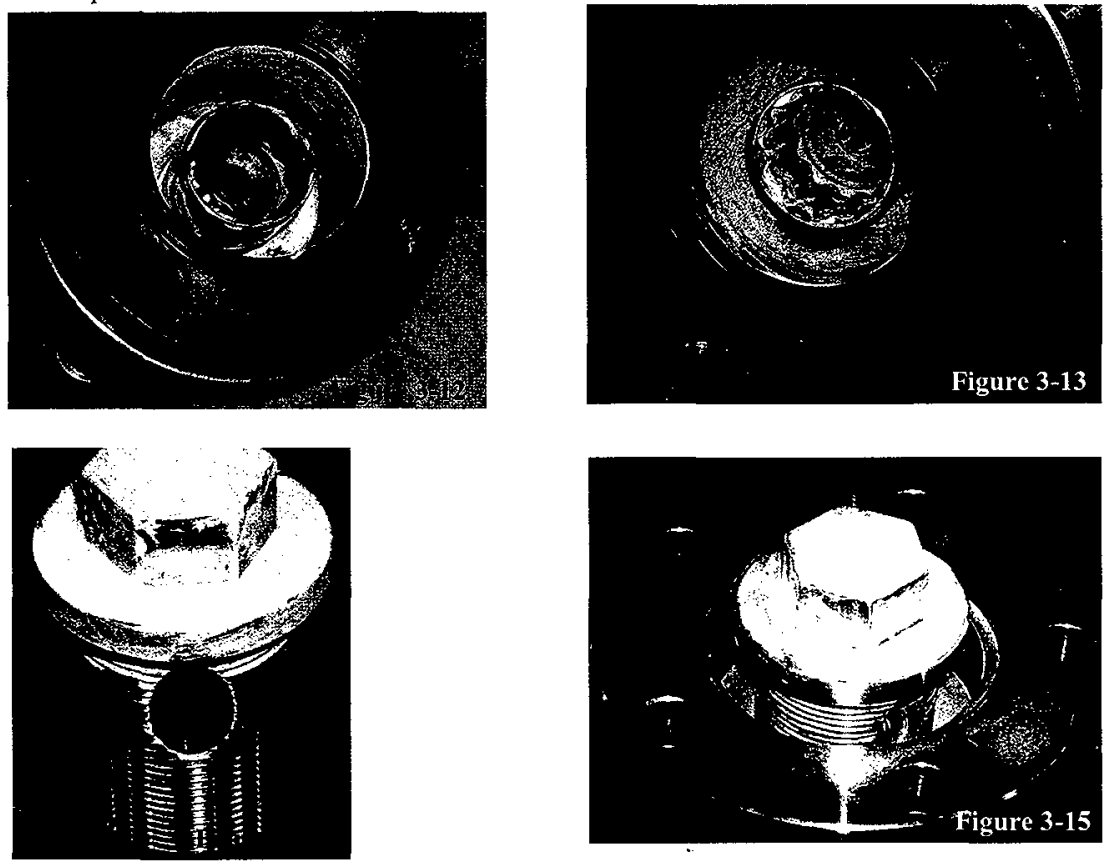
Figures 3-16 and 3-17 show a before and after results of a process connector of the final process connector flushing test. Figures 3-18 and 3-19 display the before and after results of a $\mathrm{MCO}$ process valve.
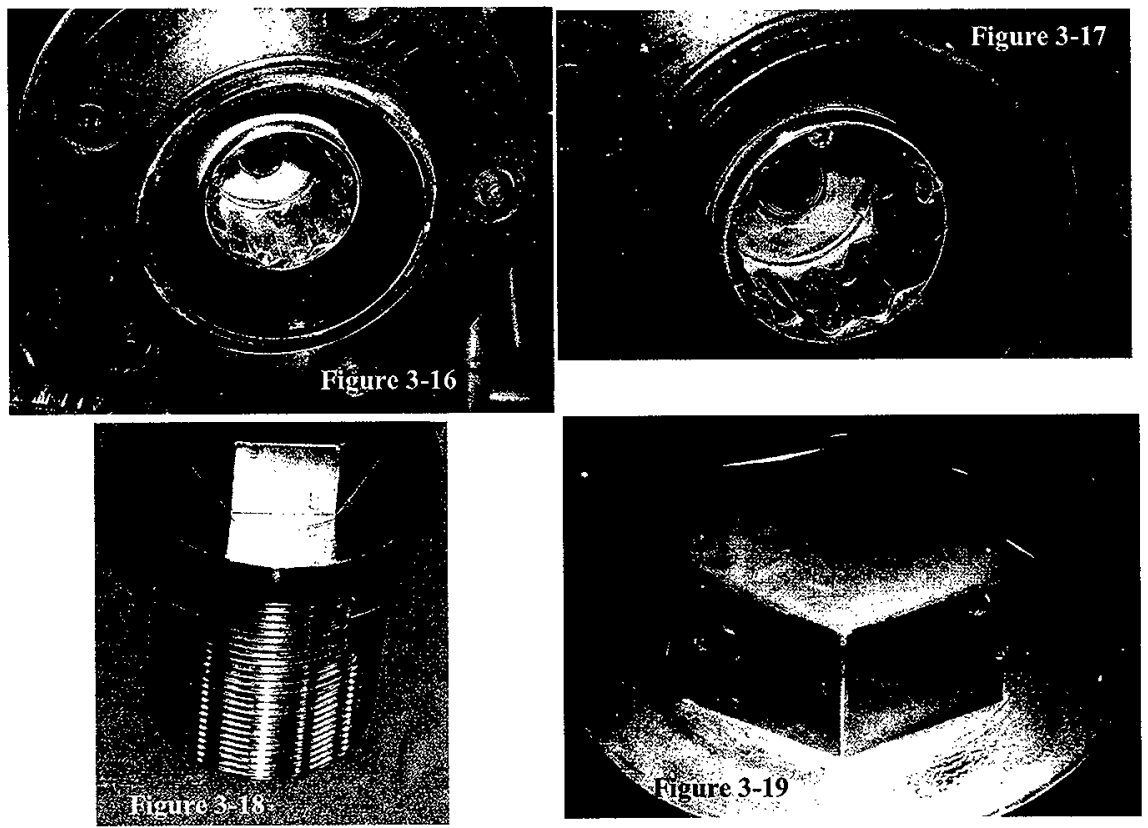

Figures 3-20, 3-21, and 3-22 show a progression of water ingress taken during step changes in the DI flushing sequence during the process connector flushing tests.

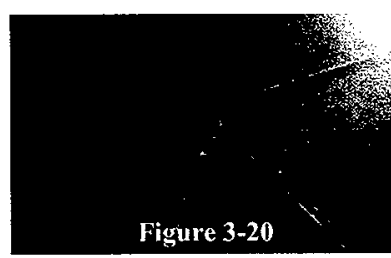

Figure 3-20

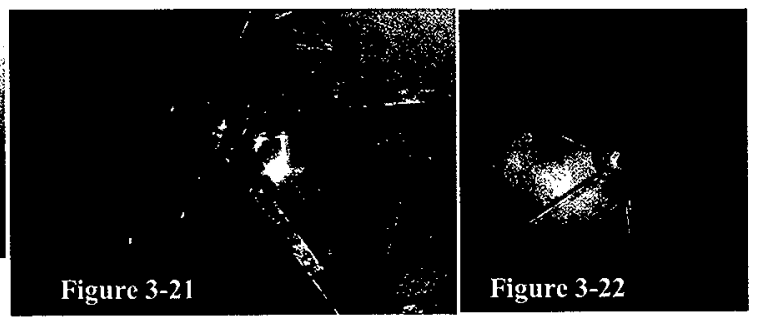




\subsubsection{Process Connector Flushing and MCO Water Ingress Test Discussion of Results}

The process connectors and process valves were smeared with cerium oxide solution consisting of cerium oxide powder and a small amount of water for the initial process connector flushing efficiency test (see Figures 3-12 and 3-13). The cerium oxide was chosen because of its density and specific weight relationship to uranium oxide. The DI flushing action inside the process connector did not produce the desired effect to clean the connector to an acceptable amount when the sludge was coating the connector internals. With a DI flow of $5 \mathrm{gpm}$ and connection to the facility line equivalent line length system, initial process connector flushing efficiency tests revealed that the sludge layer does not wash off entirely. The sludge was applied with a cotton swab to the inside of the process connector at an approximate thickness of $1 / 32 \mathrm{in}$.

The water ingress test revealed that water is allowed to enter into the MCO during the DI flush. Only a small puddle is formed at the bottom of the dip tube during the DI flush sequence (see Figure 3-20) and once the sequence is advanced to the PWC post purge sequence, through the $\mathrm{MCO}$, that small amount of water is evacuated from the $\mathrm{MCO}$ (see Figure 3-21). However, once the PWC post purge is complete, enough water enters the $\mathrm{MCO}$ to fill the MCO bottom cup (see Figure 3-22). When the helium flow is reversed to the normal flow path through the diptube to start drying, a significant amount of water (calculated at 5.67 liters) enters into the MCO from the VPS *01 line. This result is consistent with observations made during some initial drying tests. A rapid decrease in MCO pressure and water hammering in the hoses during the initial 30 minutes of drying were observed (see Figure 4-19 of section 4.4.3.2). Once the line was purged free of water, the MCO pressures returned to normal operating parameters for that process time period and the movement in the VPS $* 01$ flexible hose stopped.

The water is placed in this line during the bulk water draining sequence. Once GOV $1 * 30$ is opened, a vacuum is created by the PWC ejector which evacuates both PWC and VPS * 01 lines which are in communication through the process connector. When the water is pushed out of the MCO, it has two paths to chose. Both paths are evacuated by the eductor and water is initially drawn down both paths. One leads to the PWC ejector and the other leads to isolation valves GOV $1 * 02$ and GOV $1 * 11$. The water that travels to the isolation valve remains in VPS *01 line until the normal helium flow path is established and the water flows right back into the $\mathrm{MCO}$.

The sludge carry over test was conducted at almost twice the normal draining flow rate or $11 \mathrm{gpm}$. $2 \mathrm{~mm}$ tungsten spheres located in the MCO bottom cup were suctioned into a nonscreened diptube. Two of the 9 spheres were immediately located in the PWC tank while the remaining seven were not readily located either in the $\mathrm{MCO}$ or the piping. MCO drying, sludge extraction, and totalization were conducted to find the remaining spheres and to identify the amount of sludge carried over to the PWC. All spheres were eventually accounted for (16 in the $\mathrm{MCO}-2$ in the PWC) and the amount of sludge that was transported to the PWC was 34 grams (of the 500 grams or approximately $6.8 \%$ mass fraction removed). Process connector examination following the sludge carry over test showed that the carried up the diptube does not remain in the process connector but a small amount is deposited on top of the plug valve underneath the process connector socket head. The MCO cirain water laced with the Cerium oxide circulates under the socket and settles on top of the plug valve. When the MCO is dried, the sludge remains on the top of the plug valve after the process connector is removed. 
The sludge carryover test was renun using the appropriate flow rate through the facility equivalent line length system but with no tungsten balls. The results were the nearly the same, with 32 of the 463 grams of cerium oxide (approximately $6.9 \%$ mass fraction) being removed from the MCO. Cerium deposits were located on the top of the $\mathrm{MCO}$ plug valve.

\subsubsection{Process Connector Flushing and MCO Water Ingress Test Conclusions and Recommendations}

The initial tests for process connector flushing failed to sufficiently clean a heavily cerium oxide coated process connector.

The water ingress test showed that water does not enter the MCO during the DI flushing sequence but approximately 2 liters of water does get pushed back into the MCO when the normal helium purge path is established. It was not determined if this amount of water remained consistently every time the draining sequence was conducted. The total amount of water entering the MCO would be limited to the maximum volume of water that could be in the flex line and the piping up to GOV $1 * 02$ and GOV $1 * 11$ on the hood piping network. This water is usually purged out of the lines within the first half-hour of the drying sequence, as seen in the drying tests.

A recommendation is made to redesign the process connector. A possible fix is to place seals on the top and bottom of a six point process connector socket with a taper from the edge of the MCO plug valve to the main socket body. As the plug is removed from the $\mathrm{MCO}$, the seals will tighten against plug valve and the back of the process connector. This will provide a seal to prevent the sludge particulate from accumulating on the plug valve. The sludge transport test should be repeated to identify if the modification prevents the cerium from accumulating. The taper on the socket will prevent sludge from accumulating on the lip of the plug valve by eliminating eddy current formation around the abrupt socket to plug valve transition. If the test is not successful further, more complex redesign of the process connector may be in order.

\subsection{Bulk Water Removal and Totalization}

Bulk water removal tested the operation of the PWC system; and the bulk water totalization roughly determined the total quantity of water remaining in the MCO after the bulk water draining. The total amount of water remaining in the $\mathrm{MCO}$ directly effects the $\mathrm{MCO}$ drying time.

\subsubsection{Bulk Water Removal and Totalization Apparatus}

For the bulk water removal tests, the PWC mock-up system was utilized along with an equivalent length piping system from the CVDF design and the first article testing process hood piping system. The tests were conducted to test the PWC eductor effectiveness for removing MCO bulk water at ambient and operating temperature. 
Bulk water totalization was accomplished by a special system fabricated to remove water directly from the MCO (utilizing the ejector), the WRT, and the PWC circulation pump with lines as short as possible. Slight modifications to the PWC system were necessary such as adding in two isolation valves and a length of flexible tubing. Also another process connector was fabricated to attach to the flex tubing from the PWC. These modifications provided a direct route from the $\mathrm{MCO}$ to the $\mathrm{PWC}$ with a reduced chance for introduction of errors due to losses in extraneous line length.

\subsubsection{Bulk Water Removal and Totalization Test Procedure Summary}

The bulk water removal tests were conducted with the IXM prefilter bypassed and the MCO filled with water and maintained at ambient temperature. Other tests were conducted with MCO at operating temperature. The PWC pump was started and the system was allowed to come to a steady state pressure. Pressure was applied to the MCO through the HEPA filter port from the PES, then GOV 1230, MCO isolation valve to the PWC system, was opened and flow was established from the MCO to the PWC. PWC system instruments, flow and pressure, were monitored for indications of breakthrough.

Bulk water totalization was conducted by removing the long dip-tube process connector and the MCO plug valve. These were replaced with the modified process connector with the attached flex tubing. Initial WRT readings were recorded then the PWC pump was started. Pressure was applied to the MCO through the HEPA filter port from the PES, then the PWC isolation valves were aligned to isolate the facility equivalent line length and start the flow from the MCO. Final WRT readings were taken after break though and the PWC pump stopped. The MCO was refilled, heated, then dried using the PES. After the MCO passed a final dryness check, the condenser was drained and the water volume in the PWC and the water in a vacuum pump exhaust condensate catch tank was weighed and measured. The volumes were added together and this volume used for calculations and comparisons.

\subsubsection{Bulk Water Removal and Totalization Test Results}

The bulk water removal process functioned properly and breakthrough was recorded on both PWC pressure and flow instrumentation.

Table 3-6

\begin{tabular}{|l|c|c|c|}
\hline $\begin{array}{l}\text { MCO initial temp } \\
\text { Ambient and } 46^{\circ} \mathrm{C}\end{array}$ & $\begin{array}{c}\text { PWC Pressure (PT-4033 } \\
\text { psig) }\end{array}$ & $\begin{array}{c}\text { PWC Flow (FT- } \\
4050 \mathrm{gpm})\end{array}$ & $\begin{array}{c}\text { Drain Time } \\
\text { (min) }\end{array}$ \\
\hline Before Drain & -14.4 & $0-2$ & \\
\hline During Drain & -14.4 & $5-8$ & \\
\hline At Breakthrough & -1.6 to -2.0 & $10-12$ & 31 \\
\hline
\end{tabular}


The bulk water totalization results are displayed in the following table.

Table 3-7

\begin{tabular}{|c|c|c|c|c|c|}
\hline Tank Total & $\begin{array}{l}\text { MCO Water } \\
\text { Fill Amount } \\
\text { Average (gal) }\end{array}$ & $\begin{array}{l}\text { Nominal Fuel } \\
\text { average difference } \\
\text { after } 30 \text { minutes of } \\
\text { drip time (liter) }\end{array}$ & $\begin{array}{l}\text { Nominal Fuel } \\
\text { Average (liter) }\end{array}$ & $\begin{array}{c}\text { Pristine Fuel } \\
\text { Average } \\
\text { (liter) }\end{array}$ & $\begin{array}{l}\text { Damaged } \\
\text { Fuel } \\
\text { Average } \\
\text { (liter) }\end{array}$ \\
\hline $\begin{array}{l}\text { WRT initial drain } \\
\text { retained in MCO }\end{array}$ & $\begin{array}{c}149.5 \\
\text { (565.72 lit) }\end{array}$ & 0.45 & 10.95 & 5.82 & 22.03 \\
\hline Condensate tank & W 13 & 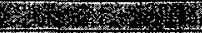 & 6.66 & 3.91 & 6.11 \\
\hline $\begin{array}{l}\text { Vacuum pump } \\
\text { exhaust }\end{array}$ & & $8 \%$ & 2.38 & 0.30 & 2.54 \\
\hline Total & 4 & & 9.04 & 4.20 & 8.65 \\
\hline $\begin{array}{l}\% \text { difference in } \\
\text { retained water } \\
\text { recovery }\end{array}$ & & & $19.1 \%$ & $27.8 \%$ & $87.2 \%$ \\
\hline $\begin{array}{l}\% \text { total water } \\
\text { recovered }\end{array}$ & & 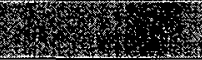 & $99.7 \%$ & $99.7 \%$ & $97.6 \%$ \\
\hline
\end{tabular}

\subsubsection{Bulk Water Removal and Totalization Discussion of Results}

As seen in Figure 3-23, the bulk water removal process worked flawlessly. The ejector performed beyond expectations and the instrumentation detected when the MCO was empty. The pressure would suddenly spike from a vacuum to near atmospheric pressure as soon as all the bulk water was removed from the MCO. Further study concluded that the best way to determine the water total removed from the $\mathrm{MCO}$ would be to use the level in the PWC tanks and use the diameter of the tanks to calculate the water total. The calculation would eliminate electronic flowmeter/totalizer errors introduced with two phase (liquid and gas) flow.

The water totalization process method assumes that the same amount of water will remain in the $\mathrm{MCO}$ after the initial bulk water totalization as the second after refilling and heating. The nominal and damaged retained water amounts shown in Table 3-7 primarily agree with expected results identified in section 3.1. The nominal fuel retained water amount was determined by averaging 6 separate tests conducted over a 3 month period. The tests were completed on dates, $11 / 05 / 98,11 / 25 / 98,12 / 02 / 98,1 / 20 / 99,1 / 24 / 99$, and 1/28/99. As a secondary check, the condenser condensate tank and vacuum pump exhaust tanks were drained and totalized to determine the percent of $\mathrm{MCO}$ water recovery. The total amount of water recovered from the system was $99.7 \%$ for nominal fuel.

The damaged fuel retained matched closely to the predicted amount from section 3.1 . However during the totalization after the damaged fuel drying test was complete, the total amount recovered was significantly less than was expected. Only 8 liters compared to the expected 22 liters retained. This test was only conducted one time during the first article testing program and many errors can not be averaged out with just one test. The drying test data in section 4.6 certainly states that there was significantly more water in the MCO than what was recovered from the condenser and vacuum pump exhaust condensate tanks. If any further damaged fuel tests were to be conducted, this tests should also be repeated. 
The pristine fuel retained water was significantly higher than what was predicted in section 3.1. In section 3.1, pristine scrap basket did not have any fines. This could account for approximately 1.7 liters of water in the remaining in the scrap basket (calculated from the difference between nominal and damaged fuel scrap basket in section 3.1). This would bring the retained water amount 5.2 liters, which is closer to the 7.4 liters seen from the bulk water totalization performed for this section. Again, if any further pristine fuel tests were to be conducted, this test should also be repeated.

\subsubsection{Bulk Water Removal and Totalization Conclusions and Recommendations}

The MCO bulk water removal methodology performs as expected in the design. The PWC system and the PES drained the MCO within 30 minutes. The ejector inlet pressure clearly indicates when the bulk water has been removed from the $\mathrm{MCO}$ by indicating a sudden increase in pressure from near absolute vacuum to slightly below atmospheric pressure. Ejector pressure is a very good parameter to key on when the $\mathrm{MCO}$ bulk water has been removed.

The bulk water totalization had mixed results. The total water recovered from the system ranged from $99.7 \%$ for a nominally loaded MCO to $97.6 \%$ for damaged fuel. Better totalization percentages for damaged and pristine fuel loaded MCOs could be increased by repeating more tests and averaging the results rather than relying on only one test. 
(uюs) M이 wn!ן바

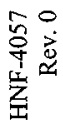
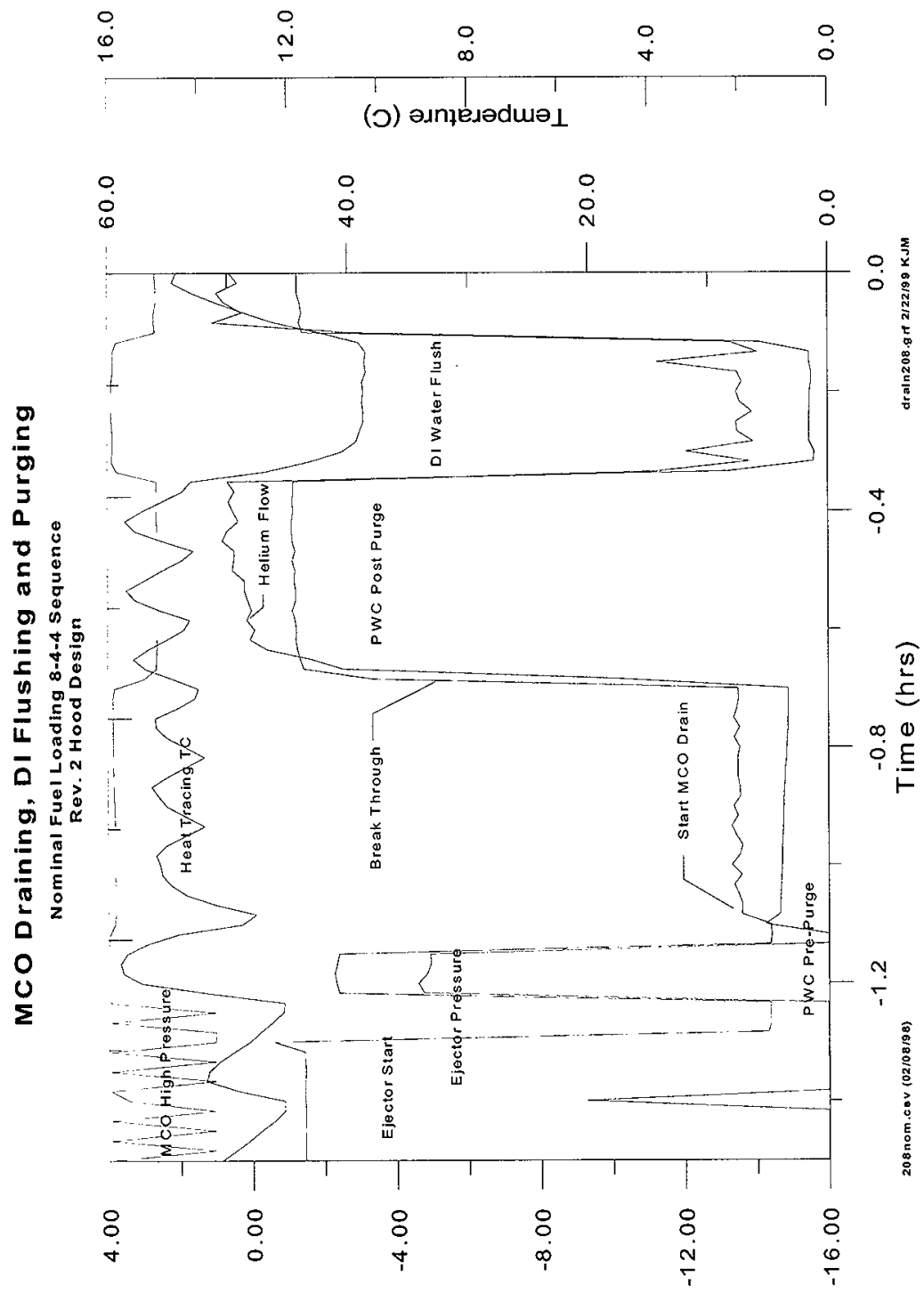

(6!sd) əגnssəגd

$\underset{\substack{2 \\ 0}}{0}$ 


\subsection{PRIMARY TESTS RESULTS}

This section provides the test description, apparatus description, general test procedure description, test results, discussion of test results, and conclusions and recommendations for the primary tests conducted during the first article testing program.

\subsection{Baseline Establishment}

The testing of a dry MCO established initial system vacuum baselines and overall system operational verification for determining VPS/MCO system evacuation times for thermal model verification (i.e., Process Simulator), MCO baseline dryness for pressure and moisture sensors, VPS/MCO system leakage, and system off-gassing for the RGA baselines. The baseline establishment will also verify operation of the helium purge system, TWS, the PWC eductor, gas operated valves, pressure control valves, flow control valves, and temperature setpoints. Several baselines were conducted to determine these parameters which were evacuating the clean, dry, and empty MCO vessel; filled with helium; filled with helium and using a $1.9 \mathrm{scfm}$ helium purge; and filled with helium and using a $3.0 \mathrm{scfm}$ helium purge. The parameters were chosen in accordance with the operating parameters defined in the Operations Sequence, SNF-2356.

\subsubsection{Baseline Test Apparatus}

All baseline tests were conducted using the components and instrumentation on the PES, on the process hood piping assembly, and in the MCO and cask. All equipment used for the testing is described in Section 2 of this document.

\subsubsection{Clean Dry Empty Helium Filled MCO}

This baseline was conducted on several occasions through out the testing program. The purpose was to determine the maximum time to evacuate a dry $\mathrm{MCO}$ and identify any vacuum pump or instrumentation degradation. Due to the complexity and time-consuming nature of the fuel loading and $\mathrm{MCO}$ leak testing, this test was repeated after the initial baselines with a full fuel load in the MCO.

\subsubsection{Clean Dry Empty Helium Filled MCO Test Procedure Summary}

The MCO was fully charged with helium to 1 psig and evacuated to 0.1 torr through the condenser bypass loop. The time to reach this base pressure was recorded and the pressure was also monitored.

\subsubsection{Clean Dry Empty Helium Filled MCO Test Results}

Figures 4-1 and 4-2 display the vacuum pump and MCO pressures throughout the evacuation.

Figure 4-3 displays the vacuum pump and MCO pressures through out different evacuations during the course of testing with a fully loaded $\mathrm{MCO}$. 


\subsubsection{Clean Dry Empty Helium Filled MCO Discussion of Results}

The evacuation of a clean dry and empty MCO took approximately 32 minutes to reach a base pressure of 0.1 torr. The MCO was initially filled with helium at 1.1 psig then evacuated to the system base pressure (see Figure 4-2).

Other baselines tests were conducted later in the testing but because of the difficulty and time consuming method of removing the mock fuel and resealing the $\mathrm{MCO}$, the baselines were conducted with the mock fuel inside the $\mathrm{MCO}$. These additional baselines were to determine if any vacuum pump degradation had occurred throughout the testing. As seen in Figure 4-3, the MCO was evacuated to 0.15 torr in 25 minutes on the $1 / 18 / 99$ baseline test with a redesigned hood configuration. The same test was completed 5 weeks later with a damaged fuel configuration. The test yielded slightly different results for the MCO pressure and the vacuum pump pressure. The vacuum pump evacuated both systems to 0.12 torr in 15 to 17 minutes but unlike the $1 / 18 / 99$ running of the test, the $2 / 25 / 99$ running did not decrease below 0.12 torr. This suggests a number of items could be impeding the system vacuum performance. First, the vacuum pump could be degrading. Second, the instrumentation could be degrading. Third, the system could be offgassing more in the $2 / 25 / 99$ test.

The system Residual Gas Analyzer (RGA) would be useful in determining the cause of this higher system base pressure but, unfortunately the RGA would not remain on-line during rapid pressure changes from vacuum to pressure which was performed frequently during these baseline tests. This was discovered only after the tests were completed.

\subsubsection{Clean Dry Empty Helium Filled MCO Conclusions and Recommendations}

The pump down of the clean, dry, and empty MCO yielded a system baseline to compare future system tests. Some further testing with an MCO fully loaded with mock fuel yielded mixed results compared to the initial baseline. The MCO reached 0.15 torr in 28 minutes with the empty $\mathrm{MCO}$ and 25 minutes with the fully fueled $\mathrm{MCO}$. The vacuum pump did not reach the same base pressure in any of the three baselines conducted. The results show an increasing base pressure of the vacuum pump which cannot be readily explained. Some explanations are offered in section 4.4 .8 of the nominal drying test results. With further investigation, this mystery, of the increased vacuum pump pressure is caused from a degrading vacuum pump, vacuum pump helium seal gas injection, degrading pressure instrumentation, or iron hydrate offgassing from the test system, could be solved.

\subsubsection{Clean Dry Empty MCO with 1.9 SCFM Helium Purge}

This test was conducted to determine the system base pressure and establish control system trippoints for a dry $\mathrm{MCO}$ at $1.9 \mathrm{scfm}$ and other flow set points.

\subsubsection{Clean Dry Empty MCO with 1.9 SCFM Helium Purge Test Procedure Summary}

This test consisted of filling the MCO with 1 psig of helium then evacuating the MCO with a $1.9 \mathrm{scfm}$ helium purge through the $\mathrm{MCO}$. This test was conducted through the condenser and the condenser bypass loops since both configurations will be utilized with this flow rate. 


\subsubsection{Clean Dry Empty MCO with 1.9 SCFM Helium Purge Test Results}

Figure 4-4 displays the vacuum pump and MCO pressures throughout the evacuation with the condenser on line and various helium purge settings.

\subsubsection{Clean Dry Empty MCO with 1.9 SCFM Helium Purge Discussion of Results}

As seen in Figure 4-4, the system is expected to operate at a base pressure of slightly above 65 torr with a nominal helium injection rate of $1.9 \mathrm{scfm}$. Given the system will be operating with a high amount of water vapor, this pressure plateau is expected to be slightly higher than seen here. Other baseline tests were conducted at varied helium flow rates if the project will require lower flow rates in the future seen in the same Figure.

\subsubsection{Clean Dry Empty MCO with 1.9 SCFM Helium Purge Conclusions and Recommendations}

The system pressure plateau was established for $1.9 \mathrm{scfm}$ of helium to be at 65 torr. This pressure was at the high end of the expected calculations, which ranged from 50 to 65 torr.

\subsubsection{Clean Dry Empty MCO with 3.0 SCFM Helium Purge}

This test was conducted to determine the system base pressure to establish control system check points for a dry $\mathrm{MCO}$ at $3.0 \mathrm{scfm}$. This particular test would determine if vacuum pump cooling or a lower helium flow rate so that vacuum pump operation above 100 torr for more than 10 minutes would be affected.

\subsubsection{Clean Dry Empty MCO with 3.0 SCFM Helium Purge Test Procedure Summary}

This test consisted of filling the MCO with 1 psig of helium then evacuating the MCO with a $3.0 \mathrm{scfm}$ helium purge through the $\mathrm{MCO}$. This test was conducted through the condenser and the condenser bypass loops.

\subsubsection{Clean Dry Empty MCO with 3.0 SCFM Helium Purge Test Results}

Figure 4-5 displays the vacuum pump and $\mathrm{MCO}$ pressures throughout the evacuation.

\subsubsection{Clean Dry Empty MCO with 3.0 SCFM Helium Purge Discussion of Results}

The vacuum pump manufacturer does not recommend operating the vacuum pump above 100 torr inlet pressure for more than 30 minutes. Extended pumping at high pressures without cooling water could be potentially detrimental to the pump. The control system was programmed to provide vacuum pump protection if the pump operated above 100 torr for more than 10 minutes. As seen in Figure 4-5, the vacuum pump, for a dry MCO, beats the timer shutdown only by seconds. Later testing identified steam and helium partial pressures above 100 torr for periods longer than 30 minutes. This discovery lead to the need for vacuum pump cooling. 


\subsubsection{Clean Dry Empty MCO with 3.0 SCFM Helium Purge Conclusions and Recommendations}

Further testing showed that the vacuum pump would require supplemental cooling or lower helium flow rates during the first 30 minutes of processing. Lower helium rates would increase the actual flow rate across the MCO internal HEPA filters. Higher flow rates, in excess of design criteria, could pass radioactive particulate into the VPS piping.

\subsection{Liters of Water Drying}

Thirty-two (32) liters of water was placed into the MCO, then heated to temperature $\left(46^{\circ} \mathrm{C}\right)$ with the TWS, and evacuated and dried using the VPS vacuum pump with the condenser operating at $1^{\circ} \mathrm{C}$. This test was expected to provide basic information such as water temperature and pressures inside the MCO. Another parameter the test was designed to provide was the thermal model verification without additional complications such as fuel, water in isolated locations, and scrap fuel.

\subsubsection{Liters of Water Drying Apparatus}

The thirty-two liter bulk water drying test used scales to weigh the water poured into the MCO. The test used the PES, VPS, TWS, a cask, a MCO, the process hood piping, and the process connectors as described in Section 2 of the document.

\subsubsection{Liters of Water Drying Test Procedure Summary}

The water was weighed on a scale, and poured into the dry MCO (thirty-two liters). The PES heated and dried the MCO with a manual 8-4-4 sequence drying described in Section 9.1 of HNF-2402, Hanford Spent Nuclear Fuel Cold Vacuum Drying Proof of Performance Test Procedure.

\subsubsection{Liters of Water Drying Test Results}

Figures 4-6 and 4-7 show the pressures, flows, and condenser temperatures for the 32liter normal drying test and Figures 4-8 and 4-9 show the results for the 32-liter retest. 


\subsubsection{Liters of Water Drying Discussion of Results}

During initial trials of this test, the system pressure would take extended periods of time to reach vacuum pump base pressure after reaching 3 torr. Investigations concluded that water was freezing in low spots in the processing and SCHe injection lines. Anywhere in the system flexible tubing that sagged, condensate would gather and freeze when the system pressure decreased below 5 torr. Figure 4-10 is a rough sketch from the test log depicting the low spots found in the system.

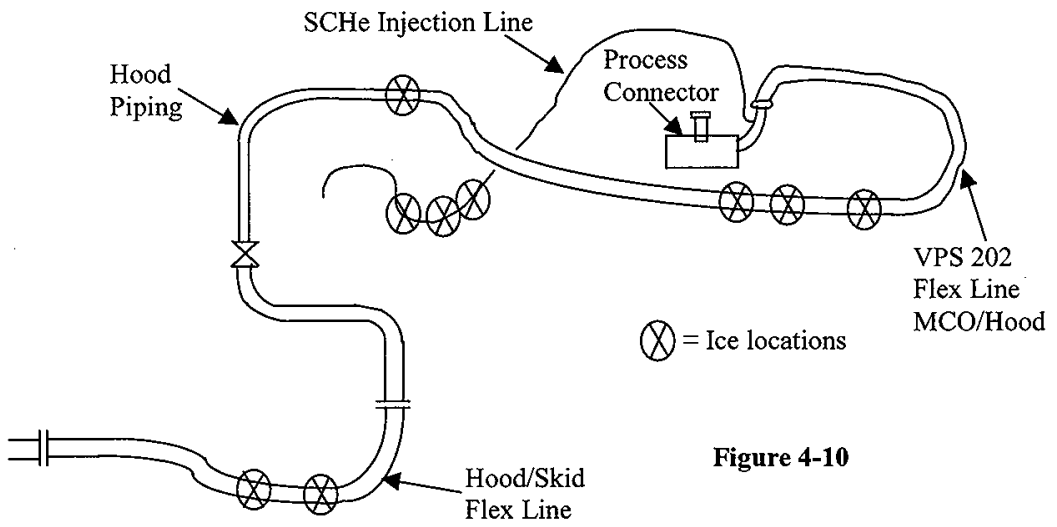

The initial 32-liter test displayed significant pressure loss between the PIT 2211 and PIT 2209 as shown in Figure 4-12. A boroscope inspection of the VPS- $* 02$ line revealed that a flange gasket in front of FIC-2212 was misaligned and over tightened to make fit-up. The flange gasket was crushed enough to protruded into the flow path creating an orifice flow restriction (see Figure 4-11). Once this flow restriction and the flow straightening device for FIC 2212 was removed the second 32-liter drying test was conducted. The pressure drop was gone and the overall drying time decreased by over 10 hours evidenced in Figure 4-13.

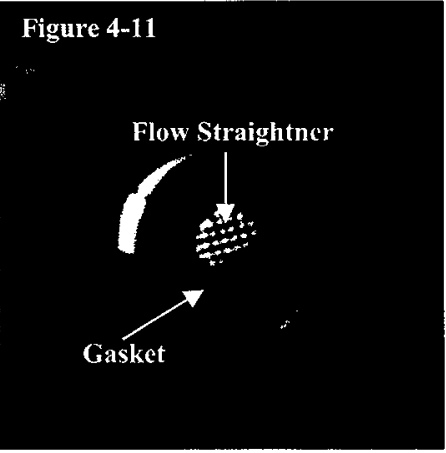




\subsubsection{Liters of Water Drying Conclusions and Recommendations}

The recommendations from these tests are to raise all flex lines and slope all lines in the system to allow them to drain either back to the MCO or the PES condenser (see Figure 4-14). The second recommendation is to conduct baseline tests on all PES skids in the facility to assure line blockages do not hinder the basic PES operation. As described in HNF 3342, First Article Initial Testing Findings Report, other metal gaskets rubber O-rings were recommended. These would replace the soft rubber that bound during installation and caused the type of flow restriction seen in the boroscope inspection.

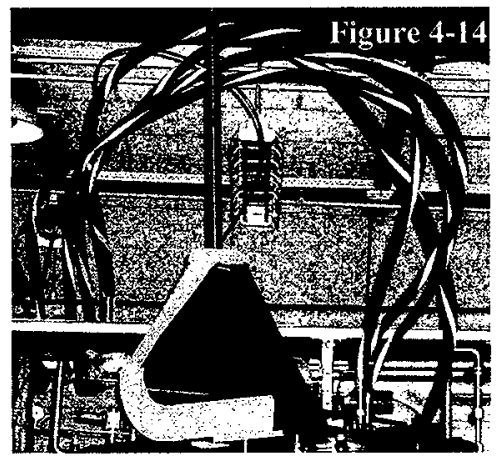

\subsection{Fuel Heat Up Establishment}

This test measures the time required to heat a $\mathrm{MCO}$ (filled with water or helium and mixed fuel from ambient room temperature to $46^{\circ} \mathrm{C}$ processing temperature. This activity demonstrated the mock fuel and MCO heat-up characteristics using a MCO with no internal heat generation from radioactive decay heat in the fuel.

\subsubsection{Fuel Heating Test Apparatus}

The fuel heating tests were conducted using the TWS portion of the PES for heating and the VPS portion of the PES for helium backfill and venting of the MCO. The MCS recorded the data transmitted from the thermocouples located on the MCO outside wall in the cask annulus and from the thermocouples located inside the $\mathrm{MCO}$ on the mock fuel elements and in the simulated scrap. Thermocouples were also installed on the exterior of the cask to verify heat loss from the system. These thermocouples were located as far away as possible from framework surrounding the cask. Figure 4-15 displays the approximate location of the thermocouples located inside and out of the MCO.

\subsubsection{Fuel Heating Test Procedure Summary}

The MCO was filled with water to the filter guard plate on the bottom of the MCO shield plug during this test. The test began with the $\mathrm{MCO}$ and mock fuel temperatures at nominal room temperature and ended when all test articles (mock fuel) reached the TWS set point temperature of $46^{\circ} \mathrm{C}$.

Another heat-up test was performed using helium as the heat transfer media rather than water. The MCO was filled with water at ambient room temperature then drained. The MCO was then back filled with helium at one psig and the TWS heat-up sequence began. The test ended when all the test articles (mock fuel) were at the TWS set point temperature of $46^{\circ} \mathrm{C}$. 

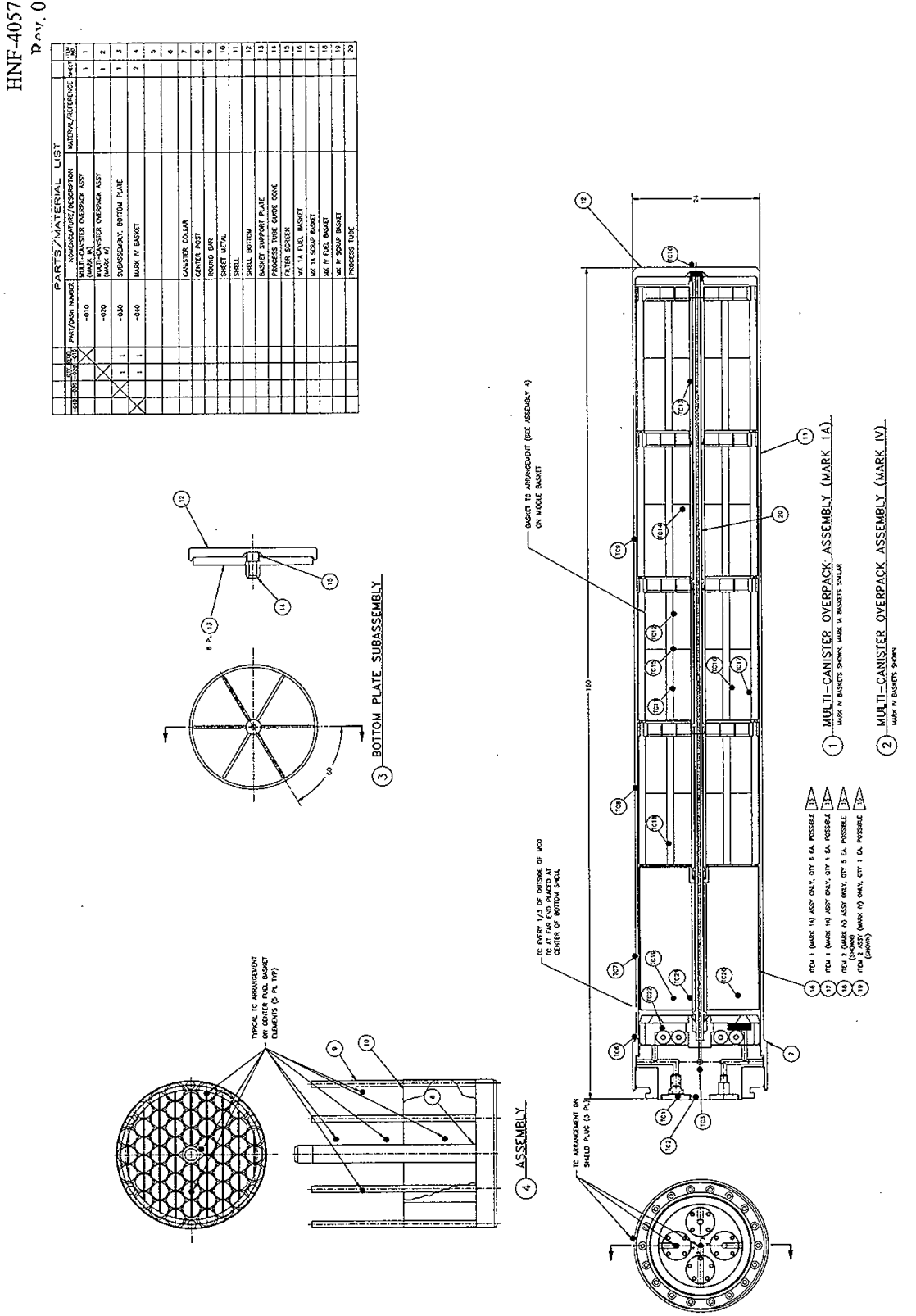


\subsubsection{Fuel Heating Establishment Test Results}

Figure 4-16 displays the fuel heating establishment typical test run with water as the heat transfer mechanism.

Figure 4-17 displays the fuel heating establishment for an MCO that has been drained cold, backfilled with helium, and then heat-up initiated.

\subsubsection{Fuel Heating Discussion of Results}

As shown in Figures 4-16 and 4-17, the heat-up took approximately $6 \frac{1}{2}$ hours with water and 21 hours with helium inside the MCO. Model results display slightly shorter heat-up times with water and uranium fuel approximately $5 \frac{1}{2}$ hours with a nominal 400 Watts of decay heat.

As seen in both the helium and water heat-up curves, the scrap warms quicker than fuel. This is most likely caused from the superior heat transfer characteristics of the copper scrap basket compared to the carbon steel fuel baskets or the higher mass ratio in the fuel baskets compared to the scrap basket. The smaller size pieces of scrap fuel tend to heat quicker than the larger more massive fuel rods.

Careful considerations must be made when determining the length of the heating cycle. Factors such as corrosion product generation, dose rates, and drying times must be considered for both helium and water heat transfer cases. The longer the heating cycle, the more corrosion product is generated increasing the dose rate around the MCO. A shorter heat-up time will extend the MCO drying time by a considerable amount.

Earlier tests, not shown here, were conducted using a smaller impeller in the TWS pump. This prolonged heat-up and the TWS was not meeting design specifications for flow and pressure requirements. The pump impeller was replaced and the results were a system flow of 20 gpm at $37 \mathrm{psig}$ pressure as shown.

\subsubsection{Fuel Heating Conclusions and Recommendations}

The fuel heating equipment performed as expected after a larger pump impeller was installed in TW-P-3211. The heat-up times were nearly double what was originally predicted. Based on the reported test results, we recommend choosing a soak time that would allow a worst case (low decay heat) MCO and fuel to heat within $1^{\circ} \mathrm{C}$ of the TW set point $\left(\sim 6^{1} / 2\right.$ hours). This will provide the fastest drying time. The hotter the fuel is initially, the faster the water vapor is removed from the MCO. Many factors, such as: corrosion product generation, MCO dose rate, and drying times, must be considered when determining the fuel heat-up soak time. 


\subsection{Nominal Fuel Load Drying Tests}

This sequence of drying tests was performed with the $\mathrm{MCO}$ in the nominal or mixed fuel configuration. This MCO fuel mockup represents an intermediate fuel condition between best and worst case drying conditions, which are more prototypic of authentic conditions, and represented as the "nominal case". Many tests were conducted using the nominal fuel configuration. These tests verified the operation of the entire process sequence software and process hardware. The tests conducted with this fuel configuration were: 1 - a normal 8-4-4 sequence drying operation, 2 - a vacuum pump and condenser drying with nominal helium purge, 3 - a vacuum pump drying with nominal helium purge, 4 - a normal 8-4-4 drying sequence with reduced helium flow, 5 - a normal 8-4-4 drying sequence with reduced tempered water temperature, and 6 - a revised hardware and software normal 8-4-4 drying sequence.

\subsubsection{Nominal Fuel Drying Test Apparatus}

The nominal fuel drying tests used all the systems in the first article test set-up. The PWC system was used to drain and totalize the bulk water from the MCO. The PES and hood piping were used to heat and dry the $\mathrm{MCO}$. The $\mathrm{MCO}$ contained the mock fuel configured in the nominal fuel configuration (see Figure 4-18). The MCS was used to control and record the process parameters.

\subsubsection{Normal Operation Sequence Drying (8-4-4 Sequence)}

This particular test starts with the $\mathrm{MCO}$ full of water and includes the Full Cycle 8-4-4 sequence operation. The data acquired will provide system verification analysis with a "nominal" fuel load and aid in the model validation.

\subsubsection{8-4-4 Sequence Test Procedure Summary}

The 8-4-4 sequence tests were conducted using the MCS automated sequence logic, detailed in $\mathrm{HNF}-2356$, or the test procedure, HNF 2402, manual sequence logic as described in section 9.1.6. A brief description of the automated

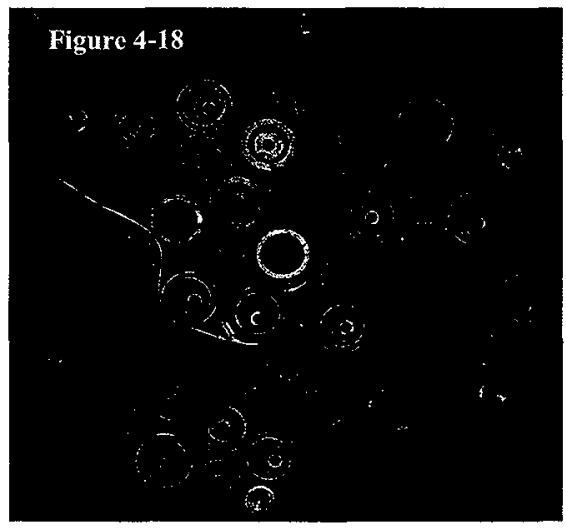
sequence follows:

- Initial Conditions check-verifies the system is capable of evacuating to the vacuum pump base pressure and verifies the condenser is operational.

- Heat-up - allows the MCO to heat-up for a period of time during backfill and venting the process lines and MCO void space with helium.

- Draining - completes a PWC pre-purge with helium, drains the MCO, post purges the PWC with Helium, and purges the SCHe system lines. 
- Drying - starts an initial 8 hour vacuum drying sequence by purging the MCO with $3 \mathrm{scfm}$ of Helium for 30 minutes then ramps to $1.9 \mathrm{scfm}$ over the next 15 minutes. The $1.9 \mathrm{scfm}$ purge continues until the condenser temperature differential is less than $0.2^{\circ} \mathrm{C}$ or the 8 hours under vacuum time limit is reached. Once the condenser temperature differential is less than $0.2^{\circ} \mathrm{C}$, the condenser is bypassed and the Helium purge is halted. Attempts are made to get the MCO below 9 torr within 5 minutes. If 9 torr is not achieved the $1.9 \mathrm{scfm}$ Helium purge is reinitiated for one hour then the 9 torr attempt is made again.

- Thermal Reset-after the 8 hours under vacuum the MCO is quickly re-pressurized with 10 scfm until the MCO pressure is $0.5 \mathrm{psig}$, then the purge is reduced to $1.9 \mathrm{scfm}$ of helium for 4 hours.

- Return to Drying - after the thermal reset, the $\mathrm{MCO}$ is retumed to vacuum for 4 hours or until the $M C O$ passes a pressure rebound test. If the $M C O$ is not dry (0.1 torr), the $M C O$ returns to thermal reset and then this vacuum sequence until the MCO dries.

- Initial Pressure Rebound-the MCO remains at 0.1 torr for 15 minutes, then the MCO is isolated and the pressure is monitored for 10 minutes. If the pressure does not rise above 0.6 torr, the $\mathrm{MCO}$ is placed into thermal reset. If the pressure does rise above 0.6 torr, the $\mathrm{MCO}$ is returned to vacuum drying for the remainder of the 4 hours.

- Final Pressure Rebound-After the initial pressure rebound and final thermal reset, the MCO is evacuated to 0.1 torr and isolated. The MCO pressure is monitored for one hour. If the pressure rises less than 3 torr in that hour, the $\mathrm{MCO}$ is declared dry and the test is complete. If the pressure rise is greater than 3 torr in one hour, the $\mathrm{MCO}$ is returned to the 4 hour drying sequence.

The MCS has a feature programmed specifically for first article testing which allowed the test director to vary a number of different process parameters such as: helium purge flow rate, tempered water temperature set point, and the condenser secondary operational temperature. By programming these settings in as variable set points in the sequence logic, testing proceeded quicker with less man power because the computer could automatically operate the entire sequence. This was opposed to a test operator observing a clock for prolonged periods of time, then manually switching valves to complete the test. After first article testing these variable set points in the logic will be replaced with "hard" values such as $1.9 \mathrm{scfm}$ for helium purge, $46^{\circ} \mathrm{C}$ for TW setpoint, and $0.2^{\circ} \mathrm{C}$ condenser operating temperature delta, for actual facility operation.

\subsubsection{8-4-4 Sequence Test Results}

Figures 4-19 and 4-20 displays the MCO pressures with the helium flow and the condenser temperature differential. Figure 4-21 displays the dew point indication as an indication of dryness. Figure 4-22 displays the MCO pressure and the pipe wall temperature above GOV 1230.

Figure 4-23 displays the differential pressure across the MCO. 


\subsubsection{8-4-4 Sequence Discussion of Results}

The final drying time to reach 0.1 torr was 34 hours. The drying time included the final thermal reset after the initial pressure check and the final one hour pressure test shown in Figure 4-19.

Figures 4-19 and 4-20 also show an initial no purge vacuum check at 7 hours and 20 minutes into the drying sequence. The operational sequence has a check timer, if the thermal limit timer has less than 35 minutes before the 8 hours or 4 hours under vacuum is met, the sequence will advance into a holding mode until the thermal limit timer is reached. If the check timer has more than 35 minutes, it will allow the process to continue with the no purge vacuum check. The nominal 8-4-4 test was conducted several times during the first article testing. During each test, the initial no purge vacuum check occurred within fifteen minutes of the time of the other tests. The average water total for a nominally loaded MCO was 10.95 liters as discussed in section 3.5.

These tests showed the dew point as another reliable means of detecting MCO drying. Figure 4-21 displays the dewpoint temperature with reference to the MCO pressure. As the MCO is dried, less moisture is present in the processing lines and the system dewpoint begins to fall.

Figure 4-22 displays the fuel and scrap temperatures during the process. This figure also displays the data collected from a thermocouple placed on the PWC piping on GOV 1230. This thermocouple placement was chosen to discern if heat tracing eliminate ice formation in that particular location. The location was identified during the reduced bath temperature tests conducted earlier (see Section 4.4.6). The thermocouple rapidly decreases in temperature during the beginning of each vacuum cycle until the water is removed from that location during the third vacuum cycle. As shown, the heat tracing cannot provide enough heat to keep the temperature in the pipe from falling but it does keep the water from freezing. The temperature does not fall in subsequent vacuum cycles (after the third) where it is postulated the water dries on the top of the valve.

The differential pressure transmitter measures the pressure losses through the MCO shield plug dip tube, fuel baskets, MCO internal HEPA filters, and shield plug port plugs and connectors. Figure 4-23 displays the results during this test.

\subsubsection{8-4-4 Sequence Conclusion and Recommendations}

The normal drying sequence for nominal fuel with a $46^{\circ} \mathrm{C}$ and a $1.9 \mathrm{scfm}$ helium purge is 34 hours. Heat tracing provides enough heat to the PWC line piping to remove water trapped in the line during bulk water draining and condensed during the drying process. The processing lines were elevated to reduced the chance for water collection in low spots and prolonged drying process times. 


\subsubsection{Vacuum Pump and Condenser Drying with 1.9 SCFM Helium Purge}

This test utilized only the vacuum pump and condenser with helium purge operations (1.9 $\mathrm{scfm}$ ), excluding the pressurized thermal reset of helium purge, to accomplish MCO drying. This test was predicted to be a shorter test when compared to the 8-4-4 sequence. This is attributed to little fuel drying accomplished during the thermal reset portions of the 8-4-4 sequence. The data acquired helped evaluate the role of the helium purge operation in $\mathrm{MCO}$ drying.

\subsubsection{Vacuum Pump and Condenser Test Procedure Summary}

As stated in the brief description above, this test uses only the condenser and the vacuum pump with a $1.9 \mathrm{scfm}$ helium purge to dry the $\mathrm{MCO}$. The $\mathrm{MCO}$ is thoroughly heated, as determined by the internal thermocouples, then drained as in the 8-4-4 sequence. The condenser and vacuum pump are valved in and drying is initiated with a $1.9 \mathrm{scfm}$ helium purge through the diptube. The helium purge is not raised to $3 \mathrm{scfm}$ for the beginning of this test, unlike the 8-4-4 sequence The condenser was isolated after the condenser secondary temperature differential was $0.2^{\circ} \mathrm{C}$ at which time the helium purge was eliminated for the duration of the test. The vacuum pump then had 5 minutes to get the MCO below 9 torr otherwise the helium purge was reinitiated for one hour, then the 5 minute evacuation was repeated. Once the vacuum pump reached 9 torr within the 5 minute time allotment, the evacuation continued with only the vacuum pump (condenser bypassed) until the $\mathrm{MCO}$ was at 0.1 torr. The pressure rebound test would begin and if the MCO passed, the test was completed. If the test failed, more vacuum pump only drying would initiated.

\subsubsection{Vacuum Pump and Condenser Test Results}

Figure 4-24 shows the MCO pressure and helium flow.

Figure 4-25 shows the condenser temperatures with pressure.

\subsubsection{Vacuum Pump and Condenser Discussion of Results}

This test utilized only the vacuum pump and condenser with helium purge operations (1.9 scfm), excluding the pressurized thermal reset of helium purge, to accomplish drying of the MCO. This test was predicted to be a shorter test compared to the 8-4-4 sequence since little fuel drying is accomplished during the thermal reset portions of the 8-4-4 sequence. The data acquired will help evaluate the role of the helium recycle operation in MCO drying.

Notable conditions observed in this test was the repeatability of the helium flow controller FIC 1219. As seen in Figure 4-24 after the fourth 9 torr check, the pressures vary in the $\mathrm{MCO}$ after every no purge vacuum check. This is not caused by an increase in steam flow but erratic behavior from the helium flow controller. Note the differences in the flow curve after each vacuum check. 
When the condenser temperature differential was at $0.2^{\circ} \mathrm{C}$ across the condenser cooling loop as seen in Figure 4-25, the condenser was isolated and the no purge vacuum checks were initiated. The first no purge vacuum check was initiated at 7 hours and 24 minutes, 36 minutes before the 8 hour limit in the normal drying 8-4-4 sequence. This no purge vacuum check timing was closely repeated in nearly all the normal 8-4-4 drying tests with Rev. $N$ hood design.

\subsubsection{Vacuum Pump and Condenser Conclusion and Recommendations}

This test was to provide results to compare with vacuum pump only drying to determine if an upset condition, such as loosing the VPS chilled water system, would dramatically increase the processing time. The drying time (time to pass the 3 torr pressure check) with the condenser operational was 18 hours compared to the vacuum pump only drying (see Section 4.4.4) of 30 hours.

A recommendation from this test and other tests was to change the helium flow control system to one that was more repeatable and reliable. This recommendation was later incorporated in the Revision 2 hood piping design.

\subsubsection{Vacuum Pump Only Drying with 1.9 SCFM helium Purge (without condenser)}

This test used only the vacuum pump with the $1.9 \mathrm{scfm}$ helium purge, to accomplish drying of the MCO. This test also excluded the pressurized thermal reset helium purge operation. The data acquired will help evaluate the role of the condenser drying operations during the process.

\subsubsection{Vacuum Pump Drying Test Procedure Summary}

The vacuum pump drying was accomplished by initially heating the $\mathrm{MCO}$ until the fuel reached the desired set point temperature, typically $46^{\circ} \mathrm{C}$. The $\mathrm{MCO}$ was drained per the established drain sequence described in Section 9.1 of HNF-2402. Then the control system was then directed to keep the condenser bypassed and valve in the vacuum pump and to flow 1.9 scfm of helium into the MCO diptube. This would continue until the MCO pressure would get below 55 torr (the equilibrium pressure for the vacuum pump with a helium flow of $1.9 \mathrm{scfm}$ ). This indicated that the water vapor sources in the MCO were nearly exhausted and the helium purge was halted. The vacuum pump then had 5 minutes to get the $\mathrm{MCO}$ below 9 torr otherwise the helium purge was reinitiated for one hour, then the 5 minute evacuation was repeated. Once the vacuum pump reached the 9 torr with in the 5 minute time allotment, the continued evacuation with the vacuum pump would continue until the MCO was at 0.1 torr. Then the pressure rebound test would begin and if the $\mathrm{MCO}$ passed, the test was completed otherwise more vacuum pump only drying was initiated.

\subsubsection{Vacuum Pump Drying Test Results}

The initial test was conducted to determine typical pressure set point to proceed with a no purge vacuum check to 9 torr. This is shown in Figure 4-26. 
The second test was conducted to determine how quickly the $\mathrm{MCO}$ could be dried using only the vacuum pump with a helium purge and the condenser bypassed. These results are shown in Figure 4-27.

Figure 4-28 displays the fuel and scrap temperatures throughout the test. This is for comparison between this mode of removing water and the 8-4-4 sequences.

\subsubsection{Vacuum Pump Drying Discussion of Results}

The initial test provided results near the calculations that when the MCO was dry the pressure would correspond to the partial pressure of helium at $1.9 \mathrm{scfm}$ flow rate, which was 50 torr. Armed with that information, the second test was conducted performing 9 torr no purge vacuum checks beginning at 55 torr. The no purge vacuum checks were conducted in one-hour increments until the MCO pressure was below 9 torr within 5 minutes of starting the check. The no purge vacuum checks were conducted three times before passing. After the 13 hours of pumping to pass the no purge vacuum check, the pump continued to evacuate the MCO for another 17 hours until the MCO reached 0.1 torr.

Figure 4-28 displays the scrap and fuel temperatures during the test. Note the rapid decrease early on in the test from the scrap temperatures. This is seen in all the tests, vacuum pump only drying, vacuum pump and condenser drying, 8-4-4 sequence drying, and even in the reduced bath temperature drying tests. This phenomena is caused from the scrap being in small pieces which do not have the same mass as the full sized fuel elements. The small pieces essentially cool faster than the larger fuel pieces.

\subsubsection{Vacuum Pump Drying Conclusion and Recommendations}

These tests essentially provided a set of baseline test results that states the total vacuum time for a nominally loaded MCO is at a minimum of 13 hours with a $1.9 \mathrm{scfm}$ helium purge. This means that this time would be extended another 8 hours because of the thermal resets in the 8-4-4 sequence. The additional 17 hours to get the $\mathrm{MCO}$ from 9 torr to 0.1 torr would also be extended another 16 hours because of the thermal resets. This total of 54 hours is inconsistent with the test results shown from the normal 8-4-4 sequence findings of 34 hour drying time. This can be attributed that the mock fuel and the scrap in the test apparatus heats up during the thermal resets resulting is faster removal rates when returning to vacuum pumping.

\subsubsection{Normal Operation Sequence Drying with 1.1 SCFM Helium Purge}

The nominal fuel loaded MCO was dried using the normal operating sequence with the vacuum pump, condenser and helium purge operations including the thermal reset operation. However, the test was conducted at a lower helium purge rate, nominally $1.1 \mathrm{scfm}$. The data acquired will help evaluate the role of the helium purge operation in MCO drying. 


\subsubsection{Normal Operation with 1.1 Purge Rate Test Procedure Summary}

This test was conducted using standard complement of PES, cask/MCO/mock fuel, PWC, and the MCS automated computer sequencing. Prior to this test the helium purge flow rate set point was decreased from $1.9 \mathrm{scfm}$ to $1.1 \mathrm{scfm}$. The $\mathrm{MCO}$ was allowed to heatup until the mock fuel was at the established temperature, $46^{\circ} \mathrm{C}$. The program then proceeded with the automatic drain sequence, then the drying sequence, and the pressure rebound test.

\subsubsection{Normal Operation with 1.1 Purge Rate Test Results}

Figure 4-29 shows the MCO pressure and helium flow relationship for this test.

Figure 4-30 displays the condenser temperature differential related to the $\mathrm{MCO}$ pressure

\subsubsection{Normal Operation with 1.1 Purge Rate Discussion of Results}

This test would have completed the final one-hour pressure rebound test at approximately 25 hours after the start of drying. Because of project time constraints, this test was stopped after the initial 10 minute pressure test prior to the final 4 hour thermal reset, as shown in Figure 4-29.

As shown in Figure 4-30, the condenser temperature differentials converge to the $0.2^{\circ} \mathrm{C}$ nearly two hours earlier than that seen in other tests. By reducing the helium flow, the condenser is allowed to remove more steam at a higher flow rate because of the high flow of ballast gas is not in the system.

\subsubsection{Normal Operation with 1.1 Purge Rate Conclusion and Recommendations}

The results of the 1.1 helium purge rate test were approximately 9 hours quicker than what was observed in the normal $1.9 \mathrm{scfm}$ helium purge 8-4-4 sequence. The thermal models predict that the hydrogen offgassing rate in the MCO is approximately $0.8 \mathrm{scfm}$. If the safety analysis could show that the helium purge rate of $1.1 \mathrm{scfm}, 0.8 \mathrm{scfm}$ combined with the instrumentation errors, approximately $0.3 \mathrm{scfm}$, is sufficient enough to remove the hydrogen to acceptable levels, the total MCO CVD processing time could be reduced.

\subsubsection{Normal Operation Sequence Drying with Reduced Bath Temperature}

This test was performed using the automated MCS 8-4-4 drying sequence procedure; however, the tempered water, "bath," was set to $35^{\circ} \mathrm{C}$. This test was to identify overall fuel removal schedule impacts because of increased drying times if CVD process requirements resulted in drying the fuel at reduced bath temperatures. This was the initial test with the automated MCS sequence.

\subsubsection{Normal Operation with Reduced Bath Temperature Test Procedure Summary}

This test was conducted using the MCS automated computer sequencing. Prior to this test the tempered water set point was decreased from $46^{\circ} \mathrm{C}$ to $35^{\circ} \mathrm{C}$. The $\mathrm{MCO}$ was allowed to heatup until the mock fuel was at the established bath temperature. The program then proceeded with the automatic drain sequence, then the drying sequence, and the pressure rebound test. 


\subsubsection{Normal Operation with Reduced Bath Temperature Test Results}

Figure 4-31 displays the initial tests results.

Figure 4-32 displays the pressure and flow curves of the final test run for this series.

Figure 4-33 displays the condenser temperatures for the initial test of the reduced bath temperature.

Figure 4-34 displays the condenser temperatures for the final test in this series.

\subsubsection{Normal Operation with Reduced Bath Temperature Discussion of Results}

This test was conducted several times to prove the automated MCS could operate the system. Each time the test was attempted, more glitches or unwanted routines were removed from the program and programming logic using established configuration control methods.

To complete the initial test, several attempts to get through the automated logic were tried and the final results are plotted in Figure 4-31. The drying times were extensive, upwards of 60 hours. The probable cause was ice isolated in the PWC lines. Another contribution to the extended drying time was a routine that did not allow the MCS to continue until the MCO pressure was below 50 torr. When noted, this setpoint trip was placed at a higher value. Previous testing showed that the partial pressure of helium for a dry MCO was approximately 52 torr. The setpoint was changed to 55 torr and allowed to proceed.

The second test was completed with the MCO pressure setpoint set at an arbitrarily high value (70 torr). This allowed the MCS to continue to use the condenser secondary cooling loop temperature differential as the primary means of identifying that the MCO was nearly dry. This test also took several attempts to complete since new logic was being tested. The final test results of this new logic change are shown in Figure 4-32. This also showed extensive drying times. The potential cause was ice build up in the flex lines, SCHe injection lines, and PWC lines.

The third and final run of this test verified the hardware changes made to reduce the ice traps. In an attempt to allow the water to drain either to MCO or to the VPS condenser, the flex lines were elevated which created condensate traps. Heat tracing was added to the PWC line above GOV 1230. The water in this line is thermally and flow isolated from the system during the process. The successful final test results are shown in Figure 4-32.

\subsubsection{Normal Operation with Reduced Bath Temperature Conclusion and Recommendations}

The tests conducted with the nominal fuel loading, 8-4-4 automated sequence, $1.9 \mathrm{scfm}$ helium purge rate, and a TW temperature of $35^{\circ} \mathrm{C}$, revealed that fuel could be dried at a lower temperature than $50^{\circ} \mathrm{C}$. The drying times were increased by nearly 8 hours, comparing the 34 hour drying during the normal drying sequence to the 42 hour drying time seen in the final test shown in this section. 
This set of tests provided valuable data on how the automated sequence operated. The initial test provided information regarding use of the MCO pressure as a control point, identifying when the MCO was dry. This proved to be a difficult parameter to control for all processed MCOs. The condenser temperature differential proved to be an effective way of providing assurance the $\mathrm{MCO}$ was dry enough to continue vacuum drying without a helium purge. Comparing the two tests showed that the change from the pressure trip point to the condenser temperature differential saved 25 hours of drying time for each MCO.

These tests showed that the PWC system from the MCO process connector to the isolation valve GOV $1 * 30$ (PWC-*01-SS-1") would retain water above GOV $1 * 30$. This water was isolated from the system with no helium flow through the PWC system after the bulk water drain and PWC post purge. This piping section was thermally isolated.

Every time the sequence entered a vacuum step the water in this line would freeze and remain frozen for extended periods of time. Only heat from the room air was being transferred to the water in the pipe. Recommendations from this test were to provide heat tracing and hood piping line inclination to prevent the occurrence of thermally isolated water in the system.

This test series took the operating sequence into logic areas that were unexpected. The new logic paths provided information for base initial upset conditions, such as when either GOV $1 * 02$ or $1 * 06$ do not open. Even though the SCIC was not used in the first article testing program, the tests identified that the SCIC system would initiate if either of these valves failed closed. This flow path is the only means of injecting helium to ensure the hydrogen is removed from the MCO other than the SCHe injection system.

\subsubsection{Redesigned Hood Piping and Revised Normal Operating Sequence Drying}

During the initial first article tests described earlier in this section, several design, operational, and safety analysis changes were made to both hardware and software (logic). This particular test incorporated some of those changes applicable to the CVD process. This test provided MCS "process logic shakedown" of the condenser available for the second vacuum cycle and identified impacts to MCO drying time. Changes included: hood piping revision, additional heat tracing and insulating; three additional SCIC switch positions for a total of seven (Bypass, Heatup, Drain, Purge/Flush, Drying, Proof, and Pressure Test); additional pressure, temperature, flow, and level instrumentation; and a new helium flow control system. The applicable changes were made to the process simulator and data acquired from the test aided in model validation and the system verification analysis under "nominal" case MCO fuel conditions.

All changes in the operating sequence (SNF 2356, Revision 1, Cold Vacuum Drying Operational Sequence) were not proven during this test and will be tested later under a separate CVD testing program. Some changes, from Revision OA to Revision 1 of the Operations Sequence, included an 8 torr pressure limitation rather than 9 torr, sequence relocation of the SCHe purge, cask purging logic enhancements, and changes to the HMI to provide a better, more descriptive process/operator interface. 


\subsubsection{Redesigned Hood Piping and Revised Sequence Test Procedure Summary}

This test was conducted using the revised automated operating sequence with the condenser available for operation during the second vacuum cycle and a nominal fuel configuration in the MCO. The normal process connections, heatup, purging, flushing, drying, and pressure rebound testing, proceeded automatically with the exception of the occasional prompting for operator inputs of required manual switch or valve position changes, or alarm acknowledgment.

\subsubsection{Redesigned Hood Piping and Revised Sequence Test Results}

Plots of the final test results are shown in Figure 4-35 for flows and pressures and Figure 4-36 for fuel temperatures. These test results stem from several weeks of testing which included identifying and updating software (logic) deficiencies and identifying hardware problems and correcting them.

Figures 4-37 displays the of MCO pressure.

Figure 4-38 display the typical pressures in the MCO during heat-up and processing.

Figure 4-39 displays the tests condenser temperature differentials.

Figure 4-40 displays the dew point temperature in the MCO during processing.

Figure 4-41 shows the heat tracing thermocouple during the draining and normal processing. The thermocouple was placed on the piping above GOV $1 * 30$ to determine if ice was forming atop GOV $1 * 30$.

During many of the pre-final tests when these hardware and software diagnostics would halt the test, the opportunity was taken to learn about the final dryness criteria established by the CVD project (evacuate to 0.1 torr, isolate, and watch for a 3 torr pressure rise in one hour). Those test results are shown in Figures 4-42 and 4-43.

Also these pre-final tests identified an ever increasing vacuum pump base pressure. The dated base pressures are shown in Figure 4-44 for comparison.

\subsubsection{Redesigned Hood Piping and Revised Sequence Discussion of Results}

When comparing results from tests prior to the hood redesign (see Figure 4-19 and 4-20) and after the hood redesign changes (see Figure 4-35 and 4-39), for the most important item, drying time, the two tests are nearly identical (see Table 4-1).

Table 4-1

\begin{tabular}{|c|c|c|c|}
\hline Test Date & Drying Time & $\begin{array}{c}\text { Condenser Utilized in } \\
2^{\text {nd }} \text { Vacuum Cycle }\end{array}$ & $\begin{array}{c}\text { Number of } 9 \text { torr } \\
\text { Attempts }\end{array}$ \\
\hline $11 / 11 / 98$ & $34.1 \mathrm{hrs}$ & No & 4 \\
\hline $2 / 10 / 99$ & $35.0 \mathrm{hrs}$ & Yes & 3 \\
\hline
\end{tabular}


During the initial test of $11 / 11 / 98$, the MCS was programmed so that the condenser would not be utilized during the second vacuum cycle. However, with the nominal MCO fuel loading, the temperature differential across the condenser secondary cooling plates met the $0.2^{\circ} \mathrm{C}$ isolation set point prior to a programmed time in the initial vacuum cycle ( 35 minutes remaining in the thermal reset timer). During the $2 / 10 / 99$ test, the MCS was programmed to allow the condenser on line during the second vacuum cycle. In this test, the condenser temperature differential did not reach the trip set point prior to the program timer and it was necessary to use the condenser in the second vacuum cycle. This can most likely be attributed to the slightly higher helium flow rate recorded by FIT 1219. The helium flow in the 11/11/98 test was controlled by FT 1219 and FIC $1219, \mathrm{Kurz}^{\circledR}$ flow control computer and control valve (FV 1219) while the $2 / 10 / 99$ test was controlled by the $\mathrm{FCI}^{(8)}$ flow transmitter (FT 1220) and the Fisher ${ }^{(B)}$ flow control valve (FV 1220) controlled by the MCS. The flow, as indicated by the FT 1219 , averaged $1.90 \mathrm{scfm}$ and 2.00 in the respective tests.

Figure 4-38 displays the fuel temperatures which were effectively modeled by the process simulator. The fuel temperatures show no unexpected or abnormalities when compared to previous tests.

Figure 4-38 quite readily displays the MCO pressure during heat-up oscillates between 1 and 4 psig. This is a feature programmed into the MCS which allows the actual MCO to purged of hydrogen generated during heat-up from the chemical reaction between water and the exposes uranium surfaces on the actual fuel. Figure 4-37 shows the MCO low pressure reaches 0.12 torr and is isolated for the initial pressure rebound but reaches 0.15 torr to start the final pressure rebound test. The final pressure after the 1 hour hold was 0.24 torr.

As shown in the previous tests and Figure 4-40, the dew point provides an indication of $\mathrm{MCO}$ dryness. Once the $\mathrm{MCO}$ is isolated in both the fourth and the final evacuation cycles the dew point rapidly decreases because the system is still actively being evacuated by the vacuum pump. The dew point shows the MCO still has remaining moisture but not enough to fail the pressure test. It is indeterminate if the remaining moisture is either in the form of bulk water or in hydrate water.

The pressure differential across the MCO could not established during the no purge vacuum checks because the automated sequence closes GOV $1 * 02$ which isolates the MCO upstream pressure indicators (PIT $1 * 34$ and PT $1 * 35$ ). The sequence should be updated to track the MCO differential pressure by keeping GOV $1 * 02$ open during all sequences except for draining. The MCO differential pressure provides indication of the internal filter plugging.

Figure 4-41 displays the heat tracing temperatures from the thermocouple that is placed above GOV $1 * 30$. The thermocouple indicates the heat tracing cycles $\pm 4^{\circ} \mathrm{C}$ around the heat tracing temperature set point. This is caused from the general design of heat tracing. The heat tracing is self-regulating which the conductive material between the power conductors expands and contracts making more or less contacts as the pipe wall requires or does not require heating. Further investigation, identified another cause of this significant swing in indication could have been caused by the routing of the thermocouple wiring. The wire routing was near the TW heater controller unit and SCRs during the tests following the hood redesign fabrication. The wire routing was changed in later tests and the oscillation amplitude decreased by nearly half but was still apparent. 
As shown in Figures 4-42 and 4-43, the MCO was isolated at, and prior to, 0.1 tor respectively. This was an effort to test the dryness criteria established by the project and to help identify potential problems with the vacuum pump. In Figure 4-42, the dryness test was started when the MCO pressure was at 0.1 torr. The results shown in Figure 4-43 display passing the dryness criteria test with a starting pressure of 0.3 torr. At this pressure level, if bulk water were remaining in the $\mathrm{MCO}$, the pressure test would fail. The test did not fail, even after 4 hours of isolation. The dew point indication in this test (see Figure 4-40), after reviewing the results of the baseline tests (Figure 4-1), suggest the presence of thermally isolated water, a hydrate, possibly iron hydrate, or other off gassing within the MCO.

Figure 4-44 shows an increasing vacuum pump base pressure over an extended period of time and multiple tests. As the base pressure of the pump increases, the MCO pressure will increase making the isolation trip pressure impossible to meet. This Figure shows that the vacuum pump pressure increases over just one test. The vacuum pump base pressure would be lowered if a nitrogen seal purge gas was placed on the vacuum pump. Once the vacuum pressure was down, a helium seal purge gas was placed back into the pump seals for the next test.

\subsubsection{Redesigned Hood Piping and Revised Sequence Conclusion and Recommendations}

The conclusions for the redesigned hood piping and revised sequence are that the design changes do not change the drying time (extend or decrease). The drying times between the two tests are similar but with different paths to final dryness. The heat tracing functions adequately to supply heat to locations of thermally isolated water in the hood piping and the hose rerouting is beneficial. The flexible hose routing will need final adjustments in the field to prevent any sagging when the hood assembly is connected to the cask and MCO.

During several pre-tests of the new design, several tests against the dryness criteria identified questions about the how the test system operates and the vacuum pump base pressure. Further testing or additional modeling is required to answer these questions about iron hydrate and vacuum pump base pressure.

Additional testing should also be conducted to determine how much the pressure rises in the $\mathrm{MCO}$, if the MCO is not evacuated to 0.1 torr. As seen in Figure 4-41, the amount of time to evacuate from 1 torr to 0.1 torr is approximately 16 hours. If the 0.1 torr criteria is changed to 0.5 torr the total amount of drying time would decrease by nearly 12 hours. The additional tests should isolate the MCO in intervals of 0.1 torr beginning at 1.0 torr down to 0.1 torr and establish what pressure would fail the given 3 torr pressure rise in any number of hours.

\subsubsection{Flooded Filter Drying}

During the course of transporting the MCO from the K-Basins to the CVDF, splashing may occur in the MCO filter void space wetting the filter media. The filter may also become wetted if an upset condition required refilling the $\mathrm{MCO}$. The tests were required to determine any increases in drying time from a wetted filter. 


\subsubsection{Flooded Filter Test Procedure Summary}

The flooded filter test was conducted with a the MCO filled with a nominal fuel load, the normal 8-4-4 drying sequence, normal bulk water draining and DI flushing sequence. The test was conducted with the revision 2 of the hood piping. The filter was flooded by filling the MCO until the filter was under water. This was verified visually using a boroscope.

\subsubsection{Flooded Filter Test Results}

Figure 4-45 shows the normal operation drying process parameters through out the test and Figure 4-46 displays the draining results during the test.

\subsubsection{Flooded Filter Discussion of Results}

As seen in Figure 4-45, the drying time of the wetted filter test was approximately 34 hours. This was not the expected results for this test. The drying time was expected to be at least 8 hours longer than the normal drying time for a total of 42 hours. When observing the bulk water draining sequence results and comparing those to the results presented for a normal MCO draining (section 3.5.3), the draining sequence for the flooded filter test is double of those seen in the for normal bulk water drains.

During the normal draining, the MCO remains pressurized at 4 psig while the ejector is operating at $-14.4 \mathrm{psig}$ as determined from PIT 4031. A sudden pressure rise, detected from PIT 403 , is referred to as "breakthrough" when the bulk water is removed from the MCO and the helium backfill begins flowing to eductor. The breakthrough trip point was determined from previous testing at -1.8 to -2.0 psig for a dry filter MCO. The pressure drop across the wetted filter was greater than expected and the pressure trip point was not met after the breakthrough had occurred. Figure 4-46 displays the MCO draining and DI flushing during this test. The MCS was programmed to alert the operator if the breakthrough pressure of -1.8 psig was not achieved in 35 minutes. The test director elected to continue purging for another 35 minutes to identify any problems during the draining sequence. As purging through the filter continued, the filter began to dry and the helium flow rate began to rise. This made the ejector pressure rise until the breakthrough trip point was reached.

\subsubsection{Flooded Filter Conclusion and Recommendations}

If the arbitrary trip point for the eductor pressure trip for breakthrough was set $1 / 4 \mathrm{psig}$ lower $(-2.25 \mathrm{psig})$, the extra time to dry the filters during the PWC would not have been available. The filters would be dried during the normal vacuum drying sequence extending the time by 8 to 16 hours. The recommendation for this test is to repeat the flooded filter drying test with a lower trip point for the PWC draining and determine how long the drying time would be extended.

Another recommendation would be to experimentally find the breakthrough pressure for each bay in the facility and train operations personnel, for the upset condition of a wetted filter, to proceed with an extended bulk water draining cycle and purge dry the filter and continue with vacuum drying as completed in this test. 


\subsection{Pristine Fuel Drying}

A sequence of drying tests will be performed with the MCO loaded with the pristine fueled configuration (as previously defined). This particular test utilizes the complete CVD process starting with the Full Cycle 8-4-4 sequence operation. This MCO pristine fuel configuration mockup represents the best case drying conditions that can be expected.

\subsubsection{Pristine Fuel 8-4-4 Sequence Apparatus}

The pristine fuel drying tests used the systems in the first article test set-up described in the nominal fuel drying cases. The PWC system was used to drain and totalize the bulk water from the MCO. The PES was used to heat and dry the $\mathrm{MCO}$ along with the process hood piping, the $\mathrm{MCO}$, and the cask. The MCO contained the mock fuel configured in the pristine fuel configuration, which is all the mock fuel elements were placed with the pristine ends facing upwards (see Figure 4-47). The MCS was used to control and record the process parameters.

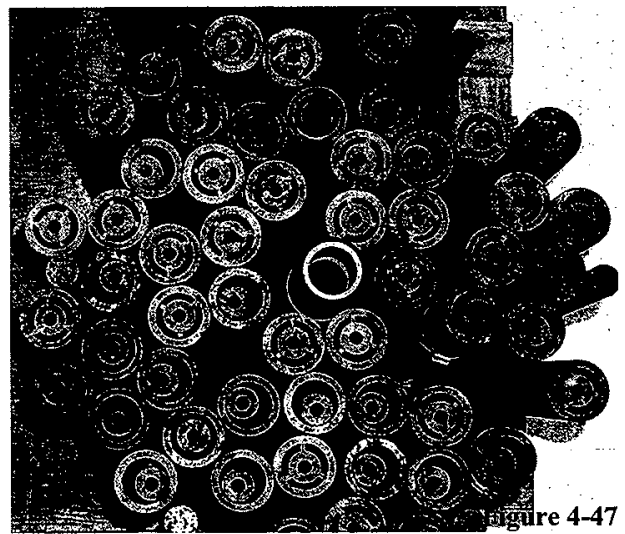

\subsubsection{Pristine Fuel 8-4-4 Sequence Test Procedure Summary}

The pristine fuel test was conducted using the revised operating sequence with the condenser available for operation during the second vacuum cycle and a nominally loaded $\mathrm{MCO}$ full of ambient temperature water. The normal process connections, heat up, purging, flushing, drying, and pressure rebound testing, proceeded automatically with the exception of the occasional prompting for operator inputs of required manual switch or valve position changes, or alarm acknowledgment. The test was completed with a full load of pristine mock fuel.

\subsubsection{Pristine Fuel 8-4-4 Sequence Test Results}

The pristine fuel water retention test results are shown in Table 4-2.

Table 4-2

\begin{tabular}{|l|l|l|}
\hline & $\begin{array}{l}\text { Pristine Fuel Initial Water } \\
\text { Totalization Test }\end{array}$ & $\begin{array}{l}\text { Pristine Fuel Final Water } \\
\text { Totalization Test }\end{array}$ \\
\hline Initial Water Amount & 565.7 liters (149.5 gal) & 565.7 liters (149.5 gal) \\
\hline Water Retained in the MCO & 7.42 liters & 5.82 liters \\
\hline
\end{tabular}

Figure 4-48 details the initial test results displaying the MCO pressure and the helium flow. 
Figure 4-49 shows retest results also displaying the MCO pressure and the helium flow.

Figure 4-50 identifies the $\mathrm{MCO}$ and mock fuel temperatures during the initial test with the MCO pressure as a reference.

The MCO and mock fuel temperatures are shown in Figure 4-51 for the retest of the pristine fuel test.

Figure 4-52 displays the condenser secondary temperatures during the first 9 hours of the tests with the MCO pressure as a reference.

\subsubsection{Pristine Fuel 8-4-4 Sequence Discussion of Results}

The retained water in the MCO was $67 \%$ higher than predicted for the initial pristine fuel test (7.4 liter to 5 liters) as shown in Table 4-2. This accounted for the much longer drying time (35 hours) shown in Figure 4-48. The tests were repeated and closer to expected results were measured. The retained water was slightly over 5 liters and the drying time was 29 hours (see Figure 4-49).

The longer dry out time could be attributed to water in the MCO internal filter housing area as shown by the temperature indication shown in Figure 4-50. When comparing the results, the temperatures in the MCO during the repeat test (see Figure 4-51) do not drop as far as in the initial test.

Figure 4-52 shows the condenser isolates within 3 hours after the start of the retest initial vacuum pump down when the condenser secondary temperatures reach the $0.2^{\circ} \mathrm{C}$ trip point. As compared to the initial test, the condenser isolates one hour later in the sequence.

\subsubsection{Pristine Fuel 8-4-4 Sequence Conclusion and Recommendations}

Longer than expected drying times were observed during the initial test because of the unexpected high water volume retained in the filter evident by reduced temperatures seen in the filter shroud assembly. The results of the second test were closed to expected results given the previous indications of iron hydrate in the system or vacuum pump degradation while using the helium seal purge gas.

The process simulator model for this test estimated drying time was to take place within the first 8 hour vacuum pumping cycle. As seen in the all the other tests, the drying time to reach 0.1 torr takes significantly longer after the 9 torr no purge vacuum check has passed.

\subsection{Damaged Fuel Drying}

The next sequence of drying tests was performed with the $\mathrm{MCO}$ in the damaged fuel configuration. This fuel mockup represents a difficult fuel condition for MCO drying. For this particular test, the MCO starts full of water and includes the Full Cycle 8-4-4 sequence operation, followed by the Post Dry Operation. The data acquired will aid in system verification and model validation analysis under difficult drying conditions for the $\mathrm{MCO}$ and fuel. 


\subsubsection{Damaged Fuel 8-4-4 Sequence Apparatus}

The damaged fuel drying tests used the systems in the first article test as described in the nominal fuel drying cases. The PWC system was used to drain and totalize the bulk water from the MCO. The PES was used to heat and dry the $\mathrm{MCO}$ along with the process hood piping, the $\mathrm{MCO}$, and the cask. The MCO contained the mock fuel configured in the damaged fuel configuration, which is all the mock fuel elements were placed with the damage ends facing upwards (see Figure 4-53) to retain as much water as possible. The MCS was used to control and record the process parameters.

\subsubsection{Damaged Fuel 8-4-4 Sequence Test Procedure Summary}

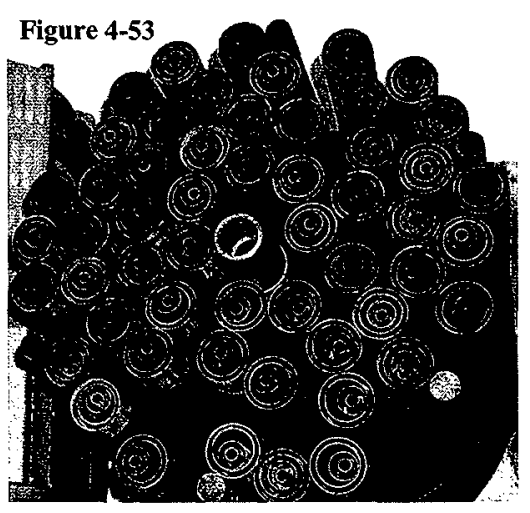

The damaged fuel test was conducted using the revised operating sequence with the condenser available for operation during the second vacuum cycle. The normal process connections, heatup, purging, flushing, drying, and pressure rebound testing, proceeded automatically with the exception of the occasional prompting for operator inputs of required manual switch position changes or alarm acknowledgment. The test was completed with a MCO fully loaded with damaged mock fuel.

\subsubsection{Damaged Fuel 8-4-4 Sequence Test Results}

Figure 4-54 shows the MCO pressure and helium flow.

Figure 4-55 shows the fuel temperatures during the drying sequence.

Figure 4-56 shows the MCO pressure and Condenser temperatures.

Figure 4-57 shows the Heat Tracing temperature and MCO high pressure.

\subsubsection{Damaged Fuel 8-4-4 Sequence Discussion of Results}

The damaged fuel test retained approximately 22 liters of water after a room temperature bulk water drain and measurement in the WRT. The process operated flawlessly throughout the cycles of the drying process. The system dried the MCO in 52 hours as shown in Figure 4-54.

The condenser was not bypassed until the third vacuum cycle (see Figure 4-56) and the no purge vacuum check passed on the fourth attempt, the first attempt of the fourth vacuum cycle (see Figure 4-54). The extra vacuum check attempt, compared to the nominal fuel tests, suggests that slightly more water was remaining in the $\mathrm{MCO}$, or system, after the condenser was isolated. Figure 4-57 clearly indicates the presence of water atop GOV 1230 until early in the fourth vacuum cycle. The water in this location would be a logical cause for not passing the no purge vacuum check earlier. 
Shown in Figure 4-55, the water remaining in the scrap actually freezes, as seen in many nominal fuel loading tests not documented in this report. The ice begins to sublimate under vacuum and continues to be removed from the system until the ice is gone. Once the ice is gone the scrap begins to heat to the cask annulus water temperature.

\subsubsection{Damaged Fuel 8-4-4 Sequence Conclusion and Recommendations}

The damaged fuel test dried over double the amount of water retained in the nominal fuel loading tests in approximately 52 hours compared to 34 hours. The system performance was unsurpassed for this extended test.

\subsection{Proof Drying}

The proof drying mode is required in the CVD process to remove water which would remain in fuel cracks and crevices after the initial drying. This requires a number of hours under vacuum at the tempered water set point (typically $46^{\circ} \mathrm{C}$ ). The number of hours which the MCO remains under vacuum is directly related to the number of scrap baskets in the $\mathrm{MCO}$ ( 8 hours for no scrap basket, 20 hours for one scrap basket, and 28 hours for two scrap baskets). After the mandatory hours under vacuum, the MCO is isolated and a pressure rise test is performed to confirm that no water was re-introduced into the $\mathrm{MCO}$ during the proof drying mode.

\subsubsection{Proof Drying Apparatus}

The proof of drying test was conducted using the same first article full scale equipment used in all of the previous drying cases including the cask/MCO and mock fuel, hood piping assembly and PES. The MCS was used to control and record the proof of drying process parameters.

\subsubsection{Proof Drying Test Procedure Summary}

After the MCO passes the one-hour pressure rise test at the end of the 8-4-4 drying sequence, the MCS operator moved the SCIC switch from "DRYING" to "PROOF" mode. The $\mathrm{MCO}$ was evacuated by opening the isolation valves to the vacuum pump. The vacuum pump evacuated the MCO for 20 hours with the TWS operating at $46^{\circ} \mathrm{C}$. The MCO was again isolated for another 3 torr in one-hour pressure rise test. The total number of hours under vacuum was 21 because the test apparatus utilized only one scrap basket.

\subsubsection{Proof Drying Test Results}

Figure 4-58 displays a pressure plot during one of the proof of dryness tests conducted during the first article testing program.

\subsubsection{Proof Drying Discussion of Results}

As seen in Figure 4-58, the pressure remains very steady during the 19 hours of vacuum pumping since the mock fuel test articles do not have cracks or crevices machined on the surfaces nor does the test apparatus contain any sludge that would dehydrate during this time. 
Reviewing the previous test data, the initial drying time in the 8-4-4 cycle could be reduced by stopping the evacuation prior to the system base pressure and it is expected that the initial pressure test would still pass, as presented in Figure 4-43. If this were to remain the case, the remaining water could also be removed during the proof drying mode and shorten the overall process time by 8 hours or more.

\subsubsection{Proof Drying Conclusion and Recommendations}

After reviewing previous test data, the process could be shorten by 8 hours or more given a nominal loaded MCO. This can be accomplished by allowing the initial 8-4-4 drying sequence to tested at a higher pressure and by removing the remaining water on the fuel while the fuel cracks and crevices are drying out during the proof mode. Obviously this is only an observation taken entirely from the test mock fuel. A thermal analysis would be required to identify if this recommendation could actually shorten the process.

\subsection{MCO Cooldown}

Prior to leaving the CVD facility, the MCO and the fuel must be cooled to a lower temperature for CSB receipt. This is accomplished by circulating cool water around the $\mathrm{MCO}$ for a number of hours until the proper temperature is met which is below the CSB receipt temperature because the actual fuel has radioactive decay heat even after drying.

\subsubsection{MCO Cooling Apparatus}

The MCO cooldown apparatus was the same as in the fuel heating tests. The MCO cooling tests were conducting using the TWS portion of the PES for heating and the VPS portion of the PES for Helium backfilling of the MCO. The MCS controlled the pressure in the MCO and recorded the data transmitted from the thermocouples located on the MCO outside wall in the cask annulus and from the thermocouples located inside the MCO on the mock fuel elements and in the simulated scrap. Thermocouples were also installed on the exterior of the cask to verify heat loss from the system. These thermocouples were located as far away as possible from framework surrounding the cask. Figure 4-15, earlier in the text, displays the approximate location of the thermocouples located inside and out of the MCO.

\subsubsection{MCO Cooling Test Procedure Summary}

Circulating cooler water into the cask annulus cooled the MCO. The MCS stopped the heater and opened GOV 3201 which allowed HVAC cooling water to flow into the TWC system heat exchanger TW-CLR-3210. The annulus water was continually circulated until the fuel was determined to be at or below the MCO shipping temperature (typically $25^{\circ} \mathrm{C}$ for the MCO wall and $40^{\circ} \mathrm{C}$ for the fuel). The MCS also monitors and controls the pressure internal to the MCO by cycling the long dip tube isolation valve (GOV 1202) to maintain a pressure of $7.3 \pm 1.5 \mathrm{psig}$ during the entire cool down. 


\subsubsection{MCO Cooling Test Results}

Figure 4-59 displays typical $\mathrm{MCO}$, fuel cooling trends, and typical pressure trends during the cooling period.

\subsubsection{MCO Cooling Discussion of Results}

The objective of this test was to cool the MCO fuel to room temperature. As shown in Figure 4-59, the test was terminated slightly before the highest fuel temperature reached $25^{\circ} \mathrm{C}$. If this graph were continued, the expected cool down time would be approximately 13 to 15 hours with a pressurized helium filled MCO at 7 psig ( 21 psia). The TW chilled water system not only has to remove the heat from the MCO and cask system but it also has to remove the heat generated by the TW pump (TW-P-3*14). After the test was terminated the inlet temperature to the cask began to rise. After allowing the TW system to circulate for a number of hours after the conclusion of this test, with the heater shut down and the chilled water isolated, the MCO temperatures equalized at $37^{\circ} \mathrm{C}$.

The scrap temperature cool off more rapidly than the fuel, as seen in the heating tests, the scrap heated faster than the fuel. Again this is caused by the smaller pieces of scrap fuel will cool off quicker than the full sized fuel elements and the better heat transfer of the copper scrap basket in helium gas.

\subsubsection{MCO Cooling Conclusion and Recommendations}

This test was conducted on mock fuel with no radioactive decay heat but the mock fuel has a higher thermal capacitance as discussed in section 2.0 of this document and was conducted with a significantly lower flow rate through the TWC chiller system than design. Results may be quicker in the field. Given results from the $\mathrm{MCO}$ heating section where results concluded heating the MCO filled with helium took three times longer than with filled water, one could expect the same time frame to cool the MCO filled with helium as it did to heat the MCO filled with helium.

\subsection{Cask Purging}

Cask purging is required to dry the external shell of the MCO prior to shipment to and receipt at the CSB. The MCO must be visually dry when MCO Handling Machine (MHM) removes the $\mathrm{MCO}$ from the cask.

\subsubsection{Cask Purging Apparatus}

The cask purging apparatus utilizes the compressed air system of the PES skid and the PWC system. The cask annulus water is purged from the MCO by pressurizing the cask with the compressed air and evacuating the cask annulus with the PWC system much like the bulk water is removed from the $\mathrm{MCO}$. 


\subsubsection{Cask Purging Test Procedure Summary}

After the $\mathrm{MCO}$ is cooled to an acceptable temperature, the cooling water is isolated, the tempered water is isolated and the tempered water pump is de-energized. The cask bottom tempered water quick disconnect (TW-QD-2018) is manually removed and replaced with the PWC quick disconnect (PWC-QD-2020). The MCS operator selects the cask purge start, which open GOV 3201 which pressurizes the cask to 20 psig then the field operator manually opens PWC-V-2048. This begins water flow from the cask to the PWC. The cask is then purged for approximately one hour after break through.

\subsubsection{Cask Purging Test Results}

Initial tests were conducted with a warm MCO shell (near $46^{\circ} \mathrm{C}$ ) and purged for only 15 minutes. Results of this test revealed slight water droplets on the MCO wall as it was being removed from the cask. The MCO bottom was slightly wetted since water was observed in the cask bottom just below the MCO standoffs. Figure 4-60 shows the water remaining in the bottom of the cask.

The cask purging test was repeated for a one hour cask purge duration and was allowed to sit for approximately four (4) hours to simulate a cask transport from the CVDF to the CSB. As shown in Figure 4-61 and 4-62, some water was still remaining inside the cask

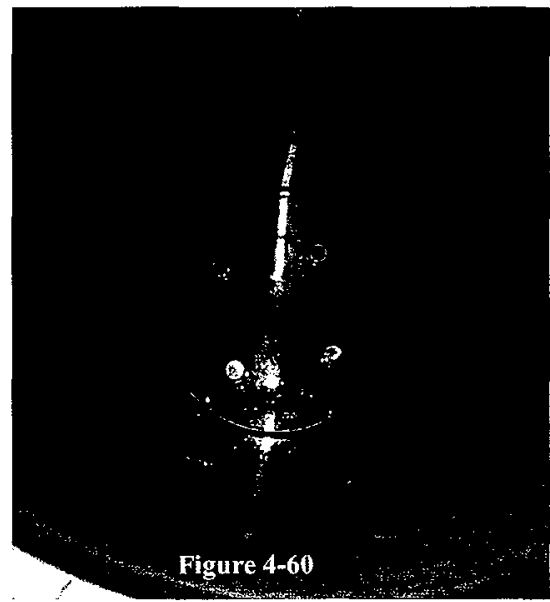
and a slight amount of water was visible on the bottom of the MCO. A slight film of water was present on the upper half of the MCO during removal from the cask but was dry within five (5) minutes after the $\mathrm{MCO}$ was in contact with open air. The water amount in the bottom of the cask was less than the amount seen in Figure 4-60. The water levels were observed from the top of the cask using the cask/MCO standoffs as a judgement of depth. The water remaining of the

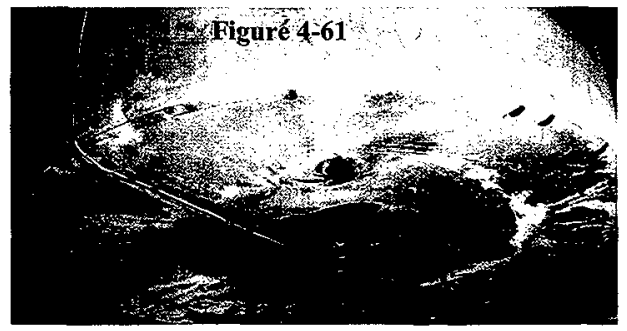
bottom of the $\mathrm{MCO}$ was significantly less on the retest than observed in the initial 15 minute purging test. Figure 4-61 shows only a few heavy water droplets whereas the initial test had significantly more and larger water droplets on the bottom of the MCO. 


\subsubsection{Cask Purging Discussion of Results}

Initial testing revealed that the manually operated ball valve, PWC-V-2048, was closed. before the MCS closed GOV 3201. This caused the cask to be pressurized to $20 \mathrm{psig}$ and when the seal ring was deflated the cask would rapidly de-pressurize spraying a water mist on the operators removing the seal ring. In later revisions to the operational sequence, the operation sequences of these valves were reversed so that the slight water spray was directed back into the cask annulus to protect the operations personnel.

\subsubsection{Cask Purging Conclusion and Recommendations}

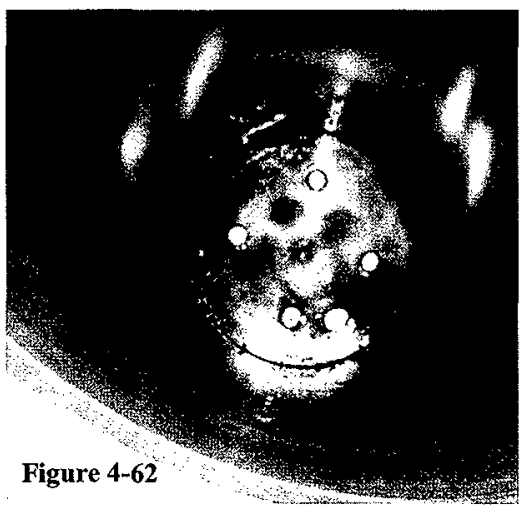

The cask dries to the requirements by blowing pressurized air through the cask for greater than one hour. MCS changes provided operator protection or at the very least eliminated the need for the operations personnel to be in full rain gear during this operation.

A possible means to quicken the cask purging process is at several times during the purging, the field operator could close PWC-V-*048 for approximately one minute and then reopen the valve. This causes an increase in velocity in the cask and would move water more quickly out of the cask. One disadvantage to operation is it causes a water hammer through out the PWC transfer line from the bay to the PWC skid.

\subsection{Upset Condition Tests}

The first article testing program was extensive and during the planning stages it was thought that by the time the testing program reached this stage a majority of the upset conditions would be thoroughly defined. However, this was not the case, therefore some of the original planned upset condition tests such as safety class isolatable and non-isolatable line break tests were pre-empted for a future testing program. Other tests were also pre-empted because hardware or software was not fully integrated into the first article test bed. During the normal course of testing, several off normal upset conditions occurred that influenced the design.

\subsubsection{Loss of Air Upset}

A credible upset condition for the CVDF is a loss of compressed air since the system is supplied by only one air compressor. The compressed air system supplies all the gas operated ball valves in the process skids. A failure of the compressed air system would cause the process valves to fail to their fail safe condition. The fail states for a majority of the valves are closed however the safety class valves fail open. This test will test the operation of these valves during this upset condition. 


\subsubsection{Loss of Air Upset Apparatus}

The loss of air upset condition test apparatus utilizes the entire PES, process hood piping, and SCHe injection system.

\subsubsection{Loss of Air Upset Test Procedure Summary}

The loss of air upset condition test was conducted during a process test. This was conducted during a test that had already been declared a failure, therefore no test data was ruined during the conduction of this test. The system was functioning normally through a vacuum process when the main air supply to the system was isolated. Observations were then recorded in the test logbook.

\subsubsection{Loss of Air Upset Test Results}

As the air system slowly depressurized the MCO main isolation valves closed and the $\mathrm{SCHe}$ injection valves opened and pressurized the MCO with helium to $4 \mathrm{psig}$. All other system valves eventually came to their fail safe conditions. When the air pressure fell below 25 psig, the inflatable seals in the seal ring assembly were not able to maintain the integrity of the tempered water system.

\subsubsection{Loss of Air Upset Discussion of Results}

The system ball valves are designed to fail safe with springs. Each valve closes at a different rate because of slightly different spring constants and air bleed off rates. When the air system was isolated, the air pressure began to bleed off slowly making each valve close at different times. This caused many different things to happen. The most apparent upset was when the seal ring inflatable o-rings failed, the TWS isolation valves were not yet fully closed. This caused a significant amount of water to be pumped out the seal ring assembly draining the TWS and spraying the outside of the cask, transporter scaffolding, and transporter.

A possibility also exists that the PES could not be entirely isolated from the MCO before the SCHe starts injecting Helium. A significant amount of Helium could be sucked to the vacuum pump before going to the MCO on the HEPA filter port. This possibility may not be of any concern because the SCHe injection on the diptube side still injects Helium into the MCO. The isolation valves, at this point, are seconds from closing entirely and the effect of the vacuum pump being on-line will not likely interfere with the rapid pressurize limitations from 145 torr to atmospheric pressure. 


\subsubsection{Loss of Air Upset Conclusion and Recommendations}

Design modification were suggested to install a check valve in front of the manual three ball valve (IA-V-*022) in the seal ring inflatable o-ring inflation line. This would prevent the loss of TWS system integxity during a loss of air upset and prevent premature draining of the TWS and the inadvertent spraying of potentially contaminated, pressurized water into the bay. As far as the isolation timing, some adjustments can be made to the valve actuator for how fast they discharge air during normal closing operations; but for this type of upset, the air will always bleed off at different rates for different valves because of slightly different spring pressures in the valve actuators.

\subsubsection{Loss of Computer/PLC Upset}

During tests where the PLC was shut down because of loss of power the isolation valves closed and the $\mathrm{SCHe}$ injection system initiated a purge and repressurized the $\mathrm{MCO}$. On one occasion during the testing, the power was lost on the main PLC and because the SCHe was on an independent power supply from the MCS and programming was not available, the SCHe injection valves were not opened.

When the system HMI computers were intentionally shut down during testing, the process continued as normal since the MCS programming resides in the PLC. The computer shut down did not interrupt processing. It did, however interrupt data logging.

\subsubsection{Loss of Power Upset}

During loss of $480 \mathrm{VAC}$ power loss, the vacuum pump stopped and the system pressure began to increase because of the injection of the vacuum pump helium seal purge gas. The PLC was not programmed for any upset conditions, therefore the system did not close any isolation valves. The TWS pump stopped and the TWS heater powered down. No effects were noted with the power failure of these components.

\subsection{Helium Usage}

A Helium tube trailer, shown in Figure 4-63, which contained 180,000 cubic feet of 99.97\% pure Helium, supplied the Helium for this project. Each test used a differing amount of Helium depending on the varied test parameters, fuel configuration, $\mathrm{MCO}$ drying time, and upset conditions experienced during a particular test. Table 4-3 summarizes the average use of Helium for normal operating conditions with different fuel configurations and drying times.

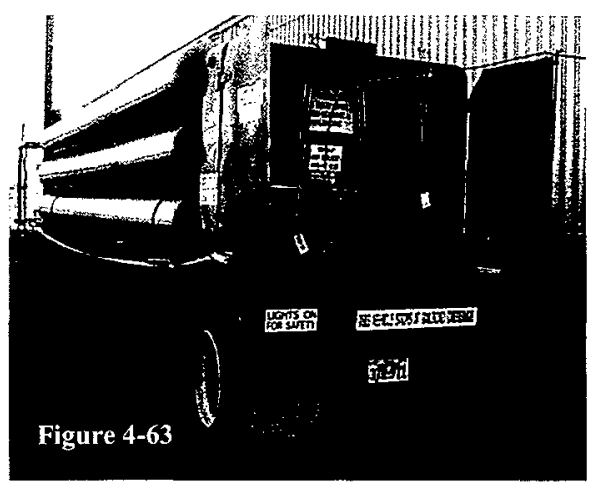


HNF-4057

Rev. 0

Table 4-3

\begin{tabular}{|l|l|c|c|c|}
\hline Fuel Configuration & \multicolumn{1}{|c|}{ Test Description } & $\begin{array}{c}\text { Drying Times or } \\
\text { Cycle Time (hrs) }\end{array}$ & $\begin{array}{c}\text { pounds of } \\
\text { helium }\end{array}$ & $\begin{array}{c}\text { Cubic feet of } \\
\text { helium }\end{array}$ \\
\hline Heat-up & Pressure-Vent cycle & 19 & 110 & $650{\mathrm{or} 34 \mathrm{ft}^{3} / \mathrm{hr}}^{-}$ \\
\hline Nominal & $\begin{array}{l}8-4-4 \text { does not include } \\
\text { heat-up }\end{array}$ & 34 & 450 & 2650 \\
\hline Pristine & $\begin{array}{l}8-4-4 \text { does not include } \\
\text { heat-up }\end{array}$ & 27 & 250 & 1485 \\
\hline Damaged & $\begin{array}{l}8-4-4 \text { does not include } \\
\text { heat-up }\end{array}$ & 52 & 450 & 2650 \\
\hline $\begin{array}{l}\text { Proof Test and } \\
\text { Cooldown }\end{array}$ & \multicolumn{1}{|c|}{ Pressurize } & $\begin{array}{c}20+8 \\
\text { respectively }\end{array}$ & $\begin{array}{c}\text { Not } \\
\text { measurable }\end{array}$ & Not measurable \\
\hline
\end{tabular}

Each tube on the helium tube trailer contained approximately $15000 \mathrm{ft}^{3}$ at an average pressure of 2525 psig. Using the basic gas law $P_{1} v_{1}=P_{2} v_{2}$, the average volume used for each test was calculated. Given a majority of the MCOs will have a nominal fuel loading, the nominal usage of helium will be $3300 \mathrm{ft}^{3}$ with a nominal heat-up of 6 hours. At this usage rate each helium tube trailer will complete approximately 56 MCOs.

\subsection{Special Tool Contingents}

All special tools used in the first article testing are described in the various tests that they were used. The only special tools utilized in the first article testing program were the process connectors, the seal ring, and the cask quick disconnect tool. The seal ring operation results are described in section 3.3 .

The majority of the process connector tests results are documented in section 3.4. The process connectors, when installed on the MCO may appear to be open when the MCO plug valves are closed. During times when the process connectors are pressurized and the plug valves are closed, the socket internal to the process connector acts as a piston and the pressure forces the process connector valve stem up making the connector have the appearance that the plug valve is open. A special socket with a spacer in the bottom was used to push down and hold the valve stem on to the process plug during times when the connectors had to actuate the plug valves while under pressure.

The special tools designed to remove the cask lower port cover and then establish connection to the cask annulus were tested for operability. The cask lower port cover removal tool was found to be end heavy and the operator was required to balance the heavy end by holding the tool over half the distance to the cask. With both of the tools, the port cover tool and the quick disconnect tool, operation personnel found connections slightly difficult to make attachments when the transporter mock-up was installed on the test set-up. Operators essentially had to make the connections kneeling on the ground to get a line-of-sight to the lower port. 


\subsection{Sequence Logic and Hardware Enhancements}

The control system logic required several enhancements during the course of first article testing. The control system logic was initially interpreted from the Operation Sequence document (HNF-2356) Revision 0. Changes were made to the operating sequence, under configuration control, to overcome logic hang-ups, logic interpretation oversights, sequence location, and to assist with operator interfacing prompts. Many of these changes resulted from the need for better system operating performance or operator protection.

\subsubsection{SCHe Logic and Hardware Enhancements}

Even before the automated sequences were programmed, first article testing impacted the control system logic. During initial manual operations, testing showed that during bulk water draining of the $\mathrm{MCO}$, partial vacuums were created in the SCHe injection lines attached to the long dip tube process connector and the normal Helium injection line. Results, during the drying cycle, indicated that water would be pulled into the SCHe lines and freeze. The results were detected by observations of condensate forming on the injection lines or by simply feeling the lines for colder locations.

The revision to the hardware was to move the SCHe injection valves into the Hood process piping and orientated them vertically. This would prevent water from going into the long small diameter injection lines.

The logic or software changes also purged the SCHe lines just after bulk water removal to remove any radioactive particulate build-up before the bulk water rinse. With the new valve location and orientation, the $\mathrm{SCHe}$ purge would not be required after the rinse.

\subsubsection{PWC Logic and Hardware Enhancements}

During bulk water draining, some water would remain in the hood process piping an gather atop the PWC isolation valves. The occurrence of this problem was inconsistent. During several bulk water draining operations, the water would appear in approximately $90 \%$ of the sequences. The water would become apparent when drying cycles would become abnormally long. Water gathering at this particular point is extremely difficult because it is thermally isolated and is not in the flow path for helium injection. A thermocouple was added to the pipe adjacent to the PWC isolation valve to detect freezing water. Heat tracing was added to this length of piping to prevent the water from freezing and increasing drying time. As shown in Figures 4-22 and 4-57, the temperature on the pipe wall still decreases with the heat tracing but eventually dries out quicker than the initial drying tests. 


\subsubsection{Helium Injection Logic and Hardware Enhancements}

As stated in the last section, water would collect in the normal Helium injection line during the bulk water drain sequence. This would be visible apparent after the drying sequence started. The water would be pulsed out of line. The flex hoses would violently pulse with the water hammer occurring when water be pushed with the inflow of Helium then the water would repuddle in the piping low spots. This can also be observed with the rapid lowering in MCO pressure during the initial drying. The water would eventually start to remove and the pressure would return to normal (see Figure 4-26). To help elevate this problem and to help prevent any build-up of ice during the vacuum process, heat tracing was added to this portion of the hood piping assembly. The operational sequence also added a PWC post drain Helium purge which also assists with water removal.

\subsubsection{Vacuum Pump Cooling Logic and Hardware Enhancements}

The vacuum pump manufacturer requirements stated that the vacuum pump must not operate above 100 torr for 30 minutes without external cooling water. An arbitrary vacuum pump shut down timer was set at ten minutes. If the pump operated above 100 torr for 10 minutes, the pump would be shut down. Early testing revealed that the vacuum pump was not able to consistently evacuate the $\mathrm{MCO}$ below 100 torr within the 10-minute time frame during the initial 3-scfm Helium injection condenser throttling sequence. This fact was also shown during the full sequence operations, where excess water would get into the main Helium injection line as described in the previous section.

To elevate the problem of operating above 100 torr, the TRB authorized installation of a vacuum pump cooling kit. This provided a steady flow of cooling water to the pump when it housing temperature increased above $40^{\circ} \mathrm{C}$. The cooling kit would allow continuous operation of the vacuum pump at pressures greater than 100 torr. The subsequent vacuum pump 10-minute timer was removed from the logic. 


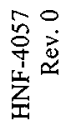

(e!sd) onssed

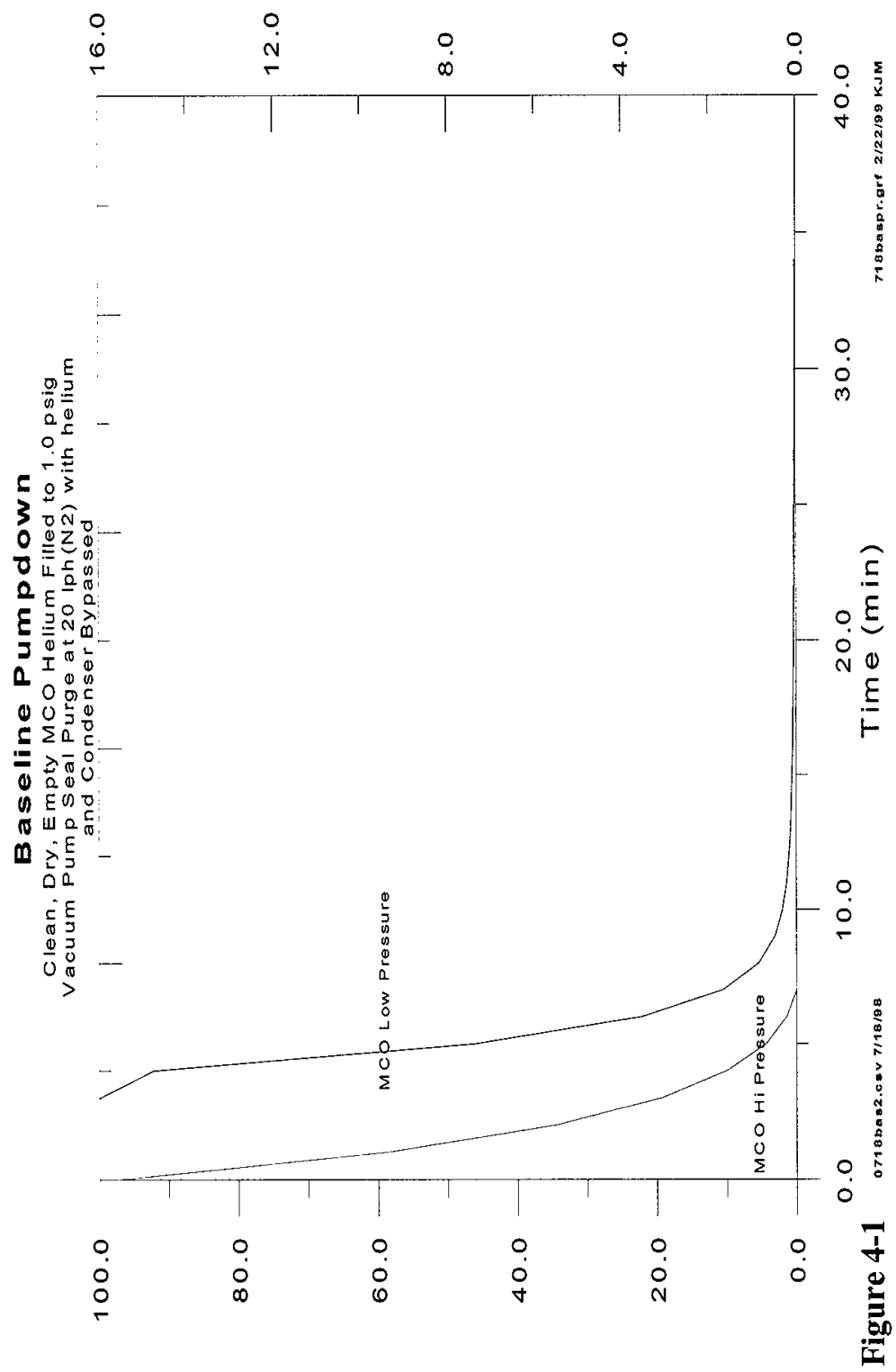

(107) onssad 


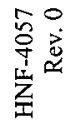

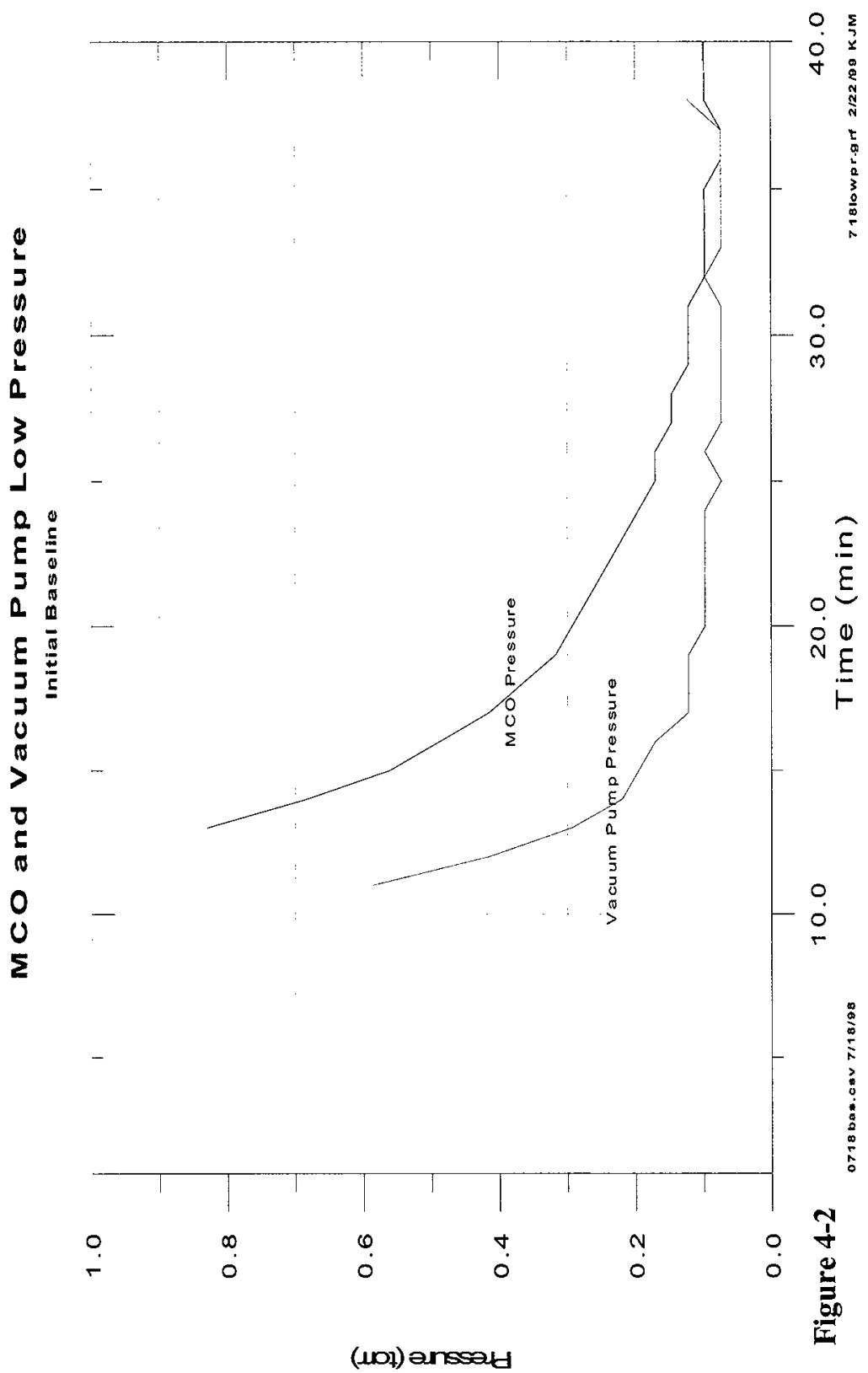




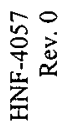

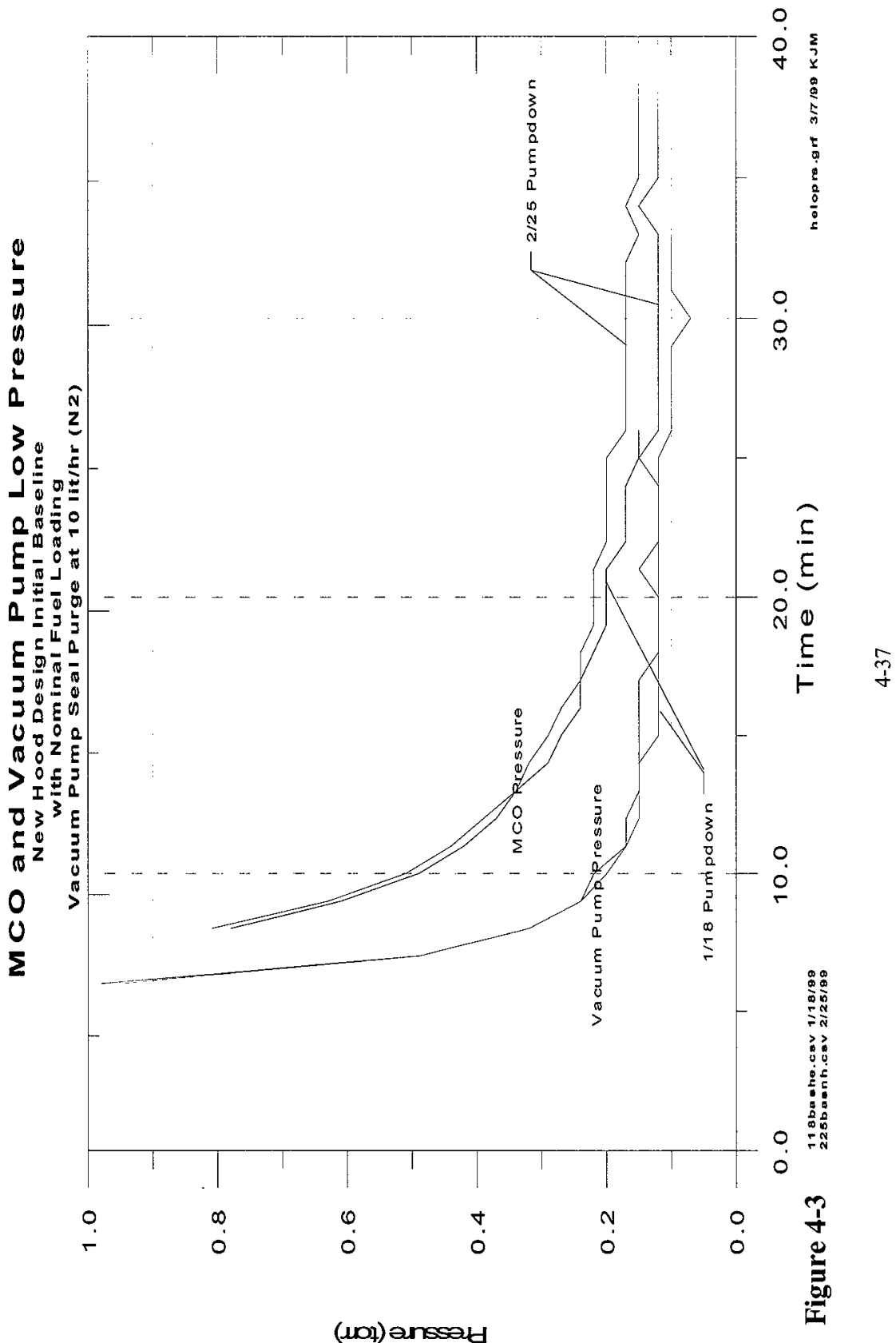


章离

(ups) МOH

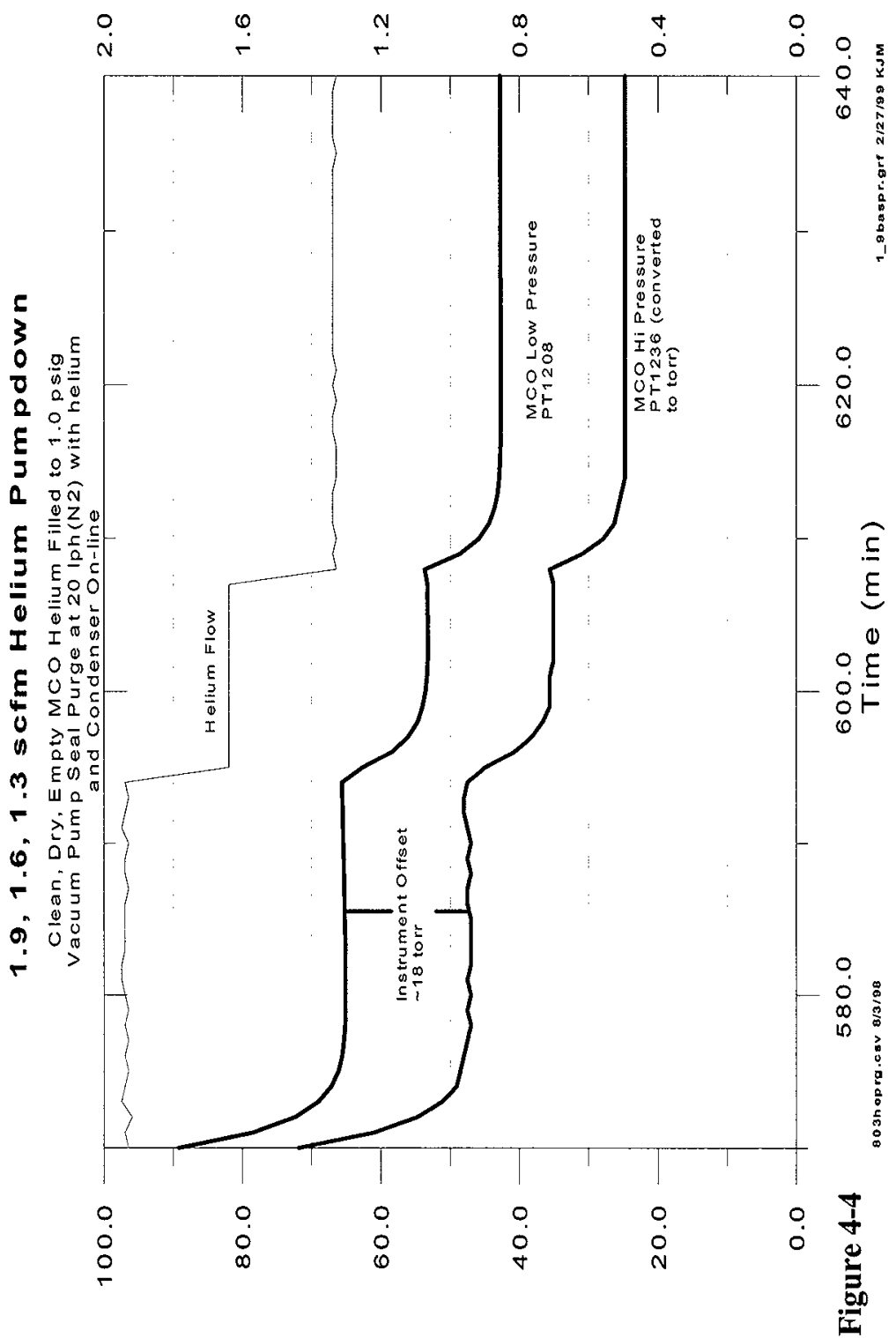

(LOI) e.nssatd 


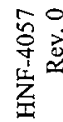

(ups) MOH

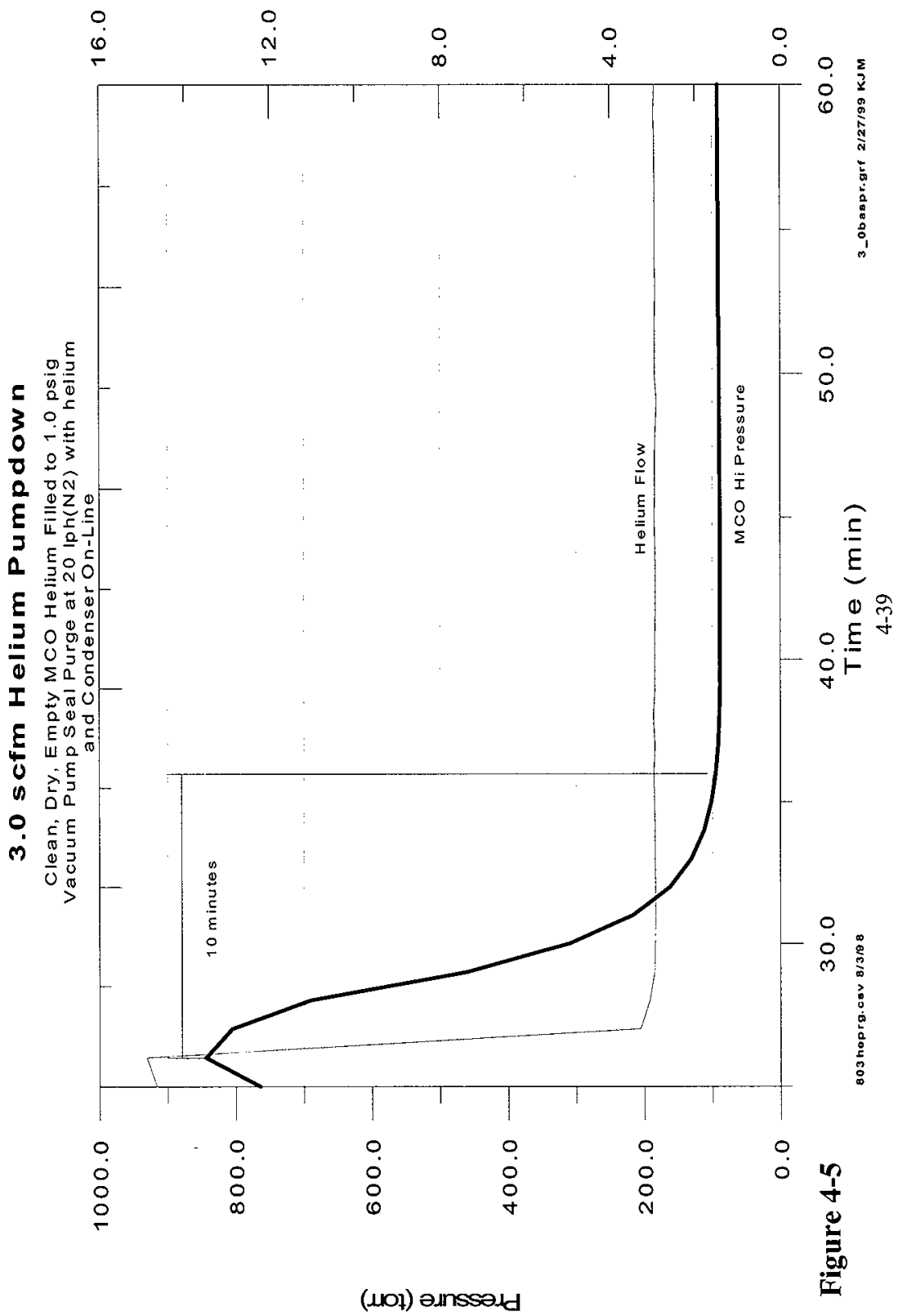


(eịsd) כ.גnssatd

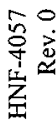

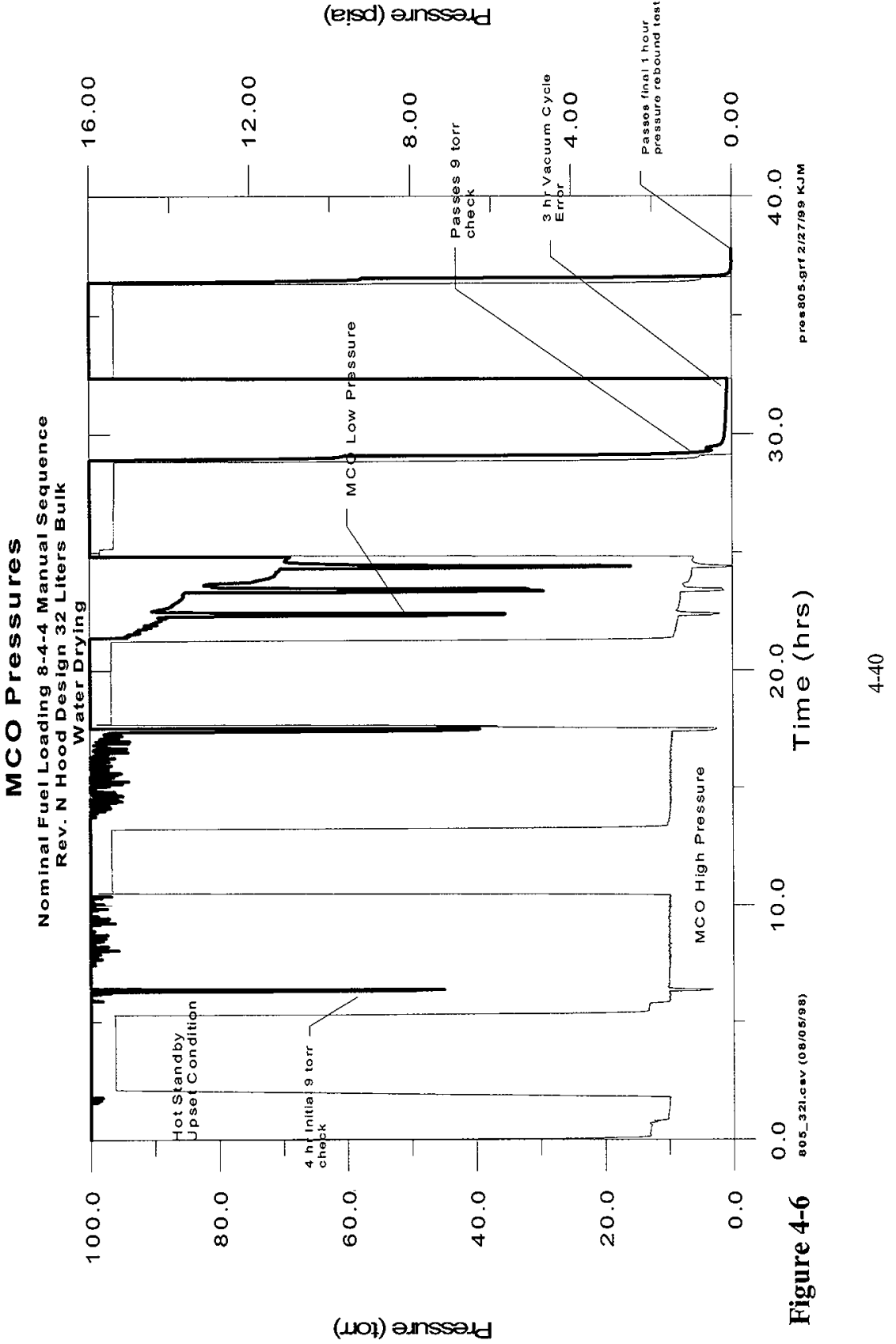




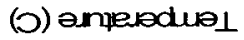

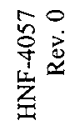

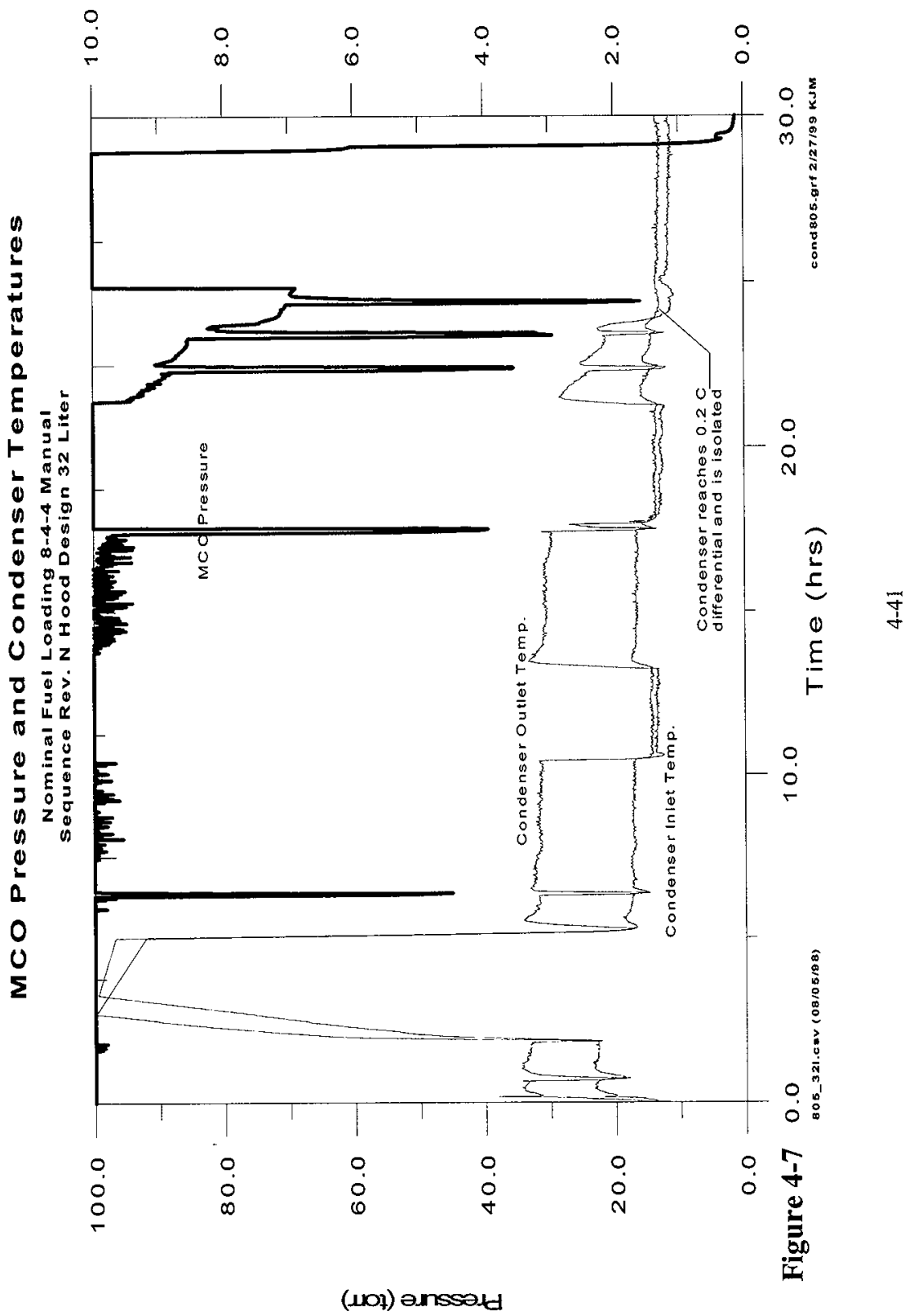


令

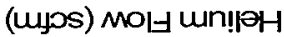

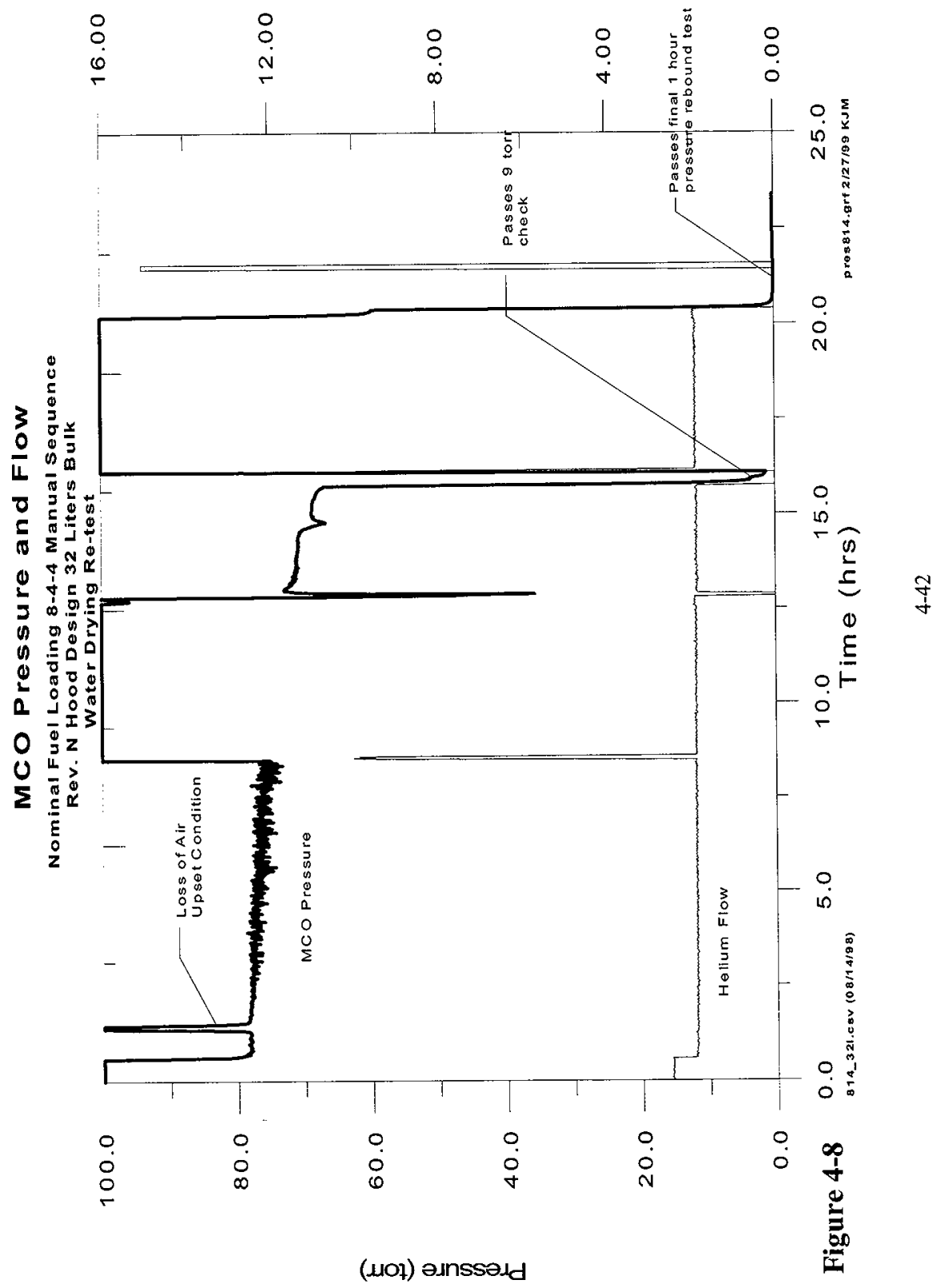




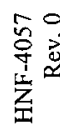

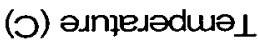

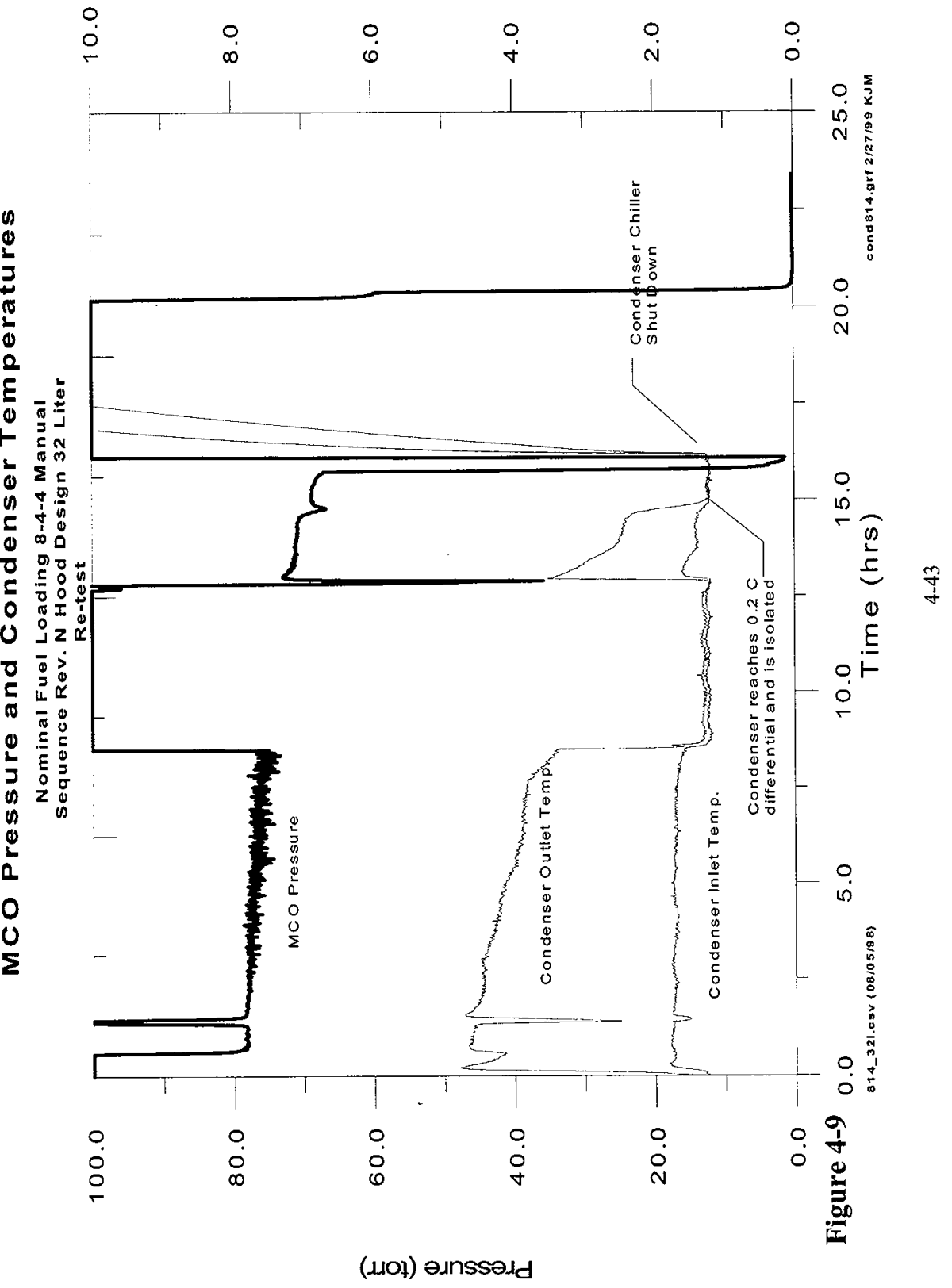




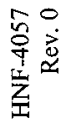

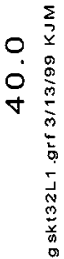

0

(1)

(1)

0

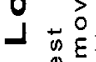

(1) $\$$

$5 \div$

() $=\frac{x}{\square}$

() $N \pi$

- ल०

-

A. $\underline{x} \mathbb{0}$

E 50
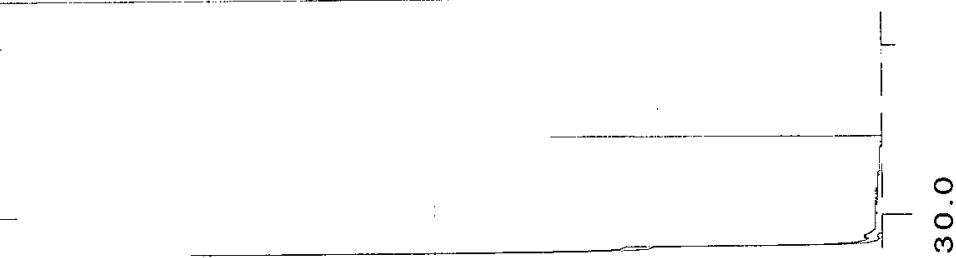

$-$

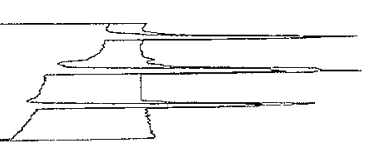

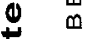

0

(1)

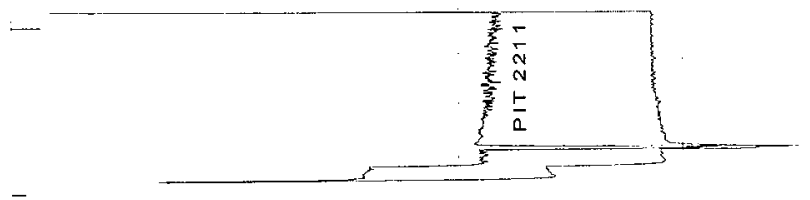

(ejsd) amssold

$0 \frac{1}{\varepsilon}$

$\circ$

E

$\underset{⿱}{\forall}$

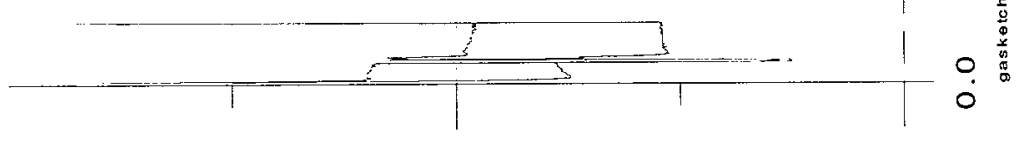

$\stackrel{0}{8}$

i

$0 \frac{1}{1}$ 


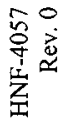

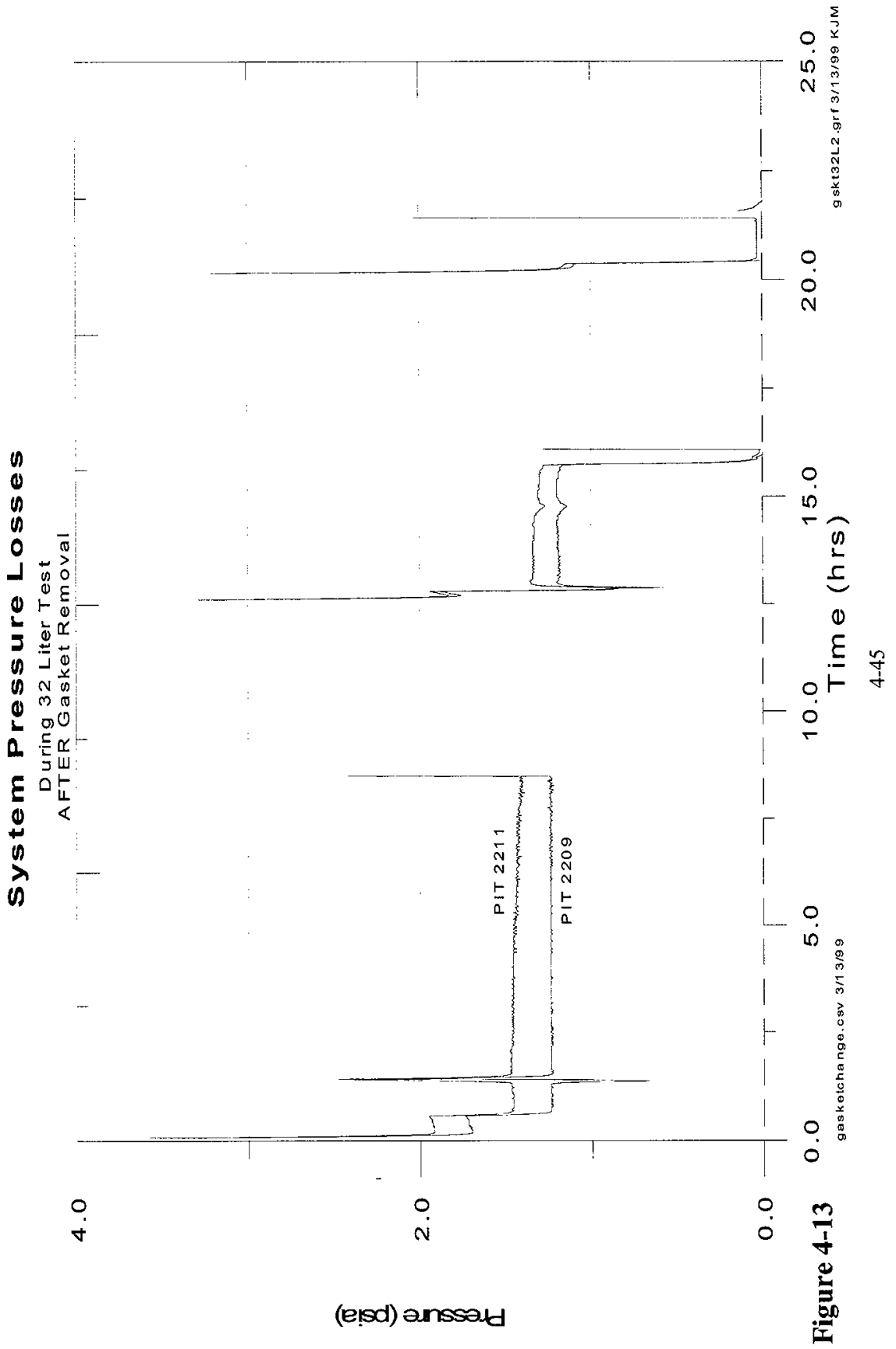




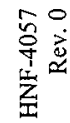

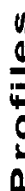

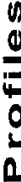

8

$F$

0

(1)

1

I

0

$\Sigma$

$\sigma$

인

in

3
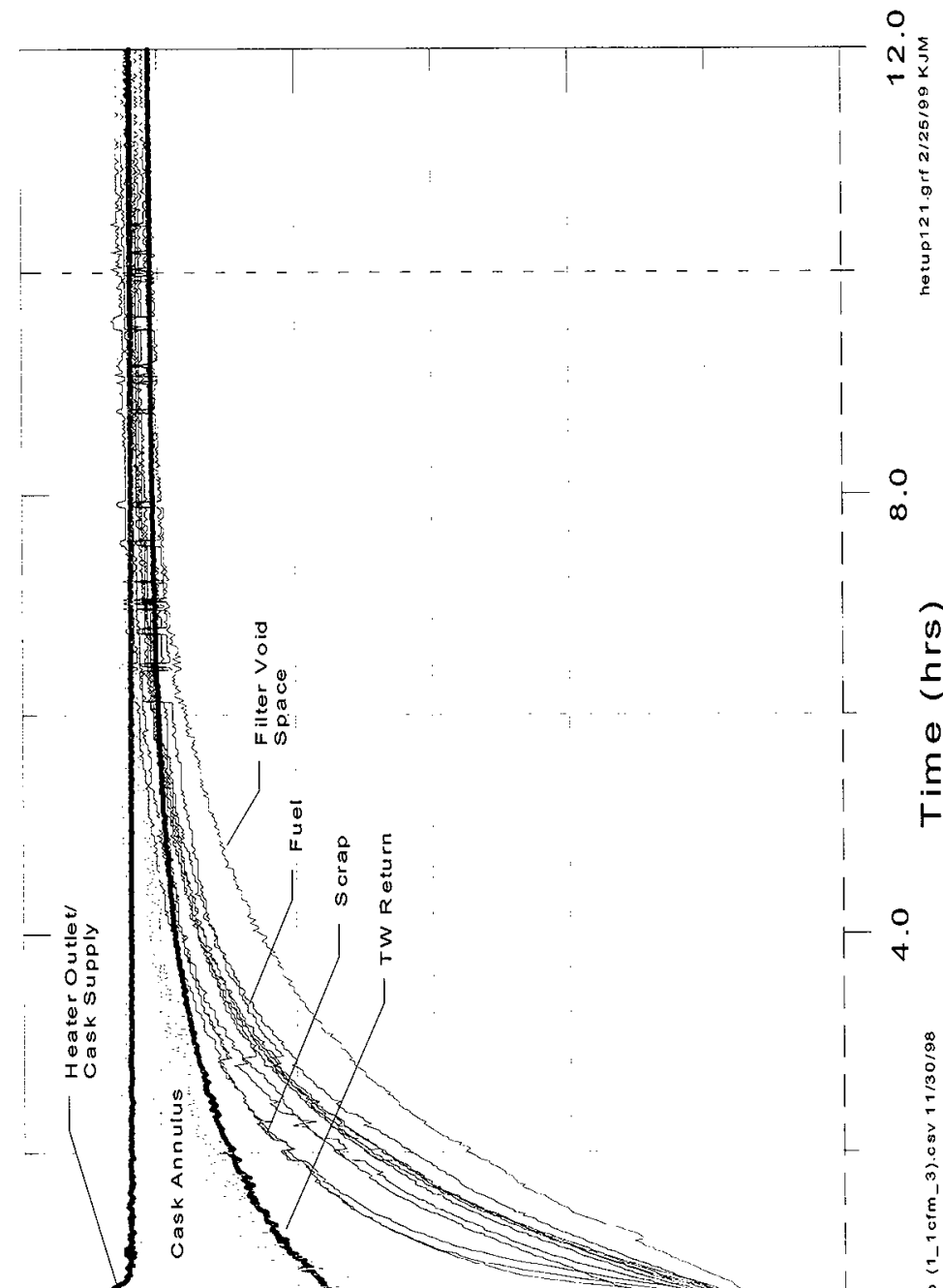

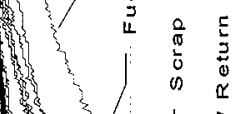

$\frac{2}{5}$

$\frac{1}{E}$

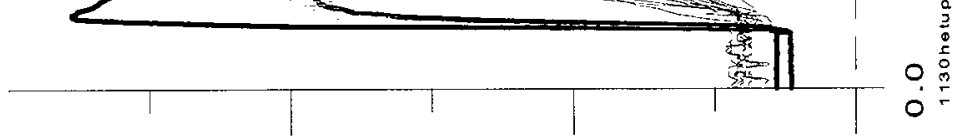

$\frac{1}{7}$
0
0
0

(D) anperdupl 


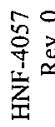

$\frac{0}{0}$

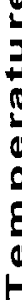

1

0
0
$\Sigma$

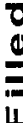

$\frac{1}{3}$

(0) anperadur|

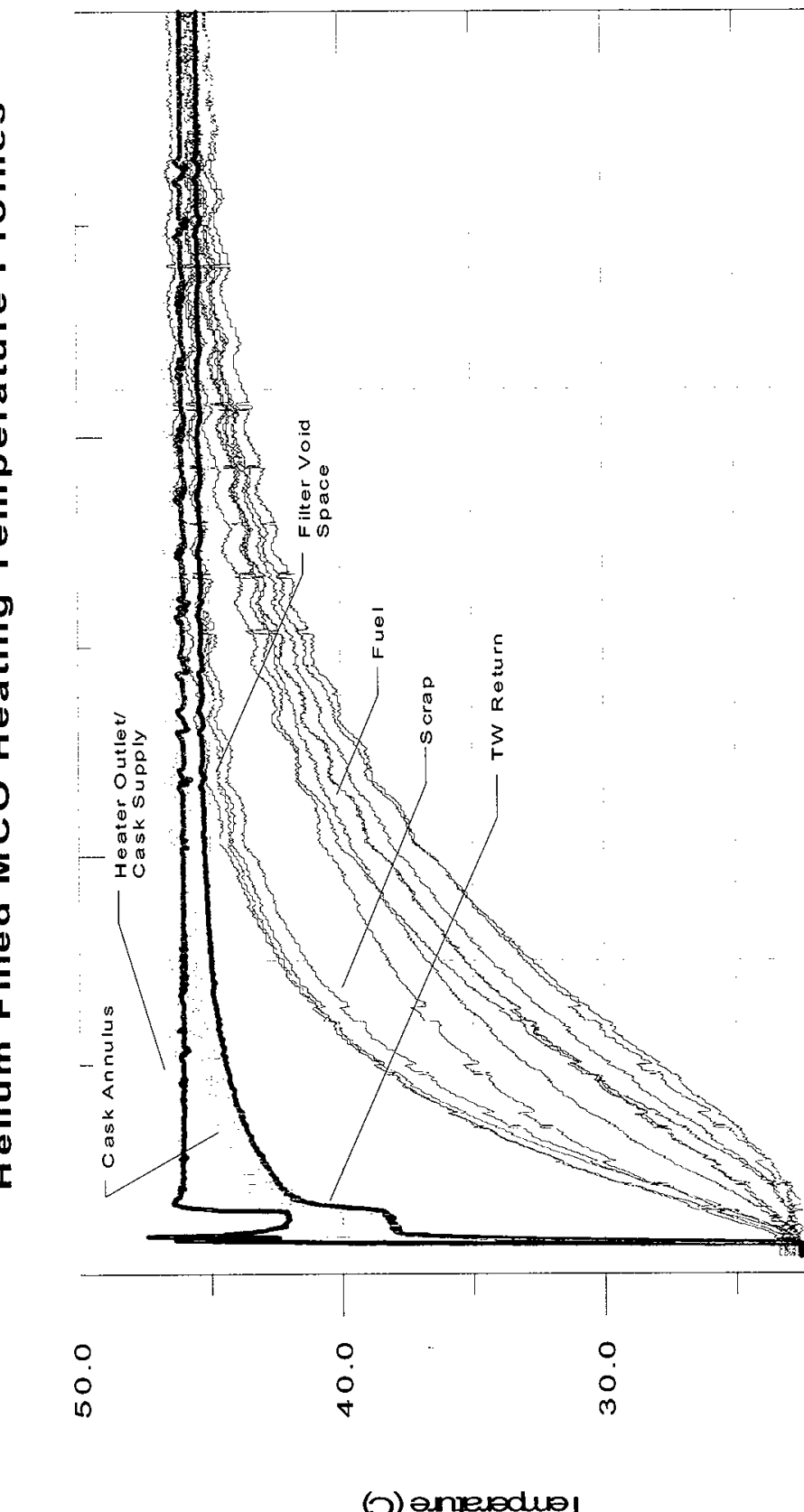


箁旁

(upos) $\mathrm{MOH}$

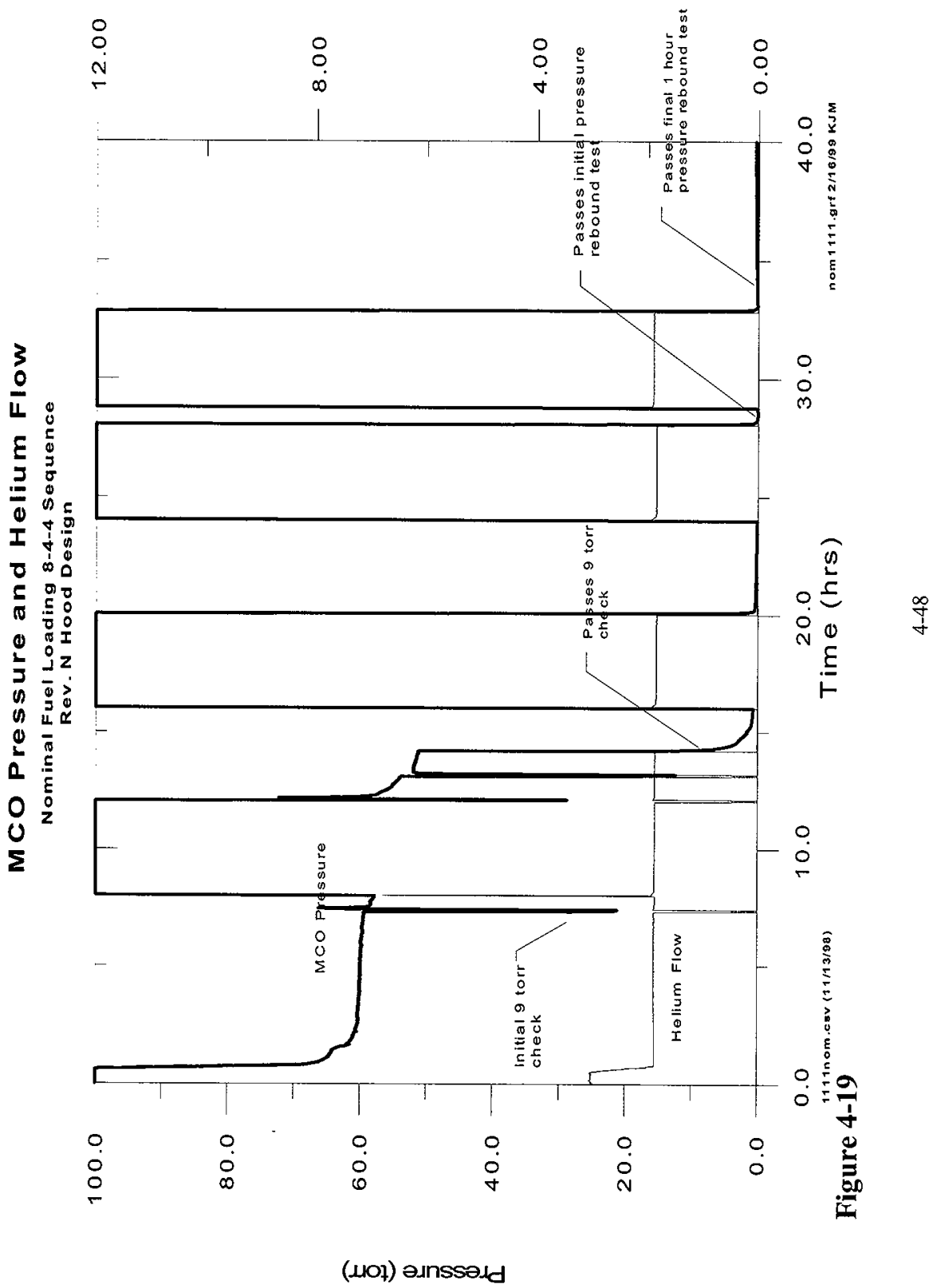


尔

(b) amperdur

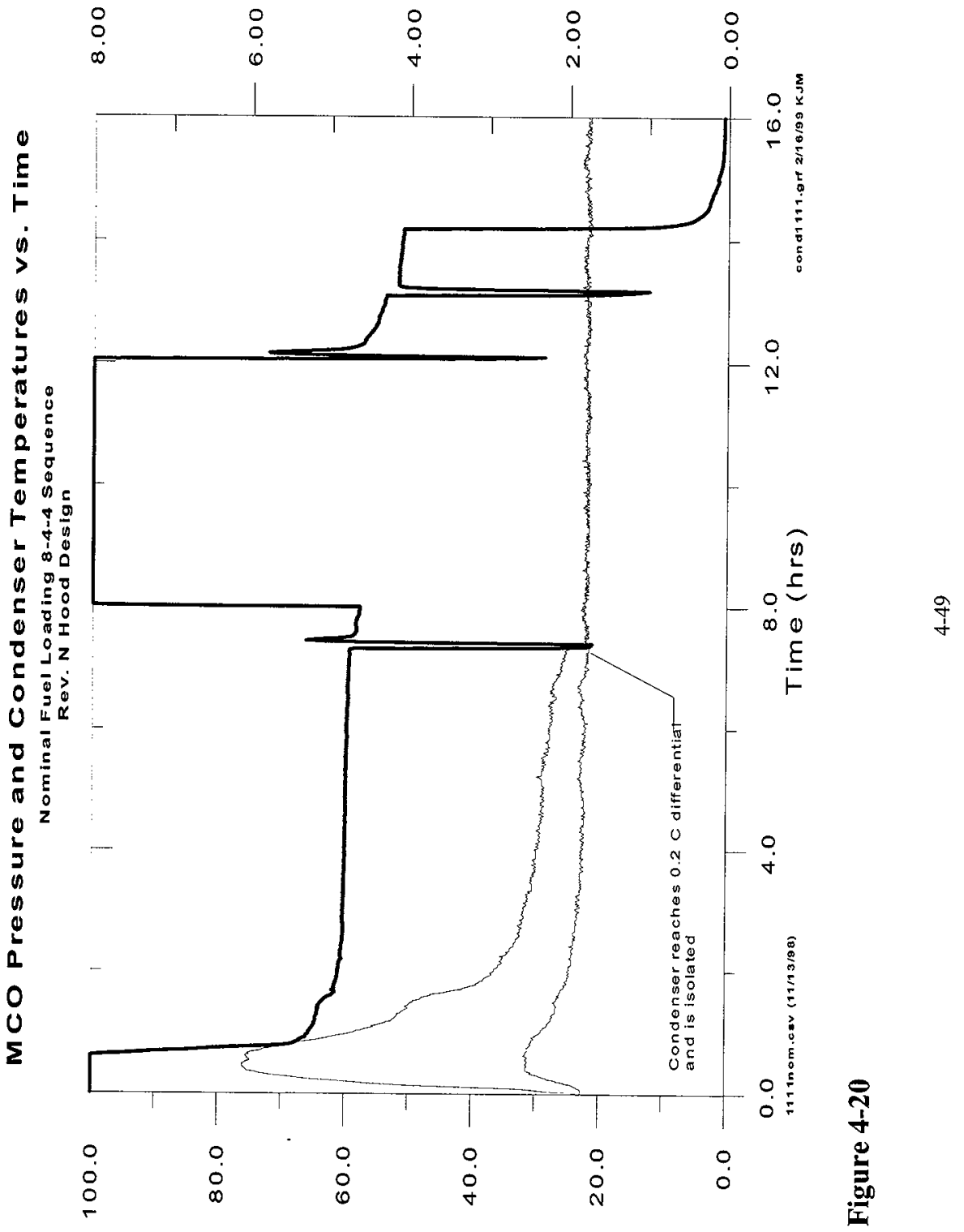

(MOl) anssold 


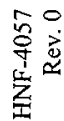

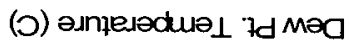

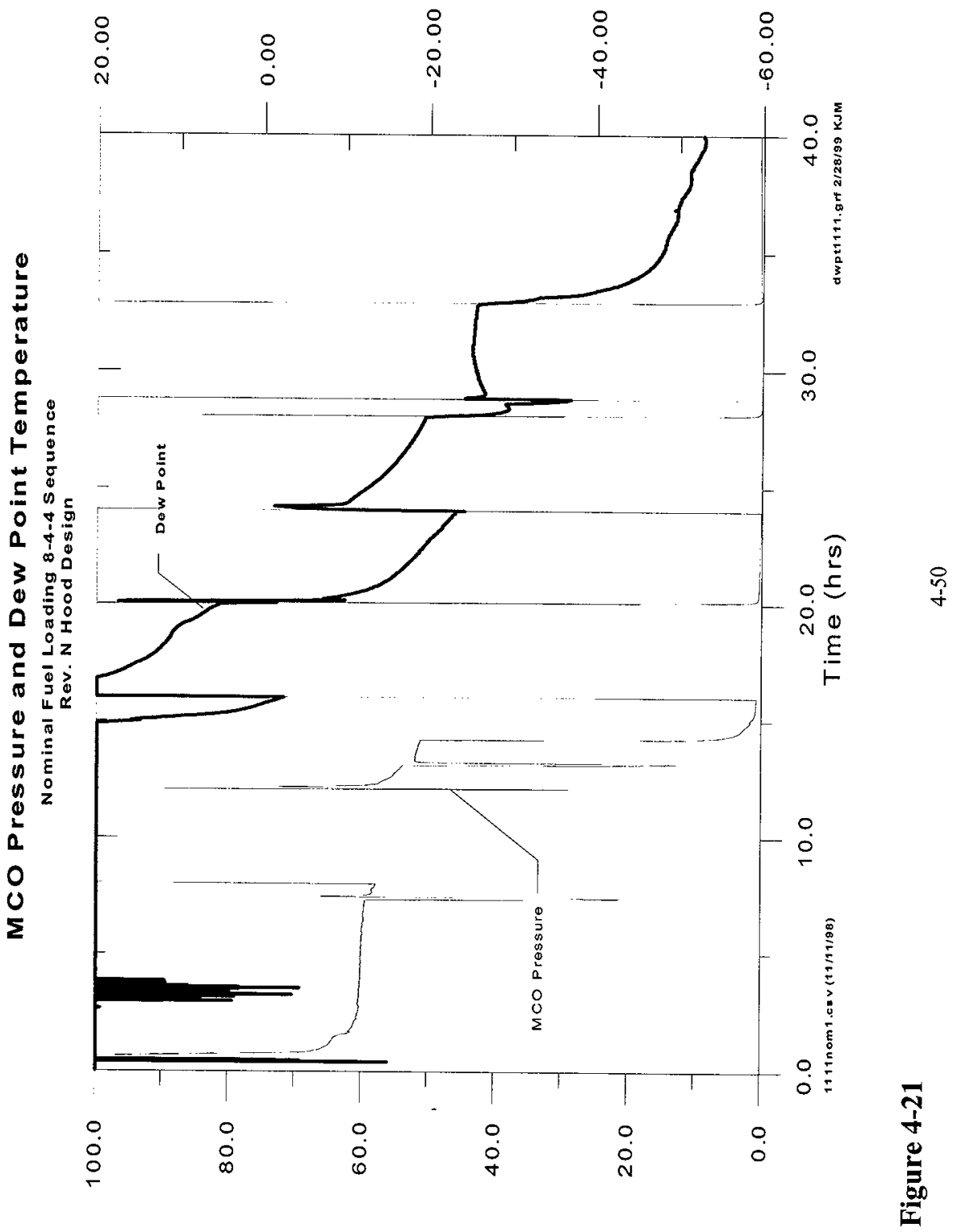

(LOI) כ.unssald 
令

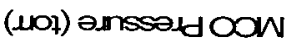

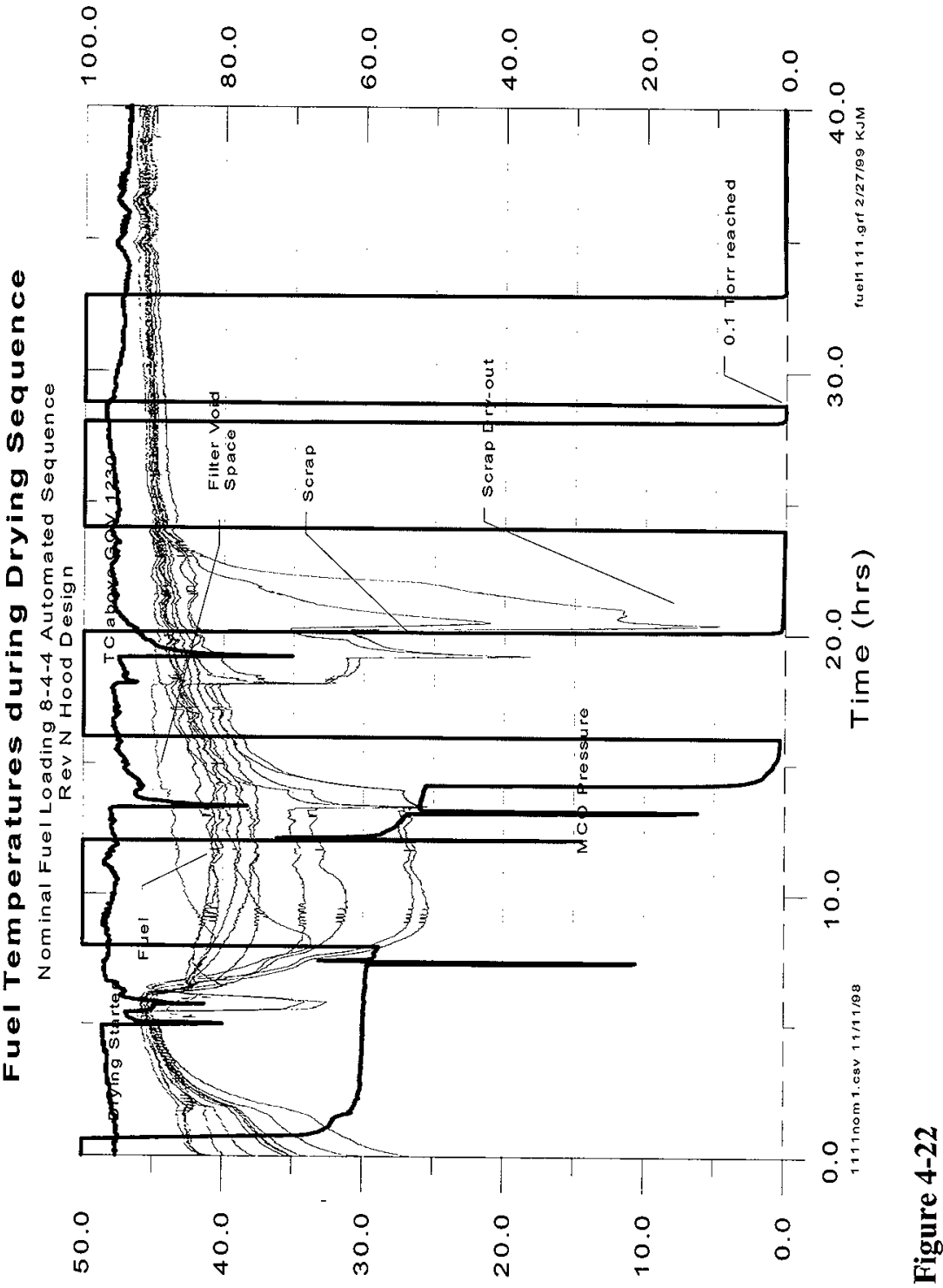


(uol) anssatd riol DON

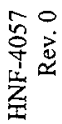

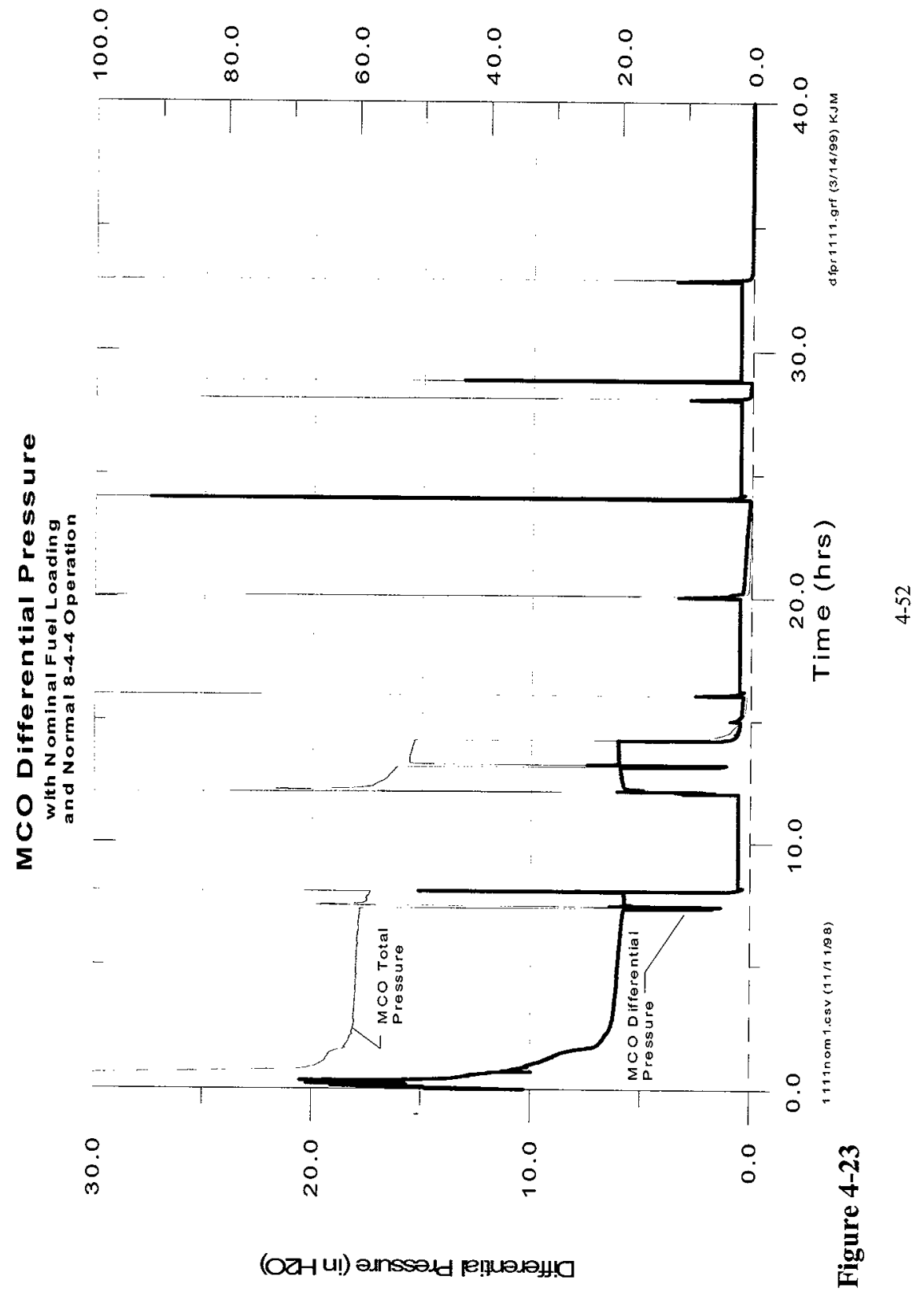




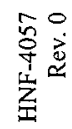

(ups) MOH
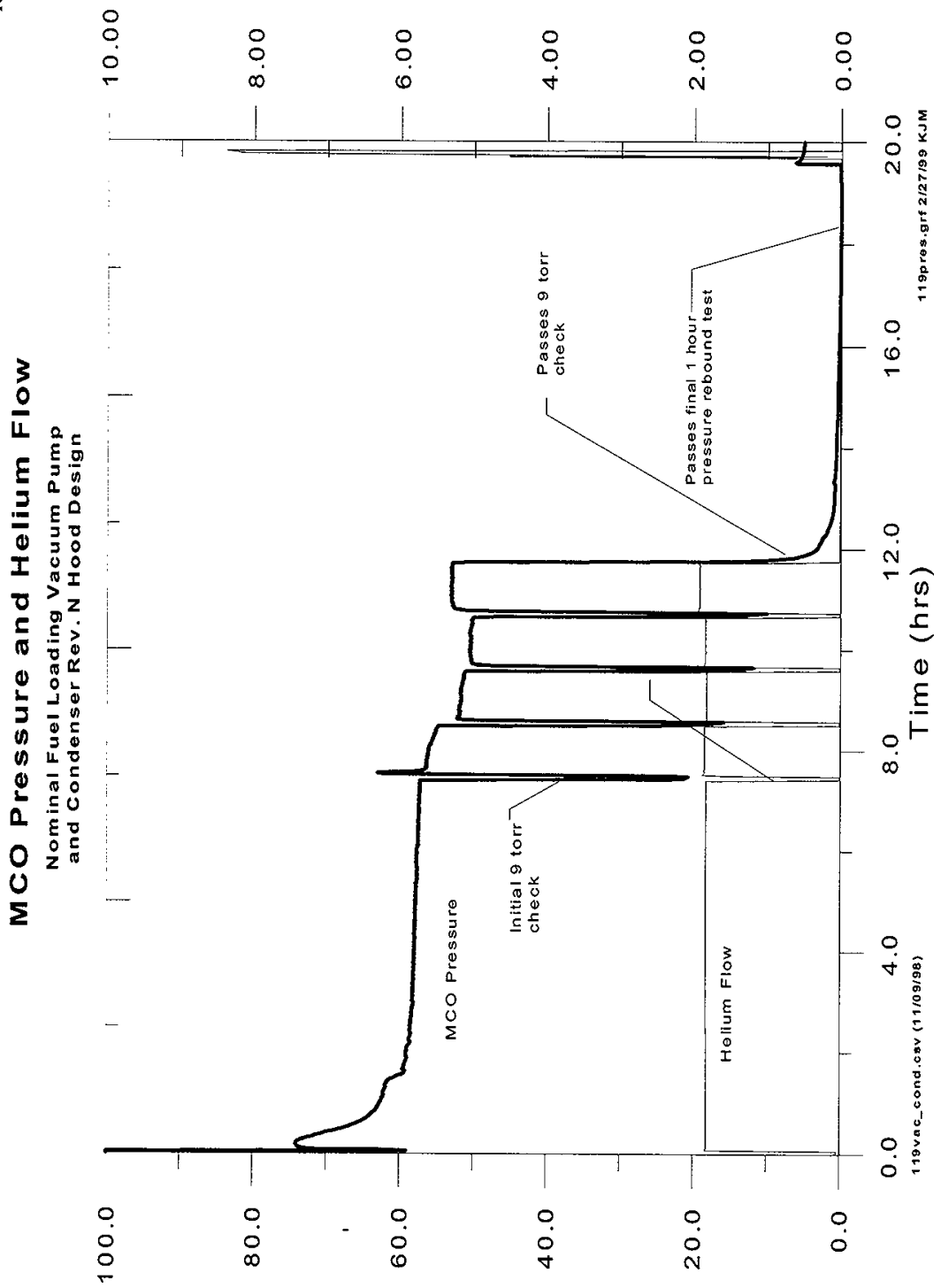

(LOl) Oגnsseld 
合京

(อ) әmpexdu甲

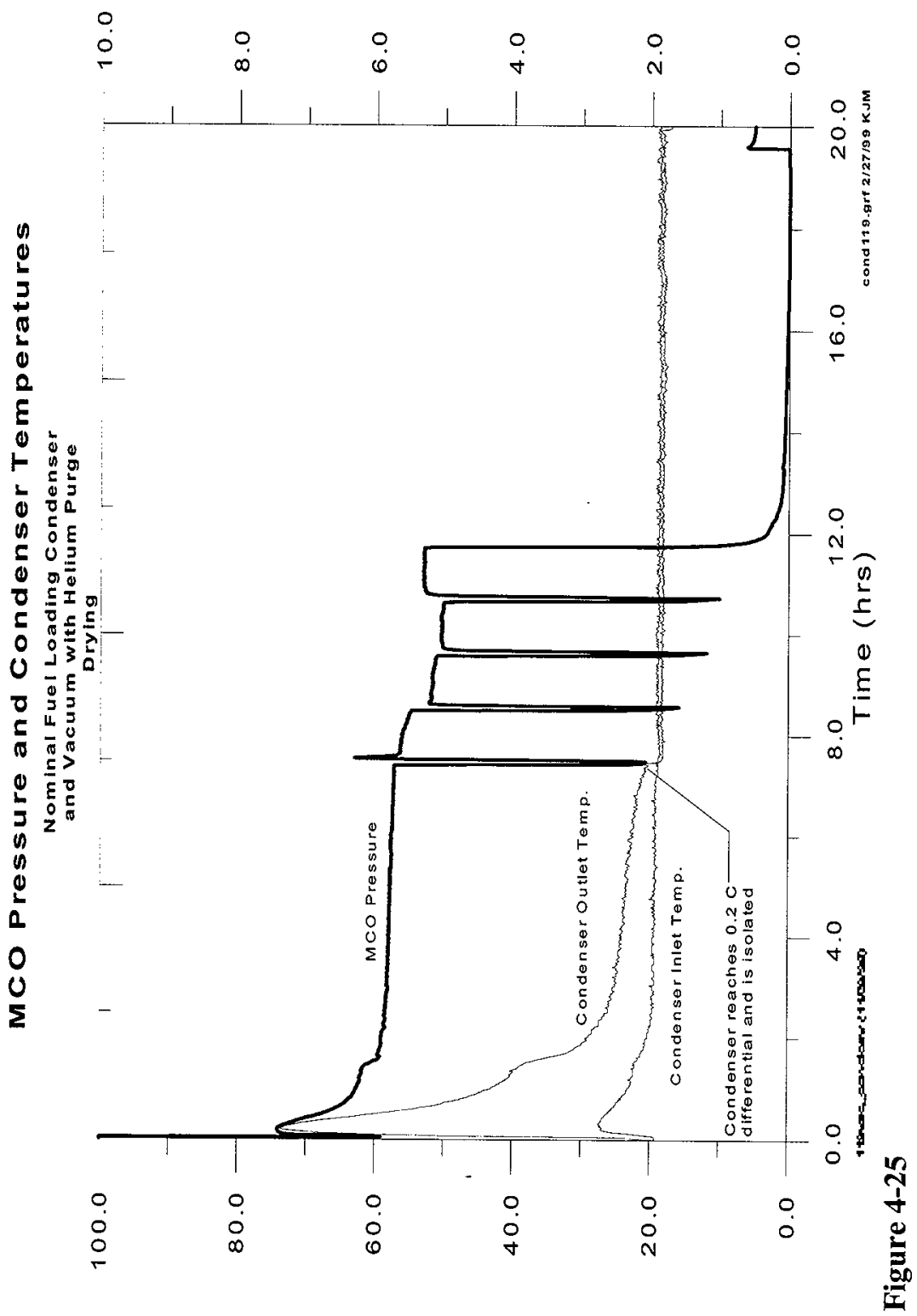

(uOZ) ednssedd 
咅高

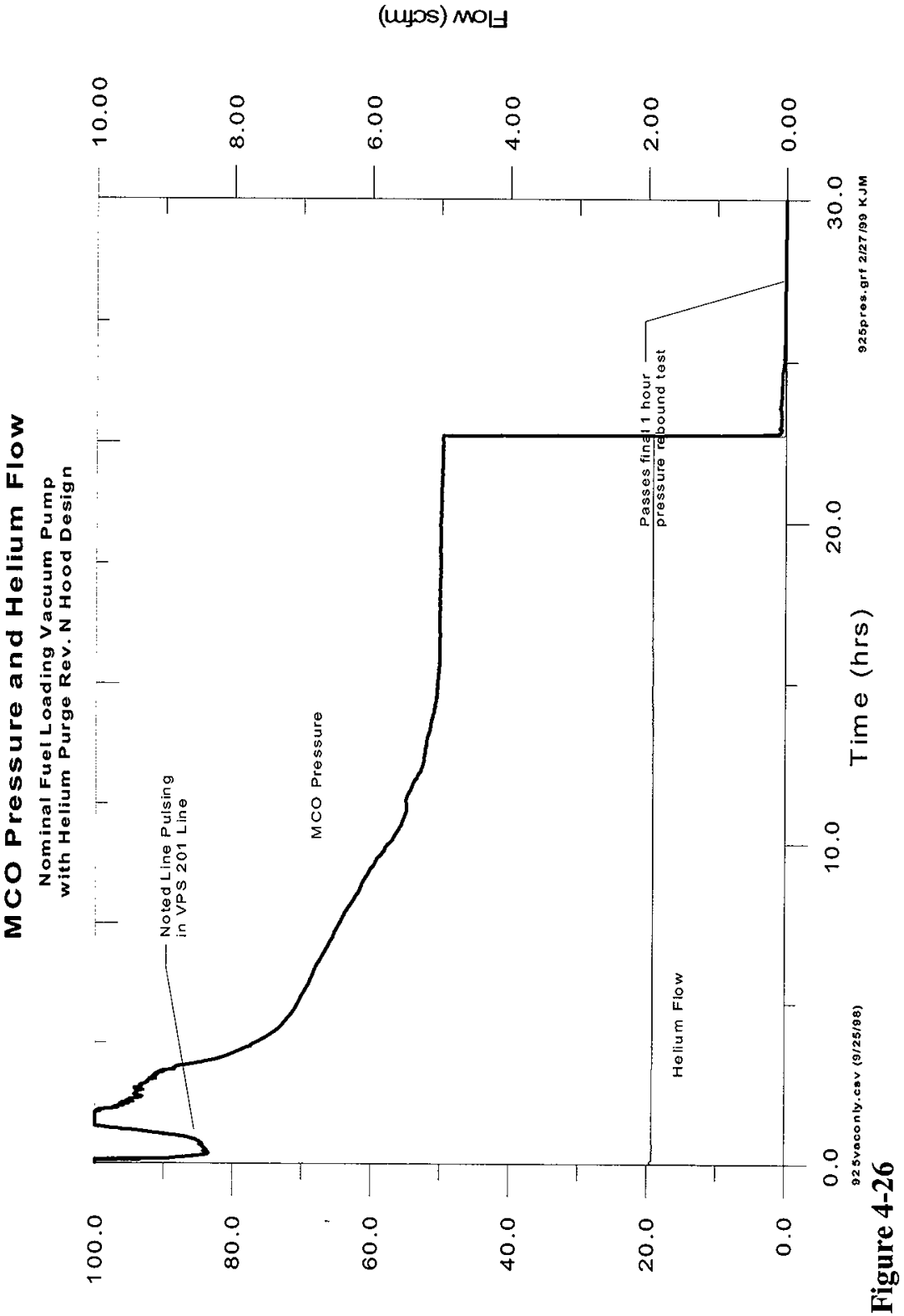

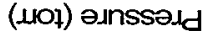




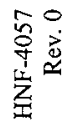

(ups) моH
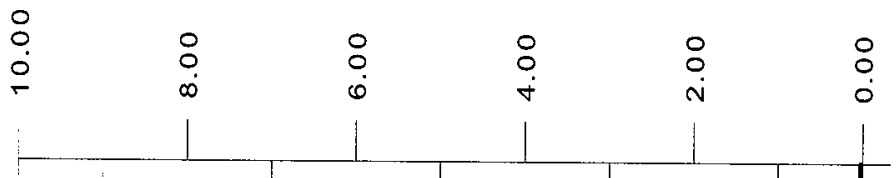

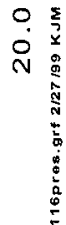

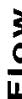

L. 을

E

틀

I

$\sigma>^{\circ} z$

E 2

(1)

(1) ㅇํㅇ

$3=$

a

o 41

(⿻)

․ $\leq 1$

0 之

0

5

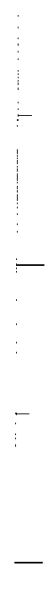




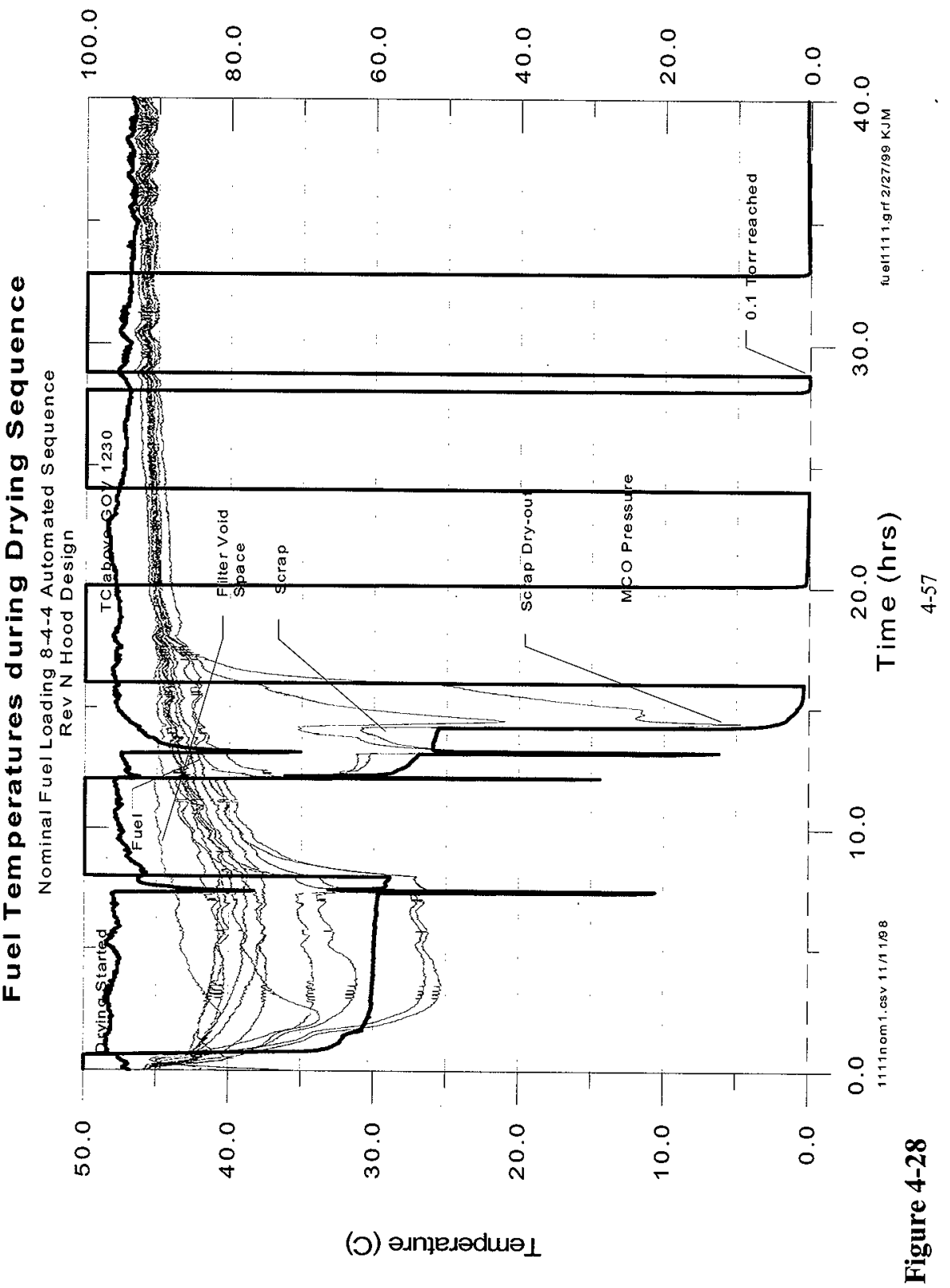


$\begin{array}{ll}n \\ 0 \\ y & 0 \\ z & 2\end{array}$

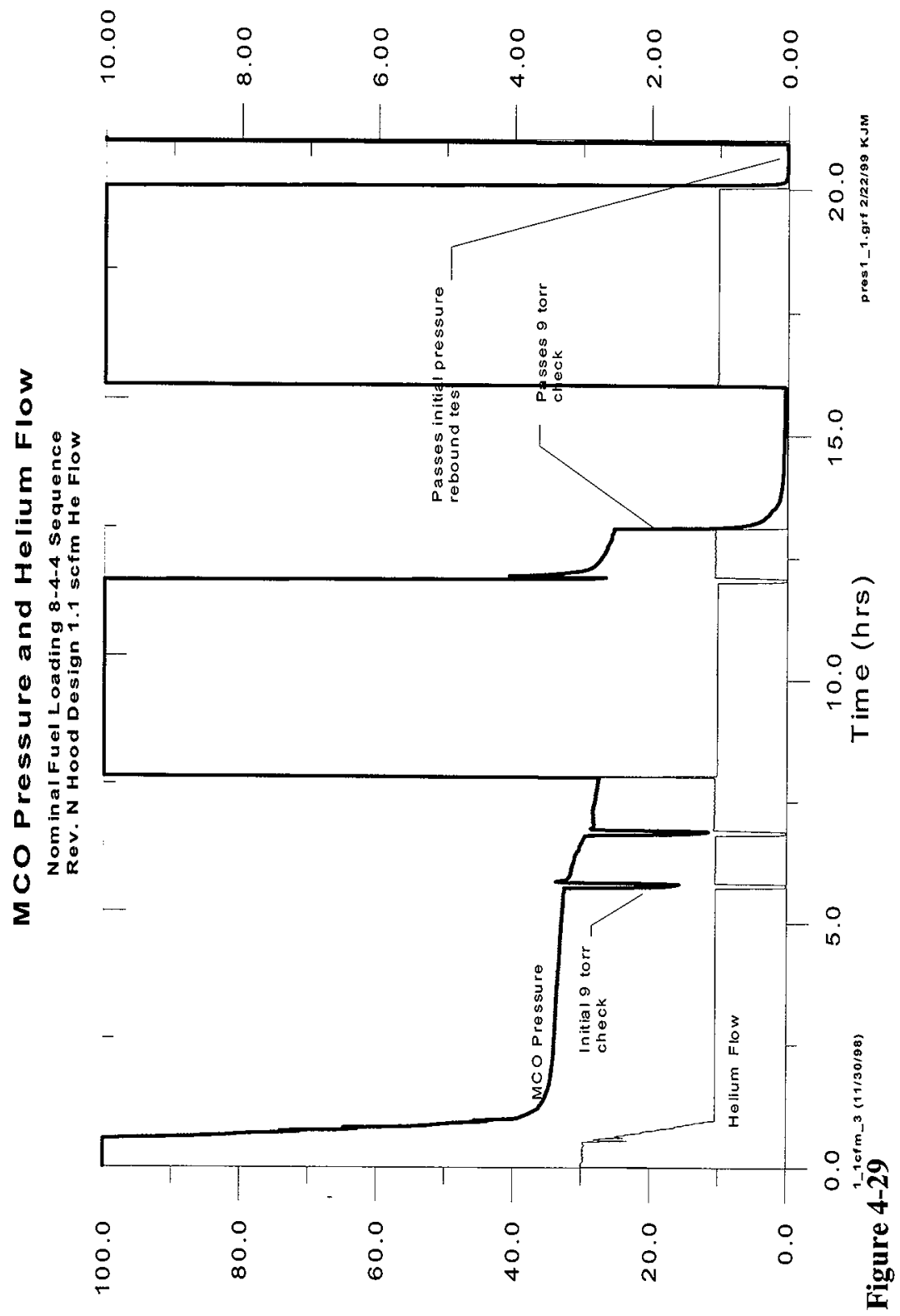




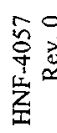

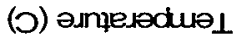

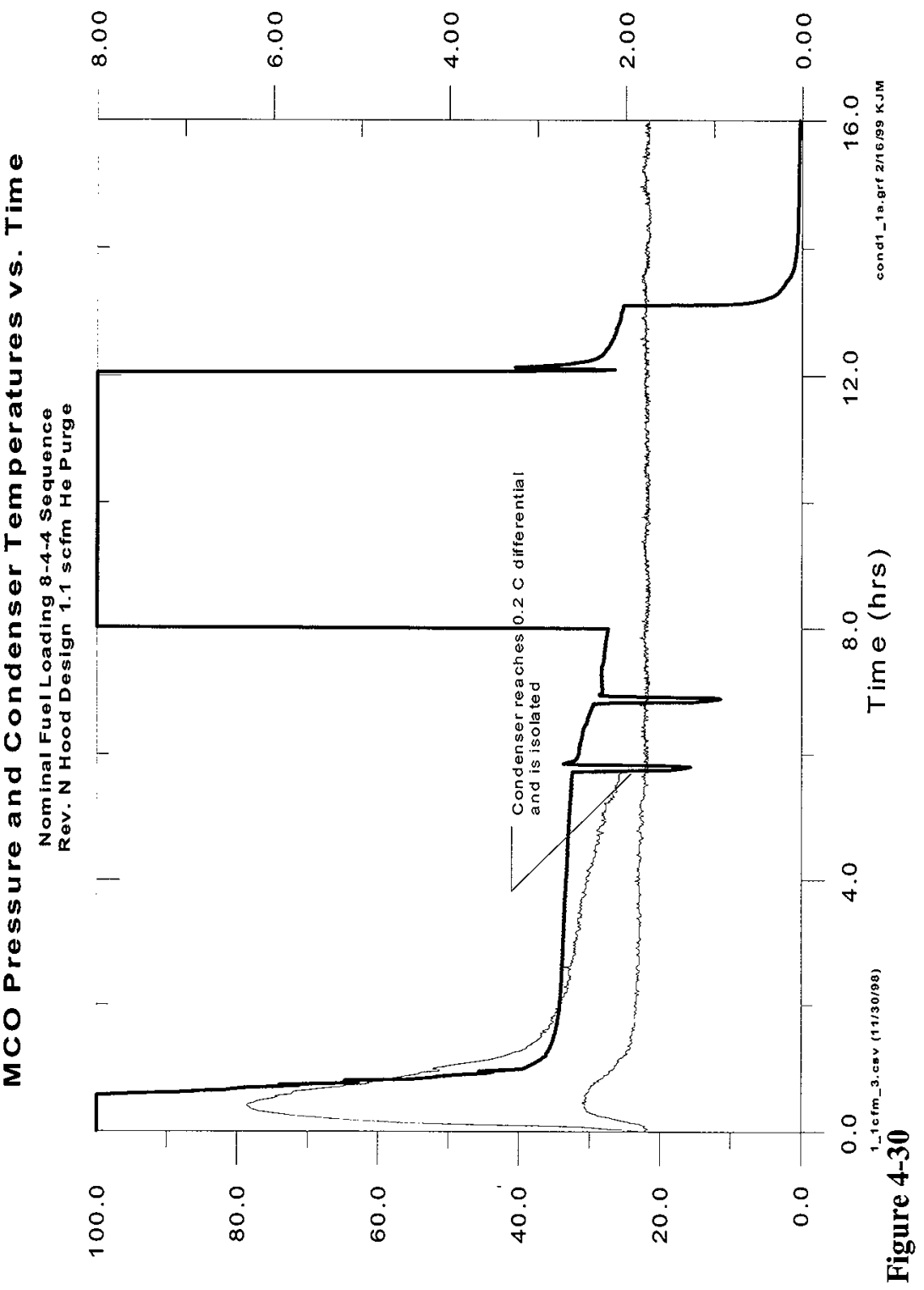

(uOI) a.nsseld 


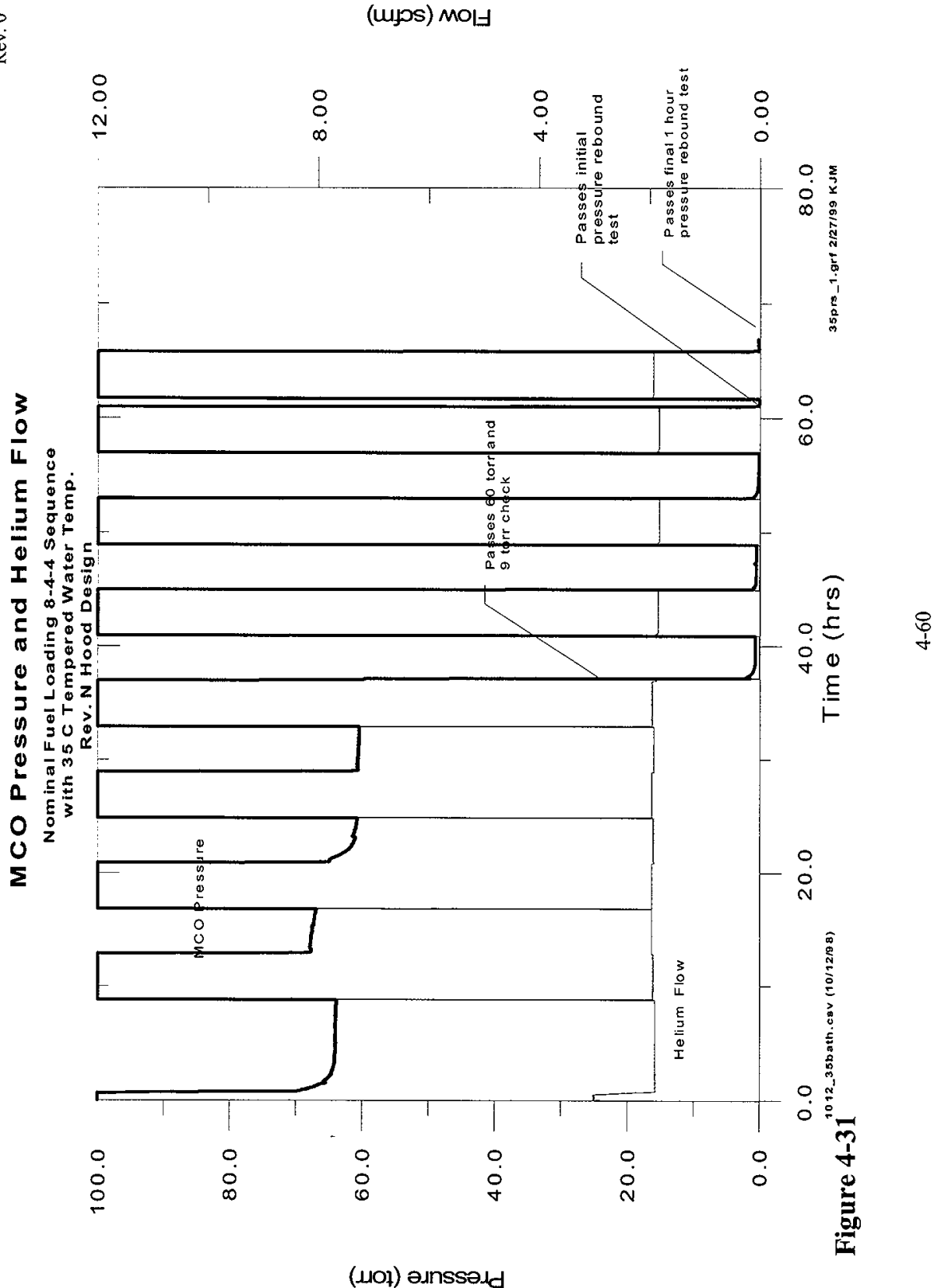


各

(ujos)

$\circ$
$\stackrel{\circ}{\circ}$
$\stackrel{2}{-}$

$\stackrel{0}{\circ}$

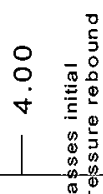

-

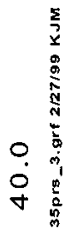
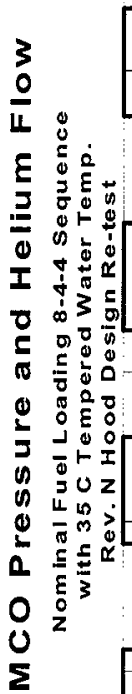

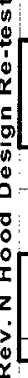
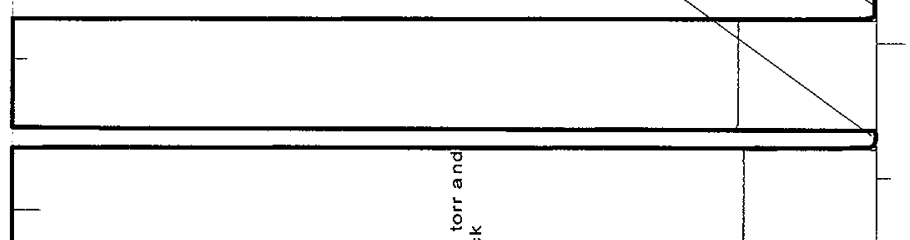

0

$\circ$

$m$

हn

0

$\overline{4}$

:.

N 1

$\circ$

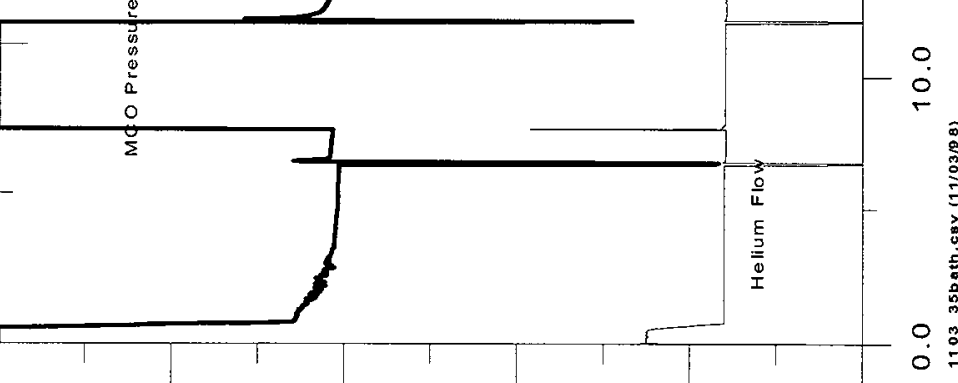

o

0

○.

0

.

$\dot{8}$

0

i

0 


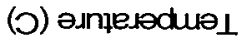

党

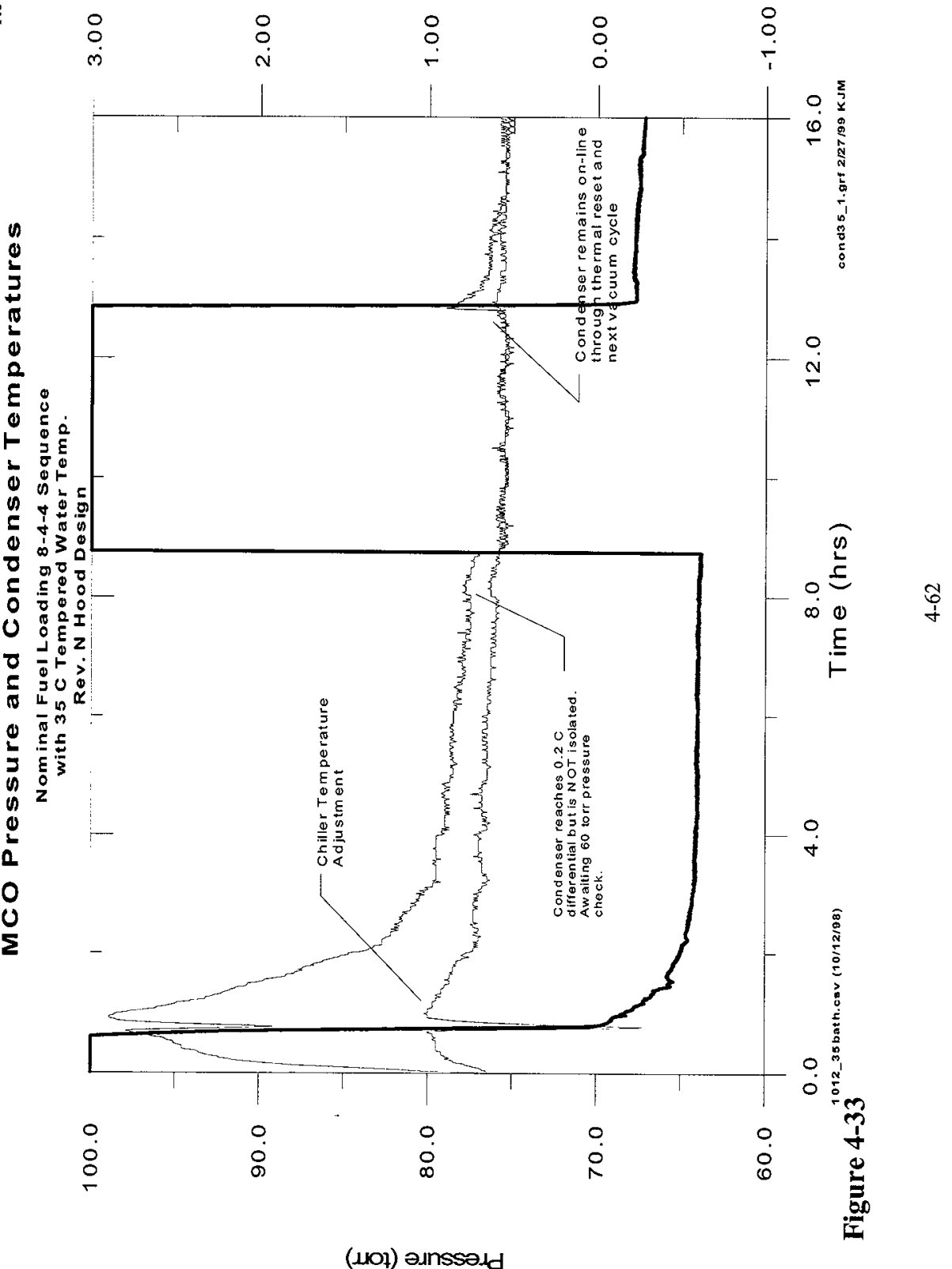




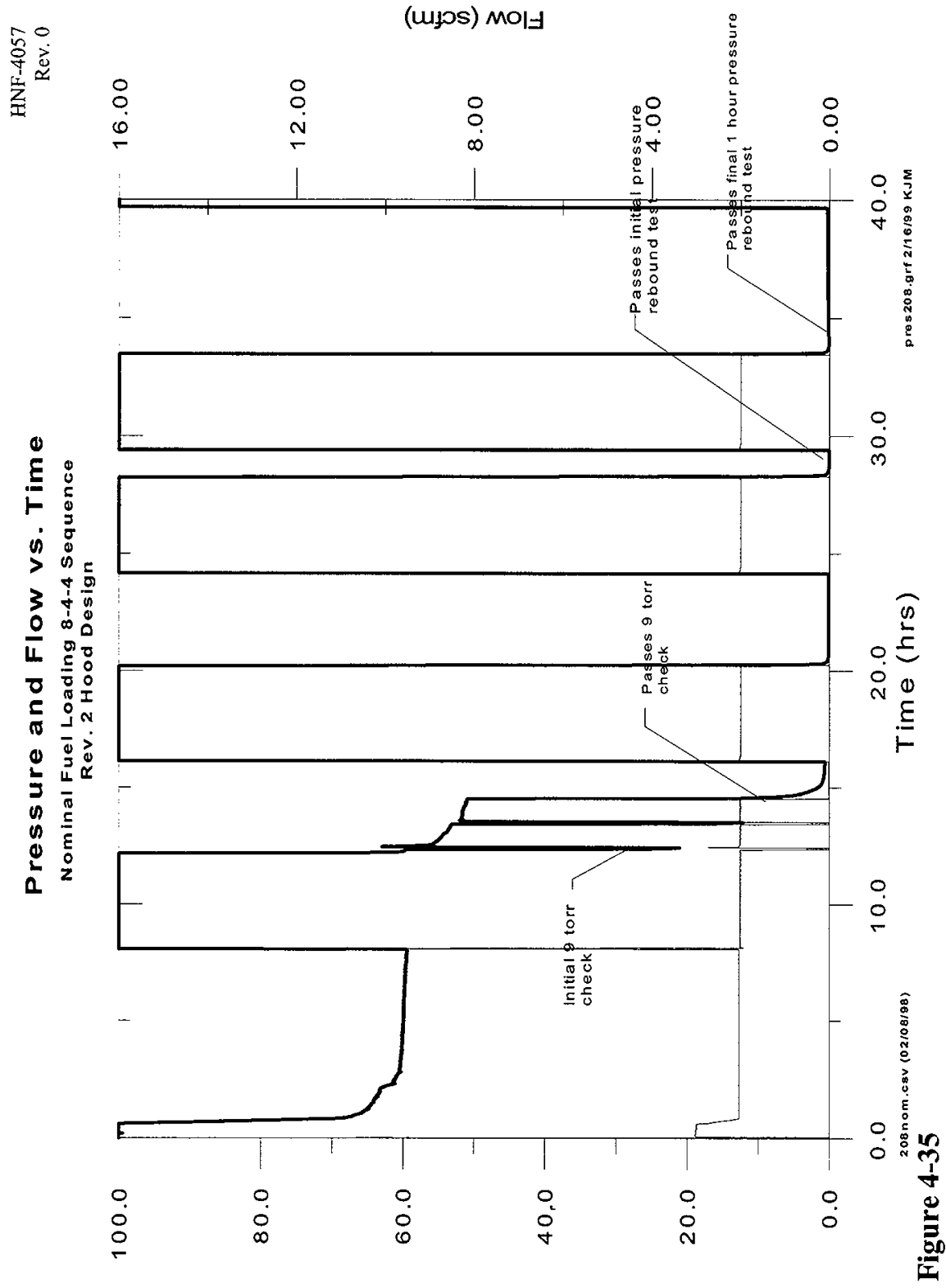

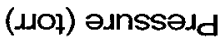




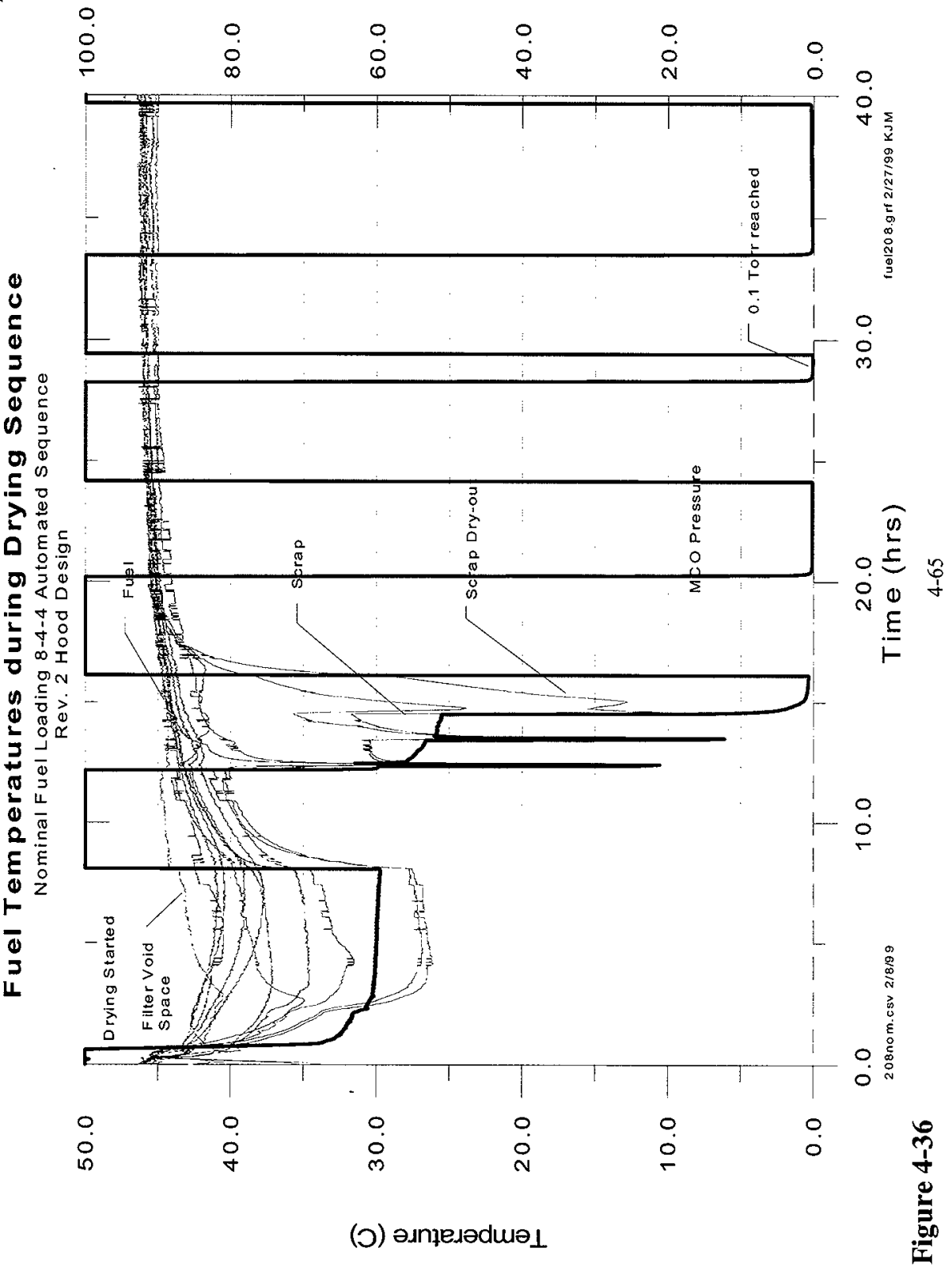




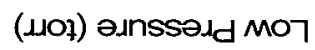

命

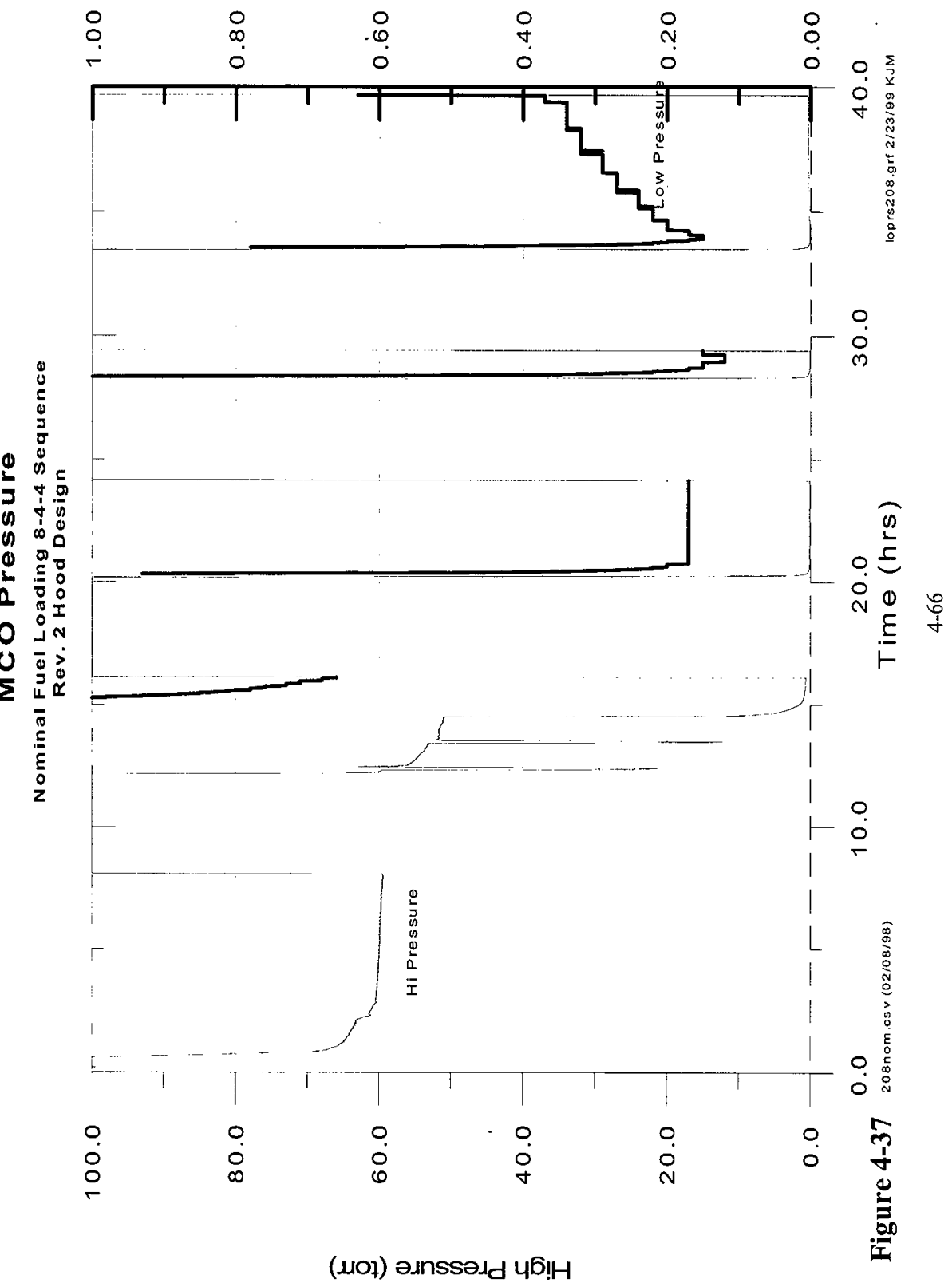


(6!sd) כגnssadd

冬

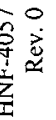
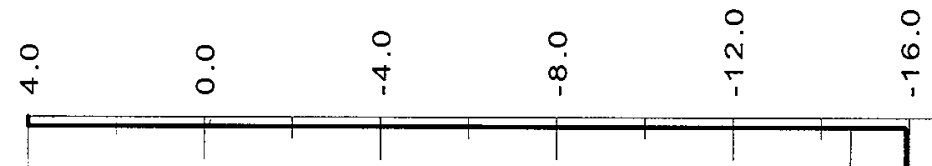

1

$0, \frac{z}{3}$

8

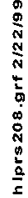

$\stackrel{0}{=}$

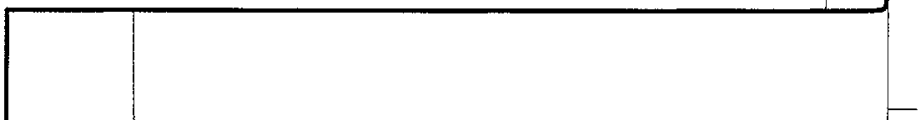

0

0.0
0
0

0 舟

0 응

0 :

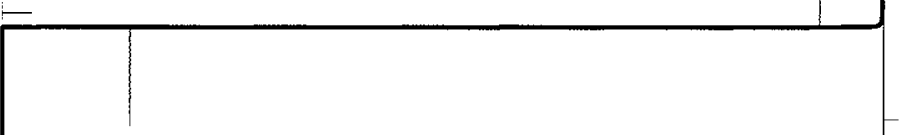

()

28

of

0

$-$
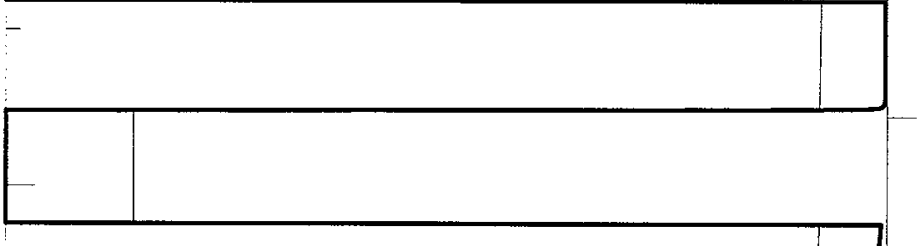

5

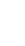

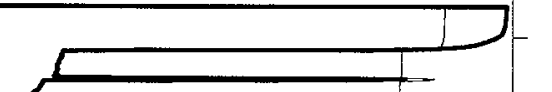

(1)

$\underline{E}$

$\underline{E}$

0

$\stackrel{\circ}{\circ}$

¿ 2

(1)
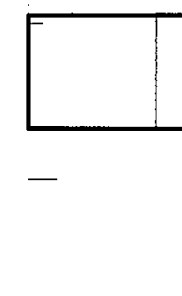

ᄃ

ס

포

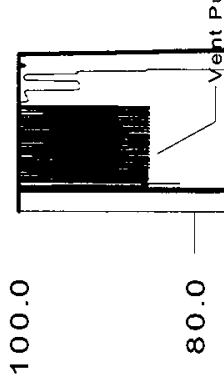

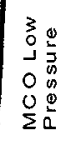

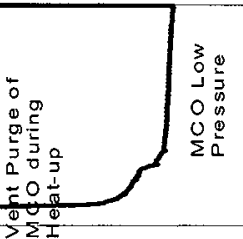

0
5
0
0
0
5
0
5
0
$I$
0
0
$\Sigma$

(د107) olnssadd 


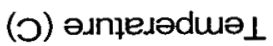

瓷

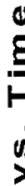

$\stackrel{0}{0}$

0

$\stackrel{0}{\circ}$

$\stackrel{0}{0}$

0
0

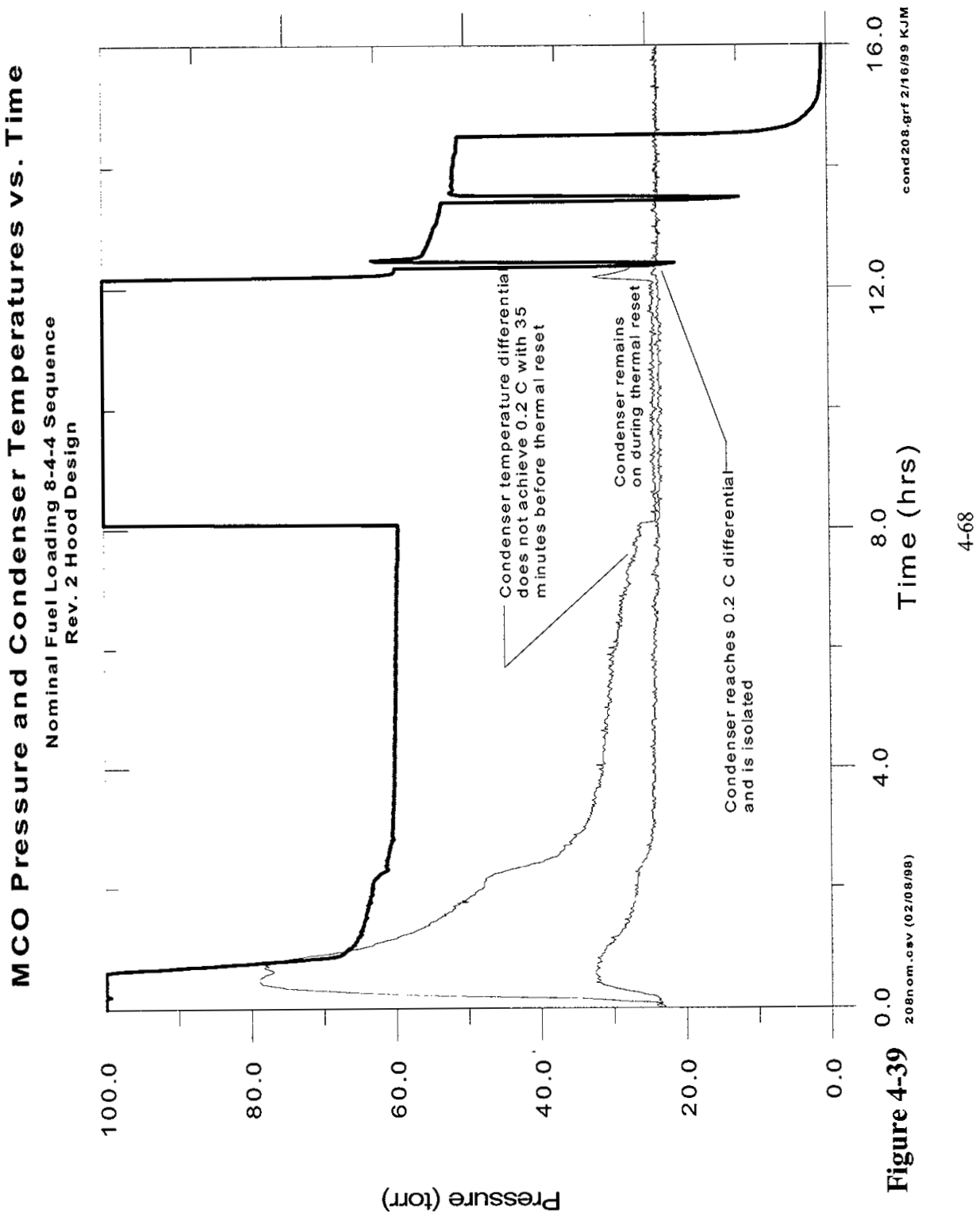


骂

(๖) әגnıe

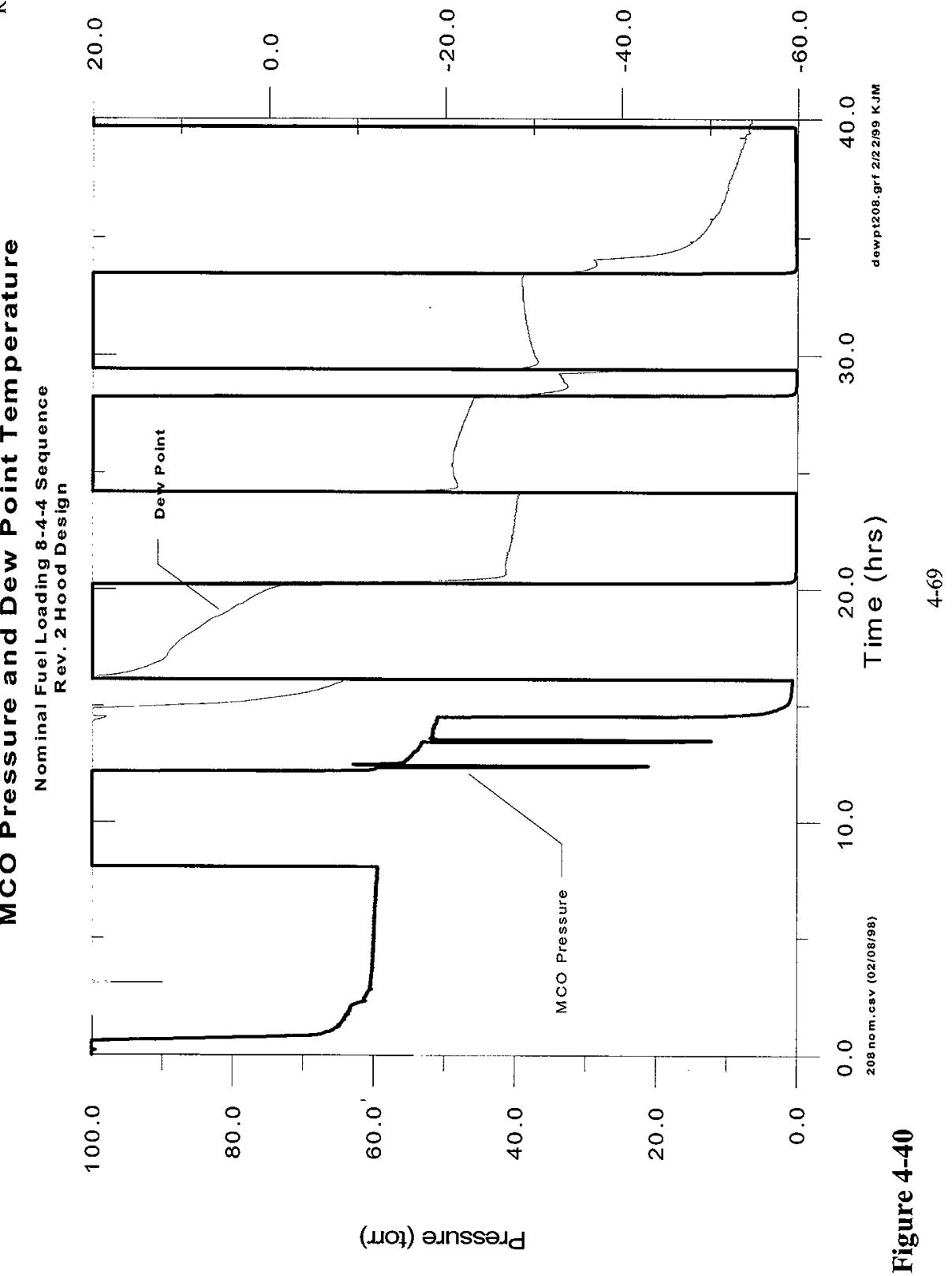




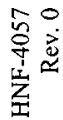

(6!̣d) əunssədd

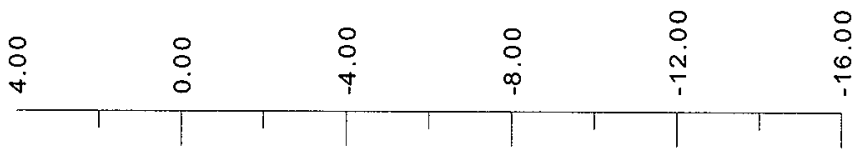

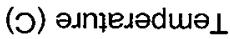



0

$\stackrel{0}{0}$

웅

0

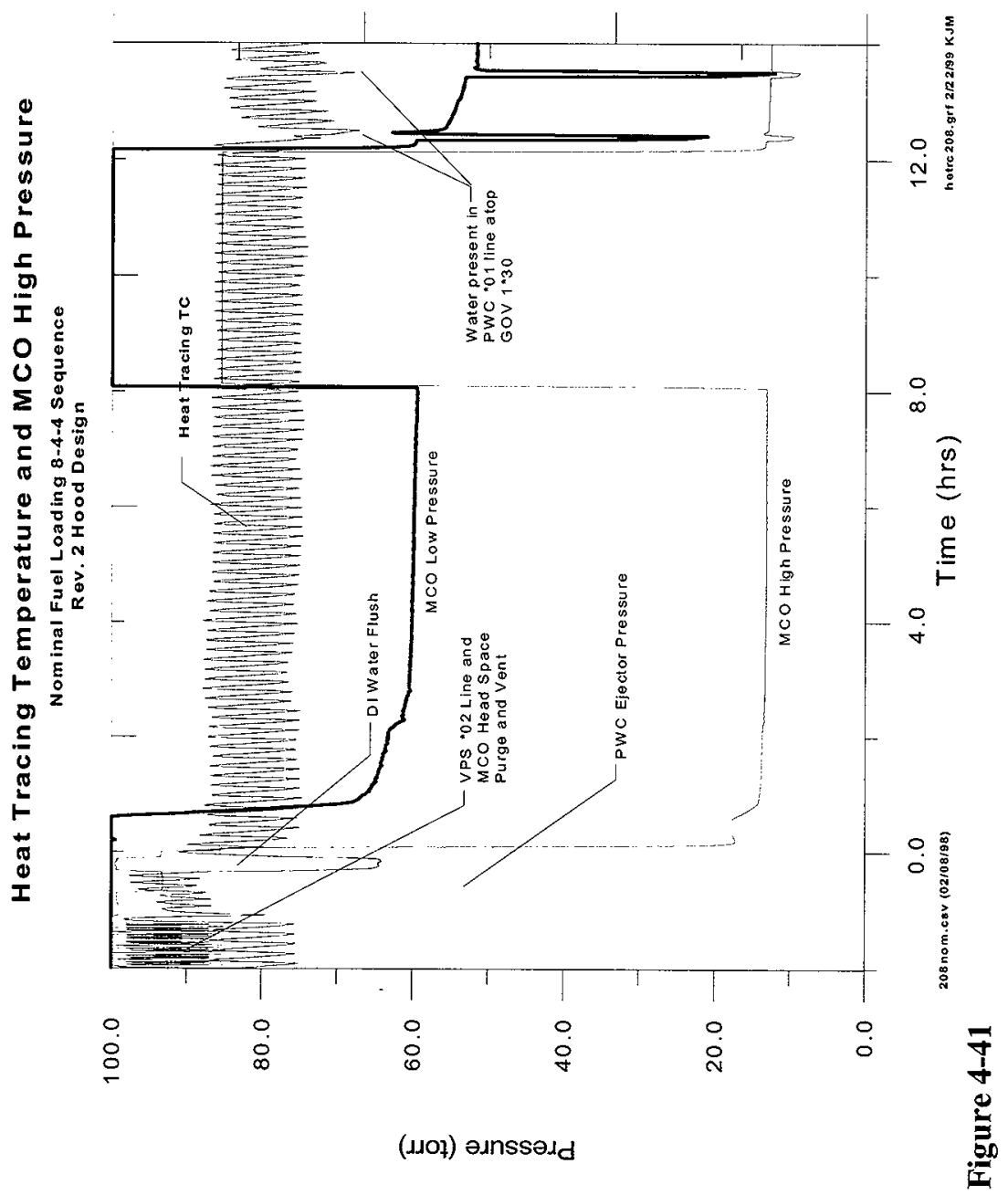




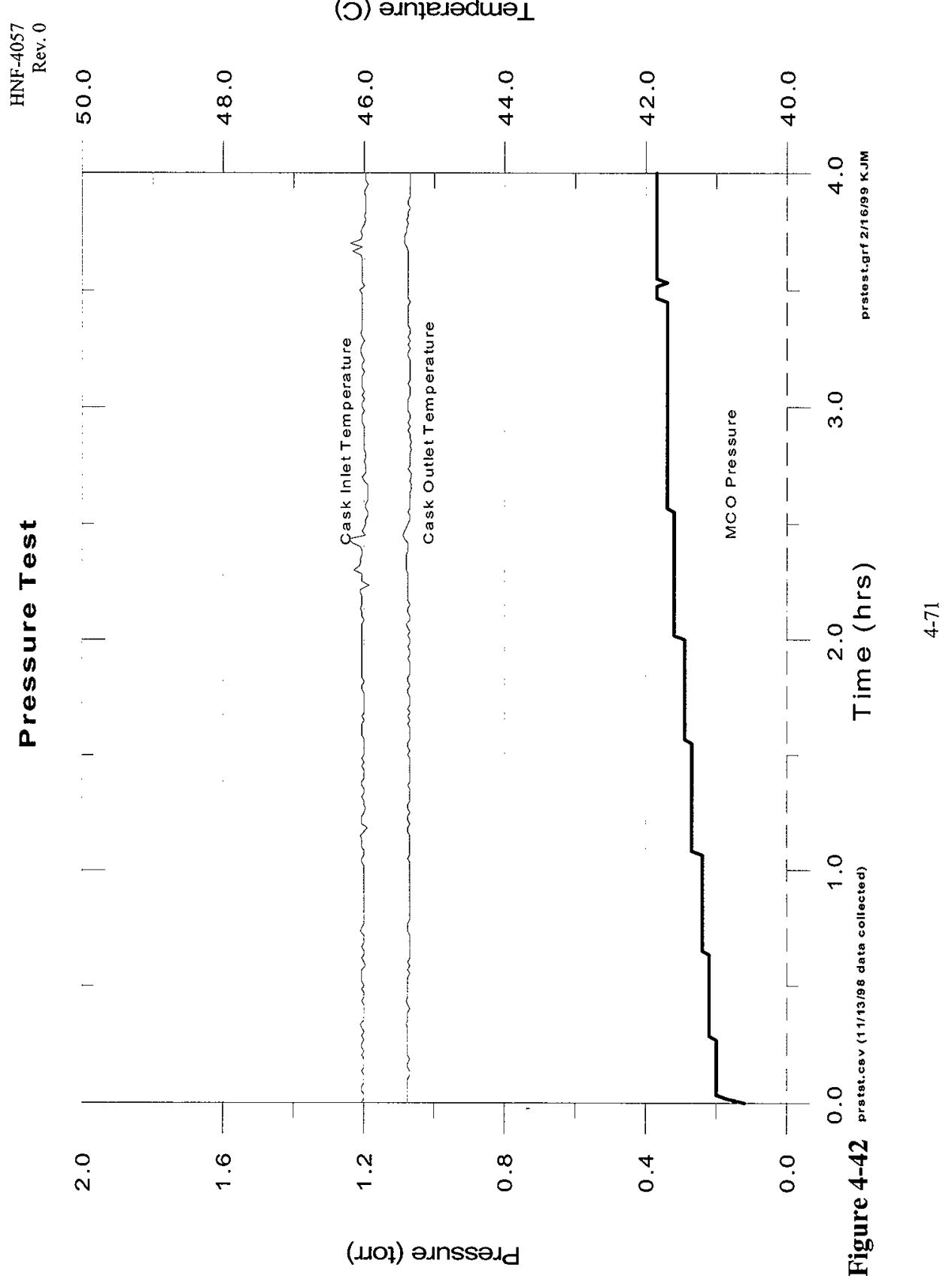


尊高
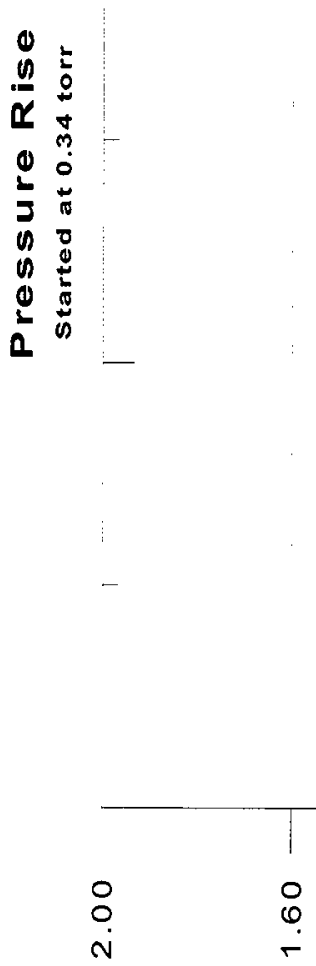

$\stackrel{\circ}{\circ}$

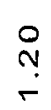

$\stackrel{\circ}{\sim}$

$\because \quad 0$

(wO1) כגnssedd

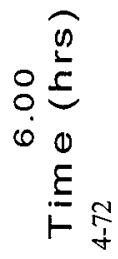

$\stackrel{0}{0}$
0
10

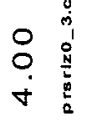

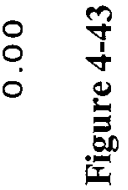


点

$\stackrel{0}{\circ}$

$\stackrel{0}{0}$

0
0
$\infty$

$\begin{array}{ll}0 & 0 \\ 0 & 0\end{array}$

$\begin{array}{ll}0 & 0 \\ 0 & 0\end{array}$

0
0
$\sim$

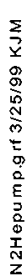

0
5
0
0
0
$\vdots$
0
0
0
0
0
0
$E$
5
0

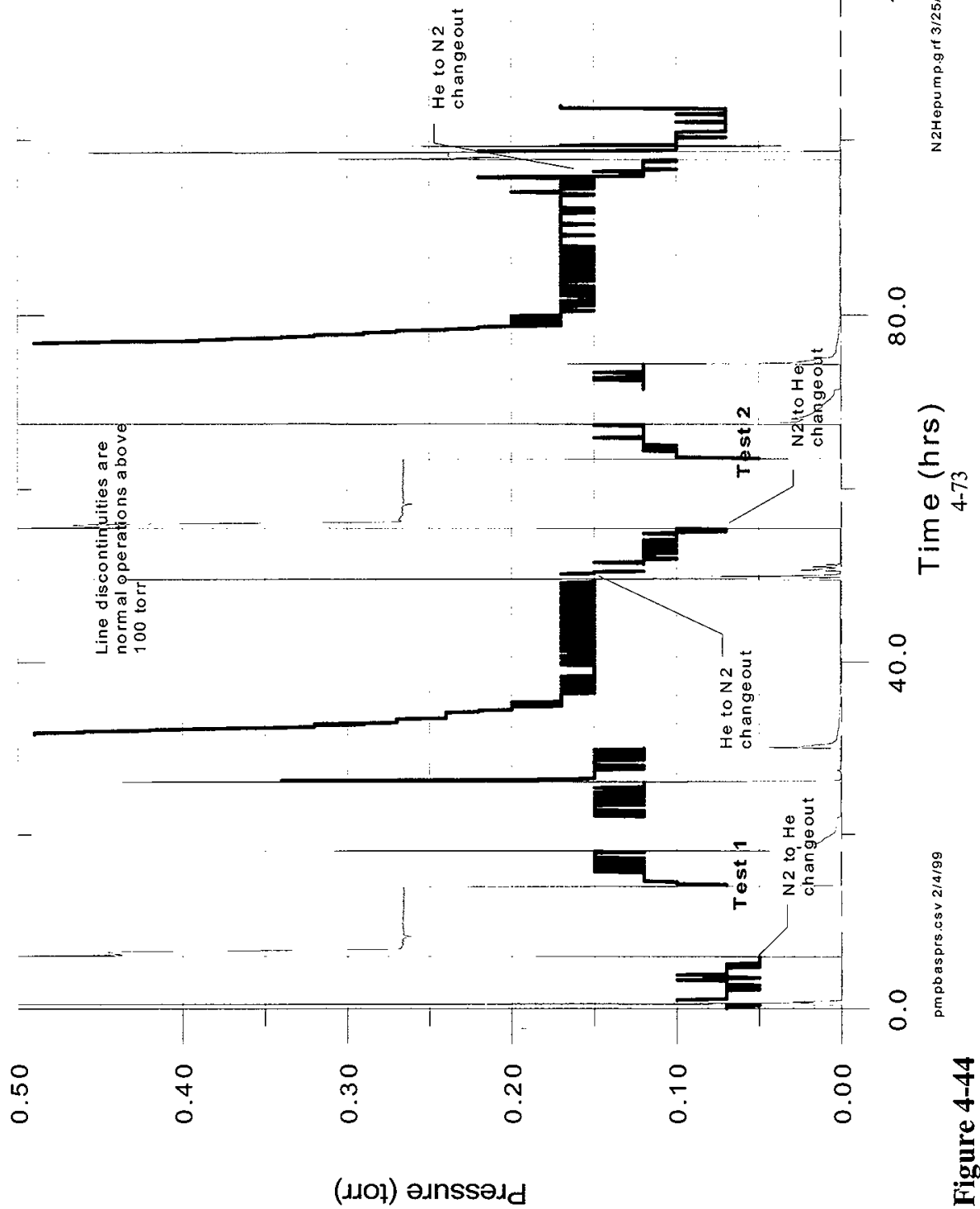




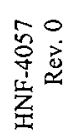

(uyos) $\mathrm{MOH}$

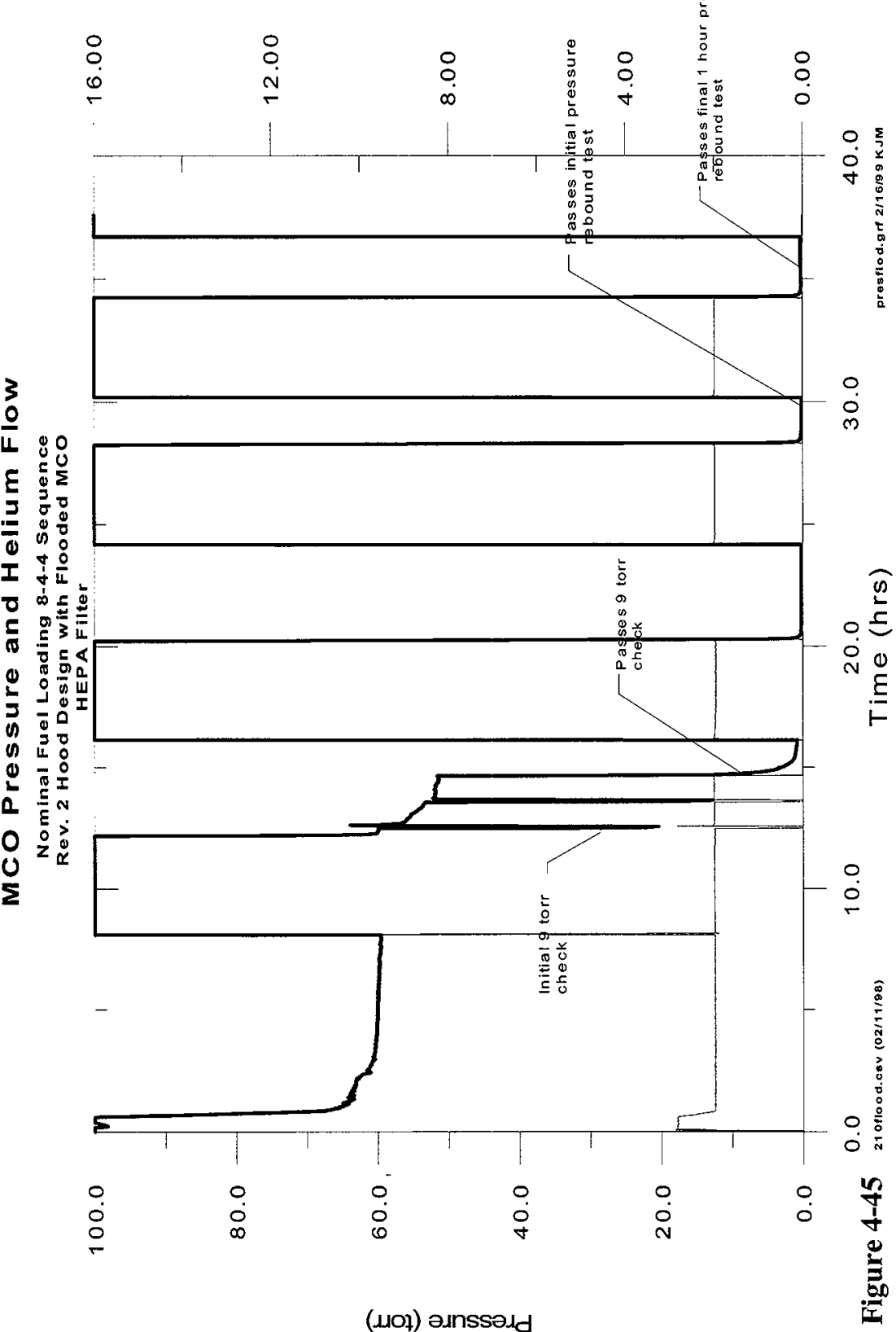




\section{(uرos) мOH wn!̣|H}

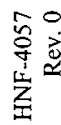

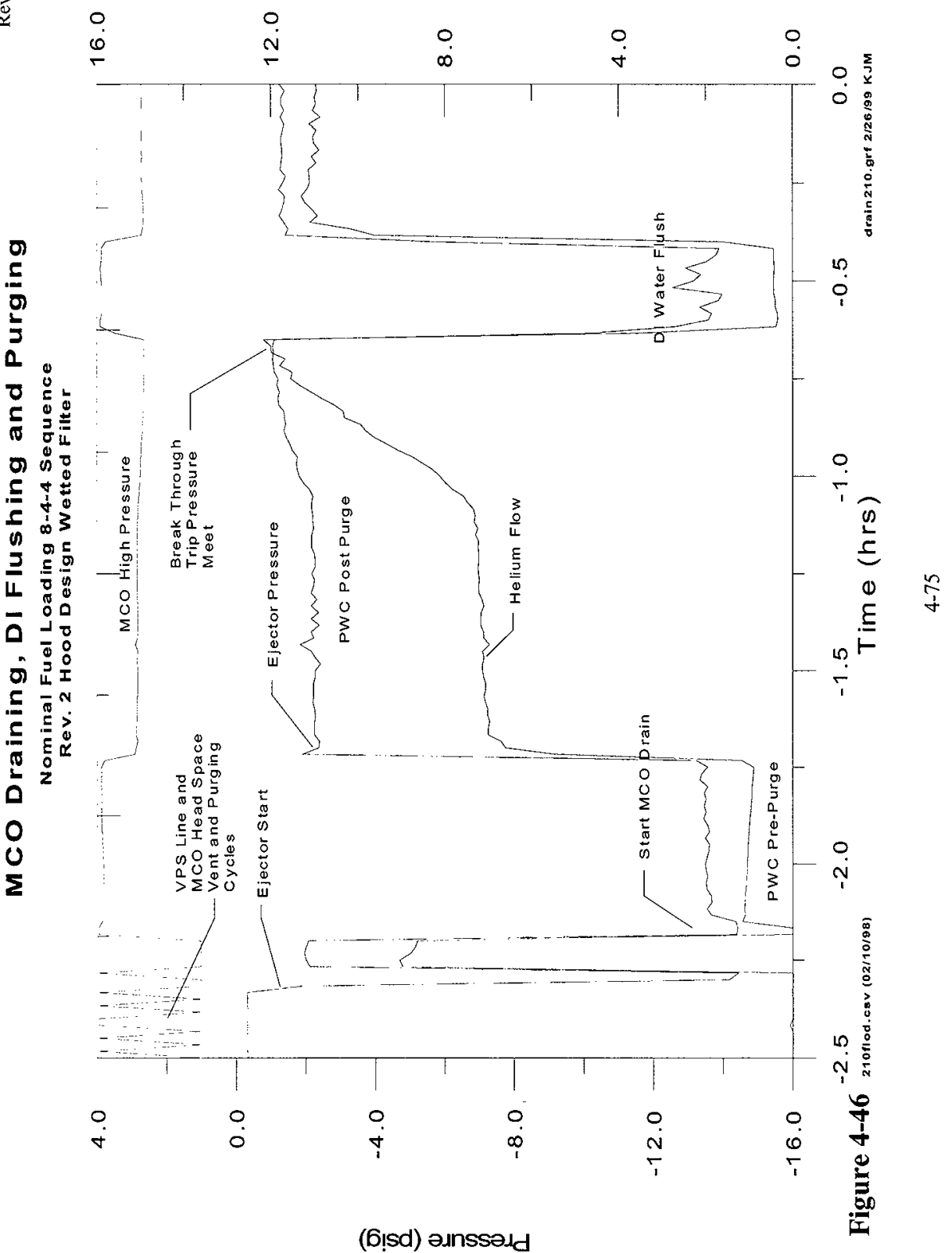


is $\quad$ (upos) MOl

要

$\stackrel{0}{0}$

$\begin{array}{ll}0 \\ 0 & 0 \\ -1 & \infty\end{array}$

$\stackrel{0}{\circ}$
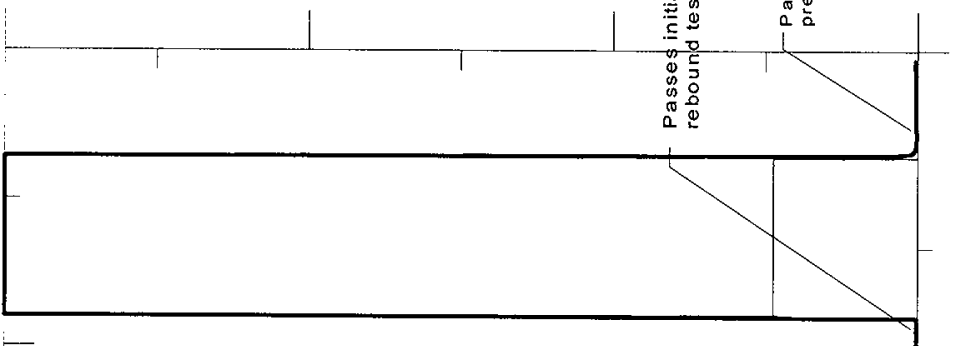

$\stackrel{\circ}{\circ}$

$\overbrace{0}^{\frac{1}{2}} \frac{0}{\frac{1}{y}}$

E

(1) $\overline{0}$ ग

ए

(D)

(1)

0 는

a
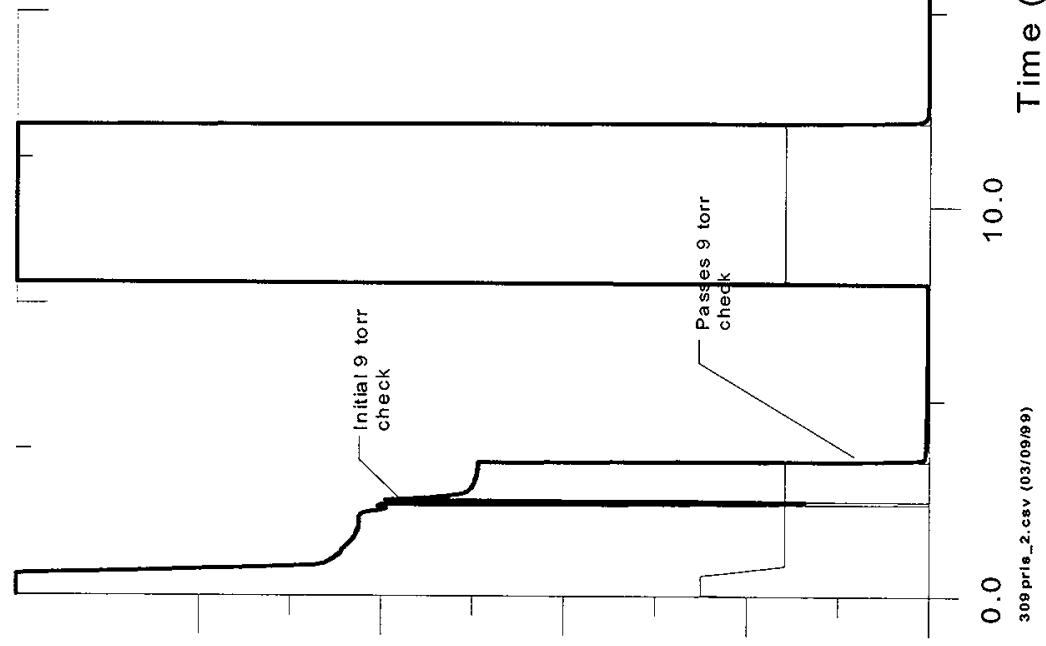

$\stackrel{0}{\circ}$

0

0
0
0

$\stackrel{0}{\circ}$

0
0
$N$

0

(נ.رOf) z.unssold 
令京

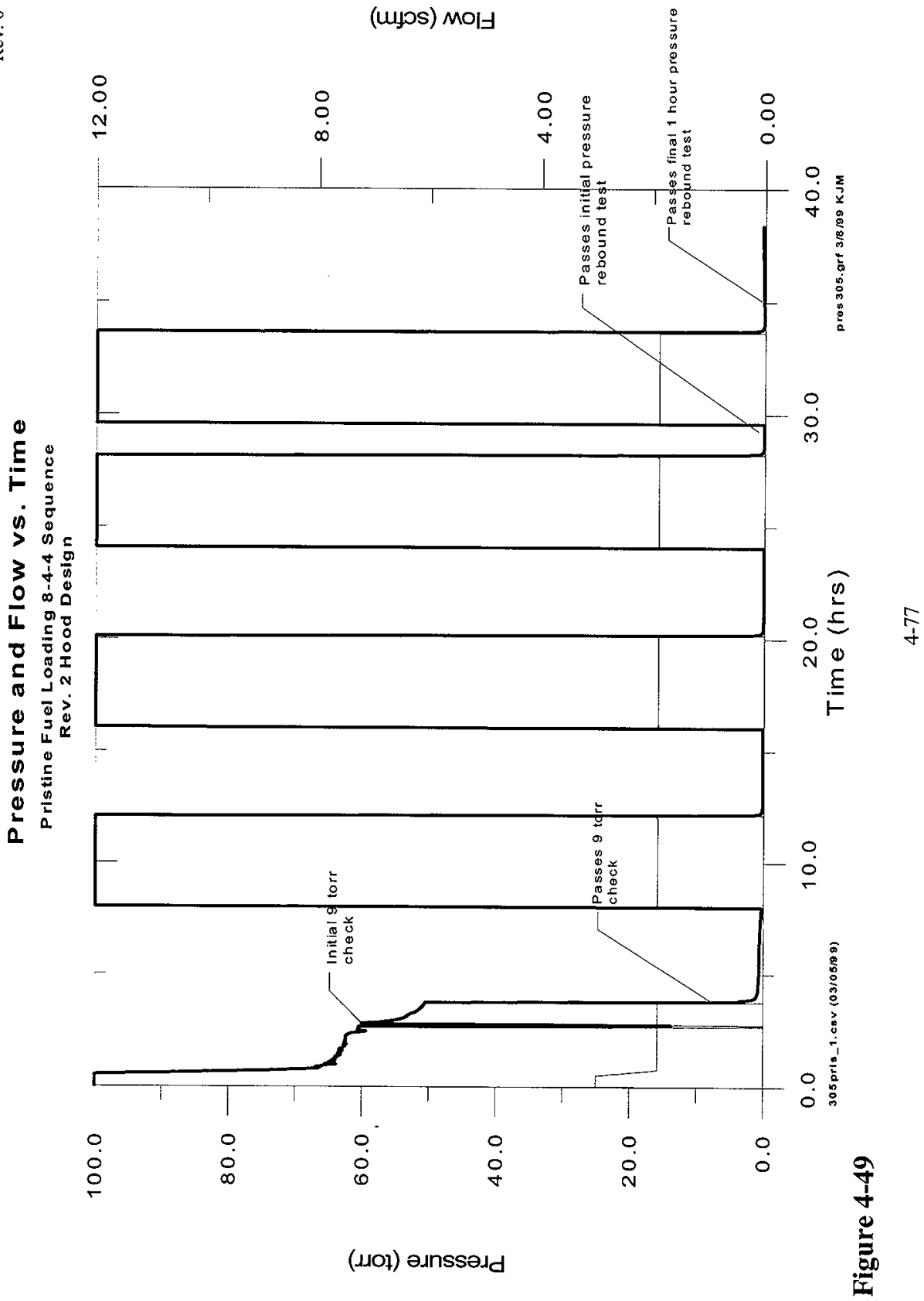


哭

(นOl) a.nssa.d OOW

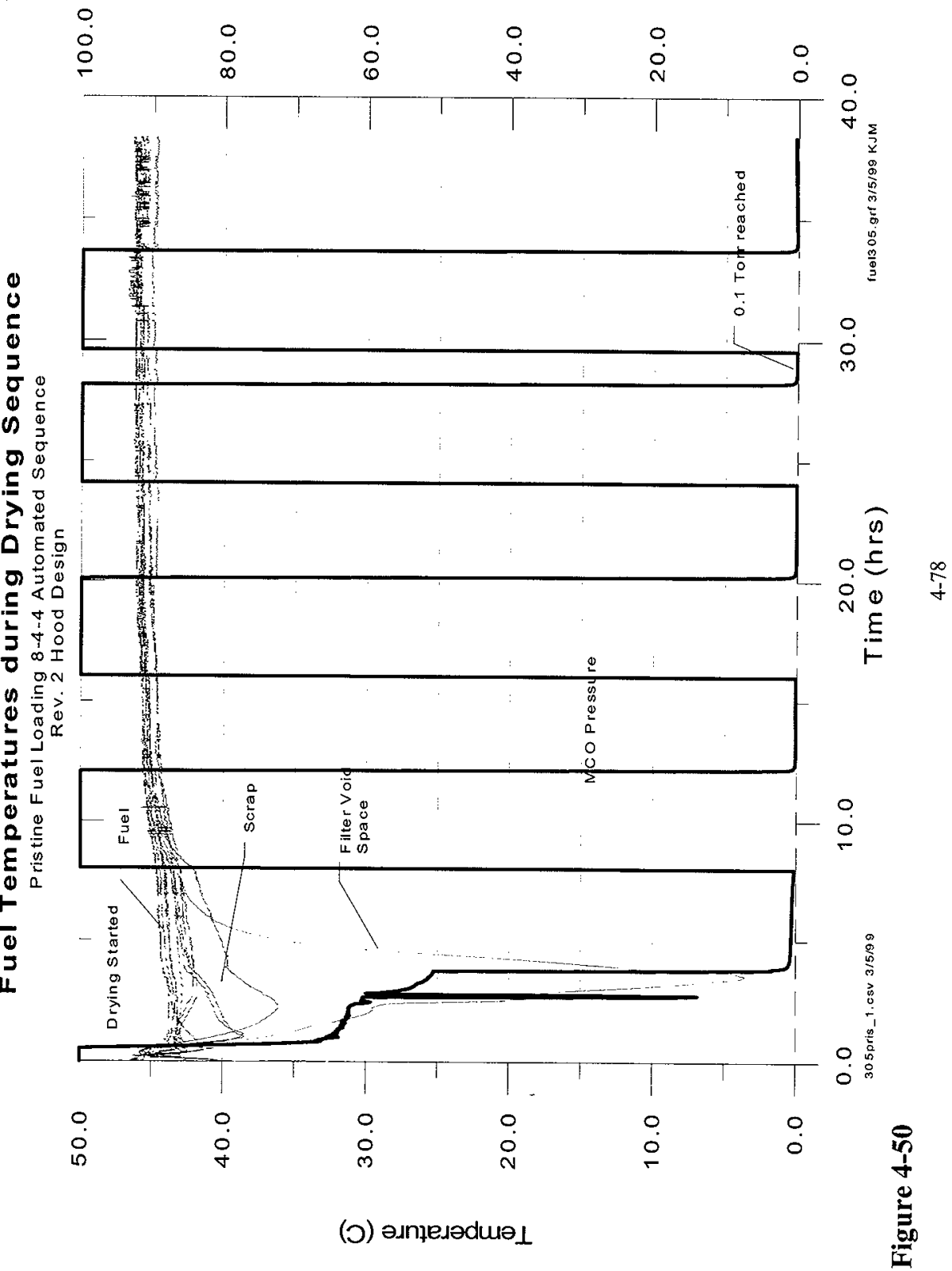


(101) anssald OOW

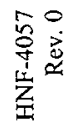

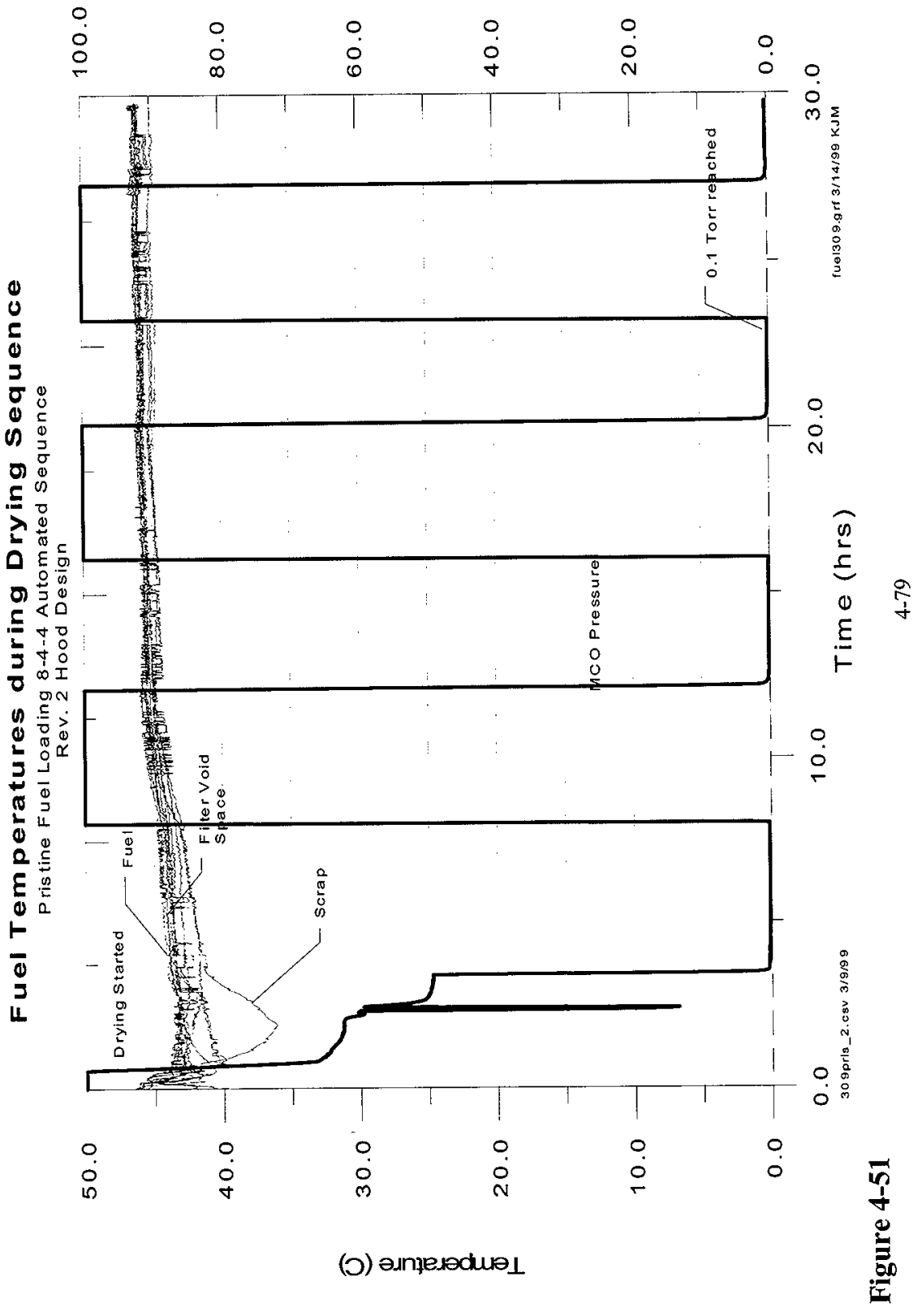


合

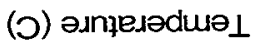
$\approx$

0
$\infty$

$\stackrel{\circ}{\circ}$

0
0

ำ
ำ

0

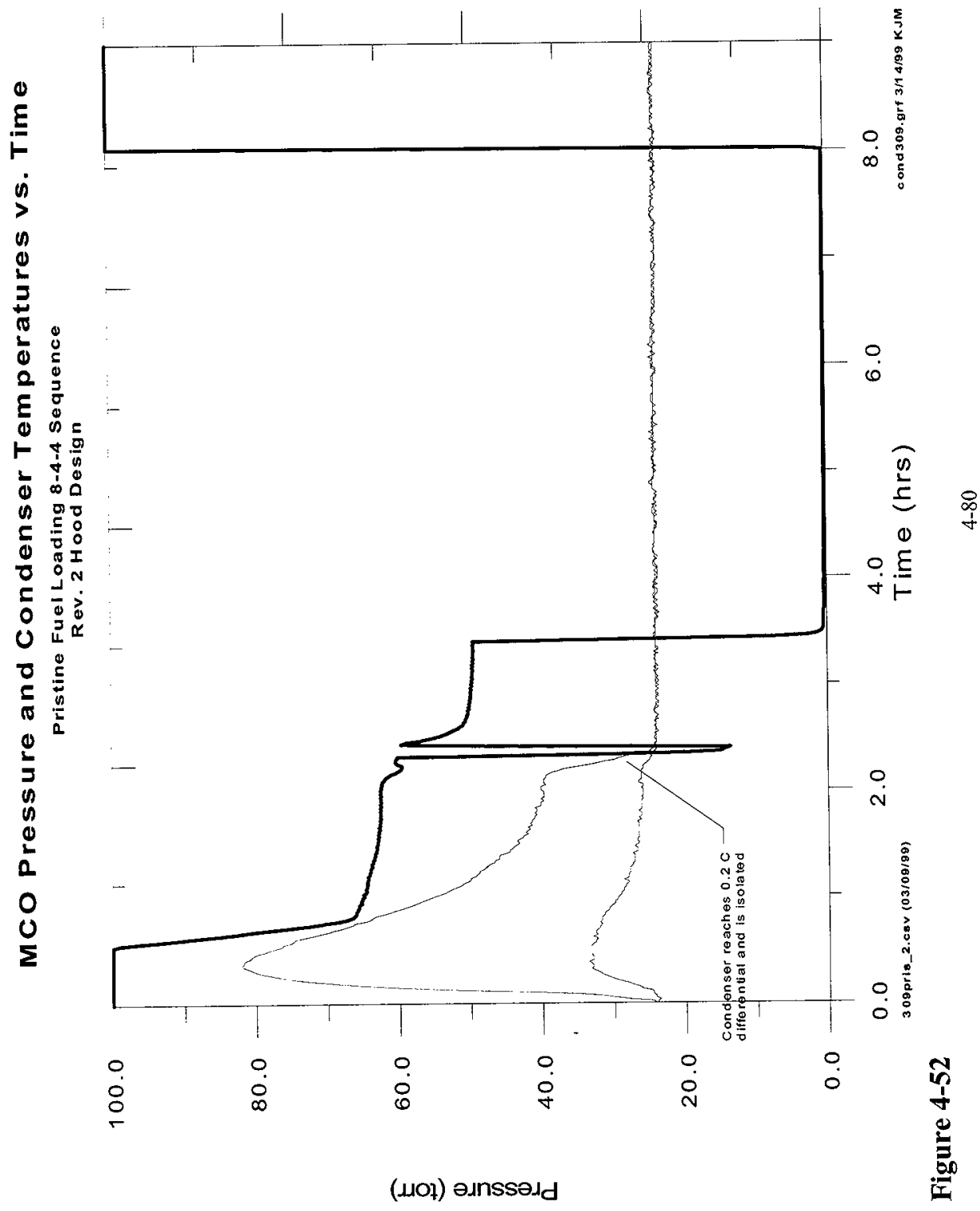




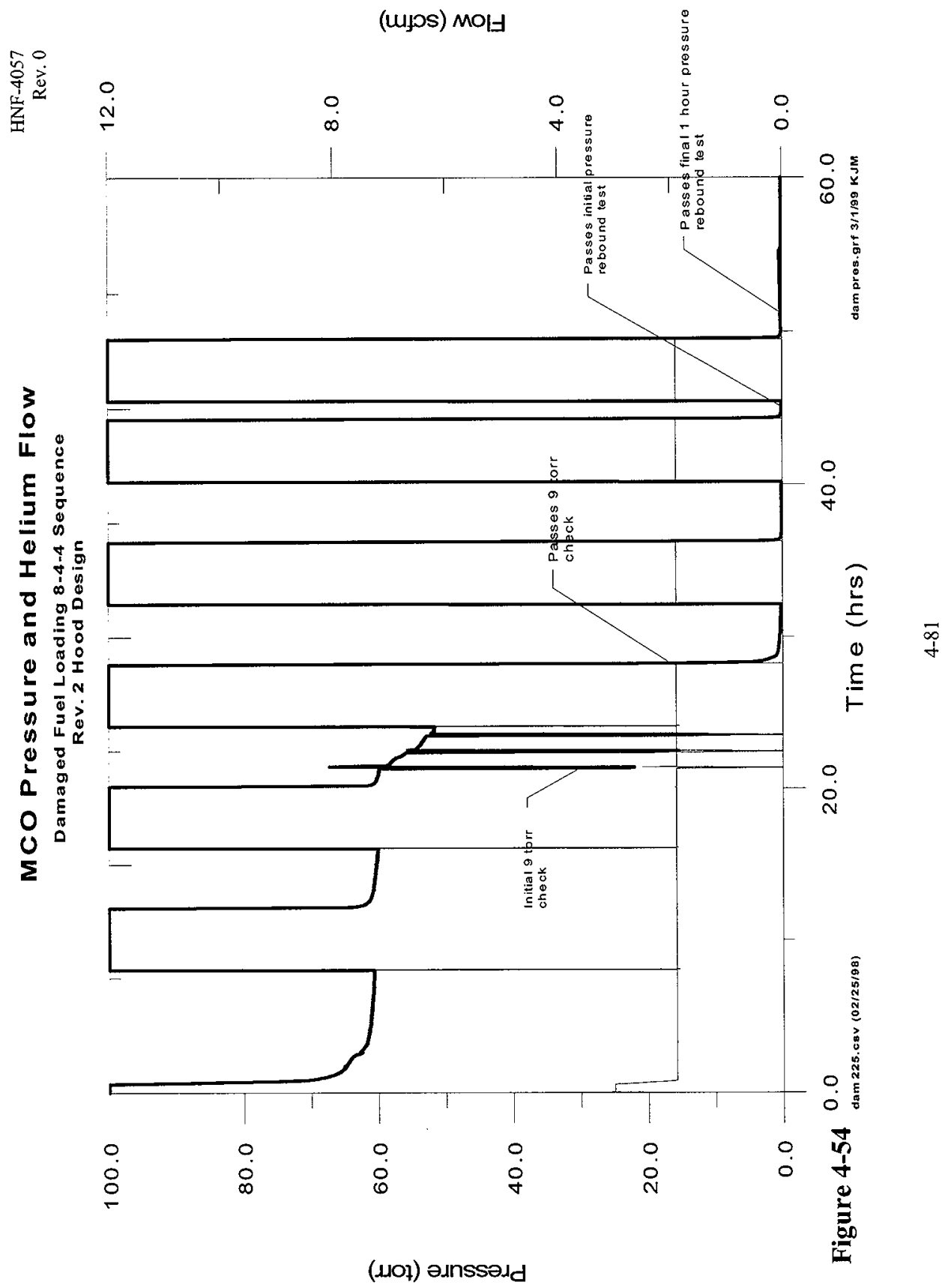


唀

(גol) oגnssadd OON

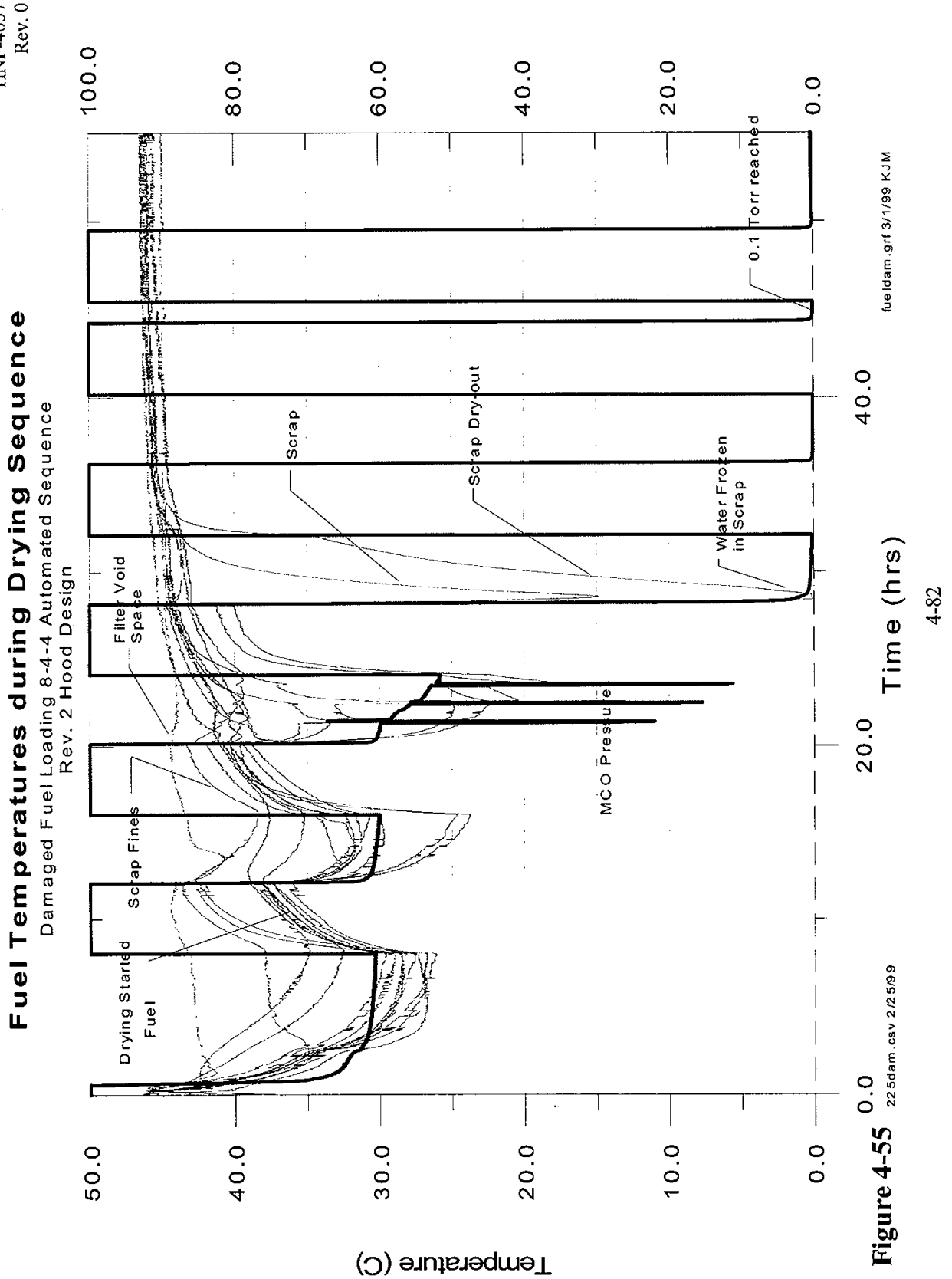




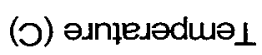

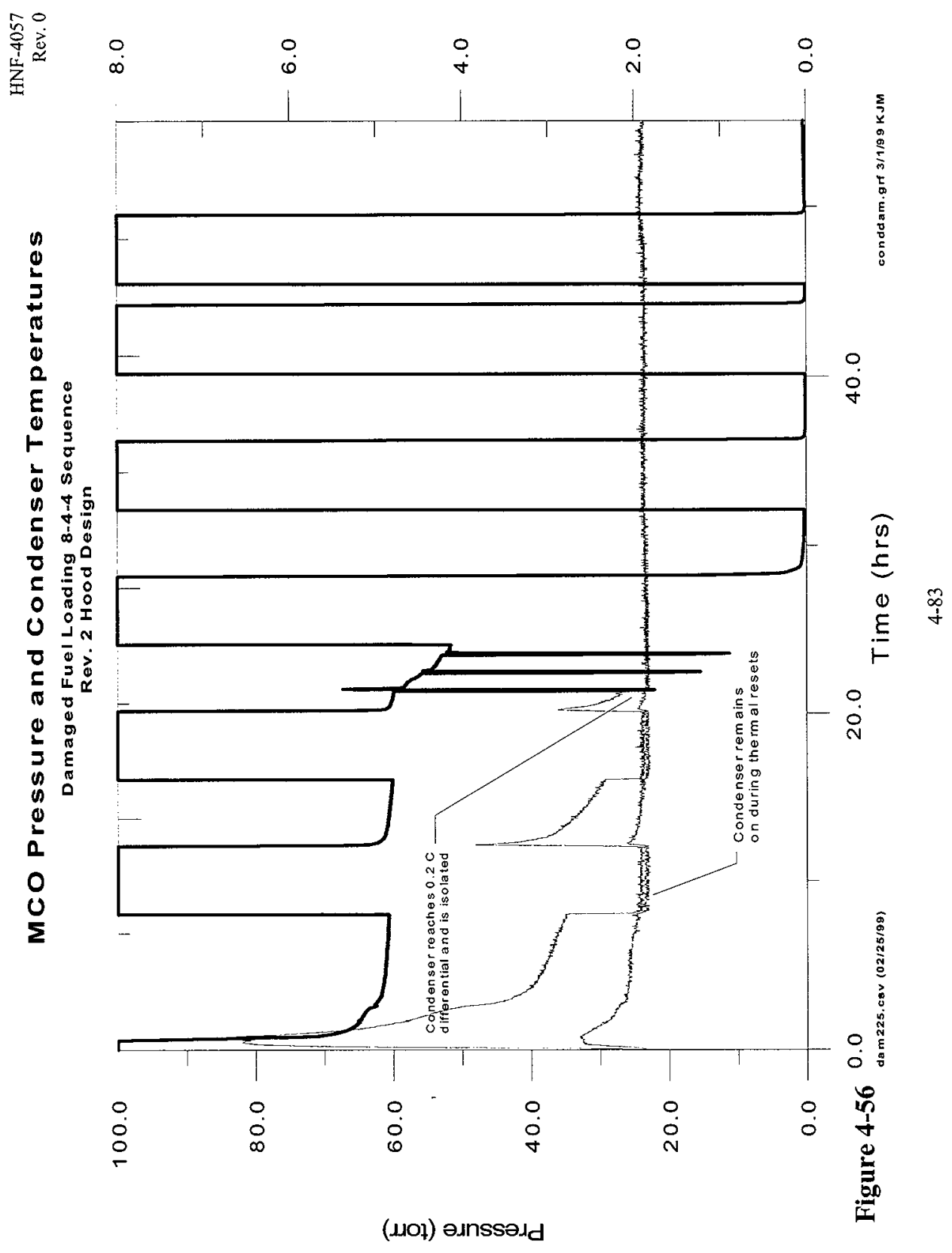




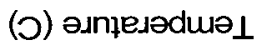

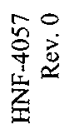

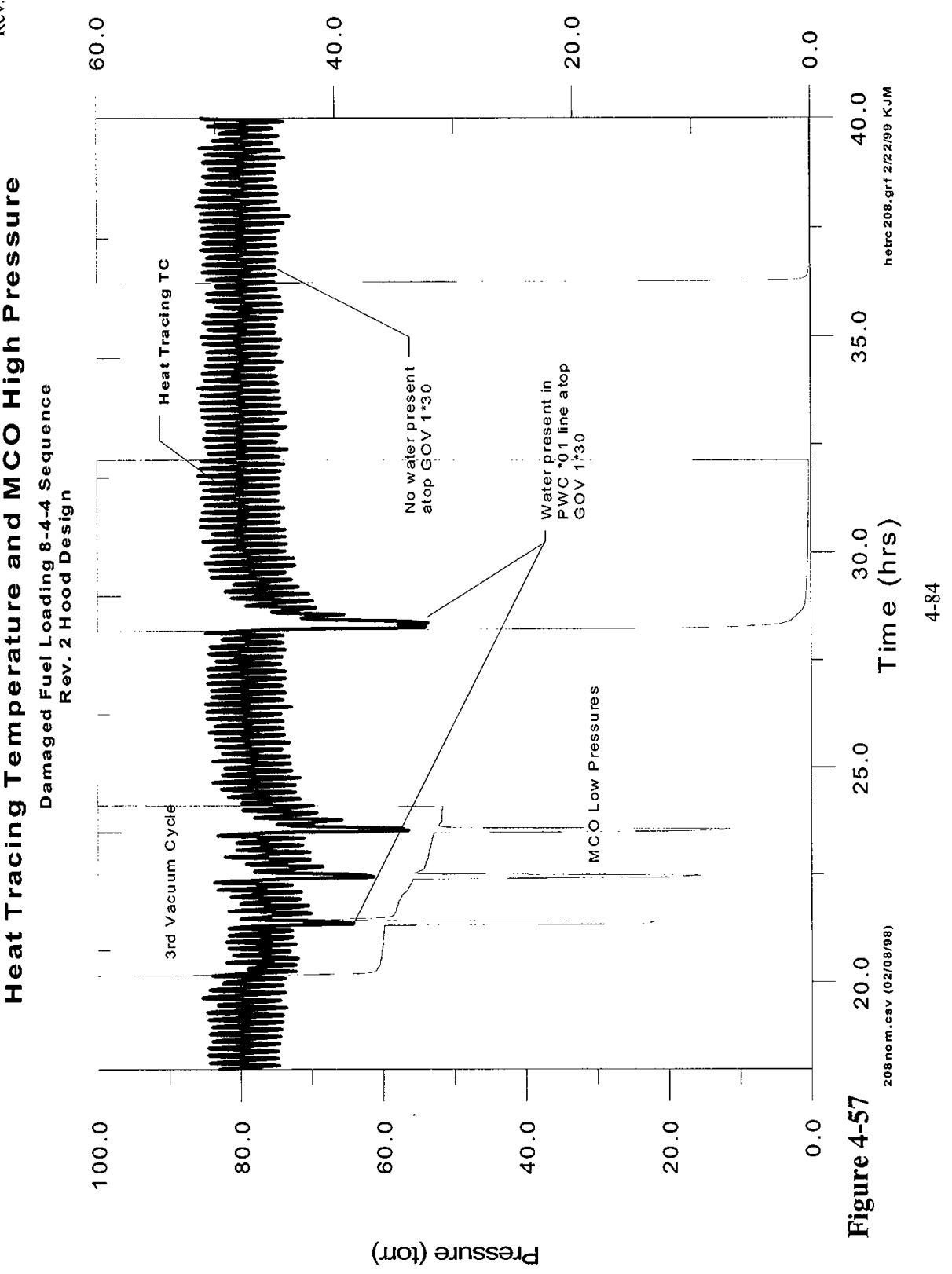




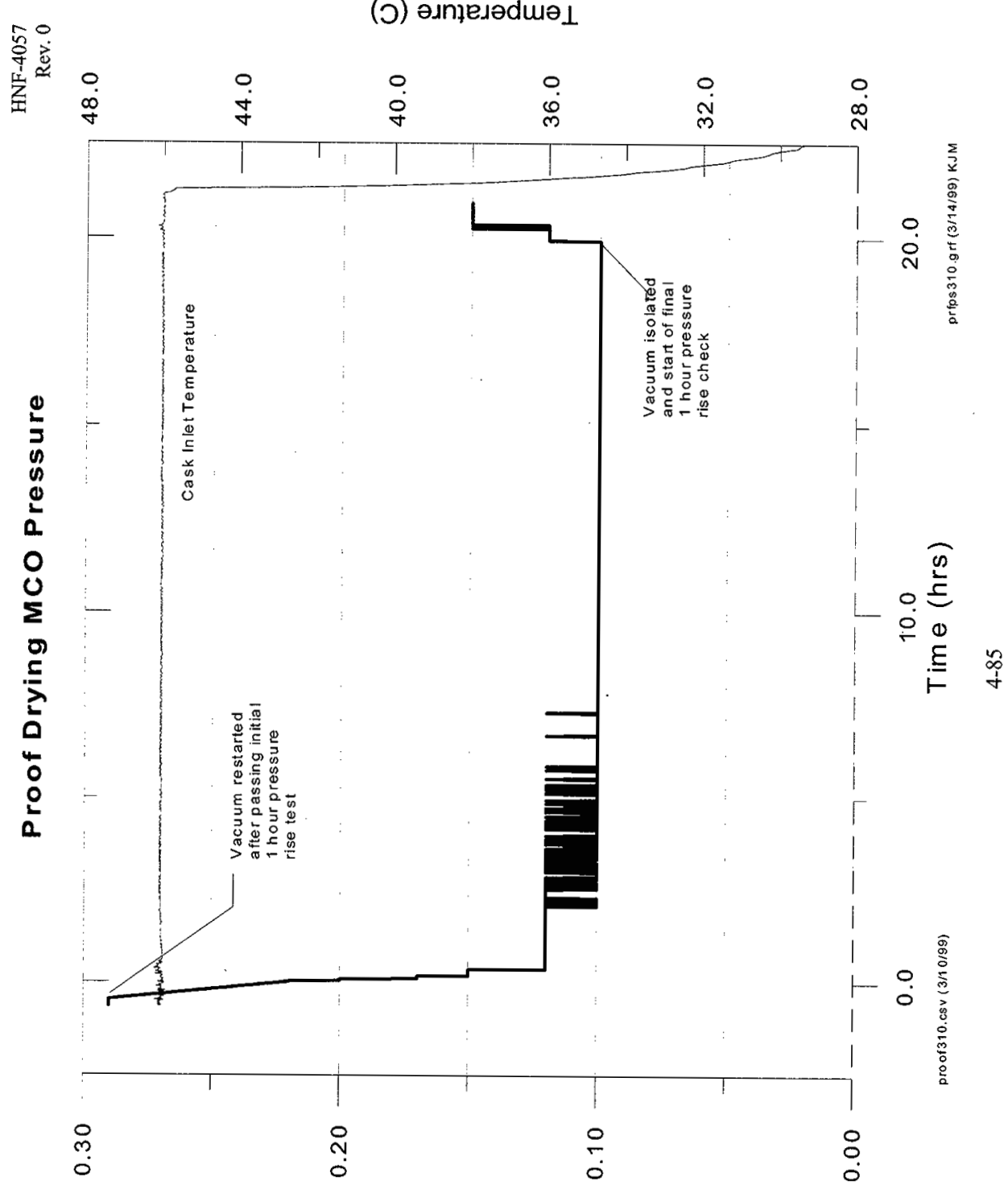

(ג.jOl) ә.jnssadd 
令

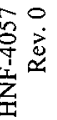

ounssadd 46!H ODW
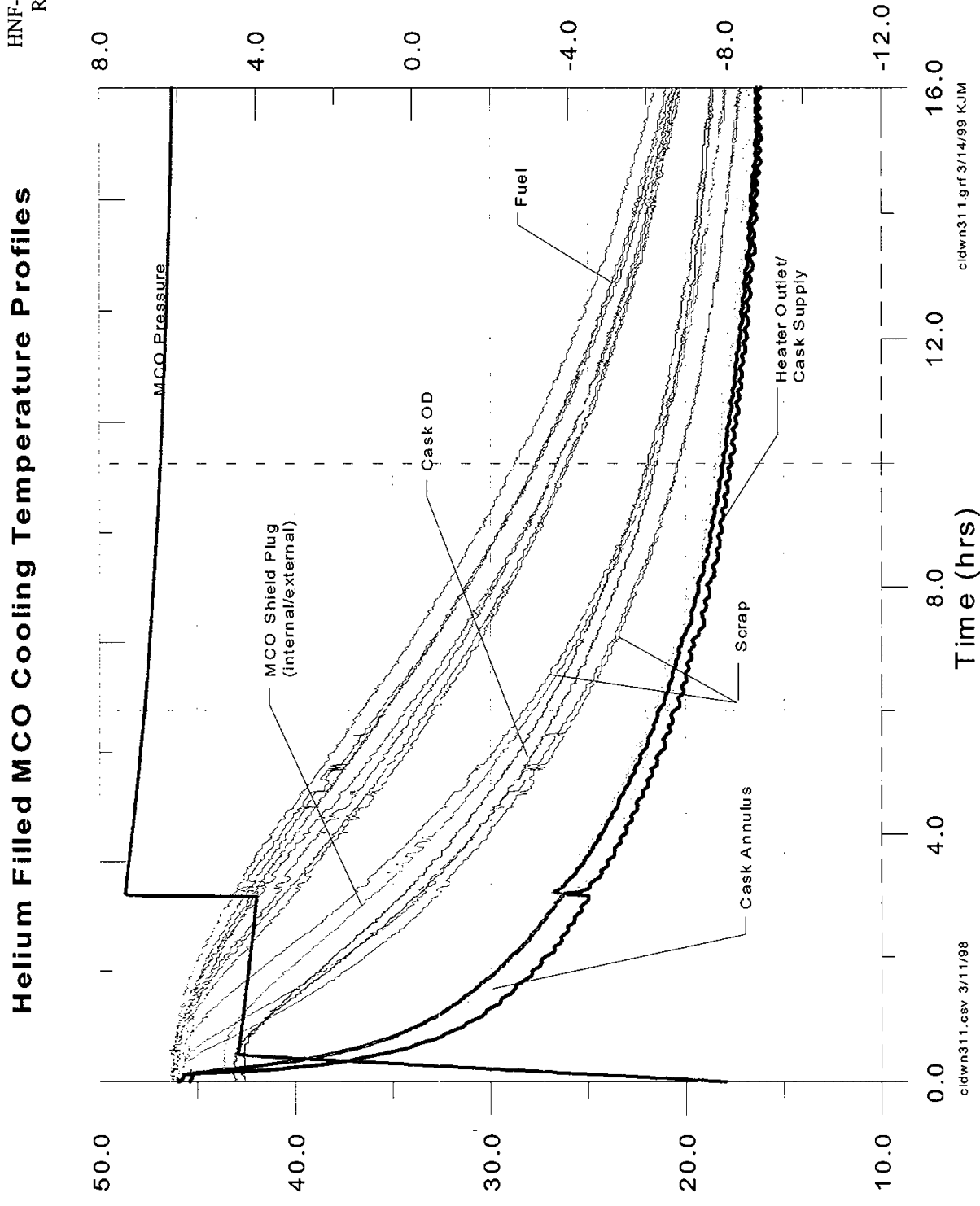

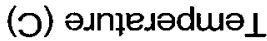




\subsection{CONCLUSIONS AND RECOMMENDATIONS}

\subsection{First Article Testing Conclusions}

First article testing provided valuable input to the CVD process system design. With the exceptions of minor adjustments to equipment that will be resolved during calibration and acceptance testing, the testing proved, first and foremost, that the CVD process equipment design meets the functions and requirements of drying an $\mathrm{MCO}$ within a reasonable amount of time.

The testing also provided valuable data to the thermal model. The test data was used to test the thermal model against actual data. The model results are documented in SNF-4083, Hanford Spent Nuclear Fuel Cold Vacuum Drying Process Post-Test GOTH-SNF Model Simulations of Proof of Performance or First Article Tests and Equipment Performance Evaluation.

Using the data provided by this testing, the CVD Start-up organization and system programmers can establish process parameters to verify and to accept each process bay equipment systems in the facility, to set process set points and trip points, and to establish alarm points. The following sections along with the drying test results with the revised hood design provide initial input to test specifications for the acceptance tests for the facility equipment.

First article testing essentially confirmed the basics of vacuum technology, the higher the temperature and the lower the vacuum ballast gas in the system, the quicker the drying time.

Table 5-1 summarizes the most significant drying tests conducted during the First Article Testing Program.

\subsection{Continued First Article Testing Recommendations}

Additional tests are recommended to validate later revisions to the system logic prior to installation in the field. If the process sequence can be debugged at the test facility, when the logic is transferred to the CVDF, diagnostics could be significantly reduced. Diagnostic reduction is accomplished by focusing on the facility functions that could be halting the sequence rather than both the facility functions and process logic.

Continued testing utilizing the first article test bed should be conducted to further investigate technical issues. These would include: investigating the dryness criteria established by the CVD project and the vacuum pump low end pressure establishment. Continued testing would also provide additional equipment run time, which would be beneficial for future maintenance, trouble shooting, and repair of the process equipment. Further testing would also provide extended operator training to become familiar with and operate the process. 
Table 5-1

\begin{tabular}{|l|c|c|c|c|c|c|c|}
\hline Test Description & $\begin{array}{c}\text { Fuel Type } \\
\text { and Test } \\
\text { Date }\end{array}$ & $\begin{array}{c}\text { Time } \\
\text { to 9 } \\
\text { torr } \\
\text { (hrs) }\end{array}$ & $\begin{array}{c}\text { Time } \\
\text { to 1 } \\
\text { torr } \\
\text { (hrs) }\end{array}$ & $\begin{array}{c}\text { Time } \\
\text { to 0.5 } \\
\text { torr } \\
\text { (hrs) }\end{array}$ & $\begin{array}{c}\text { Time } \\
\text { to 0.1 } \\
\text { torr } \\
\text { (hrs) }\end{array}$ & $\begin{array}{c}\text { Finished } \\
\text { Drying } \\
\text { Time } \\
\text { (hrs) }\end{array}$ & $\begin{array}{c}\text { Final } \\
\text { Rebound } \\
\text { Pressure } \\
\text { (torr) }\end{array}$ \\
\hline $\begin{array}{l}\text { 8-4-4 Revised Hood } \\
\text { (rev. 2) Normal Drying }\end{array}$ & $\begin{array}{c}\text { Nominal } \\
(2 / 8 / 99)\end{array}$ & 14.6 & 15.3 & 20.4 & 29.0 & 35.0 & 0.22 \\
\hline $\begin{array}{l}\text { 8-4-4 Revised Hood } \\
\text { Normal Drying }\end{array}$ & $\begin{array}{c}\text { Damaged } \\
(2 / 25 / 99)\end{array}$ & 28.3 & 28.7 & 29.7 & 45.0 & 51.2 & 0.22 \\
\hline $\begin{array}{l}\text { 8-4-4 Revised Hood } \\
\text { Normal Drying }\end{array}$ & $\begin{array}{c}\text { Pristine } \\
(3 / 9 / 99)\end{array}$ & 3.4 & 3.5 & 3.5 & 22.0 & 28.9 & 0.24 \\
\hline $\begin{array}{l}\text { 8-4-4 Normal Drying } \\
\text { (old hood design, rev. N) }\end{array}$ & $\begin{array}{c}\text { Nominal } \\
(11 / 11 / 98)\end{array}$ & 14.3 & 15.3 & 20.3 & 28.4 & 34.1 & 0.24 \\
\hline $\begin{array}{l}8-4-41.1 \text { scfm Helium } \\
\text { Nominal } \\
(12 / 2 / 98)\end{array}$ & 13.2 & 13.8 & 15.2 & 20.5 & $\sim 26.5$ & Not est. \\
\hline $\begin{array}{l}\text { 8-4-4 35 C bath temp } \\
\text { Nominal } \\
(11 / 3 / 98)\end{array}$ & 23.4 & 28.3 & 28.7 & 36.4 & 42.2 & 0.22 \\
\hline $\begin{array}{l}\text { Vacuum and Condenser } \\
\text { w/1.9 scfm helium } \\
\text { purge drying }\end{array}$ & $\begin{array}{c}\text { Nominal } \\
(11 / 9 / 98)\end{array}$ & 11.8 & 12.8 & 14.7 & 17.9 & Same & Not est. \\
\hline $\begin{array}{l}\text { Vacuum pump w/ 1.9 } \\
\text { scfm helium purge }\end{array}$ & $\begin{array}{c}\text { Nominal } \\
(11 / 7 / 98)\end{array}$ & 13.1 & 14.5 & 16.5 & 30.1 & Same & Not est. \\
\hline $\begin{array}{l}\text { Baseline Dry Helium } \\
\text { pump downs }\end{array}$ & $\begin{array}{c}\text { None } \\
(7 / 18 / 98)\end{array}$ & $\begin{array}{c}7-8 \\
\text { min }\end{array}$ & $\begin{array}{c}12-13 \\
\text { min }\end{array}$ & $16 \mathrm{~min}$ & 31 min & NA & NA \\
\hline $\begin{array}{l}\text { Baseline Dry Helium } \\
\text { pump downs Revised } \\
\text { Hood }\end{array}$ & $\begin{array}{c}\text { Nominal } \\
(1 / 18 / 99)\end{array}$ & $\begin{array}{c}4-5 \\
\text { min }\end{array}$ & $\begin{array}{c}7-8 \\
\text { min }\end{array}$ & 10 min & 35 min & NA & NA \\
\hline
\end{tabular}

As seen in many of the tests, the amount of time to evacuate from 1 torr to 0.1 torr is approximately 16 hours. If the 0.1 torr criteria is changed to 0.5 torr the total amount of drying time would decrease by over 12 hours. The additional testing to determine the soundness of the project pressure rebound criteria could be conducted by isolating the MCO in intervals of 0.1 torr beginning at 1.0 torr down to 0.1 torr and establish what pressure would fail the given 3 torr pressure rise in any number of hours.

The pump base pressure phenomena could also be investigated in these tests and model comparison results could be accomplished with a vacuum pump vendor supplied steam curve with helium injection for the pump bearings and seals. The current model does not include the precise pump curve near the low end pressures ( 0.1 torr) and a vendor supplied curve would fill in this area of the model. 


\subsection{Facility Process Start-Up Testing Recommendations}

First article testing was conducted to provide the start-up organizations specific operating parameters. These parameters are necessary indicators to determine if the process systems are operating as expected. The following sections provide suggested tests and specific operating parameters to identify proper operation of process systems including: VPS, TWS, PWC, MCS, VPSCHW, and TWC.

The following tests are recommended to fully test the future process equipment. First, system baseline tests are recommended to provide an initial system starting point for future diagnostics and system degradation checks. Second, to determine how well each process bay system can dry a given amount of water, a 32-liter bulk water 8-4-4 drying sequence is also recommended. Third, a MCO fully loaded with a nominal fuel configuration should be dried using the entire automated sequence. All of these test results should be compared to the results presented in this report and the thermal modeling report to determine if any problems such as poor vacuum pump performance, poor system performance (i.e. pressure losses, flow control problems, and temperature control issues), line freezing, and other issues that may prolong the expected drying time or cycle time.

\subsubsection{Baseline Testing}

These tests will provide the baseline results required for each bay process equipment. These tests will be used in the future to determine system and component degradation and to assist in final set point or trip set point adjustments. These tests are very easy to run and expend very little time to gain a wealth of knowledge for each process bay system. The air filled $\mathrm{MCO}$, the helium filled $\mathrm{MCO}$, the 3.0 SCFM helium purge, and the 1.9 SCFM helium purge establishes vacuum system characteristics, vacuum pump base pressures and other characteristics, and expected operation parameters. The equipment required for the baseline tests are:

- PES

- hood piping and seal ring assembly ${ }^{1}$;

- helium tube trailer or other helium source';

- process connectors;

- cask/transporter; and

- clean, dry, and empty MCO with design shield plug including internal filters, screen, and dip tube.

${ }^{1}$ requires facility support systems

\subsubsection{Helium Filled MCO}

This test will establish vacuum system characteristics, system base pressures, and the amount of time to evacuate an MCO when it is completely dry. The test results should range between 15 and 25 minutes per evacuation from $1.0 \mathrm{psig}$ to 0.1 torr. This test should be repeated through and bypass the condenser to determine any unexpected system pressure loss through the condenser. 


\subsubsection{3.0 SCFM Helium Purge}

The 3.0 SCFM Helium test will determine the operating pressures during the initial 3.0 scfm helium purge at the start of the 8-4-4 sequence. This test also provides assurance that the system pressure losses will not extend the expected drying time. The MCO will be initially filled with helium at 1 psig. The $3.0 \mathrm{scfm}$ helium purge will be started and the system will pull down to a pressure near 100 torr ( 95 to 110 torr) within 10 to 12 minutes. The test should be conducted, at a minimum, through the condenser but it is recommended to test it also with the condenser bypassed.

\subsubsection{1.9 SCFM Helium Purge}

This test will determine the operating pressures during the initial $1.9 \mathrm{scfm}$ helium purge at the start of the 8-4-4 sequence. This test also provides assurance that the system pressure losses will not extend the expected drying time. The MCO will be initially filled with helium at $1 \mathrm{psig}$. The $1.9 \mathrm{scfm}$ helium purge will be started and the system will pull down to a pressure near 60 torr ( 55 to 65 torr). This test should be conducted through both the condenser and the condenser bypass since this flow rate will be through both configurations.

\subsubsection{MCO Repressurization}

Tests should also be conducted with the pressurized helium purge to determine system pressure losses during the thermal reset conditions. The $\mathrm{MCO}$, while at $\sim 55$ torr $(50-65)$, should be pressurized with helium to $0.5 \mathrm{psig}$ at $10 \mathrm{scfm}$. Once the $0.5 \mathrm{psig}$ pressure is achieved the flow rate should be reduced to $1.9 \mathrm{scfm}$ and system pressure losses observed. This test should be repeated both through the condenser and with the condenser bypassed and again with the condenser bypassed when the MCO pressure is 0.1 torr.

\subsubsection{Liter Bulk Water Drying Testing}

The next test that will determine if the process equipment is operating as expected is the 32 liter bulk water drying test. This test will verify operation of several key facility systems related to the process such as the VPS chilled water system for PES condenser operation and the PWC system for draining the condenser. This test may be an initial test of the MCS process programming. The 8-4-4 sequence can be started automatically at the beginning of the initial vacuum drying sequence with the assistance of knowledgeable PLC experts. This will be the first time that the process and facility programming will have to work together to accomplish a drying task. The expected duration of this is less than 8 hours. The equipment for this test is:

- PES';

- $\mathrm{PWC}^{1}$;

- hood piping and seal ring assembly ${ }^{1}$;

- helium tube trailer or other helium source;

- deionized water source and accurate measuring device $( \pm 0.1$ liter $)$;

- process connectors;

- cask/transporter; and

- clean, dry, and empty MCO with design shield plug including internal filters, screen, and dip tube.

${ }^{1}$ requires facility support systems 


\subsubsection{Nominal Mock Fuel Loading with 8-4-4 Automatic Sequence Testing}

This test will essentially provide the high level of confidence that the entire facility, process, and control systems will operate together to dry a MCO in any particular bay. This test is recommended following the baseline and 32 liter bulk water drying tests because most of the system diagnostics should be finished at this point. It should be accomplished as soon as possible with as few upsets as possible. The equipment for this test is:

- PES

- PWC

- hood piping and seal ring assembly ;

- helium tube trailer or other helium source ${ }^{1}$;

- deionized water source and accurate measuring device ( \pm 0.1 liter);

- process connectors;

- first article mock fuel in nominal (mixed) configuration;

- cask/transporter; and

- clean, dry, and empty MCO with design shield plug including internal filters, screen, and dip tube.

${ }^{1}$ requires facility support systems

The TWS should be operating near $20 \mathrm{gpm}( \pm 2 \mathrm{gpm})$ at a pressure of $37 \mathrm{psig}( \pm 2 \mathrm{psig})$. The MCO fuel should heat from near $25^{\circ} \mathrm{C}$ to near $46^{\circ} \mathrm{C}$ in approximately 6 hours as determined by TIT $3 * 05$ and TIT $3 * 12$ convergence.

The PWC system should be capable of draining the MCO within 30 minutes. The normal operating pressure (PT 4031) of the PWC ejector should be $-14.4 \mathrm{psig}$ when the MCO/PWC drain line is isolated. After the 30 minute drain, break through will occur. At this time, the helium flow, as determined by FT $1 * 19$ should be between 7.5 and $10 \mathrm{scfm}$. This should produce a break through pressure at PT 4031 of greater than $-2.0 \mathrm{psig}( \pm 0.2 \mathrm{psig})$.

The expected drying time of this test is $34 \pm 1$ hours. The expected cycle time from the time the cask/MCO transporter is received until the time it is released to ship is expected to be near 80 hours.

It is unknown, at this time, if the condenser will be on-line during the second vacuum cycle depending on what flow meter (FT $1 * 19$, FT $1 * 20$, or FT $1 * 21$ ) is used for control monitoring functions and depending on system pressure losses. If the condenser isolated during the first vacuum in the 8-4-4 nominal fuel load test, it is recommended to test the MCS programming with a fully damaged $\mathrm{MCO}$ if the start-up testing window permits. A fully damaged test expected duration is $52 \pm 2$ hours and the condenser will remain on line during the second vacuum cycle or the helium flow rate may be raised to $2.0 \mathrm{scfm}$ for a nominally loaded $\mathrm{MCO}$.

\subsection{Technical Issues Discovered During First Article Testing}

First article testing identified some issues that require attention during the phases of equipment installation and start-up testing. These are explained in the following sections regarding flexible line routing, electrical heat tracing, gas operated ball valve operation and status indication, and the vacuum pump seal purge gas. 
Other technical issues were unexplainable or unresolved during the course of first article testing. The following sections in reference to process connector flushing, line purging, cask purging, instrument ranges, and MCS sequence testing detail these technical issues and recommends further testing. The testing may be conducted with either the First Article Test Bed or other future project testing programs to resolve and understand these technical issues that are important in understanding uranium fuel drying characteristics at CVDF.

\subsubsection{Flexible Line Routing}

The proper flex line routing dramatically reduces drying time. The flex lines between the process connectors and the hood piping shall be routed such that drainage is either back to the $\mathrm{MCO}$, to the heat traced hard pipe on the hood stand, or to the VPS condenser. If any low spots are created in these lines or the VPS-*02-SS-2" flex line between the VPS and the hood piping, condensate gathers in the low spots and becomes thermally isolated. This water becomes very difficult and time consuming to evaporate during the process. If these flex lines are seen to be sagging, great effort must be made to prevent them from continuing to sag.

\subsubsection{Electrical Heat Trace Settings}

The systems utilize very little heat tracing on the piping but where it is used, it is vital to the system performance. The heat tracing located on the hood piping network provides additional heat to prevent freezing during the vacuum operation modes. These sections of heat trace should be set near the operating temperature of the TWS. The heat trace operates in an oscillating pattern $\sim 5^{\circ} \mathrm{C}$ around the set point. The heat tracing from the exhaust of the vacuum pump to process vent must be set above $100^{\circ} \mathrm{C}$. If water is allowed to condense in the vacuum pump exhaust, irreparable damage could be done to the vacuum pump. First article testing utilized a collection trap at the bottom of the exhaust line to collect and measure the amount of water through the pump that will not be used at CVDF.

\subsubsection{Gas Operated Ball Valve Operation and Status Indication}

First article testing observed early on that each ball valve actuator may arrive with different actuation speeds for opening or closing depending on which direction is fail safe. If the actuator is fail closed then it must be energized to open. The air speed adjustment screw on the solenoid of the actuator controls how rapidly the ball valve will actuate. This should be adjusted so that the ball valve actuates as rapidly as possible. The fail safe speed needs adjustment to allow the air within the actuator to be released so the actuator springs can return the valve to the failed position.

First article testing also observed late in the testing program that one of the GOV position indicators was failing to properly indicate the valve position and would halt the automated sequence. If the valve was cycled manually through the MCS or physically tapped, the position switch would indicate properly. This minor annoyance halted the process at times. Adjusting the limit switch repaired the improper status indication. This finding indicates that the ball valve actuator position switches change settings after multiple actuations. 
Remedies to the problem would be: (1) during start-up testing, the valve position switches be secured with Loctite ${ }^{\circledR}$ and/or (2) the sequence have a "pause" button, with interlocks, so that the valve in question could be manually cycled by the MCS to continue the automated sequence maintaining sequence order.

Recommendations during start-up for the GOVs are to set the air speed adjustment screw to provide the quickest valve actuation and to adjust the limit switches and Loctite ${ }^{\circledR}$ them into position to provide the largest reasonable margin of error in valve position. Care must be taken when setting the position switches for GOV $1^{*} 30$ and $1 * 03$ because if these valves are slightly out of position crud traps could form just in front of the valve causing seal scarring. It is recommended that the MCS use the capability of cycling a particular valve that may have a stuck position switch to try and continue with the process sequence.

\subsubsection{Vacuum Pump Seal Purge Gas}

During first article testing, the vacuum pump base pressure continued to rise. The vacuum pump manufacturer recommends nitrogen as the vacuum pump seal purge gas, CVD operates the pump with a helium purge (measured as $10-15 \mathrm{lph} \mathrm{N}_{2}$ ). First article testing discovered, during down times of the process, if nitrogen was substituted for helium for approximately 3 to 4 hours, the pump base pressure returned to the original base pressure. If high vacuum pump pressure becomes an issue, we recommend taking the entire system off line and substituting nitrogen or argon for the helium seal gas purge (at $20 \mathrm{lph} \mathrm{N}_{2}$ ) for 3-4 hours as initial diagnostics. Another possibility is a Tee into the helium seal purge line with isolation valves. This would allow the vacuum pump to be nitrogen purged anytime the bay is empty and easily returned to a helium purge for normal processing.

\subsubsection{Process Connector Flushing}

As stated in section 3.4.3, particulate would deposit under the valve actuator socket on top of the MCO plug valve and would not be removed during the flushing sequence. Efforts are currently underway to redesign the valve actuator socket so that the top of the plug valve is sealed during the draining and flushing sequence. Further testing with the process connector flushing should be conducted and reported against the new socket redesign.

\subsubsection{Line Purging}

Also stated section 3.4.3 results, the operating sequence (SNF 2356 Revision 0a, Hanford Spent Nuclear Fuel Project Cold Vacuum Drying Facility Operations Manual) used for the bulk water draining sequence caused a significant amount of water (3-5 liters) to be reintroduced into the bottom of the MCO. The draining sequence included PWC pre-purge, MCO draining, line purging and flushing, PWC post-purging, and establishment of normal helium flow path into the MCO diptube. With changes in the current operating sequence (SNF 2356 Revision 1), the high amount of water should not be re-introduced into the $\mathrm{MCO}$ because the normal helium flow path is purged with helium while the PWC isolation valves (GOV $1 * 30$ and $1 * 03$ ) are still open. 
The data from a majority of the first article tests, when plotted against the model predictions, SNF 4083, show, in all the tests, condenser temperature differentials are higher than predicted by the model. This is evidence that more water is in the bottom of the MCO than anticipated. A few model simulations could be rerun with additional water in this location to determine the cause of this discrepancy between the model predictions and the tests. The model would not have to be permanently changed because the water should not be in this location when the new operating sequence (revision 1) is utilized.

\subsubsection{Cask Purging}

Cask purging results, as detailed in section 4.9 , showed that water droplets were remaining on the bottom of the $\mathrm{MCO}$ when it was removed from the cask and the cask bottom was not completely dry. A recommended operational sequence change to have operator open and close PWC-V - 048 several times during cask draining after break-through has occurred. When the valve is closed, the operator would need to wait until the PWC ejector reached a dead head pressure then the operator could reopen the PWC-V-*048 valve. This causes a velocity increase across the MCO and cask bottom interface sweeping more water out of the cask, which would dry the $\mathrm{MCO} /$ cask quicker. The drying could also be accomplished by extending the cask purge period longer than the one hour currently set in the operating sequence.

\subsubsection{Instrument Ranges}

The vacuum instruments on the PES (PT $2 * 08$ ) and the process hood assembly (PT $1 * 08$ ) were the design specified instruments. The transmitters respond to 0 to 100 torr pressure indications and output 4-20 $\mathrm{mA}$ and 0-10VDC from the PES and hood respectively. The project criteria, to attain 0.1 torr prior to starting the pressure rebound tests, is near the sensitivity limits of these instruments. Although problems did not occur during the testing with meeting the 0.1 torr criteria, adding lower ranged instrumentation if the low criteria are retained should increase the instrument sensitivity.

Other possibilities would be to reinstate the use of a system moisture probe similar to the one utilized on the first article PES. The dew point temperature corresponds directly to system pressures using established thermodynamic tables related to steam, water vapor, and ice. As shown in the results of the full sequence tests, dew point provides a good indication of system dryness and system pressure if the conversion from temperature to pressure is utilized.

\subsubsection{MCS Full Revision Testing}

The final full sequence mixed, damaged, pristine fuel tests were completed using a development controlled hybrid operational sequence which include updates in the process logic for the no purge vacuum checks of SNF-2356 Revision 1. The remaining portions of the sequences were conducted using SNF-2356 Revision 0a logic. Complete process sequence testing is highly recommended using the First Article Test Bed to prove the process operation sequence prior to installation in the CVDF as stated in section 5.2. A majority of the above described issues could be investigated and or resolved during MCS full revision testing. 


\subsection{Facility Operation Recommendations}

The only recommendations that first article testing can provide facility operations are related to instrument calibrations. First article testing discovered instrumentation drift in the vacuum pump low pressure instrument. Perhaps the instrumentation drift was caused by the excess moisture in the system or by rapid increases from low pressure to near atmospheric pressures during thermal reset modes. We recommend calibration of all low pressure instrumentation in the VPS system every 6 months. This includes pressure transmitters PT $1 * 08$, PT $1 * 10$, PT $1 * 35$, and PT $2 * 08$. These pressure indicators should be zeroed on a vacuum system that has a base pressure of $1.0 \times 10^{-4}$ torr or less.

All other instrumentation should remain on the recommended calibration schedule. Instrumentation (general service and safety class helium flow meters in the hood piping and PES, and rotameters in the SCHe system) should be calibrated on a bench calibration system. A number of spare components should be purchased as calibrated spares. The calibration schedules should be staggered. With this arrangement, one set of instruments can be quickly removed from the system and replaced with another calibrated set of instruments. The removed set of instruments could be calibrated and used in the next system. 


\subsection{REFERENCES}

AP-11-014, Spent Nuclear Fuel Project Quality Assurance Program Plan, Hanford Spent Nuclear Fuel Project, Fluor Daniel Hanford, Richland, WA, 1999

Cogema 98-803, Summary Report for MCO Nondestructive Examination Activities, J. K. Keve, Cogema Engineering Corporation, Richland, WA, 1998

HNF-MP-599, Project Hanford Quality Assurance Program Description, Fluor Daniel Hanford, Richland, WA. 1998

HNF-SD-TP-036 Rev. 0A, Hanford Spent Nuclear Fuel Cold Vacuum Drying Proof of Performance Test Plan and Test Specification, N. S. Cannon, K. J. McCracken, Numatec Hanford Corporation, Richland, WA, 1998

HNF 2402, Hanford Spent Nuclear Fuel Cold Vacuum Drying Proof of Performance Test Procedure, K. J. McCracken, E. A. Smith, Numatec Hanford Corporation, Richland, WA, 1998

HNF 3342, Hanford Spent Nuclear Fuel Cold Vacuum Drying First Article Initial Test Findings Report, K. J. McCracken, Numatec Hanford Corporation, 1998

HNF 4288, Hanford Spent Nuclear Fuel Cold Vacuum Drying Proof of Performance Test Report, K. J. McCracken, Numatec Hanford Corporation, 1999

SNF 2356 Rev. 0A, Hanford Spent Nuclear Fuel Project Cold Vacuum Drying Facility Operations Manual, R. Whitehurst, J. J. Irwin, Numatec Hanford Corporation, Richland, WA, 1998

SNF 2356 Rev. 1, Hanford Spent Nuclear Fuel Project Cold Vacuum Drying Facility Operations Manual, R. Whitehurst, J. J. Irwin, Numatec Hanford Corporation, Richland, WA, 1998

SNF 4083, Hanford Spent Nuclear Fuel Cold Vacuum Drying Process Post-Test GOTH-SNF Model Simulations of Proof of Performance or First Article Tests and Equipment Performance Evaluation, B. C. Fryer, John Marvin Incorporated, West Richland, WA, 1999

W-441-P1 Rev. N, Procurement Specification for the Fabrication, Acceptance Testing, and Shipment of the Cold Vacuum Drying System Equipment Process Equipment Skid, Merrick and Company, Numatec Hanford Corporation, Richland, WA, 1998

W-441-P2 Rev. N, Procurement Specification for the Fabrication, Acceptance Testing, and Shipment of the Cold Vacuum Drying Facility Process Water Conditioning Skid, Merrick and Company, Numatec Hanford Corporation, Richland, WA, 1998 
W-441-P4 Rev. N, Procurement Specification for the Fabrication, Acceptance Testing, and Shipment of the Cold Vacuum Drying Facility Process Hood, Seal Ring and Piping Assembly, Merrick and Company, Numatec Hanford Corporation, Richland, WA, 1998

W-441-P4 Rev. 2, Procurement Specification for the Fabrication, Acceptance Testing, and Shipment of the Cold Vacuum Drying Facility Process Hood and Piping Assembly, Merrick and Company, Numatec Hanford Corporation, Richland, WA, 1998

W-441-P5 Rev. N, Procurement Specification for the Fabrication, Acceptance Testing, and Shipment of the Cold Vacuum Drying Facility Safety Class Helium System Equipment, Merrick and Company, Numatec Hanford Corporation, Richland, WA, 1998 


\section{DISTRIBUTION SHEET}

To

Distribution

Project Title/Work Order

Cold Vacuum Drying Proof of Performance (First Article Testing) Test Results

\section{Name}

w. c. Alaconis

J. R. Brehm

T. Choho (4)

B. A. Crea

D. R. Duncan (2)

R. D. Dunlap (2)

J. R. Fredrickson

J. R. Gregoxy

C. S. Haller (2)

J. J. Irwin

J. D. Mathews

K. J. McCracken (2)

M. A. Medsker

S. I. Mischke

C. R. Miska

R. P. Omberg

R. G. Pedigo

L. R. Schroeder

J. P. Sloughter

J. R. Thielges

C. A. Thompson

R. Whitehurst

M. J. Wiemers

Central Files (Correspondence Control)

CVD Project Files

SNF Project Files
From

Kurt J. McCracken
Page 1 of 1

Date March 29, 1999

EDT No. 140132

ECN No. NA

\begin{tabular}{|c|c|c|c|c|} 
MSIN & $\begin{array}{c}\text { Text } \\
\text { With All } \\
\text { Attach. }\end{array}$ & Text Only & $\begin{array}{c}\text { Attach./ } \\
\text { Appendix } \\
\text { Only }\end{array}$ & $\begin{array}{c}\text { EDT/ECN } \\
\text { Only }\end{array}$ \\
\hline
\end{tabular}

